Portland State University

PDXScholar

Spring 5-21-2015

\title{
Behavior of Reinforced Concrete Beams Retrofitted in Flexure Using CFRP-NSM Technique
}

Salam Al-Obaidi

Portland State University

Follow this and additional works at: https://pdxscholar.library.pdx.edu/open_access_etds

Part of the Structural Engineering Commons

Let us know how access to this document benefits you.

\section{Recommended Citation}

Al-Obaidi, Salam, "Behavior of Reinforced Concrete Beams Retrofitted in Flexure Using CFRP-NSM Technique" (2015). Dissertations and Theses. Paper 2294.

https://doi.org/10.15760/etd.2291

This Thesis is brought to you for free and open access. It has been accepted for inclusion in Dissertations and Theses by an authorized administrator of PDXScholar. Please contact us if we can make this document more accessible: pdxscholar@pdx.edu. 
Behavior of Reinforced Concrete Beams Retrofitted in Flexure Using CFRP-NSM Technique

by

Salam Al-Obaidi

A thesis submitted in partial fulfillment of the requirements for the degree of

Master of Science

in

Civil and Environmental Engineering

Thesis Committee:

Franz Rad, Chair

Peter Dusicka

Evan Kristof

Portland State University

2015 


\begin{abstract}
A variety of retrofitting methods are used to upgrade existing structures. For example, steel plates and Fiber Reinforced Polymer (FRP) jackets are externally bonded to members to increase their capacity in flexure and shear. However, due to the issue of corrosion these strengthening systems may lose their efficiency with time. FRP materials have been used to strengthen many structural components of different shapes and types. FRP jackets, FRP Strips, and FRP rods have commonly been used to rehabilitate existing structural components. The many advantages of using FRP as strengthening materials have made this material an attractive alternative: advantages such as lightweight, high strength, and ease of setting up. Among the many applications using FRP, Near Surface Mounted -Fiber Reinforced polymer (NSM-FRP) is a promising technique used to strengthen concrete members. However, de-bonding issues have to be overcome to make this technique efficient and reliable. The NSM-FRP technique consists of making a groove along the surface of the concrete member to be retrofitted with depth less than the cover of the member. After cleaning the groove, epoxy paste is used to fill two-thirds of the groove's depth. The FRP element is then mounted in the groove. Finally, the groove is filled with epoxy and the excessive epoxy is leveled with surface of the concrete. This technique makes the FRP material completely covered by epoxy in the cover of the concrete. This method can be used for strengthening both the positive and negative moment regions of girders and slabs. Groove size, paste, concrete, and rods properties are the main variables that control the efficiency of the NSM-FRP rods. The main objective
\end{abstract}


of this research project is to determine the behavior of reinforced concrete beams that are strengthened with NSM-CFRP reinforcement bars. In this research project, the bond characteristics of NSM-CFRP reinforcement bars are first determined from pullout tests. Then, NSM-CFRP rods are installed in reinforced concrete beams and the beams are tested. Loads, strains, and deflections are measured and theoretical and measured capacities are compared. Finally, the reliability and efficiency of using NSM-CFRP rods technique in retrofitting existing structures is observed. 


\section{Acknowledgment}

The author would like to thank Professor Franz Rad for his guidance and advice on this project. The author also would thank the committee members: professors Peter Dusicka and Evan Kristof for serving the thesis defense. The author would also like to thank the following graduate students for their support and help in the experimental work of this

project: Yasir Saeed, Karrar Al-Lami, Hayder Alkhafaji, Salih Mahmmod, Ali Salih, and Anas Yousifani. The author extends his sincere appreciation to Mr. Tom Bennett for his help in setting up the data acquisition system and facilitating the experimental works. Special thanks to Robert Kosowski for his help with most of the experimental research. Special thanks to The Higher Committee for Education Development in Iraq for funding this project. 


\section{Table of Contents}

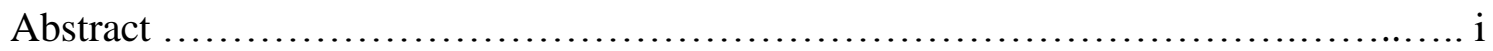

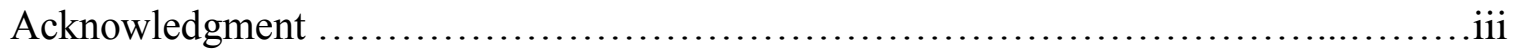

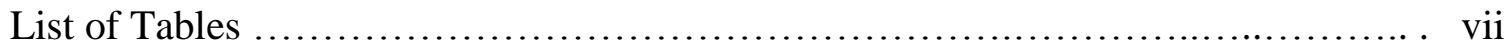

Lists of Figures ................................................................ vii

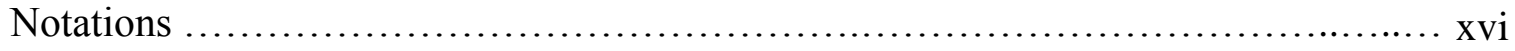

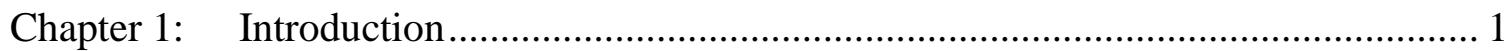

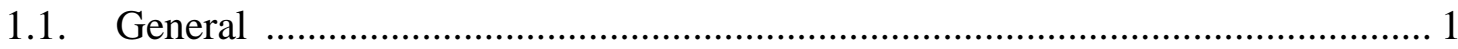

1.2. Near Surface Mounted Technique (NSM) ……............................................. 2

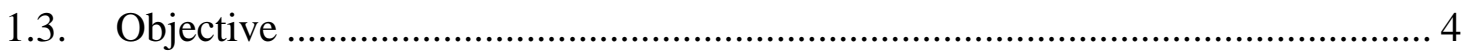

Chapter 2: $\quad$ Literature Review................................................................................ 5

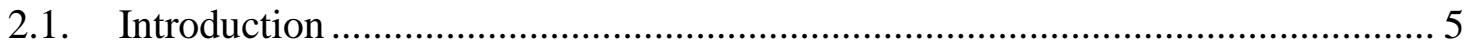

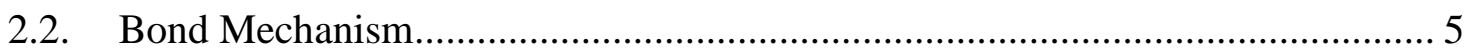

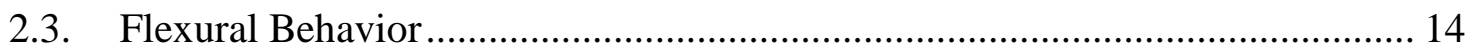

2.4. Summary of the Literature Review and Discussion........................................ 26

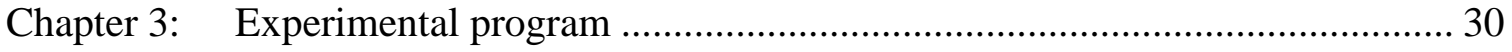

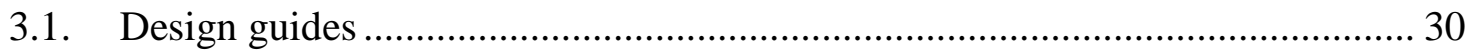

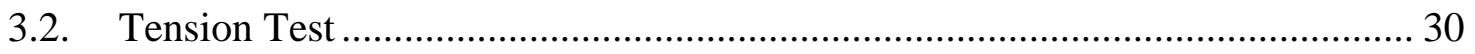




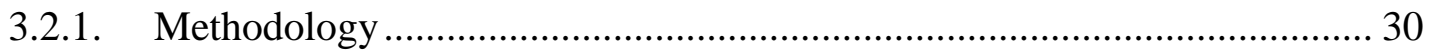

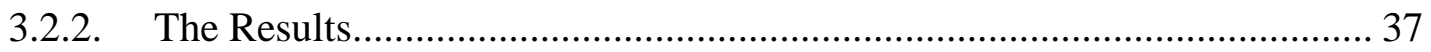

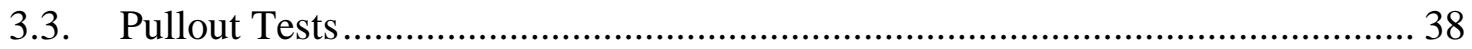

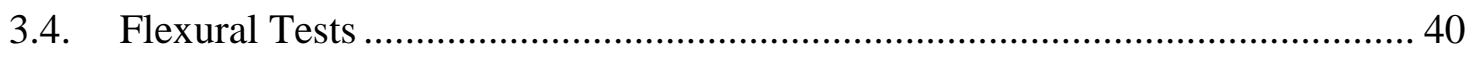

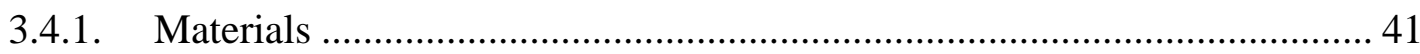

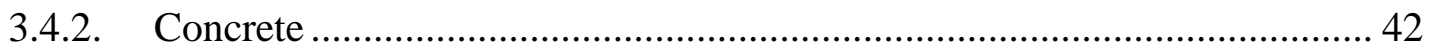

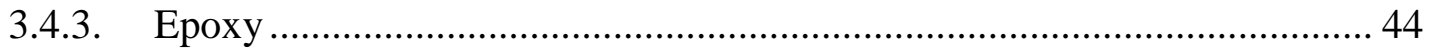

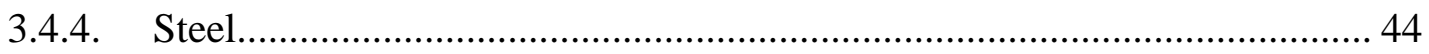

3.4.5. Specimens' Analysis and Design .............................................................. 46

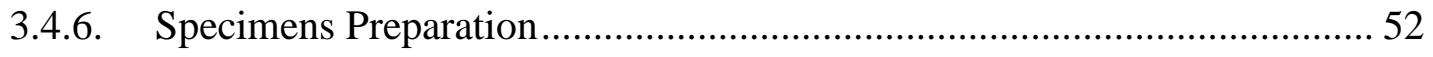

3.4.7. Concrete Casting and Curing ..................................................................... 53

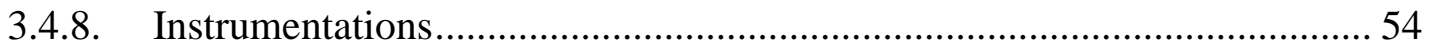

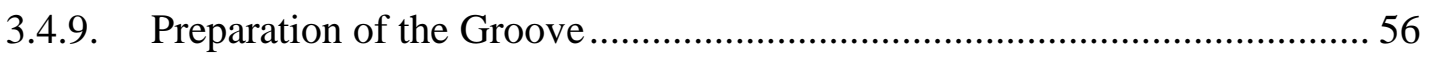

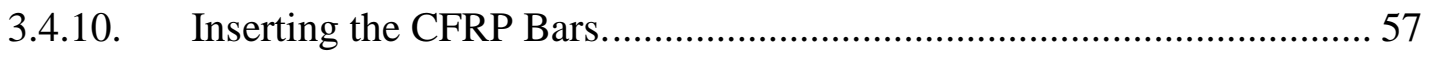

3.4.11. Instrumentations and Procedure ........................................................... 57

Chapter 4: The Results........................................................................................... 59

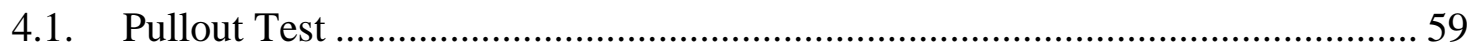

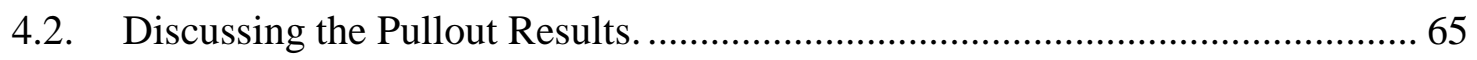

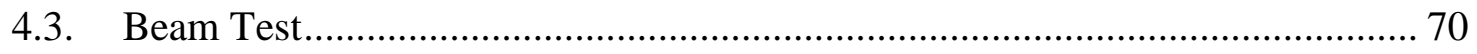




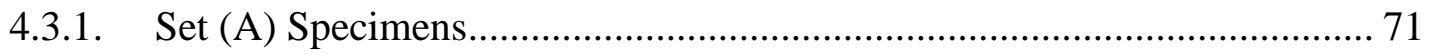

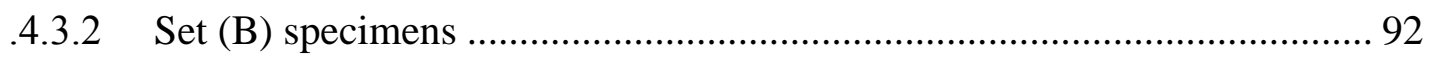

4.3.3. Set A and B Results Comparison ...................................................... 108

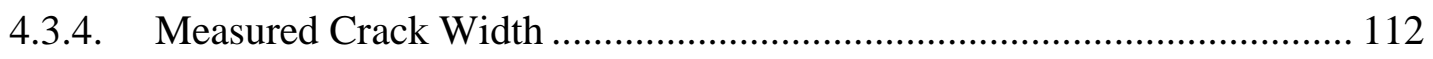

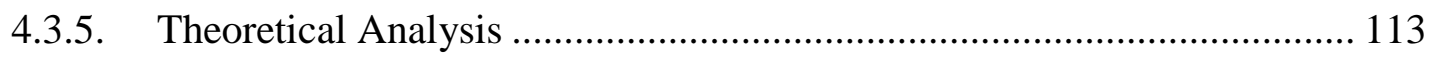

Chapter 5: Summery Conclusions and Recommendations................................... 122

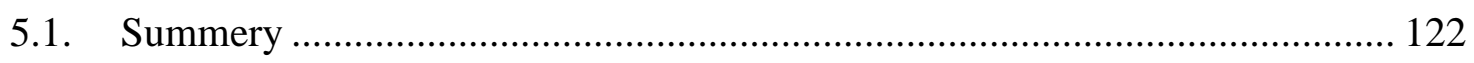

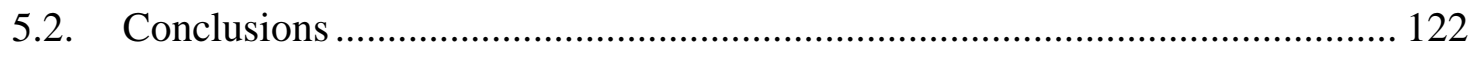

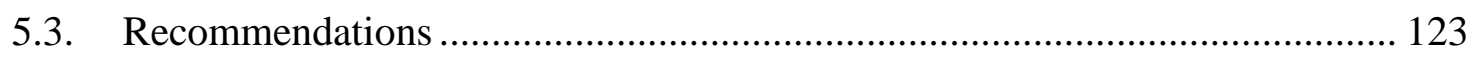

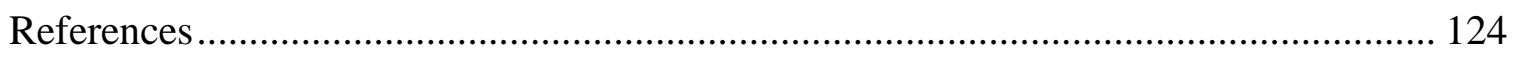

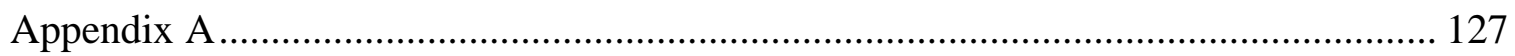

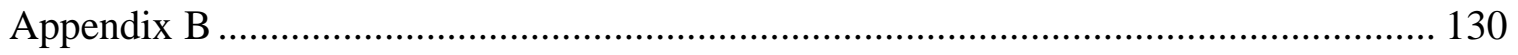




\section{List of Tables}

Table 1-1-1 Typical properties of steel and FRP materials. ............................................ 2

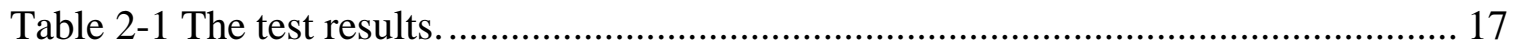

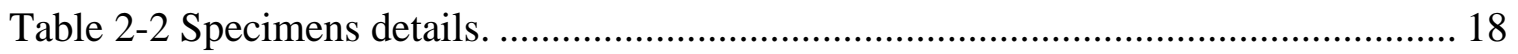

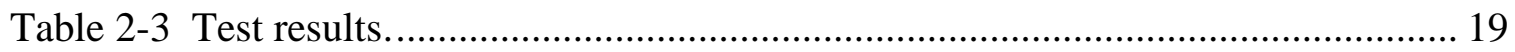

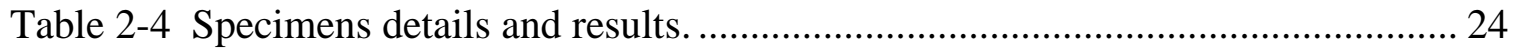

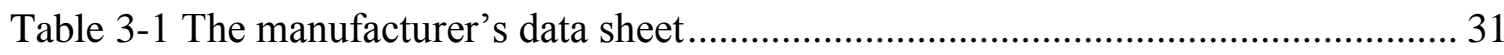

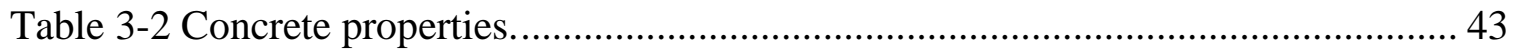

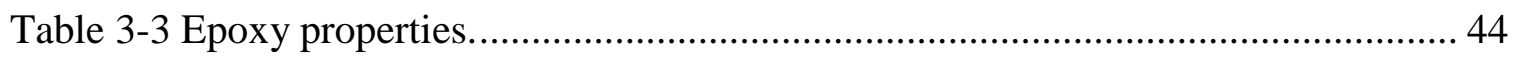

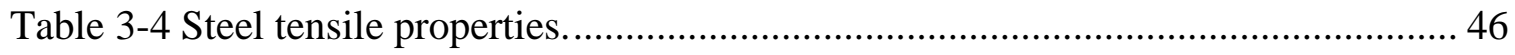

Table 3-5 NSM-CFRP flexural cross section analysis for set A................................... 49

Table 3-6 NSM-CFRP flexural cross section analysis for set B ................................ 51

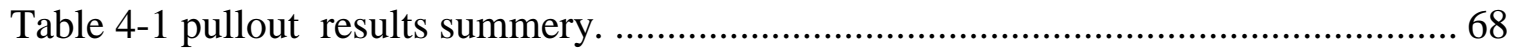

Table 4-2 Set A specimens results summery....................................................... 71

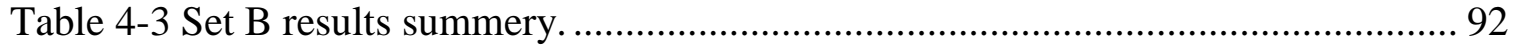

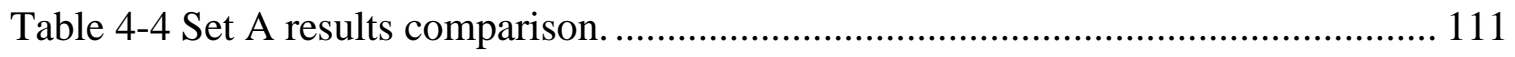

Table 4-5 Set B results comparison. .................................................................. 111

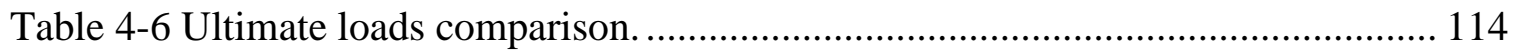




\section{List of Figures}

Figure 1-1 Stress-strain curve comparison of steel and FRP bars. .................................. 2

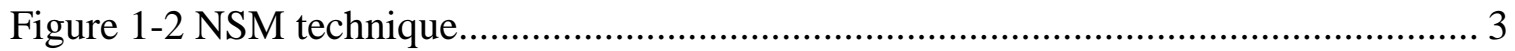

Figure 2-1 Hinged beam pullout test with inverted $\mathrm{T}$ beam section.............................. 7

Figure 2-2 Modified pullout test scheme............................................................ 8

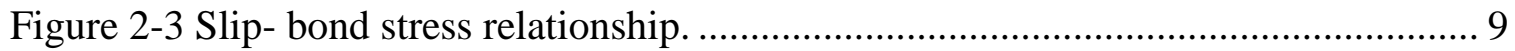

Figure 2-4 Direct puulout test with spurious stress breakers..................................... 10

Figure 2-5 Pull out test setup and specimen dimensions......................................... 11

Figure 2-6 Modified pullout test with instrument...................................................... 12

Figure 2-7 Specimens with mechanical interloching ............................................ 13

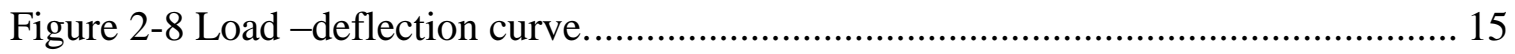

Figure 2-9 Load -deflection curve for retrofitted beams......................................... 20

Figure 2-10 Load -deflection curve for retrofitted cantilever beams with FRP bars...... 21

Figure 2-11 Retrofitteed beam sections details................................................... 22

Figure 2-12 NSM CFRP mechanical interlocking details....................................... 25

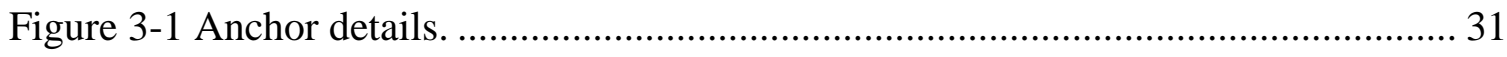

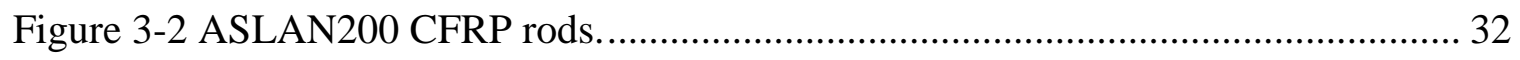

Figure 3-3 Steel pipe used to grip \#2 CFRP rod...................................................... 33

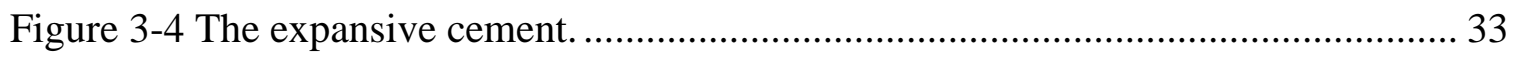

Figure 3-5 The expansive cement' properties manufacturer's data sheet...................... 33

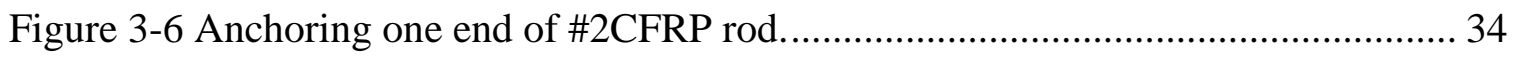

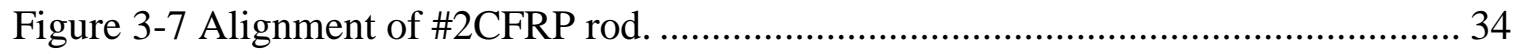


Figure 3-8 \#2 CFRP specimen ready to be tested 35

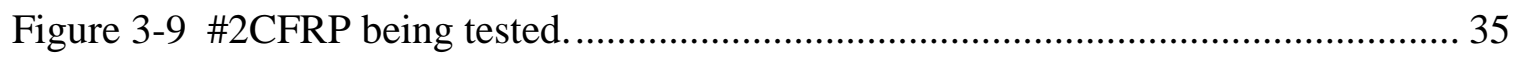

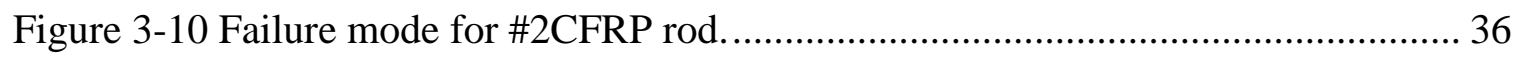

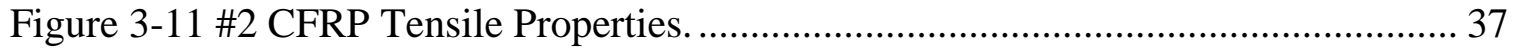

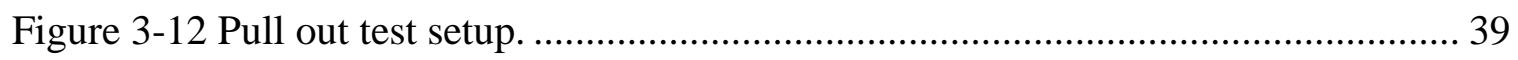

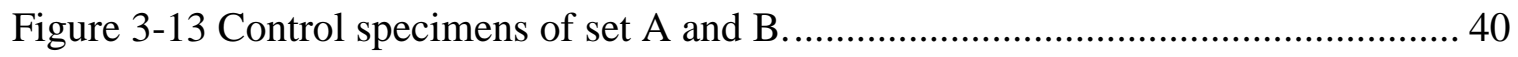

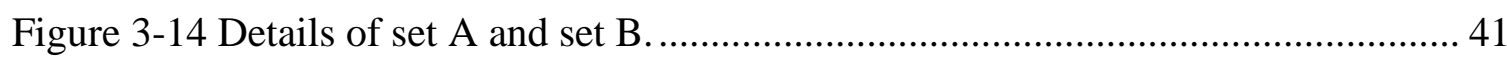

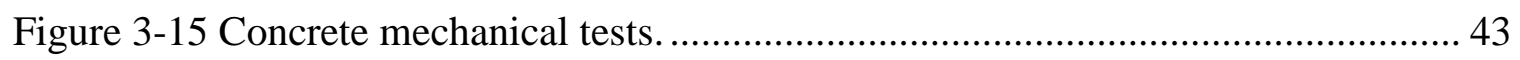

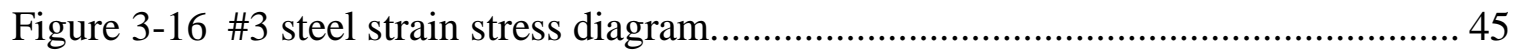

Figure 3-17 \#4 steel strain stress diagram....................................................... 45

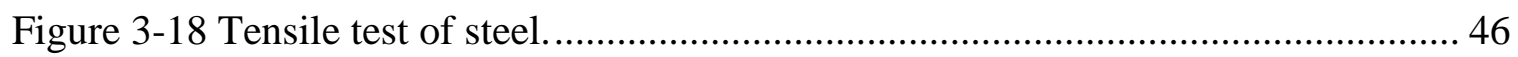

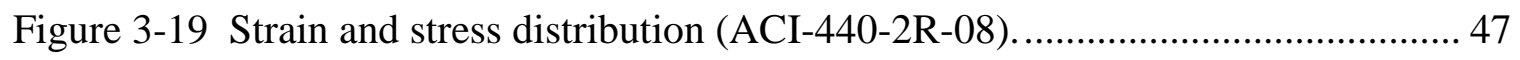

Figure 3-20 Steel cage and mold fabrication. ..................................................... 52

Figure 3-21 Steel cage inside the molds with the required cover............................. 52

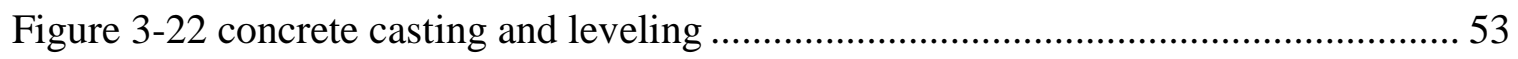

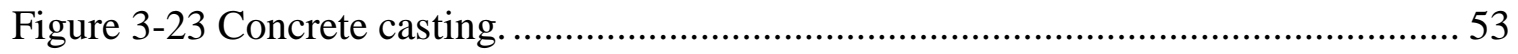

Figure 3-24 Concrete finishing and curing. ....................................................... 54

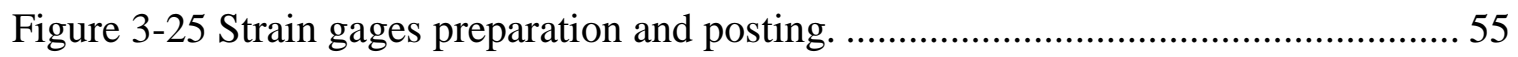

Figure 3-26 Making grooves in the tension side of the strengthened beams.................. 56

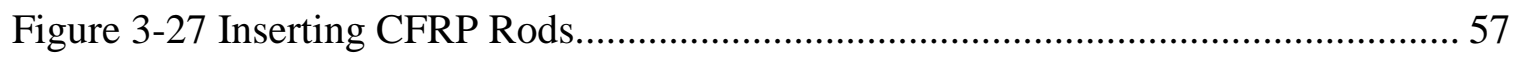

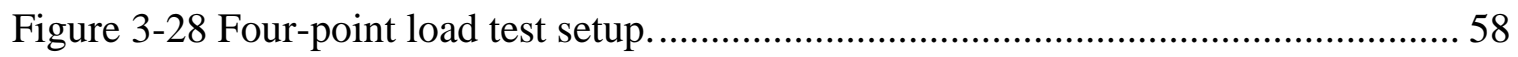

Figure 4-1 Pull out test failure without lateral grooves. ........................................ 59 


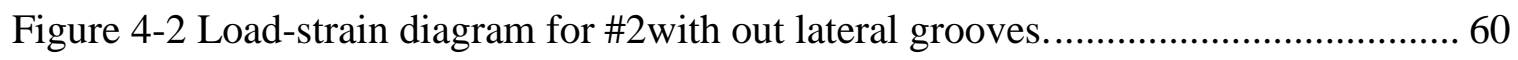

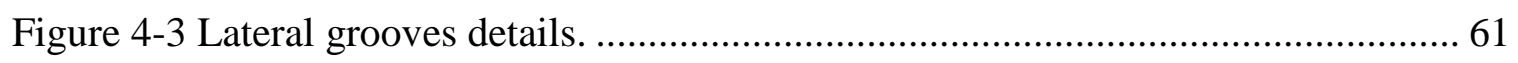

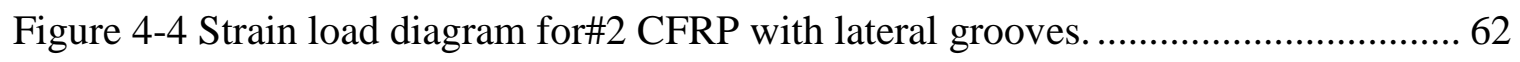

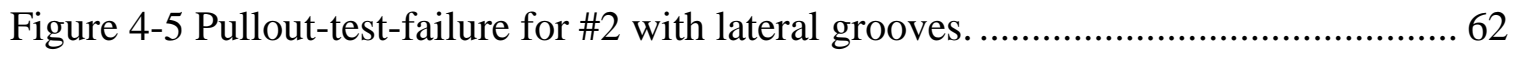

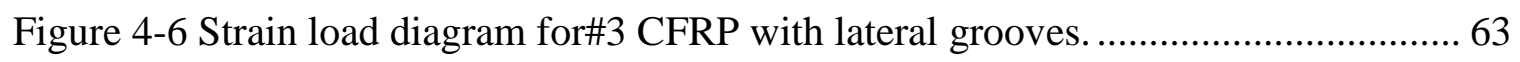

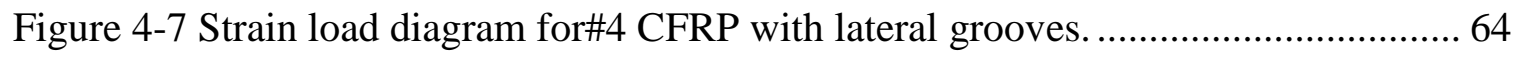

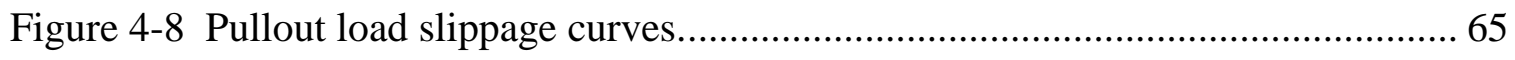

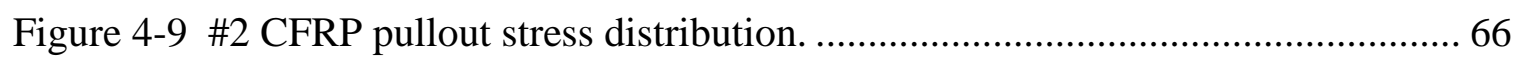

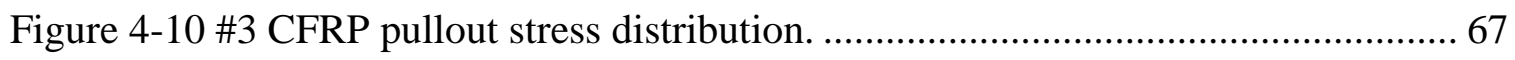

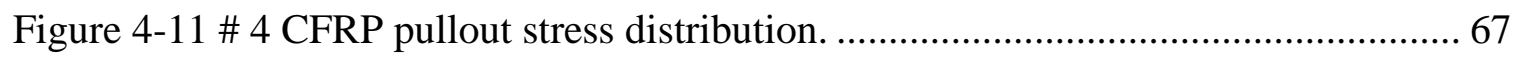

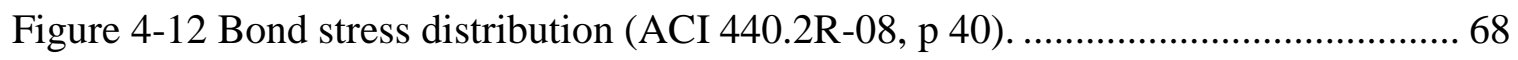

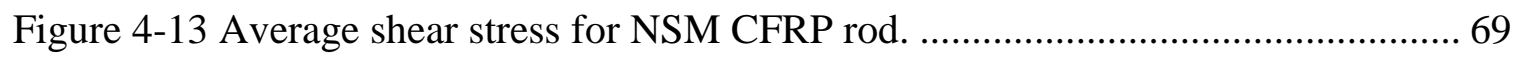

Figure 4-14 Two point load flexural test. .......................................................... 70

Figure 4-15 Specimen AC strain and stress profile according to ACI. ......................... 72

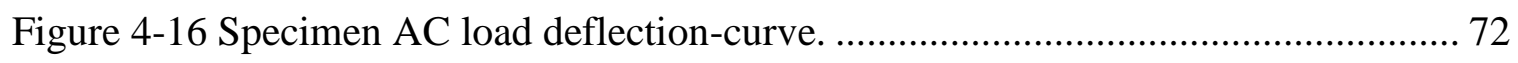

Figure 4-17 Specimen AC strain profile at different load level.................................. 73

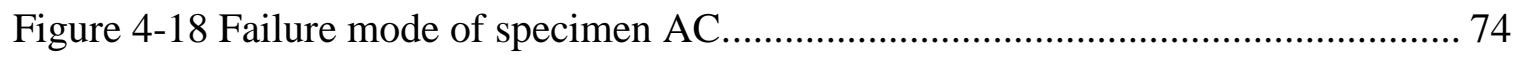

Figure 4-19 ACI strain and stress analysis of specimen AR2 ................................ 75

Figure 4-20 Specimen AR2 load -deflection curve. ........................................... 76

Figure 4-21 Section strain profile for specimen AR2 at different load levels............... 77

Figure 4-22 Tension layer delamination (ACI440.2R-08, p 38) ............................... 77

Figure 4-23 CFRP load-strain relationship for specimen AR2 ............................... 78 


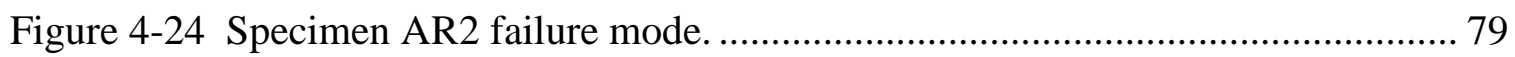

Figure 4-25 stress and strain analysis of specimen AR3 ............................................ 79

Figure 4-26 Load deflection curve for specimenAR3............................................... 80

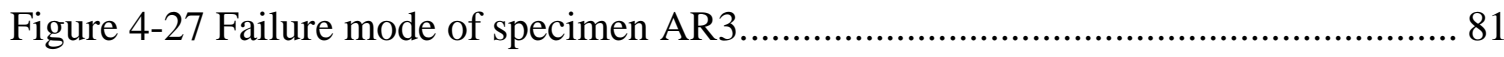

Figure 4-28 Strain profile for specimen AR3 at different load level.............................. 82

Figure 4-29 CFRP load-strain relationship for specimen AR3 ...................................... 83

Figure 4-30 Strain and stress analysis of specimen AR4 ............................................... 83

Figure 4-31 Load deflection curve of specimen AR4 ................................................. 84

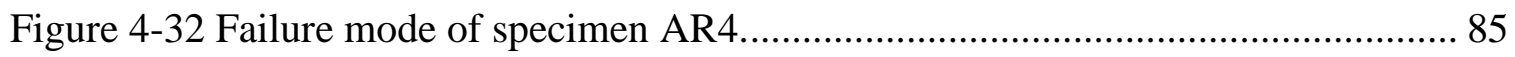

Figure 4-33 Strain profile of specimenAR4 at different load levels................................ 85

Figure 4-34 CFRP load-strain relationship for specimen AR4 ....................................... 86

Figure 4-35 Strain and stress analysis of specimen AR4-S......................................... 87

Figure 4-36 Load deflection curve for specimen AR4-S............................................. 88

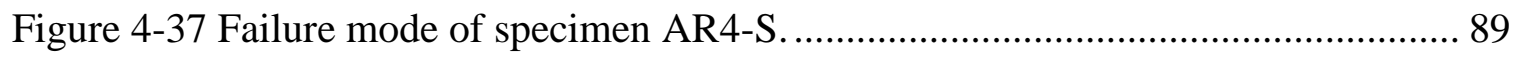

Figure 4-38 Strain profile for specimen AR4-S at different load levels.......................... 90

Figure 4-39 CFRP load-strain relationship for specimen AR4-S. .................................. 91

Figure 4-40 ACI 318 strain and strain profile for specimen BC...................................... 93

Figure 4-41 Load deflection curve of specimen BC.................................................... 93

Figure 4-42 Failure mode of specimen BC................................................................ 94

Figure 4-43 Strain profile for specimen BC at different load levels............................... 95

Figure 4-44 Strain and stress analysis of specimen BR2 ............................................ 95

Figure 4-45 Load deflection curve of specimen BC.................................................. 96 


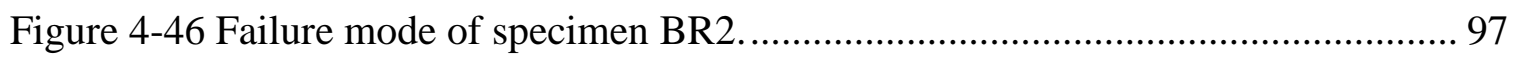

Figure 4-47 Strain profile for specimen BR2 at different load levels.......................... 97

Figure 4-48 CFRP load-strain relationship for specimen BR2 ............................... 98

Figure 4-49 Strain and stress analysis of specimen BR3 ...................................... 99

Figure 4-50 Load deflection curve of specimen BR3 .......................................... 100

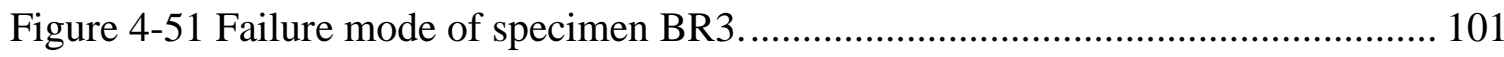

Figure 4-52 Strain profile for specimen BR3 at different load levels........................ 102

Figure 4-53 CFRP load-strain relationship for specimen BR3 ................................. 103

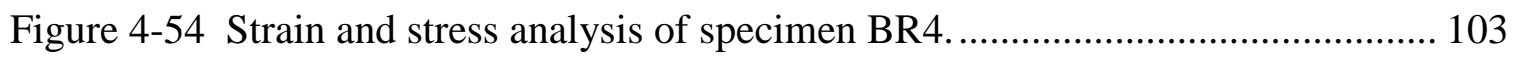

Figure 4-55 Load deflection curve of specimen BR4 ......................................... 104

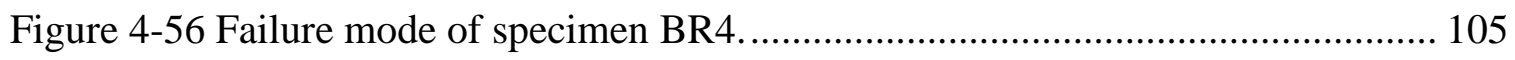

Figure 4-57 Strain profile for specimen BR4 at different load levels......................... 106

Figure 4-58 CFRP load-strain relationship for specimen BR4 ................................ 107

Figure 4-59 Set A load deflection curves. ....................................................... 108

Figure 4-60 Set A normalized load deflection curves. .......................................... 108

Figure 4-61 Set B load deflection curves.......................................................... 109

Figure 4-62 Set B normalized load deflection curves............................................ 109

Figure 4-63 Set A normalized load crack-width curve........................................... 112

Figure 4-64 Set B Normalized load crack-width curves....................................... 113

Figure 4-65 Theoretical load deflection curves for set A...................................... 115

Figure 4-66 Normalized theoretical load deflection curves for set A........................ 115

Figure 4-67 Theoretical Load deflection curves for set B.................................... 116 
Figure 4-68 Normalized load deflection curves for set B. 116

Figure 4-69 Specimen AC theoretical and experimental load deflection comparison. .. 117 Figure 4-70 Specimen AR2 theoretical and experimental load deflection comparison. 118 Figure 4-71 Specimen AR3theoretical and experimental load deflection comparison. . 118 Figure 4-72 Specimen AR4-S theoretical and experimental load deflection curves ..... 119 Figure 4-73 Specimen AR4 theoretical and experimental load deflection comparison. 119 Figure 4-74 Specimen BC theoretical and experimental load deflection comparison.... 120 Figure 4-75 Specimen BR2 theoretical and experimental load deflection comparison.. 120 Figure 4-76 Specimen BR3Theoretical and experimental load deflection comparison. 121 Figure 4-77 Specimen BR4 Theoretical and experimental load deflection. 121 


\section{Notations}

\begin{tabular}{|c|c|c|}
\hline NSM & $=$ & Near Surface Mounted Retrofitting Technique. \\
\hline CFRP & $=$ & Carbon Fiber Reinforced Polymer. \\
\hline GFRP & $=$ & Glass Fiber Reinforced Polymer. \\
\hline AFRP & $=$ & Aramid Fiber Reinforced Polymer. \\
\hline EFRP & $=$ & External Bonded Reinforcement. \\
\hline $\mathrm{D}_{\mathrm{b}}$ & $=$ & Bar Diameter. \\
\hline$f_{y}$ & $=$ & Steel Yielding Stress. \\
\hline$\varepsilon_{y}$ & $=$ & Steel Yielding Strain. \\
\hline$f_{f u}$ & $=$ & CFRP Ultimate Tensile Stress \\
\hline$L_{d b}$ & $=$ & Development Length. \\
\hline$f_{c}^{\prime}$ & $=$ & Concrete Compressive Strength. \\
\hline$\tau_{r-e}$ & $=$ & Shear Stress at Epoxy Rod Interface. \\
\hline$\tau_{e-c}$ & $=$ & Shear Stress at Epoxy Concrete Interface. \\
\hline$d_{f r p}$ & $=$ & The Flexural Depth of CFRP Reinforcement. \\
\hline$\varepsilon_{f r p}$ & $=$ & CFRP Strain. \\
\hline$\varepsilon_{s 1}$ & $=$ & Compressive Steel Strain. \\
\hline
\end{tabular}




\begin{tabular}{|c|c|c|}
\hline$E_{f r p}$ & $=$ & Modulus of Elasticity for CFRP Material. \\
\hline$A_{\text {frp }}$ & $=$ & CFRP Cross Sectional Area. \\
\hline$E_{s}$ & $=$ & Steel Modulus of Elasticity. \\
\hline$A_{s 1}$ & $=$ & Cross Sectional area of Compressive Steel Reinforcement. \\
\hline$\varepsilon_{s}$ & $=$ & Strain in the Steel Reinforcement. \\
\hline$A_{s}$ & $=$ & Cross Sectional Area of Tensile Steel Reinforcement. \\
\hline$d_{1}$ & $=$ & The Depth of Compressive Steel Reinforcement. \\
\hline $\mathrm{C}$ & $=$ & The Depth of Compressive Concrete Section. \\
\hline$d$ & $=$ & The Depth of Tensile Steel Reinforcement. \\
\hline$M_{c}$ & $=$ & Concrete Bending Moment Capacity. \\
\hline$M_{s t 1}$ & $=$ & Compressive Steel Bending Moment Capacity. \\
\hline$M_{f r p}$ & $=$ & CFRP Bending Moment Capacity. \\
\hline$M_{s t}$ & $=$ & Tensile Steel Bending Moment Capacity. \\
\hline$\Phi_{y}$ & $=$ & Section Curvature at Steel Yielding Step. \\
\hline$\Phi_{c}$ & $=$ & Section Curvature at Concrete Crushing Step. \\
\hline $\mathrm{a}, \mathrm{b}$ & $=$ & Dimensions of the Grooves. \\
\hline
\end{tabular}




\section{Chapter 1: Introduction}

\subsection{General}

Many of the existing reinforced concrete (RC) members are exposed to degradation. Repairing these components is costly and demanding. Plenty of strengthening members and techniques have been carried out to repair the deteriorated elements. Steel plates and bars are the common ones that are used to rehabilitate the concrete and masonry members such as slabs, beams, columns, and walls. However, this technique has some drawbacks such as corrosion, enlargement of the original repaired sections, and the difficulty of lifting, and installation process. The most attractive alternative is the FRP materials. They do not corrode, are lightweight, and have high level of strength compared to steel. Nevertheless, they are expensive, are brittle, and have a low modulus of elasticity. Generally, the FRP materials consist of fibers that are impregnated in the matrix of vinyl ester which transvers the loads between the fibers and protects them. The fibers could be made of glass, aramid, and Carbone. The fibers provide the composites materials with the strength and the required stiffness. This composition makes the FRP materials strong in the direction of the fibers and weak in the transverse direction. The CFRP's tensile strength is about more than four times the tensile yielding strength of the steel, and it is much lighter. Table 1-1 and Figure 1-1 show the comparison in behavior between the steel and different types of FRP rods. There are different texture of CFRP rods available in the industries such as smooth surface, sand coated, ribbed, and sand coated with helical wrap. These textures work as mechanical interlocking to provide good adhesion when they are used as strengthening elements. 
Table 1-1-1 Typical properties of steel and FRP materials.

\begin{tabular}{|c|c|c|}
\hline Bar type & Tensile strength (ksi) & Modulus of elasticity (ksi) \\
\hline Steel & 60 & 29000 \\
\hline GFRP & 100 & 6000 \\
\hline AFRP & 170 & 12000 \\
\hline CFRP & 315 & 18000 \\
\hline
\end{tabular}

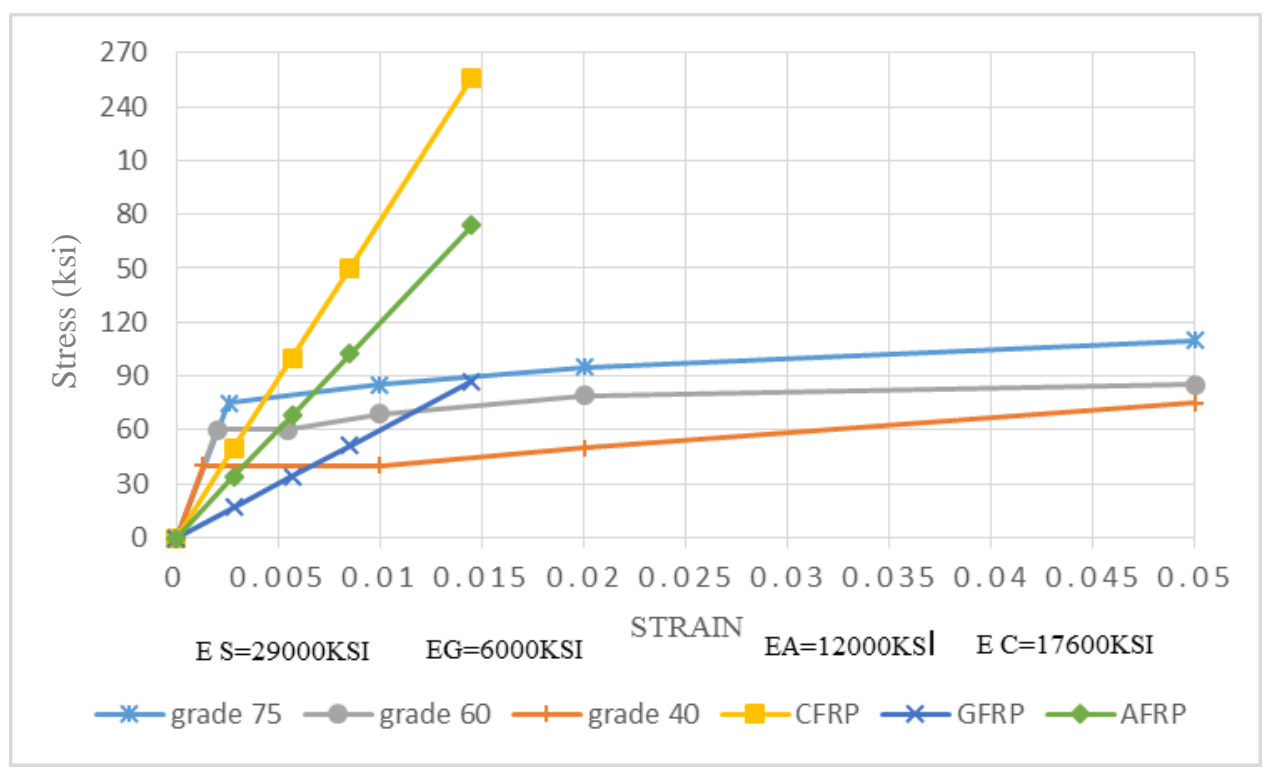

Figure 1-1 Stress-strain curve comparison of steel and FRP bars.

\subsection{Near Surface Mounted Technique (NSM)}

According to the 2013 report card for America's infrastructure as published by American Society of Civil Engineers (ASCE) “one in nine of the nation's bridges are rated as structurally deficient". Since many structures, especially bridges, are classified as structurally deficient, rehabilitation of these structures is a serious concern for engineers. A variety of retrofitting methods are in process to upgrade the existing structures. Steel 
plates and FRP jackets are externally bonded to the retrofitted members to increase their capacity of flexure and shear. However, due to the corrosion issue, theses strengthening systems loss their efficiency with time. The near surface mounted technique has recently become a promising and accepted method. It essentially makes a groove along the surface of the retrofitted concrete with depth less than the cover of the member. After cleaning the groove, an epoxy paste is used to fill a $2 / 3$ of the groove's depth. The FRP element then is mounted in the groove. Finally, the groove is completely filled with epoxy and the excessive epoxy is leveled with surface of the concrete. This technique makes the FRP material completely covered by epoxy in the cover of the concrete. NSM is also desirable for strengthening the negative regions of girders and slabs where the mechanical and corrosions factors are severely damaging for externally bonded steel or FRP plates. FRP rods or strips can be used to perform this technique. However, the relatively small contacting surface of the FRP strips to the surrounding concrete surface makes the de-bonding more feasible and controlling. As compared with the externally bonding reinforcement (EBR), the NSM does not require any preparation for the grove prior to the installation. CFRP material is more secured and protected in NSM than the EBR system.

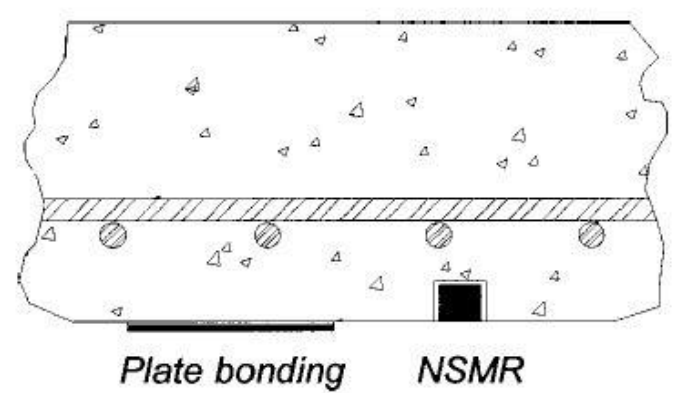

Figure 1-2 NSM technique (Taljisten et al. 2003). 


\subsection{Objective}

The main objective of this research project is to investigate the behavior of the rectangular beams that are strengthened with NSM-CFRP reinforcement bars. By obtaining the characteristics of bonding behavior from the pullout test, the NSM-CFRP rebars are going to be implemented in rectangular concrete beams. The efficiency of using this method in retrofitting existing structures and bridges can be obtained by understanding the behavior and parameter of NSM-CFRP rods technique. This research contributes to and provides more knowledge regarding this method so that engineers can judge and demonstrate the rehabilitation of the deteriorated structures. 


\section{Chapter 2: Literature Review}

\subsection{Introduction}

FRP materials have been used to strengthen many structural components in many different shapes and types. FRP jackets, FRP Strips, and FRP rods are the common types that have been used to rehabilitate the existing structural components. The many advantages of using FRP as strengthening materials have made this material an attractive alternative. The main benefits of using FRP are that it is lightweight, high in strength, and easy to set-up. Among the many applications of using FRP, NSM-FRP is a promising technique of strengthening the concrete members. However, de-bonding issues have to be overcome to make this technique more efficient and reliable. The NSM-FRP rod is basically pressing the FRP rod into a cut that is pre made in the concrete cover of the strengthened components. The FRP rods are attached to the concrete by epoxy paste. Groove size, paste, concrete, rods properties are the main variables that control the efficiency of the NSM-FRP rods.

\subsection{Bond Mechanism}

As stated above, the main characteristic that controls the efficiency of the NSM technique is the bonding. Much research on the pullouts-FRP rods has been done in the last recent years. The pullout test aims to investigate the bonding behavior of the NSM-FRP joint. Laura De Lorenzis et al. (2002) performed an experimental test on the bond between the NSM rods and concrete that had compressive strength of $27.6 \mathrm{MPa}$ (4000psi). Bond length, diameter of the rod, material types of FRP, surface treatment, and the size of the 
groove were the main characteristics that were addressed in the study. Four different bonded lengths were chosen: $6,12,18$, and 24 times the rod diameter. Two diameters of \#3 and \#4 rods for carbon and glass FRP were investigated. The CFRP rod had a two surface configuration: deformed and sand coated. Three different sizes of groove were tested. The test was performed on an inverted $\mathrm{T}$ beam where the tension face was strengthened with the NSM technique as shown in Figure 2-1. It was observed that the specimens with deformed rods failed by splitting the epoxy paste and cracking the concrete surrounding the groove. However, the pullout phenomenon was dominant in the specimens retrofitted with sand blasted rods. It was also observed that the groove size had a significant effect on increasing the bonding strength. As the groove thickness increased, the strength of the epoxy past increased and the failure shifted from the epoxy to the surrounding concrete. The bond length also had a remarkable influence on the bond behavior. By increasing the bond length, the stress was distributed over the length so that it prevented the early de-bonding in the epoxy-rod interface. It was also reported that the optimum groove size for \#3and \#4 rods is $3 / 4$ in and 1.0 in respectively. 


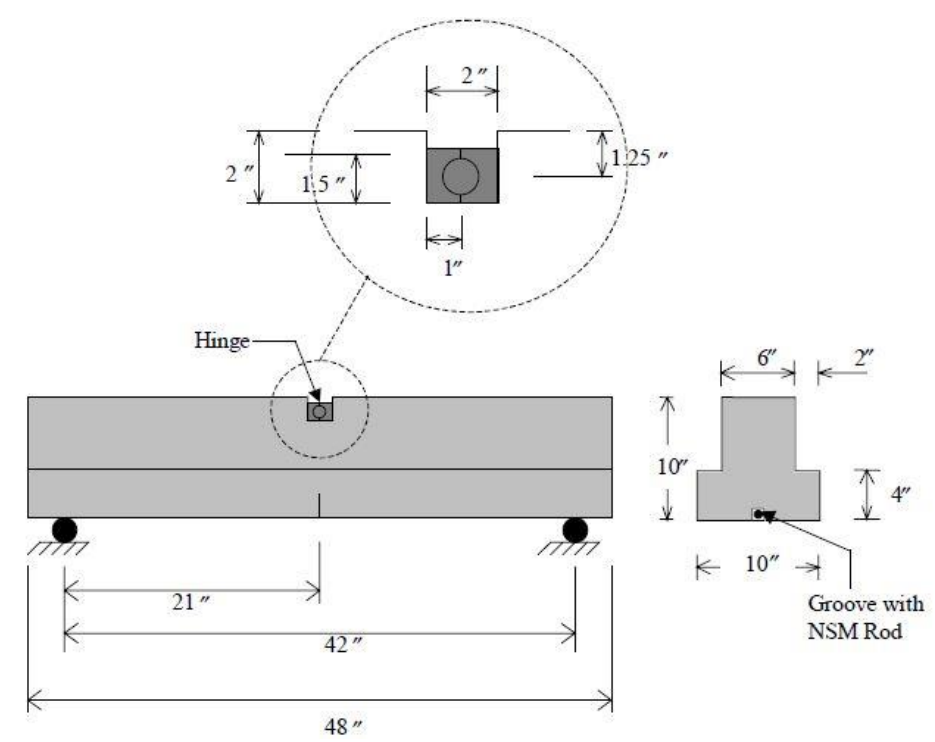

Figure 2-1 Hinged beam pullout test with inverted T beam section(Laura De Lorenzis et al. 2002).

Laura De Lorenzis et al. (2002) conducted an experimental work on the configuration of a new specimen as shown in Figure 2-2. This modified pullout test was conducted with the purpose of eliminating any eccentricity that would occur in the conventional pullout test. The test has investigated 36 specimens with various variables. Type of the FRP rod, adhesive material, development length, and the groove size were the parametric study of this research. Carbone FRP with ribbed and sand coated, as well as glass FRP, were investigated under the pullout test. The filling adhesive materials were epoxy-based and cement mortar. The compressive strength of the concrete was $22 \mathrm{MPa}(3.19 \mathrm{ksi})$. The development lengths of the rod were varied as $4 \mathrm{D}_{\mathrm{b}}, 12 \mathrm{D}_{\mathrm{b}}$, and $24 \mathrm{D}_{\mathrm{b}}$. Finally, four groove sizes were cut in the specimens to find out the sensitivity of the groove size on the overall bonding behavior: $1.25 \mathrm{D}_{\mathrm{b}}, 1.5 \mathrm{D}_{\mathrm{b}}, 2 \mathrm{D}_{\mathrm{b}}$, and $2.5 \mathrm{D}_{\mathrm{b}}$. From the test results, many failure modes were reported: pullout at the concrete- adhesive interface; pullout at the rodadhesive interface; splitting of the adhesive's cover with no concrete cracking; and 
crushing the concrete surrounding the groove with formation of crack in the adhesive's cover. Curve (a) shown in Figure 2-3 represents the typical slip-stress diagram for epoxy adhesive with the precut groove, which is usually smooth and sand coated surface. The failure in curve (a) occurred at the concrete adhesive interface. Curve (b) represents the typical slip-bond stress curve for a glass FRP rod when the failure is the epoxy-concrete interface. As the groove size increased, the failure shifted from epoxy-rod interface to concrete- epoxy interface with initiation of cracks in the surrounding concrete. It was also reported in this study that the epoxy adhesive provides a better bonding strength than the cement mortar adhesives due to its high shear strength. It should also be noted that the surface configuration of the CFRP played no significant role in the bonding behaviors since the controlling failure was at concrete-epoxy interface.

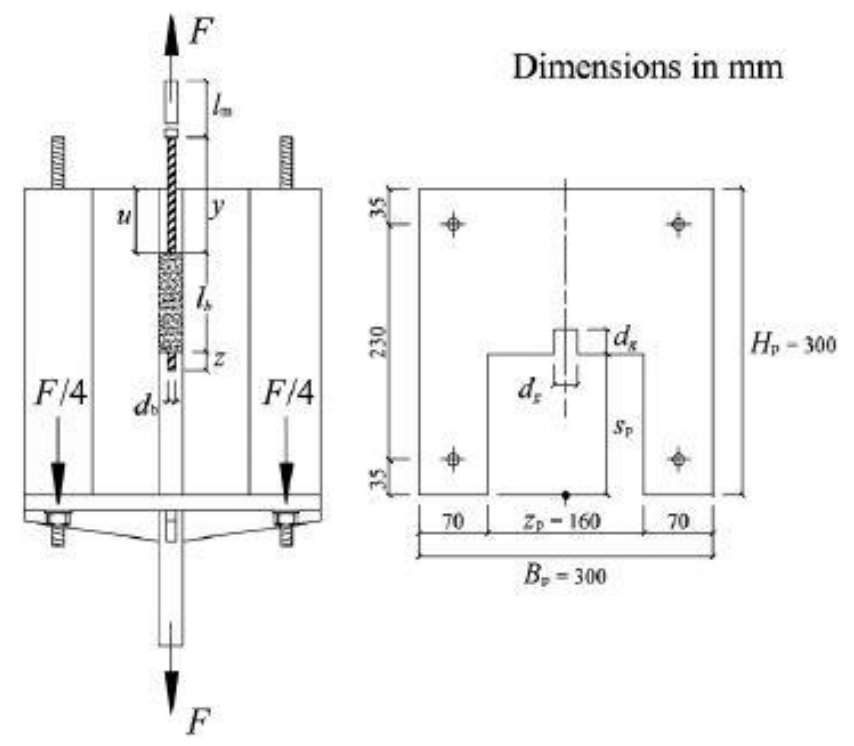

Figure 2-2 Modified pullout test scheme(Laura De Lorenzis et al. 2002). 

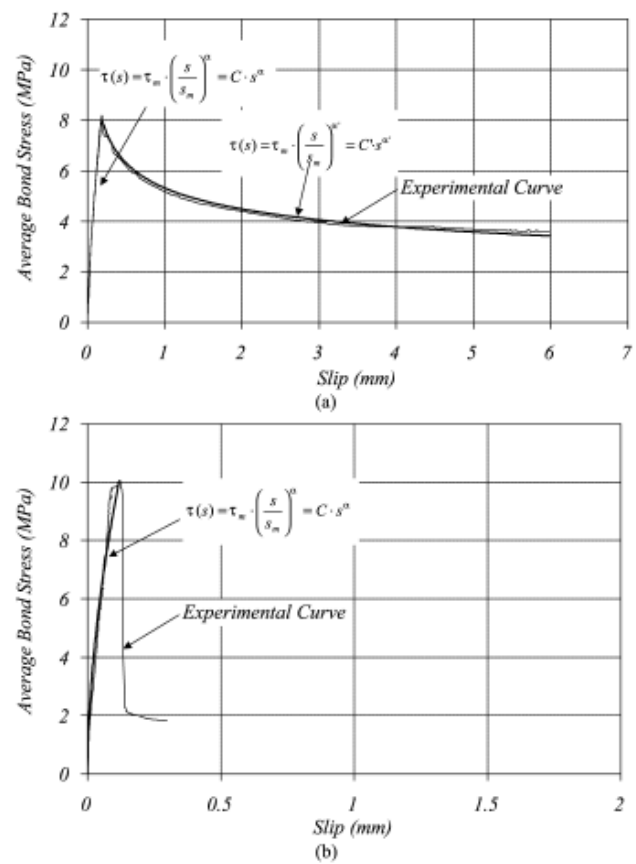

Figure 2-3 Slip- bond stress relationship(Laura De Lorenzis et al. 2002).

D. Novidis et al. (2008) did a direct pullout test by using the testing system shown in Figure 2-4. The parametric study was the development length and the groove size. Twenty-four concrete specimens were used with compressive strength of $34.5 \mathrm{MPa}$ (5000 psi). The specimens' dimensions were $150 \mathrm{~mm}$ (6.0 in) squared, and $300 \mathrm{~mm}$ (12.0 in) was the length of the concrete block. The various embedded lengths were $3 \mathrm{D}_{\mathrm{b}}, 5 \mathrm{D}_{\mathrm{b}}$, $7.5 \mathrm{D}_{\mathrm{b}}$, and $10 \mathrm{D}_{\mathrm{b}}$, and the groove dimensions were either $25 \mathrm{~mm}(1.0 \mathrm{in})$ or $20 \mathrm{~mm}$ (0.8in). The conclusion indicated that the adopted pullout test gave reliable results with a manageable specimen size. Two failure modes were obtained: pullout of the rod at concrete-epoxy interface, and pullout of the rod at epoxy-rod interface. As the groove size increased, the strength of the joint increased. In the same manner for a given groove size, the bonding strength increased as the development length increased up to a certain 
length. The non-uniformly distributed stress occurred after a limit increasing of development length, resulting in a decrease in the bonding strength.
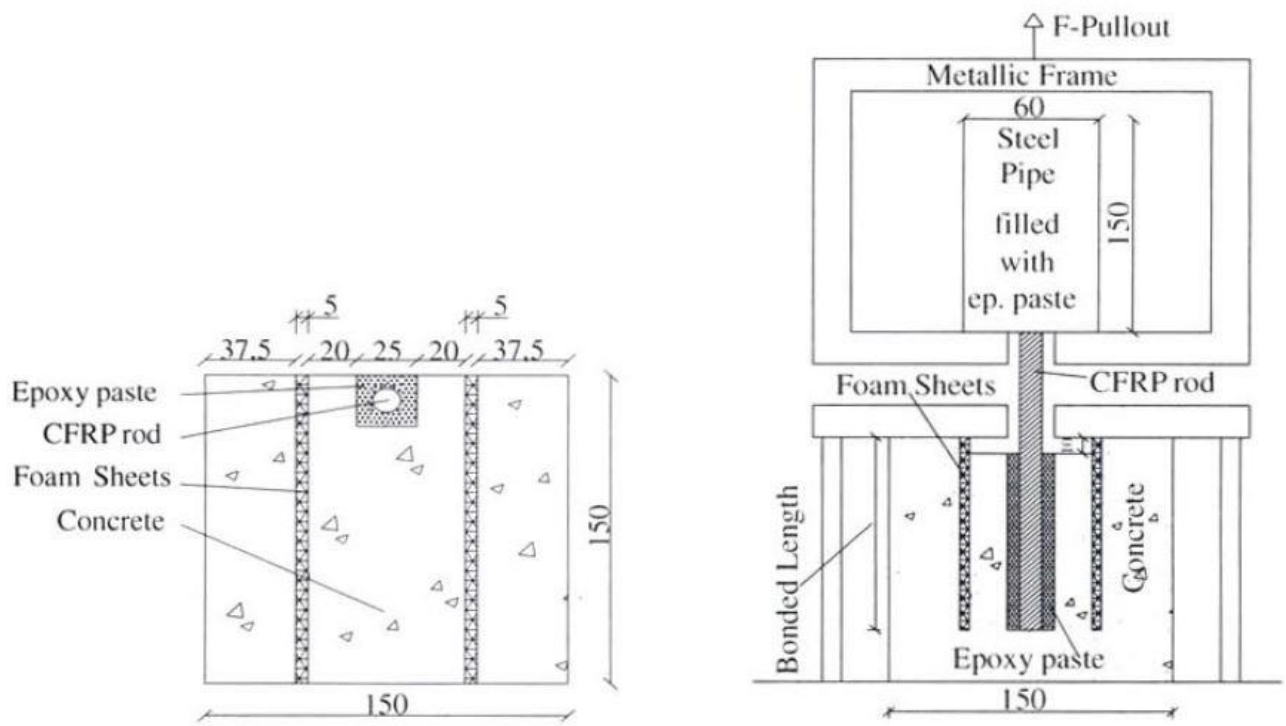

Figure 2-4 Direct puulout test with spurious stress breakers(D. Novidis et al. 2008).

Bilotta A. et al. (2011) conducted experimental research comparing the EBR and NSM systems. For the NSM technique, basalts, glass, and Carbone materials were used with different geometries. All the pullout tests were performed on prisms that have dimensions of 160x200 $\mathrm{mm}$ and $400 \mathrm{~mm}$ height as shown in Figure 2-5. The CFRP rods had 8mm diameter with smooth surface. The groove dimensions were $1.75 \mathrm{D}_{\mathrm{b}}$ and $300 \mathrm{~mm}$ as development length $\left(37.5 \mathrm{D}_{\mathrm{b}}\right)$. It was reported that the pullout test of CFRP rod failed at $50 \mathrm{kN}$ (11.0 kips) with de-bonding at the epoxy-concrete interface, and with the detachment of the concrete layer as a mode of failure. It is worth noting that the concrete compressive strength was $19 \mathrm{MPa}$ (3.0 ksi) to simulate the poor existing RC components. As a comparison between the EBR and NSM systems, it was concluded that the NSM 
system worked more efficiently than the EBR system. For NSM system, the CFRP rod was fully bonded to the concrete subsurface by the adhesive. Therefore, more than $50 \%$ of the CFRP's tensile strength could be extracted. For NSM system, the CFRP rod was full bonded to the concrete by the adhesives. Therefore, more than $50 \%$ of the CFRP tensile strength could be extracted by using the NSM system.

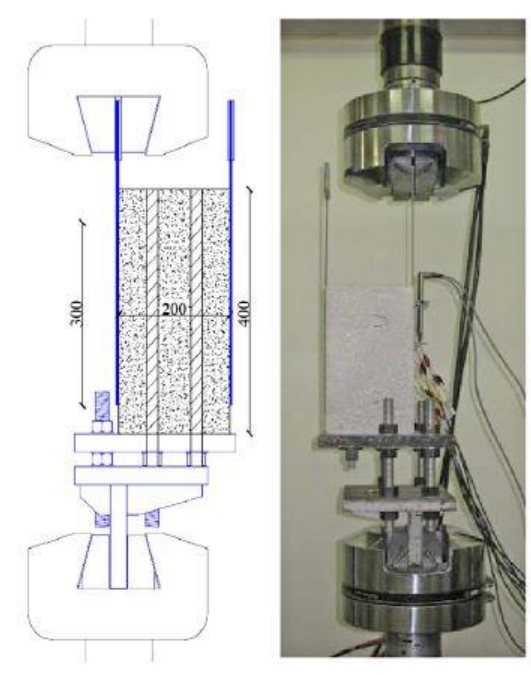

Figure 2-5 Pull out test setup and specimen dimensions(Bilotta A. et al. 2011).

Shehab M. Soliman et al. (2013) conducted an extensive bonding test on 80 specimens with the compressive strength range between (38-44 MPa). They adopted the modified test system that was used by De Lorezis of $340 \mathrm{~mm}$ x40 mm (13.38 in x13.38 in) and 500 $\mathrm{mm}$ (20.0 in) height as shown in Figure 2-6. The main aim of the study was to investigate the weather effect on the bonds' behavior. However, many bond characteristics were investigated such as: FRP type_-glass and carbon with sand coated ; embedment length: $6 \mathrm{D}_{\mathrm{b}}, 12 \mathrm{D}_{\mathrm{b}}, 18 \mathrm{D}_{\mathrm{b}}, 24 \mathrm{D}_{\mathrm{b}}, 36 \mathrm{D}_{\mathrm{b}}$, and 48D ; adhesive type: epoxy based and cement based adhesive; and groove size: $1.5 \mathrm{D}_{\mathrm{b}}$ and $2.0 \mathrm{D}_{\mathrm{b}}$. Two diameters of CFRP rods were used 
9.5mm (0.37 in.) and $12.7 \mathrm{~mm}(0.5 \mathrm{in}$.$) , which had a tensile strength of 1546 \mathrm{MPa}(224$ ksi) and $1250 \mathrm{MPa}(181 \mathrm{ksi})$ respectively. The results indicated that the conditioned specimens performed less efficiently than the reference ones. In terms of the adhesive types, the reference specimens with the epoxy based adhesive had a consistently higher bond strength than the specimens with the cement based adhesive. It should be mentioned that increasing the bonding length, increased the strength of the joint. However in the study, the rupture of the CFRP and GFRP rods was reported for the $24 \mathrm{D}_{\mathrm{b}}$, $36 \mathrm{D}_{\mathrm{b}}$, and $48 \mathrm{D}_{\mathrm{b}}$, which gave full efficiency for bonding. Shear tension failure of the surrounding concrete was the controlling mode failure for the reference specimens with the epoxy based adhesive. However, for the conditioned specimens, the failure was controlled by the epoxy splitting. The controlling failure mode for the reference specimens with the cement based adhesive was the de-bonding in the concrete-adhesive interface.

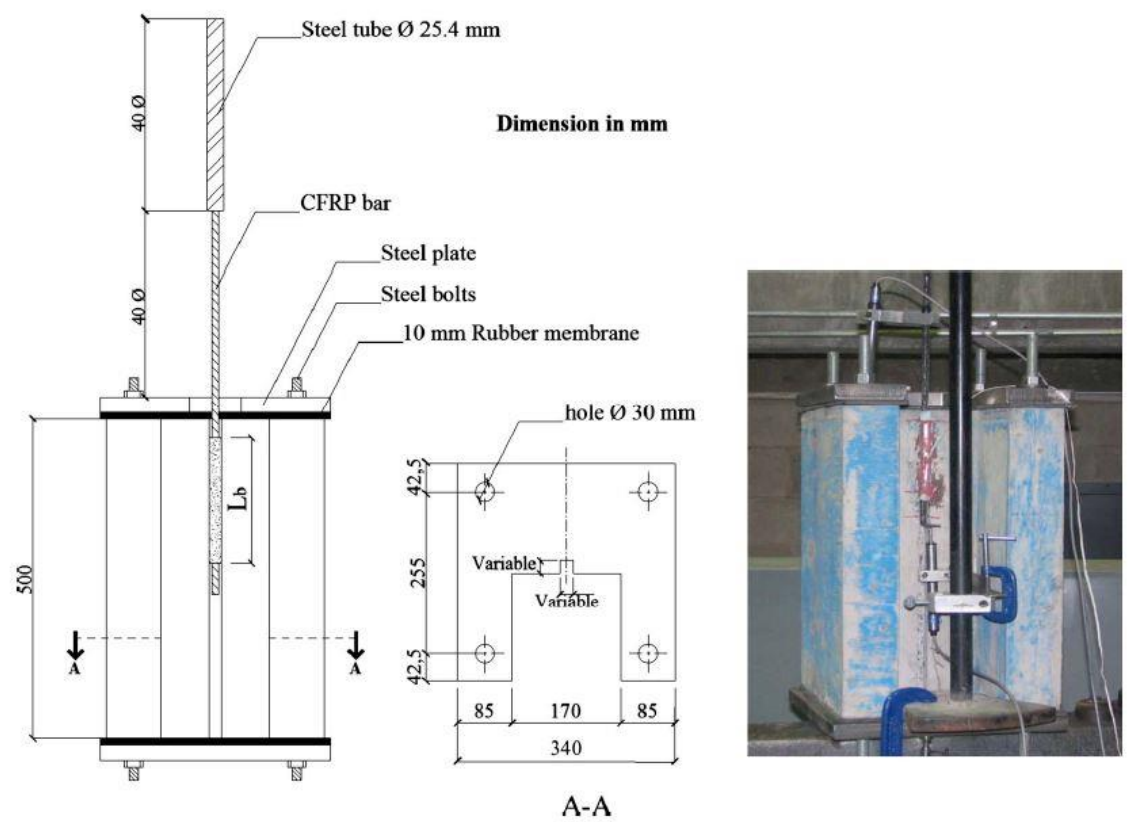

Figure 2-6 Modified pullout test with instrument (Shehab M. Soliman et al. 2013). 
Sharaky, I. A. et al. (2013) investigated many bond parameters. The main characteristics that were implemented and investigated by using the modified pullout test were: groove surface, groove geometry, FRP bar type, bond length, and construction details of the groove. Two CFRP rods were used in the test $8 \mathrm{~mm}(0.315 \mathrm{in})$ with smooth surface texture and $9.05 \mathrm{~mm}(0.356 \mathrm{in})$ with surface texture. The compressive strength of the concrete ranged between (35.2-42.2 MPa) (5-6.12 ksi). Many conclusions have been drawn and addressed out of the test's results. It was reported that the groove surface had no effect on the bond capacity if the failure was at the bar-epoxy interface. As the bond length increased from $40 \mathrm{~mm}\left(5 \mathrm{D}_{\mathrm{b}}\right)$ to $192 \mathrm{~mm}\left(24 \mathrm{D}_{\mathrm{b}}\right)$ for the CFRP $8 \mathrm{~mm}$ rod, the failure load increased from $12.75 \mathrm{kN}$ (2.866 kips) to $36.59 \mathrm{kN}$ (8.225 kips). Increasing the groove dimensions from $1.5 \mathrm{db}$ to $2 \mathrm{db}$, delayed the bar epoxy interface failure. It was also reported that the interlocking increased the joint capacity by $14.8 \%$. It is interesting to mention that the transverse interlocking, which is shown in Figure 2-7 below had a remarkable impact on the transfer load failure and stress from concrete epoxy interface to the surrounding concrete and enhancement of the concrete epoxy interface bond.

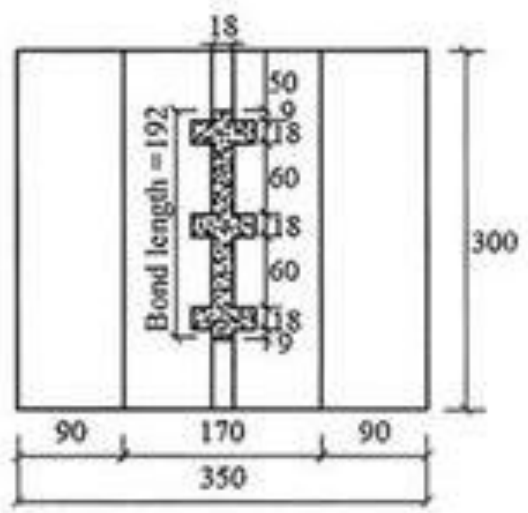

Figure 2-7 Specimens with mechanical interloching(Sharaky, I. A. et al. 2013, p 353). 


\subsection{Flexural Behavior}

Täljsten et al. (2003) conducted an experimental work on eight rectangular full-scale beams. In this study, an experimental work was carried out to investigate the flexural behavior of the beams that strengthened with NSM CFRR. The strengthening was with the pre-stressed NSM CFRP and without pre-stressed NSM CFRP. The flexural reinforcement of all specimens consisted of two $16 \mathrm{~mm}$ steel rebars, and had concrete compressive strength of $60 \mathrm{MPa}(9000 \mathrm{psi})$. The beams of $4 \mathrm{~m}(13.2 \mathrm{ft}$.) length and 300x200 mm (11.811x7.874 in) cross section were tested under four-point loads. The shear span was 1300 mm reinforced with 10mm steel stirrups spaced @ 75 mm. Four beams were tested for each series. For the first series of the four specimens, one was a control specimen and three were strengthened with two NSM CFRP $10 \mathrm{~mm}$ (0.39 in) squared rods. Epoxy bond was used to bond the beam (E4) with full development length and E3 with a development length of $3000 \mathrm{~mm}$. However, a cement grout bond was used to reinforce beam (C3) with a development length of $3000 \mathrm{~mm}$. For the second series, pre-stressed NSM CFRP rods were used. The groove size for the epoxy retrofitting beam was $15 \times 15 \mathrm{~mm}(0.6 \times 0.6 \mathrm{in})$ and $20 \times 20 \mathrm{~mm}(0.787 \times 0.787 \mathrm{in})$ for the cement based adhesive beam. The reference beam had overall flexural strength of $79 \mathrm{kN}$ (17.76 kips). The cement grout strengthened beam had an overall flexural strength of $123 \mathrm{kN}(27.652$ kips) and failed by anchorage slippage. However, the overall flexural strength of the epoxy-strengthened beam was $140 \mathrm{kN}$ (31.473 kips) and failed by anchorage failure. Finally, the full-developed length of epoxy strengthened beam failed by rupture at an overall flexural strength of $152 \mathrm{kN}$ (34.171 kips). In general, the strengthened beams 
exhibited a significant improvement in the flexural performance over the reference beam as shown in Figure 2-8 below.

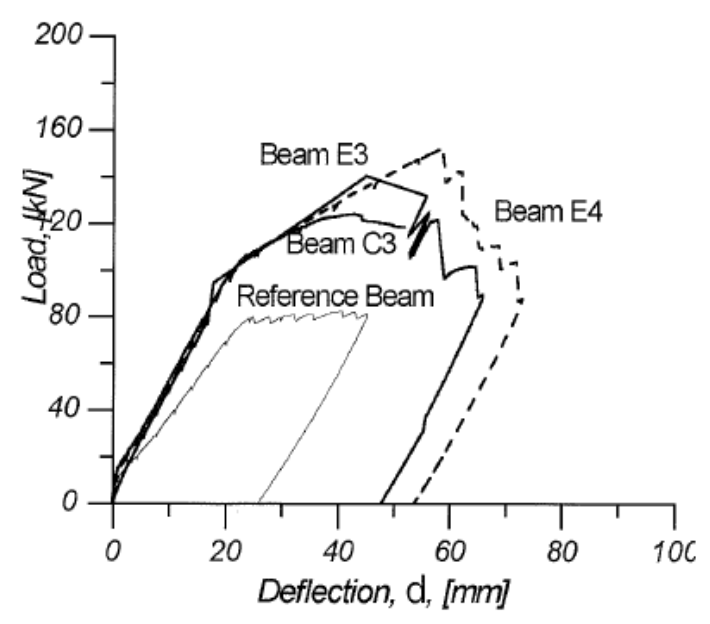

Figure 2-8 Load-deflection curve(Täljsten et al. 2003).

Hassan, T et al. (2004) conducted an experimental and analytical study on eight simply supported T- beams. Flexural and bond performance was investigated in this study. The beam had a total depth of $300 \mathrm{~mm}$ (11.811in) and clear span of $2.5 \mathrm{~m}(8.2 \mathrm{ft})$. The parameters of this study were the development length and adhesive materials. One of the beams designated as $A_{o}$ shown in Table 2-1 below was reinforced with only steel and considered as a reference beam. The flexural reinforcement consisted of two No.10 and two No15 rebars as secondary reinforcement. The others specimens were retrofitted with $9.5 \mathrm{~mm}$ (0.375 in) CFRP bars that had a modulus of elasticity of $111 \mathrm{GPa}(16099.0 \mathrm{ksi})$ and an ultimate tensile strength of $1918 \mathrm{MPa}(278.0 \mathrm{ksi})$. All of the beams had a concrete compressive strength of $48 \mathrm{MPa}$ (6.96 ksi) and the groove size of $18 \mathrm{~mm}$ (0.71in) width and $30 \mathrm{~mm}$ (1.18 in) depth. Different development lengths for NSM-CFRP rods were 
used for the rest of the specimens. A1, A2, A3, and A4 were strengthened with gel epoxy adhesive that had a modulus of elasticity of $1200 \mathrm{MPa}(174.0 \mathrm{ksi})$, a tensile strength of $48 \mathrm{MPa}$ (7.0 ksi), and a development length of $150 \mathrm{~mm}$ (6.0 in), $550 \mathrm{~mm}$ (22.0 in), 800 $\mathrm{mm}$ (31.5 in), and $1200 \mathrm{~mm}$ (4.0 ft) respectively. Whereas, A5, A6, and A7 were retrofitted with epoxy adhesive that had a modulus of elasticity of $3000 \mathrm{MPa}(435.0 \mathrm{ksi})$, a tensile strength of $62 \mathrm{MPa}(9.0 \mathrm{ksi})$, and a development length for the CFRP bars of 550 $\mathrm{mm}$ (22.0 in), $800 \mathrm{~mm}$ (31.5 in), and $1200 \mathrm{~mm}$ (47.0 in) respectively. The results are shown in Table 2-1 below. It can be observed that the adhesive type did not have a significant effect on the behavior of the bonding. It also shows that the failure modes were mostly the de-bonding at the concrete epoxy interface. This de-bonding occurred at the zone where the secondary reinforcing steel was terminated. The maximum stress at the CFRP bars was $45 \%$ of the ultimate strength of the CFRP bars for the maximum development length. This indicated that the rupture of the FRP bars did not occur before the de-bonding failure. A new analytical relationship for bonding was proposed based on the finite element modeling and the experimental works. By using the new proposal, a chart of finding a development length based of the rods size was constructed and verified with ACI code. The summary of the study indicated that the NSM FRP technique can improve the stiffness and the flexural strength of the strengthened beam. A clear spacing, edge distance, and development length of achieving a good tensile strength before de-bonding were suggested. However, this length depended on many parameters such as the dimension of the bars, concrete and adhesive properties, reinforcement configuration, and groove width. 
Table 2-1 The test results (Hassan, $T$ et al. 2004,).

\begin{tabular}{|c|c|c|c|c|c|c|c|c|c|}
\hline Beam no. & $L, \mathrm{~mm}$ & Epoxy used & $P_{t}, \mathrm{kN}$ & $\Delta_{u}, \mathrm{~mm}$ & $\varepsilon_{d}, \%$ & $f_{F R P}, \mathrm{MPa}$ & $f_{F R P} / f_{L}, \%$ & $\tau_{f}, \mathrm{MPa}$ & Failure mode \\
\hline $\mathrm{A} 0$ & N/A & N/A & 56 & 64 & - & - & - & - & $C^{\prime}$ \\
\hline A1 & 150 & \multirow{4}{*}{ Duralith-gel } & 56 & 78 & 0.11 & 122 & 6.4 & 1.93 & $\mathrm{D}^{\dagger}$ \\
\hline $\mathrm{A} 2$ & 550 & & 67 & 15.3 & 0.63 & 699 & 36.4 & 3.0 & D \\
\hline $\mathrm{A} 3$ & 800 & & 73 & 21.2 & 0.73 & 810 & 42.2 & 2.40 & D \\
\hline $\mathrm{A} 4$ & 1200 & & 79 & 24.2 & 0.78 & 866 & 45 & 1.72 & $\mathrm{D}$ \\
\hline A5 & 550 & \multirow{3}{*}{ Kemko 040} & 59 & 12 & 0.60 & 666 & 34.7 & 2.9 & D \\
\hline A6 & 800 & & 70 & 16.5 & 0.68 & 755 & 39.3 & 2.3 & $\mathrm{D}$ \\
\hline A7 & 1200 & & 76 & 25.8 & 0.73 & 810 & 42.2 & 1.61 & D \\
\hline \multirow{2}{*}{\multicolumn{5}{|c|}{$\begin{array}{l}\text { "C refers to crushing of concrete and steel yielding. } \\
{ }^{+} \mathrm{D} \text { refers to debonding of CFRP bars. }\end{array}$}} & & $\bar{L}$ & \multicolumn{2}{|c|}{$\mathrm{L}$} & \\
\hline & & & & & \multicolumn{2}{|l|}{7} & 2500 & & \\
\hline
\end{tabular}
bars at debonding failure; $f_{u}=$ tensile strength of CFRP bars (1918 MPa); and $\tau_{f}=$ average bond stress at failure.

Tang, W. C. et al. (2006) conducted an experimental test on ten beams that were tested under flexural to investigate the moment-deflection behavior. The parameters of this research were the compressive strength of the concrete 58,37, and $21 \mathrm{MPa}(8.41,5.36$,and $3.04 \mathrm{ksi}$ ); the types of reinforcements - steel reinforcing, sand blasted GFRP reinforcing, and NSM sand blasted GFRP reinforcing; and the type of adhesive-epoxy past XH-130 and XH-111. All of the specimens were tested under two point symmetrical loads. The specimens' dimensions were $250 \mathrm{~mm} \times 180 \mathrm{~mm}(9.84 \times 7.08 \mathrm{in})$ cross section and 1500 mm (4.9 ft) span length. Two different diameters of GFRP bars were used: a \#3 sand coated with a diameter of $9.5 \mathrm{~mm}(0.374 \mathrm{in})$ and an ultimate strength of $650 \mathrm{MPa}(94.0$ ksi), and a \# 5 sand coated with diameter of $16 \mathrm{~mm}$ (0.629 in) and an ultimate tensile strength of $512 \mathrm{MPa}(74.0 \mathrm{ksi})$. The reinforcing steel bar was $16 \mathrm{~mm}$ (0.629 in) diameter with an ultimate tensile strength of $478 \mathrm{MPa}(69.328 \mathrm{ksi})$. The specimens' configurations are shown in Table 2-2 below. In Table 2-3, the results of each specimen are reported. Different mode failure and moment-deflection behaviors were observed for different reinforcing characteristics. The steel-reinforced concrete beams exhibited flexural failure where the cracks were initiated near the tension face, and widely extended to the center 
line of the beam until the failure. The GFRP reinforced concrete beams failed in a combination of shear and concrete compression failure. For the \# 5 bars, the rapture was a remarkable failure. The steel- reinforced concrete strengthened with NSM GFRP exhibited splitting of the epoxy simultaneously with shear failure followed by the rupture of the NSM GFRP, particularly for the concrete with high compressive strength. As a comparison between the steel and GFRP reinforcing, the GFRP exhibited nonlinear behavior due to the extensive cracking. The moment capacity remained the same for both materials. However, the GFRP attained the same moment at a high deflection rate. The NSM GFRP reinforced beams showed a significant increasing (23\% $-53 \%$ over the same corresponding to specimens without NSM technique) in the flexural stiffness and moment capacity. The lightweight concrete performed better with the NSM GFRP. In general, the epoxy paste type XH-130performed better than epoxy paste type $\mathrm{XH}-111$.

\begin{tabular}{|c|c|c|c|c|}
\hline Beam code & Concrete mix & Rebar & Adhesives & NSM GFRP bar \\
\hline S-NC & Normal concrete & $16 \mathrm{~mm}$ Round Steel & XH-111 & Nil \\
\hline $\mathrm{G}-\mathrm{NC}$ & Normal concrete & GFRP no. 5 & XH-111 & Nil \\
\hline S-PA20 & PA20 & $16 \mathrm{~mm}$ Round Steel & XH-111 & Nil \\
\hline G-PA20 & PA20 & GFRP no. 5 & XH-111 & Nil \\
\hline S-PA40 & PA40 & $16 \mathrm{~mm}$ Round Steel & $\mathrm{XH}-111$ & Nil \\
\hline S-PA40-G5-A & PA40 & $16 \mathrm{~mm}$ Round Steel & XH-111 & GFRP no. 5 \\
\hline S-PA20-G5-A & PA20 & $16 \mathrm{~mm}$ Round Steel & XH-111 & GFRP no. 5 \\
\hline S-PA20-G3-A & PA20 & $16 \mathrm{~mm}$ Round Steel & XH-111 & GFRP no.3 \\
\hline S-NC-G5-A & Normal concrete & $16 \mathrm{~mm}$ Round Steel & XH-111 & GFRP no. 5 \\
\hline S-NC-G5-B & Normal concrete & $16 \mathrm{~mm}$ Round Steel & XH-130 & GFRP no. 5 \\
\hline
\end{tabular}


Table 2-3 Test results (Tang, W. C. et al. 2006).

\begin{tabular}{|c|c|c|c|c|c|c|c|c|}
\hline \multirow[t]{2}{*}{ Beam notation } & \multirow{2}{*}{$\begin{array}{l}\text { NSM } \\
\text { GFRP dia. } \\
(\mathrm{mm})\end{array}$} & \multirow{2}{*}{$\begin{array}{l}\text { 1st Crack } \\
\text { def. } \\
(\mathrm{mm})\end{array}$} & \multirow{2}{*}{$\begin{array}{l}\text { Failure } \\
\text { load, } P_{\mathrm{u}} \\
(\mathrm{kN})\end{array}$} & \multirow{2}{*}{$\begin{array}{l}\text { Ultimate } \\
\text { moment, } \\
M_{\mathrm{u}}(\mathrm{kN} \mathrm{m})\end{array}$} & \multirow{2}{*}{$\begin{array}{l}\text { Def. to } \\
\text { achieve } 1 / 2 \\
M_{\mathrm{u}}(\mathrm{mm})\end{array}$} & \multirow{2}{*}{$\begin{array}{l}\text { Max. } \\
\text { def. } \\
(\mathrm{mm})\end{array}$} & \multicolumn{2}{|c|}{ Failure mode } \\
\hline & & & & & & & RC Beam & NSM GFRP \\
\hline $\mathrm{S}-\mathrm{NC}$ & - & 0.26 & 118 & 28.7 & 1.51 & 11.85 & Flexure & - \\
\hline G-NC & - & 0.27 & 111 & 27.6 & 3.82 & 14.85 & $\begin{array}{l}\text { Shear/Bar } \\
\text { rupture }\end{array}$ & - \\
\hline S-NC-G5-A & 16 & 0.27 & 149 & 37.3 & 2.52 & 7.75 & Shear & Bar rupture \\
\hline S-NC-G5-B & 16 & 0.29 & 159 & 39.8 & 1.62 & 5.60 & Shear & Bar rupture \\
\hline S-PA20 & - & 0.25 & 95 & 23.6 & 1.21 & 8.05 & Flexure & - \\
\hline G-PA20 & - & 0.28 & 92 & 23.0 & 3.24 & 12.75 & $\begin{array}{l}\text { Shear/Bar } \\
\text { rupture }\end{array}$ & - \\
\hline S-PA20-G5-A & 16 & 0.31 & 144 & 36.2 & 1.26 & 4.65 & Shear & Bar rupture \\
\hline S-PA20-G3-A & 9.5 & 0.32 & 131 & 32.7 & 1.62 & 8.45 & $\begin{array}{l}\text { Concrete } \\
\text { crushing }\end{array}$ & $\begin{array}{l}\text { Epoxy paste } \\
\text { splitting }\end{array}$ \\
\hline S-PA 40 & - & 0.25 & 93 & 23.2 & 1.17 & 3.90 & Flexure & - \\
\hline S-PA40-G5-A & 16 & 0.27 & 115 & 28.5 & 1.26 & 2.90 & Shear & $\begin{array}{l}\text { Bar } \\
\text { debonding }\end{array}$ \\
\hline
\end{tabular}

Al-Mahmoud, F.et al. (2010) carried out an experimental work on concrete beams strengthened by two \# 2 CFRP rods. In this study, seven beams were categorized into two groups: one group was tested as conventional beams under four-point load, and the other group was tested as a cantilever beam. For each group, different development lengths were applied and tested. The main purpose of this study was to investigate the flexural behavior of each group after rehabilitating with CFRP rods. Each group had the controlling beam, which had a cross section of $150 \times 280 \mathrm{~mm}(5.9 \times 11.02 \mathrm{in})$ and $3 \mathrm{~m}$ $(9.84 \mathrm{ft})$ span length reinforced with two- $12 \mathrm{~mm}$ steel bars $(0.47 \mathrm{in})$ at the tension face. The compressive strength of the concrete for all specimens was 37.0 MPa. The retrofitted specimens had two grooves at the tension face and two CFRP rods of $6 \mathrm{~mm}$ that had a young modulus of $146 \mathrm{GPa}(21175.5 \mathrm{ksi})$, and a tensile stress of $1875 \mathrm{MPa}(271.945 \mathrm{ksi})$ was placed inside the groove. Depending on the development length, two modes of failure were observed: pullout and peeling-off failure. For the first group, two 
development lengths were used: one with $2700 \mathrm{~mm}$ (106.0 in.) along the beam's length, and the other $2100 \mathrm{~mm}$ (83.0 in) ending before the supports. The beam with $2700 \mathrm{~mm}$ (106.0 in.) exhibited the pullout de-bonding at the load of $53.3 \mathrm{kN}$ (12.0 kips). The other beam with $2100 \mathrm{~mm}(83.0 \mathrm{in})$ failed at $44 \mathrm{kN}$ (10.0 kips) with peeling-off failure as shown in Figure 2-9 below. The other group had three different development lengths: $2400 \mathrm{~mm}(9.44 \mathrm{in}), 190 \mathrm{~mm}(7.5 \mathrm{in})$, and $150 \mathrm{~mm}(6.0 \mathrm{in})$. The beam with the $240 \mathrm{~mm}$ (94.4 in) development length cracked at $8 \mathrm{kN}$ (1.798 kips), then the steel yielded at $38 \mathrm{kN}$ (8.542 kips), after which the failure occurred at $59.5 \mathrm{kN}$ (13.4 kips). The beam with the $1900 \mathrm{~mm}$ (75.0 in) development length cracked at $10 \mathrm{kN}$ (2.25 kips), and failed at 52.0 $\mathrm{kN}$ (11.6 kips) by peeling off the concrete surrounding the groove. This beam maintained a $72 \%$ flexural strength over the reference beam. Finally, the beam with the $1500 \mathrm{~mm}$ (59.0 in.) development length cracked at $25 \mathrm{kN}$ (5.620 kips), then at $31 \mathrm{kN}$ (6.969 kips) the steel yielded, after which the failure occurred at $36 \mathrm{kN}$ (8.093kips) by peeling of the concrete. This beam maintained a $20 \%$ flexural strength over the reference beam as shown in Figure 2-10 below.

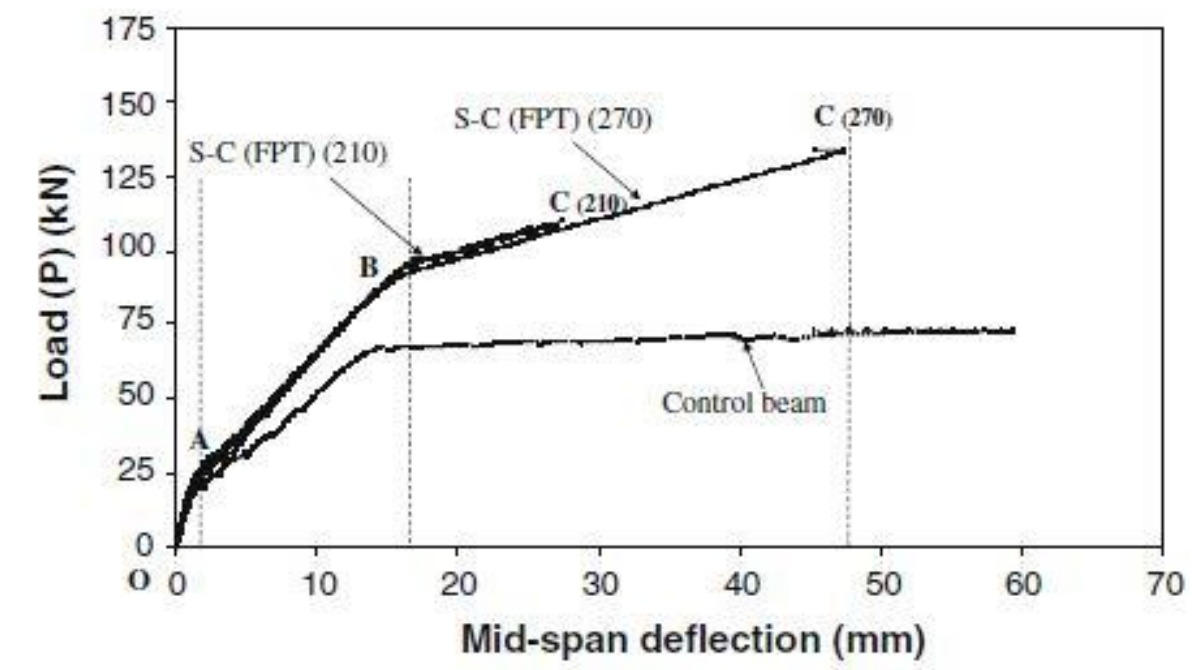

Figure 2-9 Load-deflection curve for retrofitted beams (Al-Mahmoud, F.et al. 2010). 


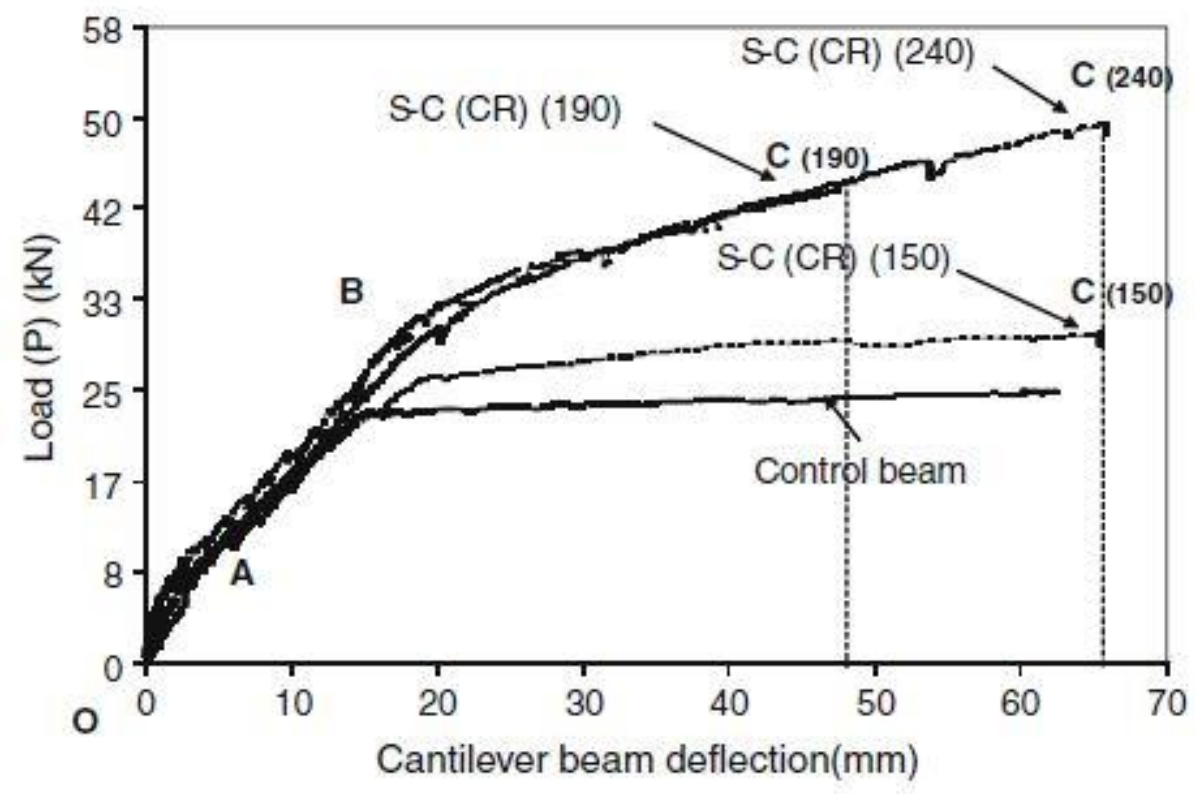

Figure 2-10 Load-deflection curve for retrofitted cantilever beams with FRP bars(Al-Mahmoud, F.et al. 2010).

Soliman, S. M. et al. (2010) investigated many characteristics of NSM-FRP bars. Twenty specimens were tested to investigate their flexural behavior. The specimens were strengthened with NSM-FRP rods to enhance their loads-deflection relationship. The parameters of the study were the types of NSM-FRP rods, FRP bar diameter, bonded length, and groove size. Three series were set and casted with ready mix concrete that had a compressive strength of $40.0 \mathrm{MPa}$ (6000 psi). All specimens were tested under four point load with shear span of $800 \mathrm{~mm}$. Three series were categorized based on the steel ratio as shown in Figure 2-11 below. 


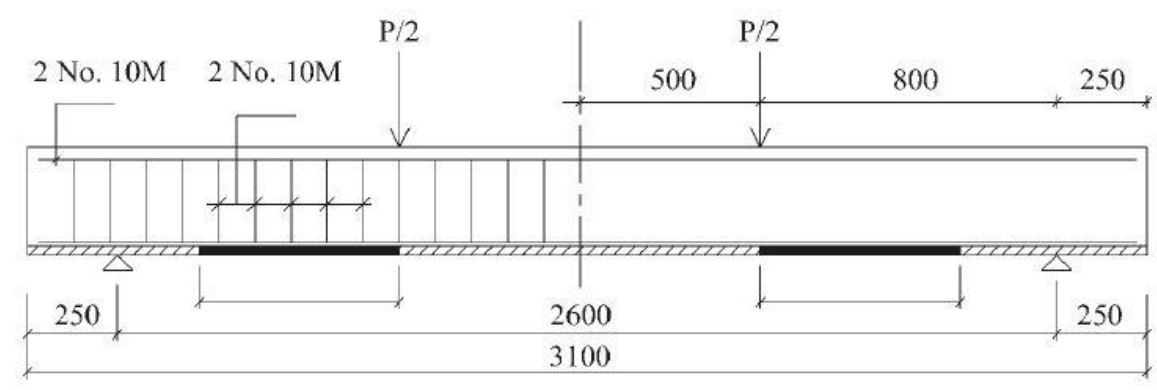

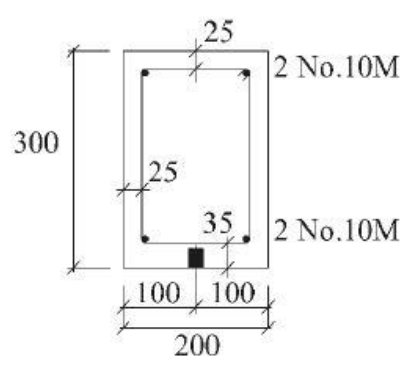

Series A

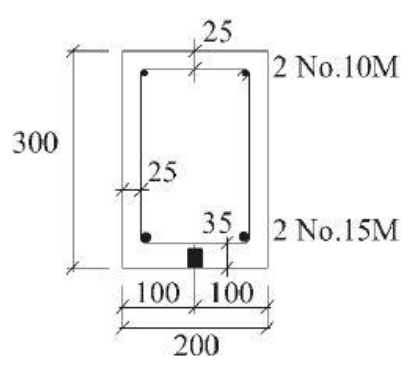

Series B

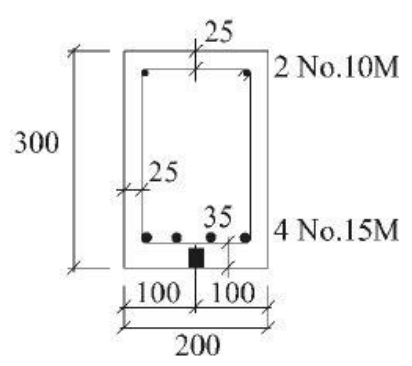

Series C

Figure 2-11 Retrofitteed beam sections details(Soliman, S. M. et al. 2010,p 1373).

Series A consisted of twelve beams. The control beam was reinforced with $0.4 \%$ steel reinforcement. The rest of the specimens were reinforced with $9.5 \mathrm{~mm}(0.374 \mathrm{in}) \mathrm{CFRP}$ bar. The development lengths were $12 \mathrm{D}_{\mathrm{b}}, 24 \mathrm{D}_{\mathrm{b}}, 48 \mathrm{D}_{\mathrm{b}}$, and $60 \mathrm{D}_{\mathrm{b}}$ with a groove size of $1.5 \mathrm{D}_{\mathrm{b}}$ and $2 \mathrm{D}_{\mathrm{b}}$. The objective of this series was to investigate the development length and the groove size. Series B included three specimens. The control specimens were reinforced with $0.8 \%$ of steel. The other two beams were retrofitted with $9.5 \mathrm{~mm}(0.374$ in) CFRP bars that had a development length of $24 \mathrm{D}_{b}$ and $48 \mathrm{D}_{\mathrm{b}}$ with $2 \mathrm{D}_{\mathrm{b}}$ as the groove size. The objective of this series was to investigate the moderate steel ration on the performance of the NSM-FRP technique. Finally, series C consisted of five beams. The control specimens were reinforced with $1.6 \%$ steel. The rest of the specimens were additionally reinforced with $9.5 \mathrm{~mm}$ (0.374 in) CFRP bars that had a development length 
of $12 \mathrm{D}_{\mathrm{b}}, 18 \mathrm{D}_{\mathrm{b}}, 24 \mathrm{D}_{\mathrm{b}}$, and $48 \mathrm{D}_{\mathrm{b}}$ with $2 \mathrm{D}_{\mathrm{b}}$ as the groove size. The obtained results in terms of load-deflection curve showed the same behavior as it was observed by Al-Mahmoud, F.et al. (2010). The general behavior had three limits: the first limit was the concrete cracking limit where all of the specimens have the same value and behavior; the second limit was the steel yielding limit where the steel started to yield and the FRP bars started to involve more; and the last limit was where the FRP bars rupture occurred. From series A, it was found that the gaining capacity was achieved by $22 \%, 33 \%, 71 \%$, and $75 \%$ by increasing the development length from $12 \mathrm{D}_{\mathrm{b}}$ up to $60 \mathrm{D}_{\mathrm{b}}$. However, the gaining capacity in series B was found to be $4 \%-19 \%$ only. This ration decreases dramatically in series C down to $1 \%-9 \%$. Generally, the efficiency of using NSM-FRP was increasing with the decreasing of the steel reinforcement ratio. In this research, the optimum development length was found to be $48 \mathrm{D}_{\mathrm{b}}$ and the optimum steel ratio $0.4 \%$. It was discovered that using the smaller groove size delays the de-bonding failure by increasing the distance between the FRP rods and the steel reinforcements. CFRP and GFRP give the same load carrying capacity at failure. However, GFRP gave more ductility due its relatively low modulus of elasticity. A good indication of this was observed when the maximum measured strains of FRP rods were between $75 \%-85 \%$ of the rupture strains depending on the development lengths.

Micelli, F. et al (2013) investigated the flexural behavior of six reinforced concrete rectangular beams that were strengthened with CFRP rods. The beams were $200 \mathrm{~mm} x$ $400 \mathrm{~mm}$ ( $7.87 \mathrm{in} \mathrm{x} 15.75 \mathrm{in})$ and $4.3 \mathrm{~m}$ long. Two parameters were used: the ratio of the internal steel and the ratio of the CFRP reinforcing bars. Series A had two $14 \mathrm{~mm}$ in 
diameter internal steel bars as tensile reinforcement, whereas series B had two $18 \mathrm{~mm}$ in diameter internal steel bars as tensile reinforcement. Both series had a concrete compressive strength of $15 \mathrm{MPa}(2.17 \mathrm{ksi})$ and NSM reinforcement of one and two $8 \mathrm{~mm}$ (0.315 in) CFRP rods. As shown in the Table 2-4 below, the results indicated that the NSM system sufficiently improved the overall behavior of the flexural capacity for the strengthened beams.

Table 2-4 Specimens details and results (Micelli, F. et al 2013).

\begin{tabular}{|c|c|c|c|c|c|c|c|c|}
\hline \multirow[b]{2}{*}{ Beam } & \multirow[b]{2}{*}{$\begin{array}{l}\text { Flex. reinf. } \\
\text { (tension) }\end{array}$} & \multirow[b]{2}{*}{$\begin{array}{l}\text { FRP } \\
\text { reinf. }\end{array}$} & \multicolumn{2}{|c|}{ Experimental } & \multicolumn{2}{|c|}{ Theoretical } & \multirow[b]{2}{*}{$\%$ Error } & \multirow[b]{2}{*}{$\begin{array}{c}\% \text { increase } \\
\text { over BC (exp.) }\end{array}$} \\
\hline & & & $\begin{array}{l}\text { Ultimate load: } \\
\text { kN }\end{array}$ & Failure mode & $\begin{array}{l}\text { Ultimate } \\
\text { load: kN }\end{array}$ & Failure mode & & \\
\hline$B C-a$ & $2 \phi 14$ & - & $60 \cdot 6$ & CC after SY & $60 \cdot 7$ & CC after SY & 0.2 & - \\
\hline$B C-b$ & $2 \phi 18$ & - & $103 \cdot 1$ & CC after SY & $100 \cdot 4$ & CC after SY & $-2 \cdot 6$ & - \\
\hline BR1-a & $2 \phi 14$ & $1 \phi 8$ & $84 \cdot 7$ & DB after SY & $95 \cdot 4$ & CC after SY & $12 \cdot 6$ & $39 \cdot 8$ \\
\hline$B R 1-b$ & $2 \phi 18$ & $1 \phi 8$ & $125 \cdot 1$ & CC after SY & $121 \cdot 7$ & CC after SY & $-2 \cdot 7$ & $21 \cdot 3$ \\
\hline BR2-a & $2 \phi 14$ & $2 \phi 8$ & $97 \cdot 3$ & DB after SY & $113 \cdot 5$ & CC after SY & $16 \cdot 6$ & $60 \cdot 6$ \\
\hline BR2-b & $2 \phi 18$ & $2 \phi 8$ & $135 \cdot 4$ & CC after SY-DB & $134 \cdot 2$ & CC after SY & -0.9 & $31 \cdot 3$ \\
\hline
\end{tabular}

CC, concrete crushing; DB, debonding; SY, steel yielding.

Table 2-4 also shows a comparison between the theoretical and experimental results which are in a reasonable agreement with each other. The results also show that the high steel ratio beams failed by concrete crushing after the steel yielding. Whereas, the low steel ratio steel failed by CFRP rods de-bonding after the steel yielding. It was reported that the de-bonding of the CFRP rods for (BRl-a) and BR2-a, which they have less steel ratio, was due to the low concrete compressive strength where the crack extended rapidly after the imitation. Therefore, de-bonding between the CFRP rods and concrete occurred. On the other hand, BR1-b and BR2-b, which had two NSM CFRP rods, suffered from the stress concentration at the edges and between the CFRP rods prior to the failure. 
W.T. Jung, et al (2005) investigated the flexural behavior of the RC beams strengthened with EBR and NSM. Eight specimens of 200 x 300 mm (7.87 in x 11.8 in) cross section with $3.0 \mathrm{~m}$ long span were tested under two-point load system. All specimens had compressive strength of $31 \mathrm{MPa}(4.5 \mathrm{ksi})$ at twenty-eight days and tested. The main flexural reinforcement consisted of three $10 \mathrm{~mm}$ steel rebars and the shear reinforcements were $10 \mathrm{~mm}$ steel rebar spaced @ $100 \mathrm{~mm}$ (4.0 in). The control beam failed at $50 \mathrm{kN}$ (11.24 kips) by the yielding of the steel, and then by the crushing of the concrete. The EBR beams that were strengthened with sheet and strip gave about $61.0 \mathrm{kN}$ (13.71 kips) before the CFRP sheet de-bonded. The NSM beams failed at $62.0 \mathrm{kN}$ (14.0 kips) before the NSM FRP reinforcement de-bonding, which was caused by the cracking of the concrete surrounding the groove. Finally, the beams that were reinforced with NSM plate and rod, in addition to the mechanical interlocking, failed at $62.0 \mathrm{kN}$ (14.0 kips) and $65.0 \mathrm{kN}$ (14.6 kips) respectively before the rupture of the NSM FRP reinforcement. The mechanical interlocking was added to enhance the bonding capacity by increasing the concrete epoxy bonding efficiency . Therefore, the concrete splitting failure was delayed.

Figure 2-12 below illustrates the mechanical interlocking details and dimensions.

NSM Strengthening

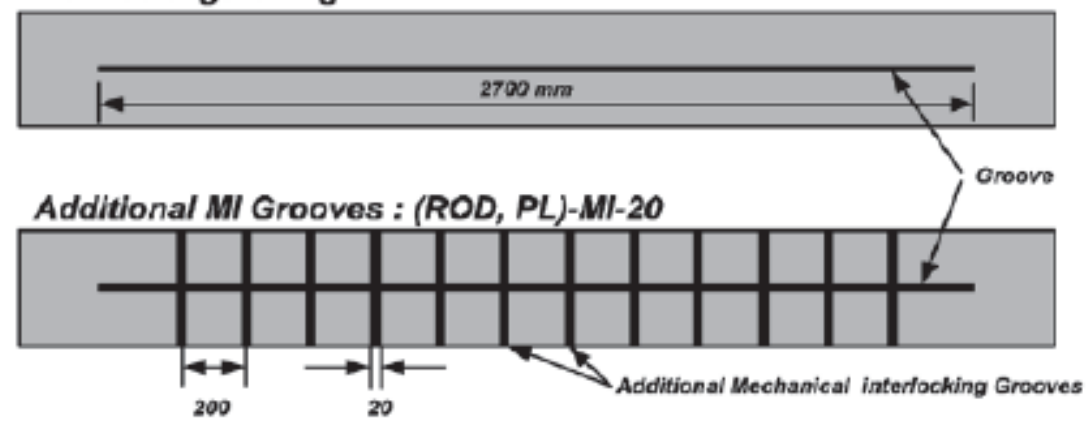

Figure 2-12 NSM CFRP mechanical interlocking details(W.T. Jung, et al 2005). 


\subsection{Summary of the Literature Review and Discussion}

From the literature review, it can be concluded that the bonding of NSM CFRP rod is mainly influenced by some of the following characteristics: the groove size, the surface texture of the FRP and the groove, the development length, and the concrete compressive strength. These characteristics are the main parameters that affect the bonding behavior. Much of the research focused on the load-slip behavior by conducting the pullout tests. The load-slip relationship is crucial for modeling the behavior of NSM-CFRP interface. Therefore, many of the studies were performed on short development lengths. Nonetheless, Shehab.M .Soliman et al. (2013) investigated the behavior of the longer development lengths such as $36 \mathrm{D}_{\mathrm{b}}$ and $48 \mathrm{D}_{\mathrm{b}}$ groove sizes of $1.25 \mathrm{D}_{\mathrm{b}}, 1.5 \mathrm{D}_{\mathrm{b}}, 1.75 \mathrm{D}_{\mathrm{b}}, 2 \mathrm{D}_{\mathrm{b}}$, and $2.25 \mathrm{D}_{\mathrm{b}}$. As the groove size increased, the bond failure mode shifted from epoxy splitting failure mode to concrete epoxy interface de-bonding failure. De Lorenzis. (2002) suggested that the groove size of $2 \mathrm{D}_{\mathrm{b}}$ as an optimum groove size. The four possible failure modes were: the FRP rod-epoxy interface de-bonding, or splitting of the epoxy; the epoxy-concrete interface de-bonding; the epoxy-concrete interface de-bonding with crushing of the concrete surrounding the groove; and the FRP rod rupture. The first and the second failure could be avoided by increasing the development length and the groove size respectively.

Sharaky et al. (2013) used mechanical interlocking to increase the joint capacity. However, the reported failure mode was de-bonding at epoxy-concrete interface with diagonal concrete cracking. Cement grout and epoxy-based paste were used as adhesive agents. It was concluded that the epoxy-based paste performs and interacts with FRP 
material better than cement-based paste. As long as the tensile strength of the epoxy was greater than the tensile strength of the concrete, the difference in the performance of different types of epoxy was negligible. It is interesting to mention that many researchers use the modified pullout test that was invented by De Lornzis. (2002) to eliminate the eccentricity, and the effect of bearing stress on the NSM-CFRP joint. The surface texture of the CFRP rod does not play a significant role if the failure mode is at concrete-epoxy interface (De Lornzis, 2002). Shehab M. Soliman et al. (2013) reported that the FRP rod rupture in the pullout test with $36 \mathrm{D}_{\mathrm{b}}$ and $48 \mathrm{D}_{\mathrm{b}}$ development length. However, the tensile strength of the FRP rod was $1546 \mathrm{MPa}(224 \mathrm{ksi})$ for $9.5 \mathrm{~mm} \# 3 \mathrm{rod}$, and $1250 \mathrm{MPa}$ (181.3 ksi) for $12.2 \mathrm{~mm} \# 4$ rod. These values are less the capacity of the FRP bar that is available in the industry. The compressive strength of the concrete in most studies ranged from between $19 \mathrm{MPa}(2.75 \mathrm{ksi})$ and $44 \mathrm{MPa}(6.38 \mathrm{ksi})$. This range covers most of the existing systems that need to be retrofitted. Finally, it is interesting to mention that the channel shape of the specimens was chosen to eliminate the bearing effect on the joint performance (De Novidis et al., 2007).

As a flexural behavior, the NSM CFRP technique significantly improved the overall behavior of load deflection relationship. Most of studies implemented a full development length and a groove size of $2 \mathrm{D}_{\mathrm{b}}$ to perform the NSM CFRP systems. Most of the specimens' cross-section ranged between $(200 \mathrm{~mm} \times 300 \mathrm{~mm}-180 \mathrm{~mm} \times 250 \mathrm{~mm})$ that is (7.87 in $\times 11.811$ in-7 in $\times 9.84$ in). This range provided enough room to accommodate two CFRP of \#3 or \#5 as the maximum limits for the beam. The beam size is also easy to carry and to maneuver in the laboratory area. The main steel reinforcement ranged from 
$0.4 \%$ to $1.6 \%$. These ratios covered the minimum and the maximum steel ration that could be found in most of the existing beams. The minimum steel ratio simulated the deteriorated beams so that their reinforcement was corroded or accidentally lost. On the other hand, the medium or maximum steel ratio simulated the existing components that needed upgrading for their flexural performance to satisfy the new applied loads. The concrete compressive strength ranged from $15 \mathrm{MPa}(2.17 \mathrm{ksi})$ to $60 \mathrm{MPa}(8.7 \mathrm{ksi})$. This range covered almost all of the existing reinforced concrete components. However, the high compressive strength was rarely found in the old concrete beams. Since the test is for flexural behavior, most of the beams were tested under two-point load. The two-point load test gives a pure flexural region to be observed and monitored. Therefore, the results will be more reliable. As it was stated previously, the NSM CFRP provides an excellent improvement for the flexural performance of the RC beams.

Al.Mohamoud.F.et al. (2010) and Soliman S. M. et al. (2010) classified the load deflection curve of NSM-CFRP RC beams into three stages. The first limit is the concrete cracking limit where the retrofitted and the not retrofitted beams attend this limit at the same time and behavior. In this limit, the steel and the CFRP bars have not engaged. The second limit is the steel yielding limit where the steel rebar starts to yield and the FRP rods start to engage. In this limit, the not retrofitted beams will stop picking up additional load and behave ductile until it reaches the failure limit. Whereas, the retrofitted beams continue picking up more load. Therefore, the NSM-CFRP beams have different stiffness and capacity. The third limit is where the beam reaches its maximum capacity and after this point, three possible failure scenarios occur depending on the NSM parameter. The 
extreme scenario is the rupture of the FRP. The rupture of the FRP would occur if the beam has low steel ratio and low FRP ratio. The second scenario is the pullout of the FRP rod. This behavior occurs if the development length is not sufficient and the concrete compressive strength is relatively low. The last scenario is the peeling off of the bottom concrete layer with the NSM CFRP. This phenomenon occurs if the steel and the FRP ratio is high, and if the CFRP has sufficient development length. W.T. Jung, et al (2005) has introduced mechanical interlocking to overcome the premature de-bonding and increase the overall flexural behavior by $14 \%$. As described previously, the mechanical interlocking increases the concrete-epoxy bonding area and delays the early bonding, especially for concrete beams that have low compressive strength. The overall gaining capacity in flexural for RC beams ranges from (23\%-80\%). This range depends on many characteristics and parameters of NSM that described previously. 


\section{Chapter 3: $\quad$ Experimental program}

\subsection{Design guides}

Two design guides were adopted to analyze and design the NSM-CFRP system. The ASTM D7205/D7205M - 06 has the instructions and details for preparing and testing the CFRP rod samples. The ultimate tensile strength, the ultimate tensile strain, and the modulus of elasticity were obtained by using the ASTM D7205/D7205M - 06 guidelines.

The ACI 440.2R-08 "Guide for the Design and Construction of Externally Bonded FRP Systems for Strengthening Concrete Structures" has the guidelines and philosophy of analysis and design the NSM-FRP beams. The flexural design of the NSM-CFRP rectangular concrete beam system was analyzed and designed using the ACI 440.2R-08.

\subsection{Tension Test}

\subsubsection{Methodology}

As described previously, the FRP materials are relatively weak in the transverse direction compare to the longitudinal direction. This inherent property of the composite materials causes premature failure due to the griping action in the tensile test. Therefore, ASTM D7205/D7205M - 06 was adopted in this research to perform the tensile test properly. The axial stress-strain behavior and the CFRP rods modulus of elasticity can be evaluated later, and compared with the results of the manufacturer's data sheet. The figures provided below are adopted from the ASTM to illustrate the process of preparing the specimens for the test. A steel tube, anchor filling materials, and the FRP samples are the main elements of the test. Each of these elements is described in figures below. 


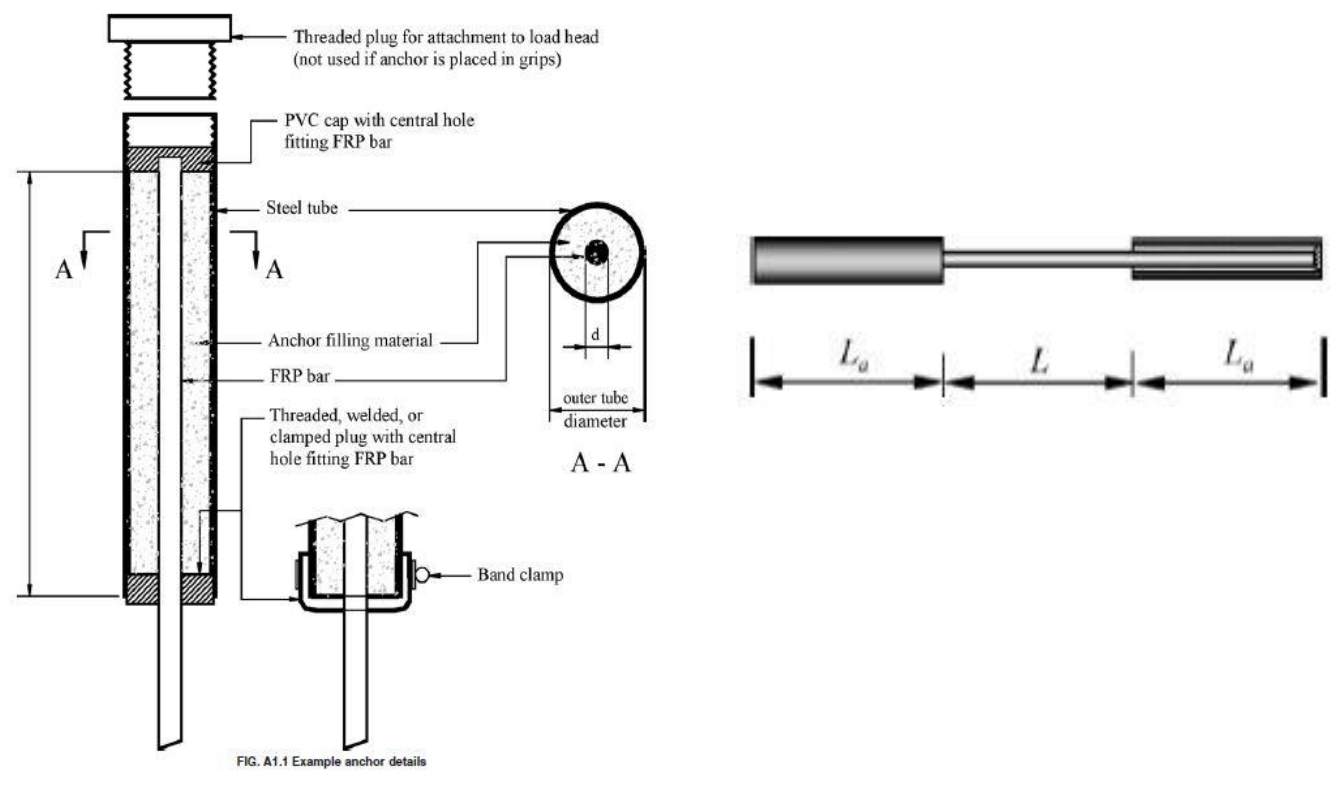

Figure 3-1 Anchor details(ASTM D7205/D7205M - 06, p 8).

The CFRP material, the Aslan ${ }^{\mathrm{TM}} 200$ series, was purchased from ASLAN FRP (Hughes Brothers, Inc). Three CFRP rod diameters were ordered from ASLAN FRP for which the tensile properties are shown in Table 3-1 described by the manufacturer. The CFRP rod \#2 was selected for the tensile stress.

Table 3-1 The manufacturer's data sheet

\begin{tabular}{cccccccccccc}
\hline \multicolumn{2}{c}{ Nominal Diameter } & \multicolumn{2}{c}{ Nominal Area } & \multicolumn{2}{c}{$\begin{array}{c}f^{*} \text { fu - Guaranteed } \\
\text { Tensile Strength }\end{array}$} & \multicolumn{2}{c}{$\begin{array}{c}\text { Ultimate Tensile } \\
\text { Load }\end{array}$} & \multicolumn{2}{c}{$\begin{array}{c}E_{f} \text { - Tensile Modulus } \\
\text { of Elasticity }\end{array}$} & $\begin{array}{c}\text { Ultimate } \\
\text { Strain }\end{array}$ \\
\hline Size & $\mathrm{mm}$ & in & $\mathrm{mm}^{2}$ & $\mathrm{in}^{2}$ & $\mathrm{MPa}$ & $\mathrm{ksi}$ & $\mathrm{kN}$ & $\mathrm{kips}$ & GPa & psi $10^{6}$ & $\%$ \\
2 & 6 & $1 / 4$ & 31.67 & 0.049 & 2241 & 325 & 70.8 & 15.92 & 124 & 18 & $1.81 \%$ \\
3 & 10 & $3 / 8$ & 71.26 & 0.110 & 2172 & 315 & 154.1 & 34.65 & 124 & 18 & $1.75 \%$ \\
$4^{*}$ & 13 & $1 / 2$ & 126.7 & 0.196 & 2068 & 300 & 261.6 & 58.80 & 124 & 18 & $1.67 \%$ \\
\hline
\end{tabular}




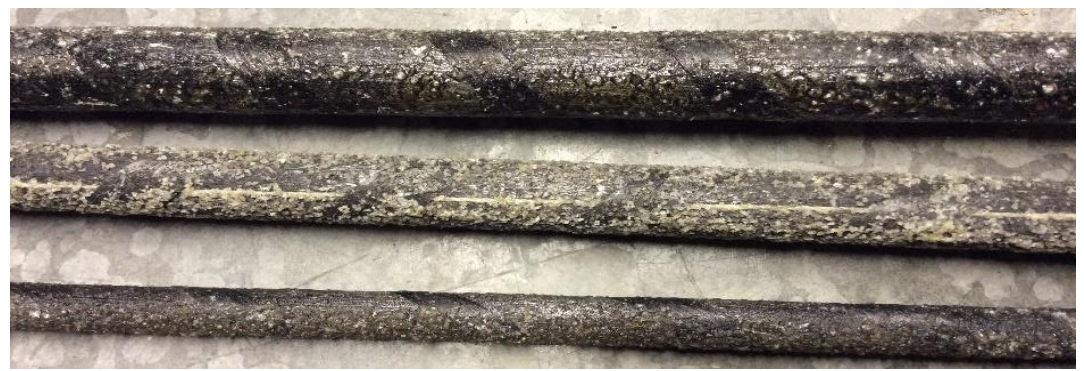

Figure 3-2 ASLAN200 CFRP rods.

The specimen was cut to the desired length. The steel pipe measuring a diameter of $32 \mathrm{~mm}$ and an inner diameter of $20 \mathrm{~mm}$ was ordered from Williams Form Engineering Corp., as shown in Figure 3-3. The chosen length of the steel tube was 10" so that the total length of the specimen was $30 \mathrm{in}$, and the available accommodating room in the testing machine was $36 \mathrm{in}$. The ASTM suggests a filling material that provides (30-50 $\mathrm{MPa}$ ) with an embedment length of diameter ratio of approximately 50 . The commercially available demolition agent known as BUSTAR was selected for the grouting. It provides about $60 \mathrm{MPa}$ pressure after 70 hours curing with $20^{\circ} \mathrm{c}$ temperature as shown in Figure 3-5 below. 


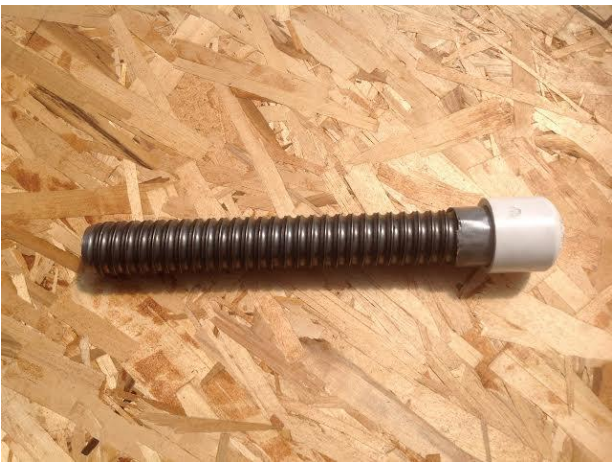

Figure 3-3 Steel pipe used to grip \#2 CFRP rod.

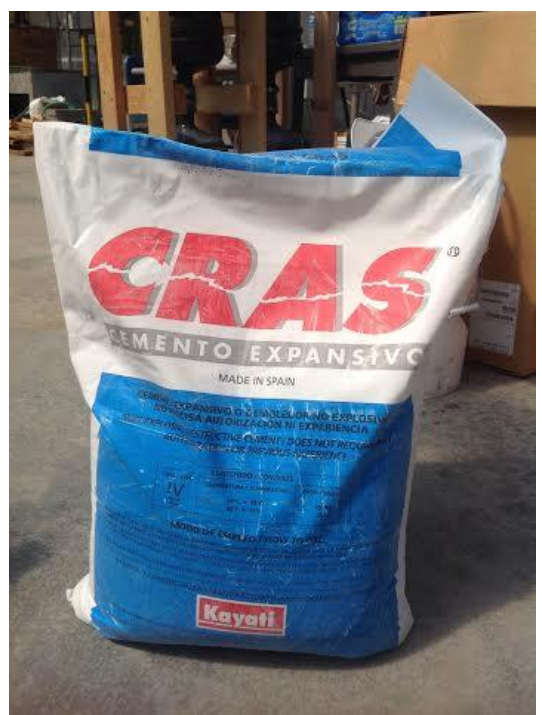

Figure 3-4 The expansive cement.

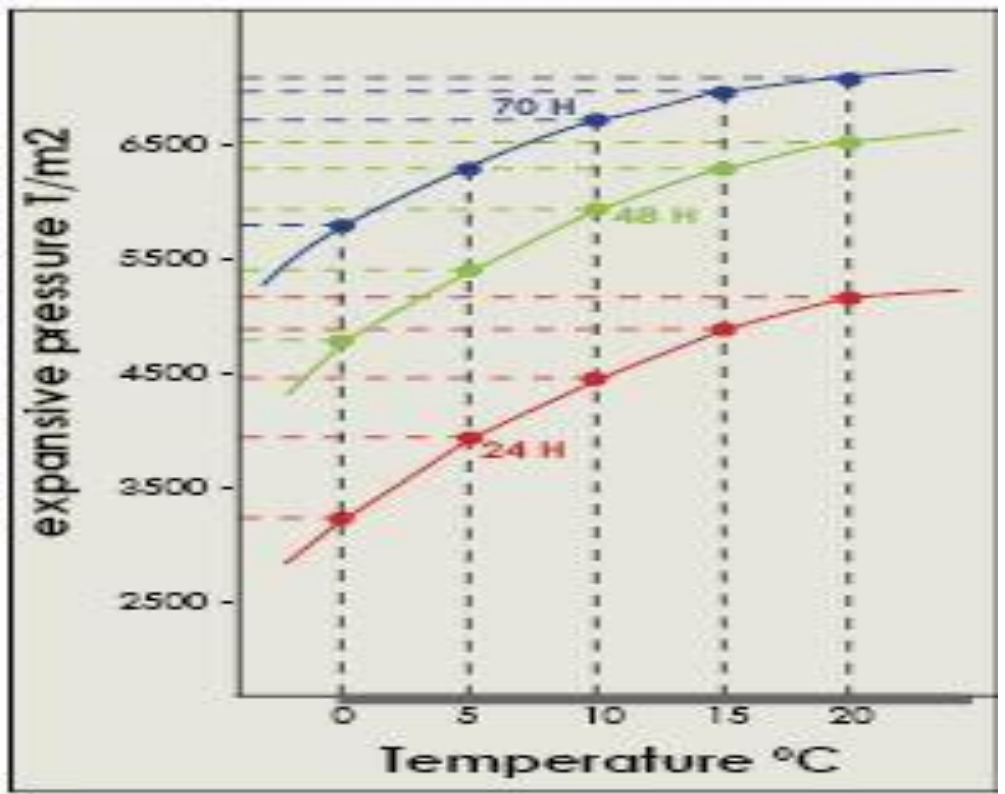

Figure 3-5 The expansive cement' properties manufacturer's data sheet.

The slurry was mixed per the instructions on the manufacturer's data sheet, and then poured inside the steel tube, which had been plugged with a PVC cap from one side as shown below. The CFRP rod then was inserted inside the steel tube. After twelve hours 
of curing, the same process was repeated on the other side. The specimens were then left to cure for another two days, and to wait for the expansive agent to reach the $60 \mathrm{MPa}$ pressure.

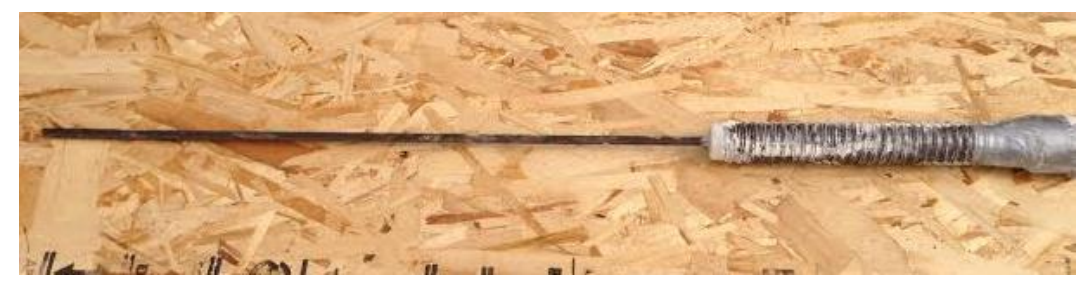

Figure 3-6 Anchoring one end of \#2CFRP rod.

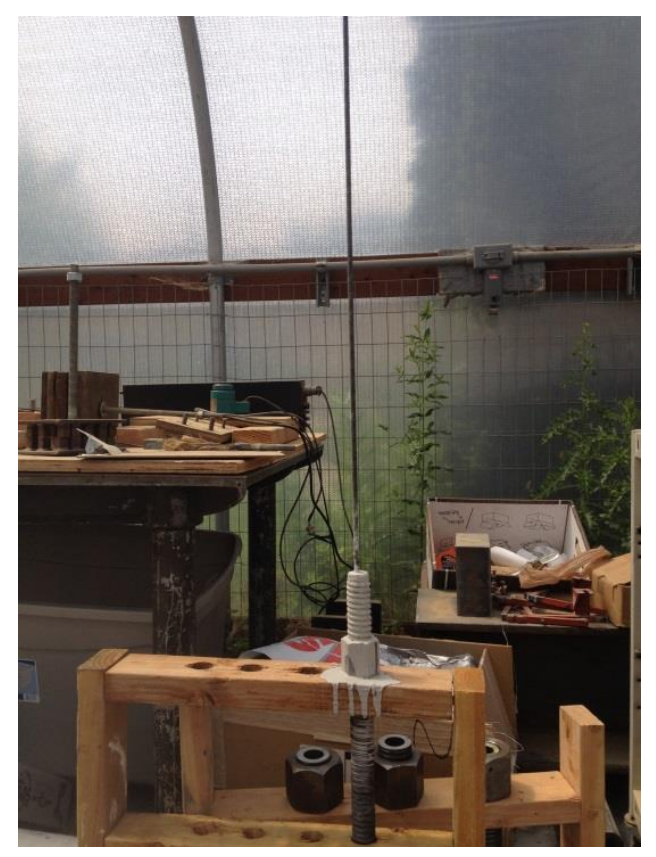

Figure 3-7 Alignment of \#2CFRP rod.

Extra care was taken to ensure the alignment of the CFRP rod inside the tube before the test to prevent any eccentricity from taking place. 


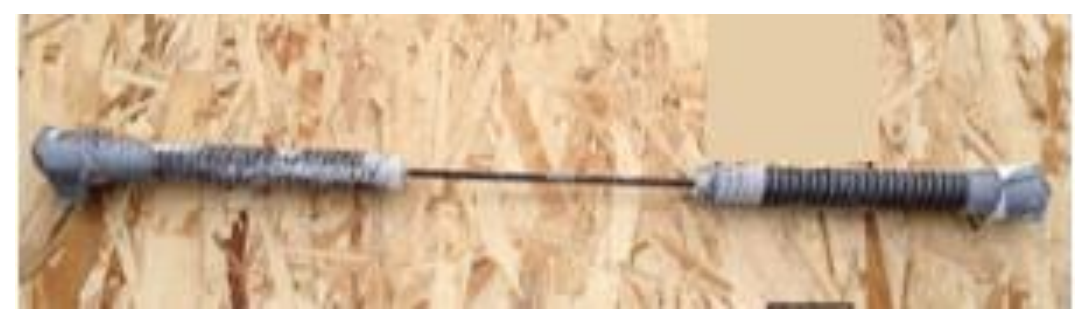

Figure 3-8 \#2 CFRP specimen ready to be tested.

The test (short-term static strength) was carried out in a MTS machine at the iSTAR LAB. The strain-stress relationship was measured by laser extensometer and strain gauges as shown in the results below. The obtained tensile stress and the modulus of elasticity were as described by the manufacturer. However, one of the specimens indicated higher tensile strength than manufacturer data sheet.

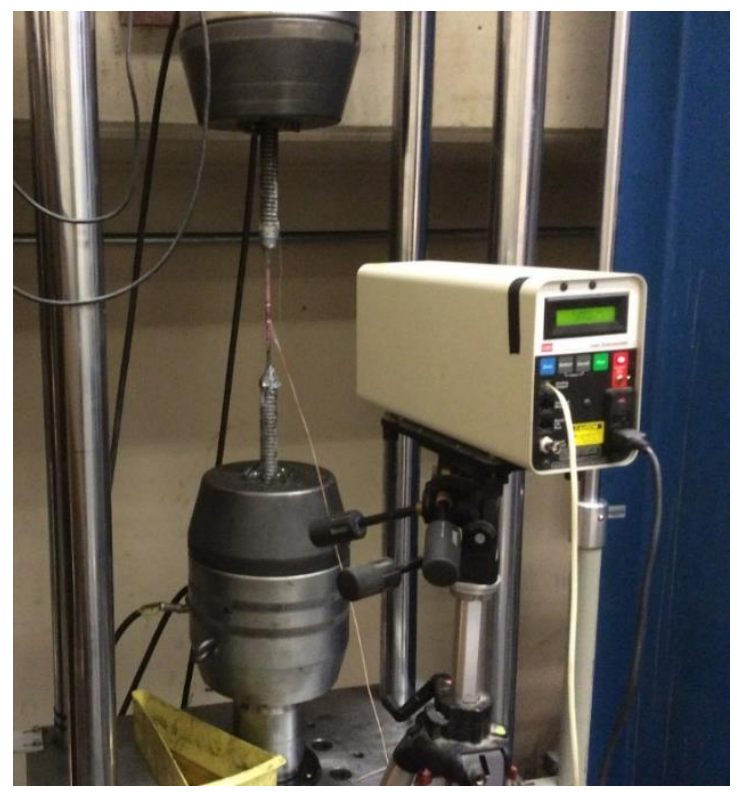

Figure 3-9 \#2CFRP being tested. 
It is interesting to mention that the failure happened exactly at the middle of the specimen as shown in Figure 3-10. Prior to the rupture, a breaking of the helical fibers was heard, after which the carbon fibers lost their composites and started to rupture.
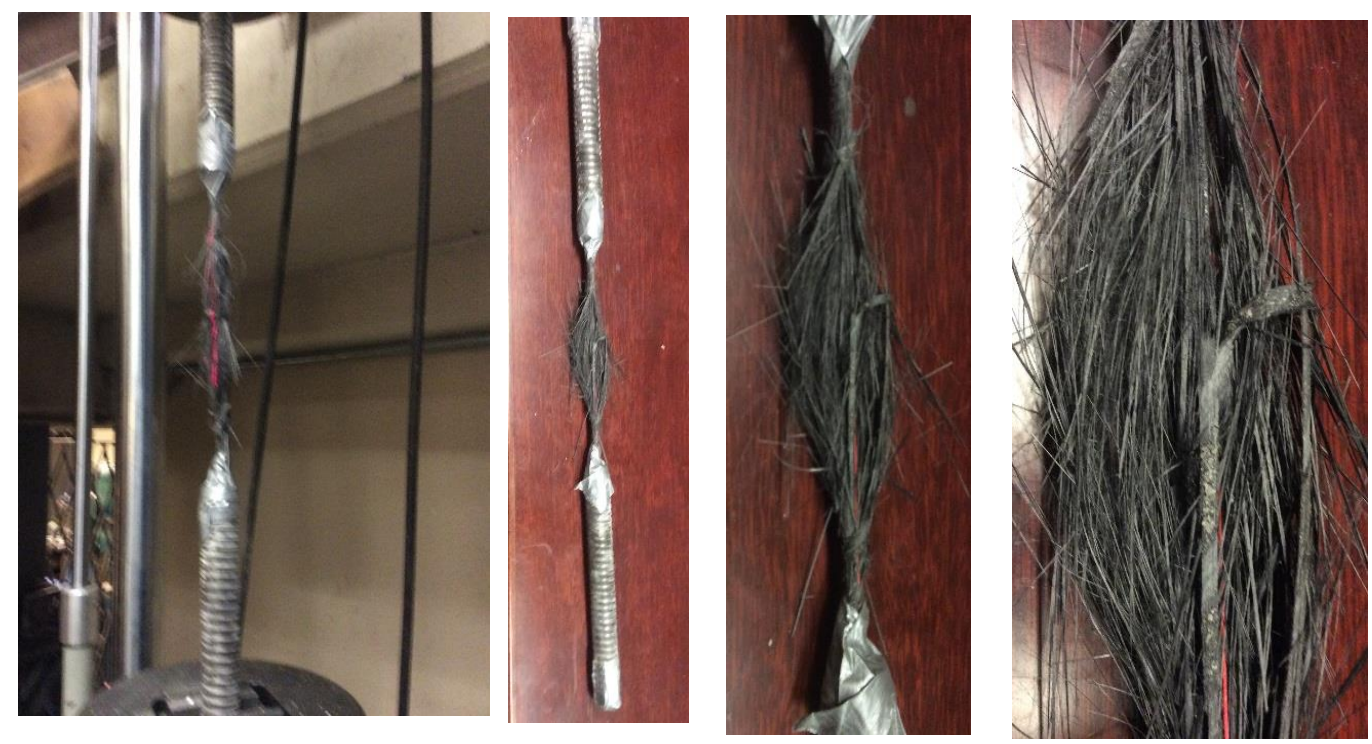

Figure 3-10 Failure mode for \#2CFRP rod. 


\subsubsection{The Results}

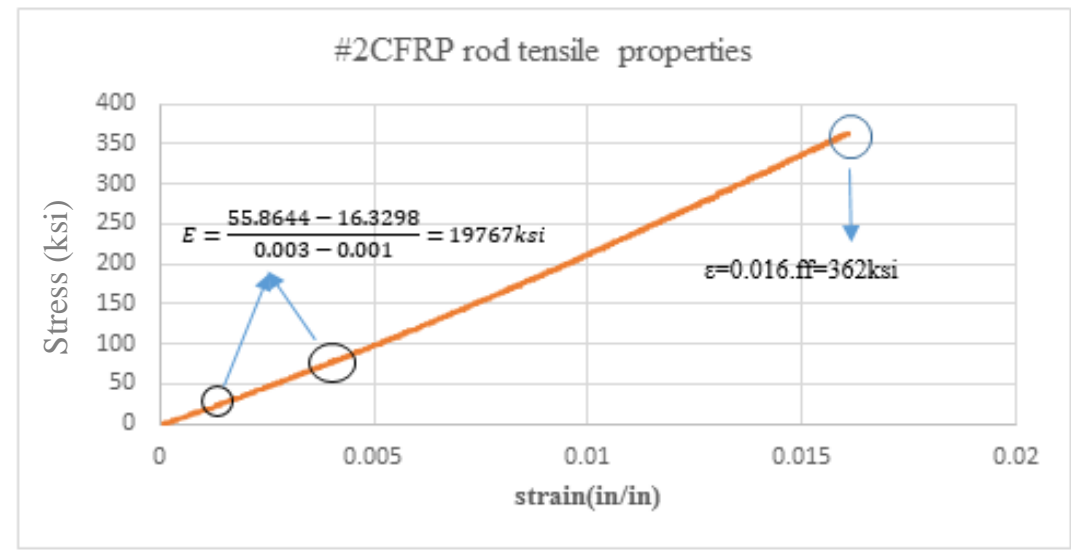

(a) \#2 CFRP Tensile Properties.

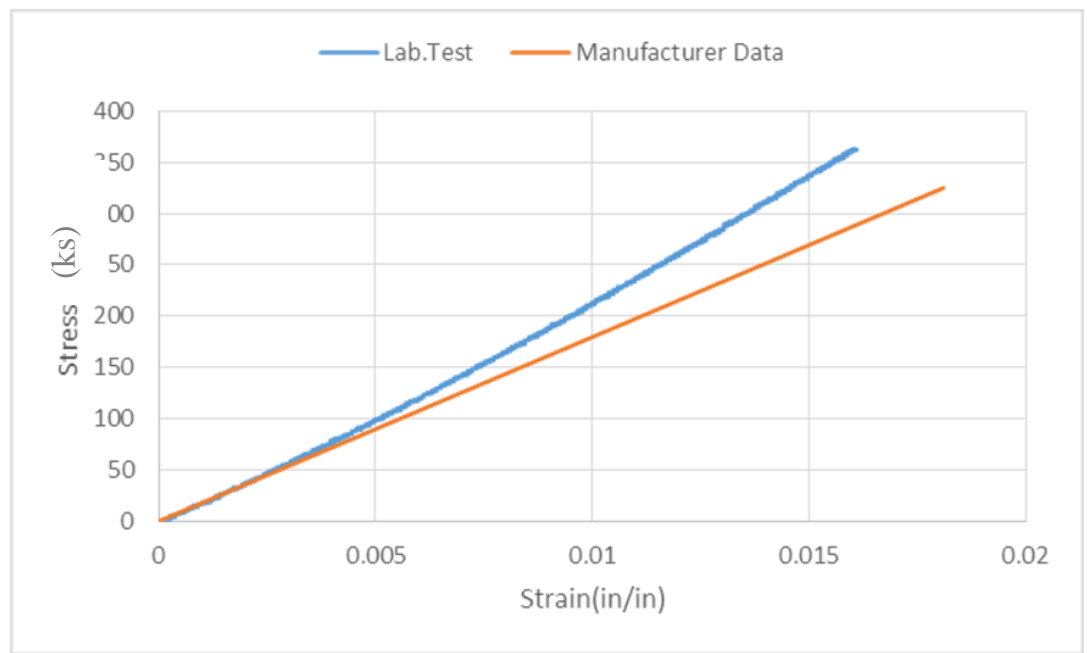

(b) CFRP Tensile Properties comparison.

Figure 3-11 \#2 CFRP Tensile Properties.

As shown in the Figure 3-11 (b) above, the tensile stress is higher than the manufacturer data stated for the \#2 CFRP rod. However, the ultimate tensile strain is slightly lower than the reported value. These values will result in a modulus of elasticity slightly higher than the manufacture's data. The overall trend of the tensile stress-strain relationship is 
elastic until failure. This trend was reported by the manufacture, and pointed out by the ASTM test. Therefore, these values will be used for the analysis and design of the NSMCFRP technique.

\subsection{Pullout Tests}

The modified pullout test was adopted in this study to investigate the bonding behavior of NSM-CFRP rod. Some of the parameters of the bonding test were: the CFRP rods size, the groove characteristic, and the development length. The objective of this test was to obtain a pullout load of at least $50 \%$ of the rod's capacity before de-bonding occurred. All of the variables above were implemented in the concrete specimen blocks as described in figure below. A grove size of $2 \mathrm{D}_{\mathrm{b}}$ was selected as suggested by the literature. As mentioned in the literature, Shehab M. Soliman et al. (2013) reported the FRP rod rupture in the pullout test with $\mathrm{a} 36 \mathrm{D}_{\mathrm{b}}$ and $48 \mathrm{D}_{\mathrm{b}}$ development length. However, the tensile strength of the FRP rod was $1546 \mathrm{MPa}(224 \mathrm{ksi})$ for $9.5 \mathrm{~mm} \# 3$ rod and 1250 MPa (181.3 ksi) for $12.2 \mathrm{~mm} \# 4$ rod. These values were less than the capacity of the FRP bar obtained from the tensile stress of the $\# 2$ CFRP rod. Therefore, $60 \mathrm{D}_{\mathrm{b}}$ was used as the development length. Six specimens (two for each bar size) were investigated for their NSM bonding. The specimens were pulled out the concrete block as shown in the test setup Figure 3-12 below. 


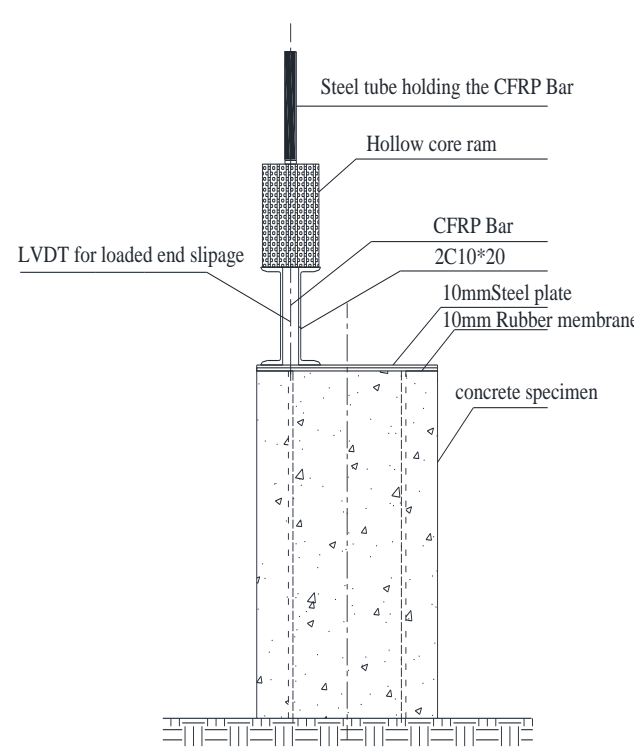

Side view
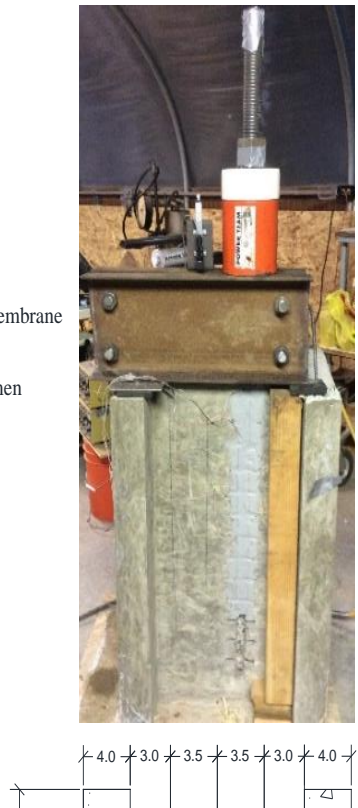

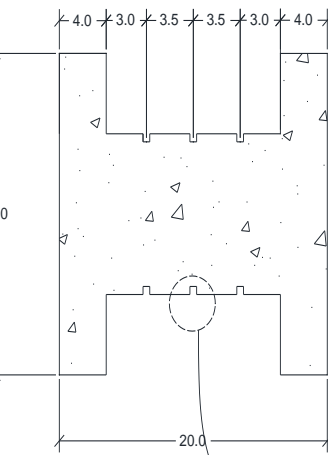

Top view

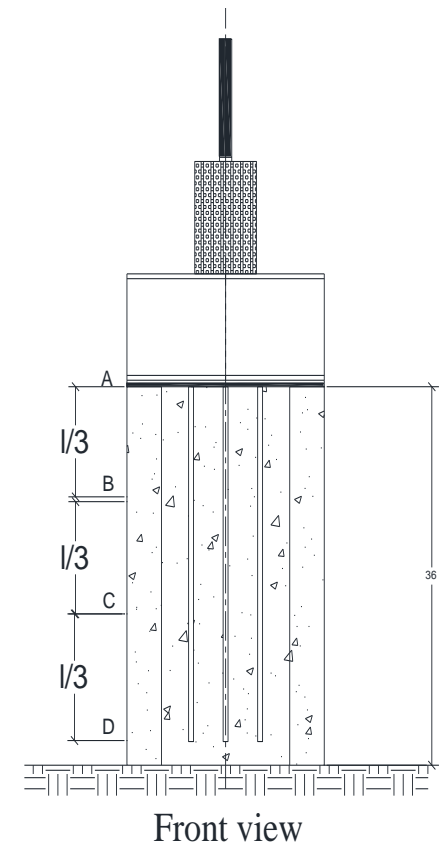

Front view

Figure 3-12 Pull out test setup. 


\subsection{Flexural Tests}

After obtaining the bond characteristics from the pullout test, CFRP rods were inserted into grooves that were made in the bottom surface of each of the beams. Two CFRP rods were inserted in a groove size of $2 \mathrm{D}_{\mathrm{b}}$. Two sets of reinforced concrete beams were fabricated and casted. Each set contains four beams. One of them was the control beam, and the rest were additionally reinforced with two CFRP rods of \#2, \#3, and \#4. Each set had a different internal steel ratio. The first set had the minimum steel ratio, which was $0.4 \%$. This steel ratio simulated the poorly reinforced concrete beams in the real application or the corroded reinforced concrete beams. The second set had a steel ratio of $0.7 \%$. This series representd the existing beams that needed to be upgraded to satisfy the new applied load. The cross section of the beams was 10 in $x 6.5$ in with span length of 8ft. Figure 3-14 shows set A and B cross sections.

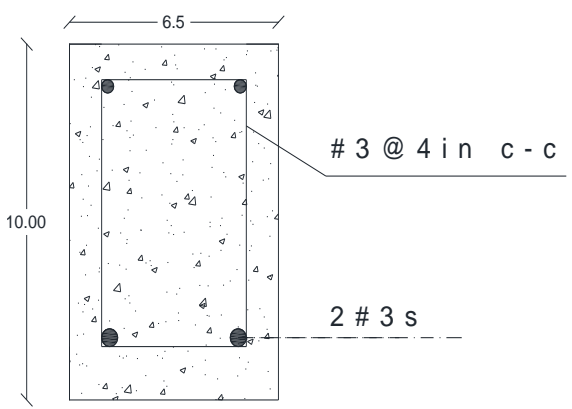

SET (B)

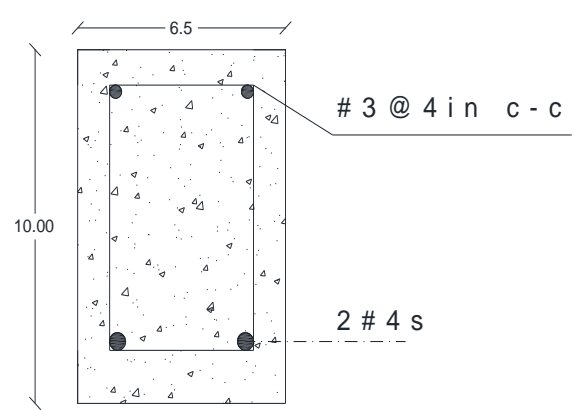

SET (A)

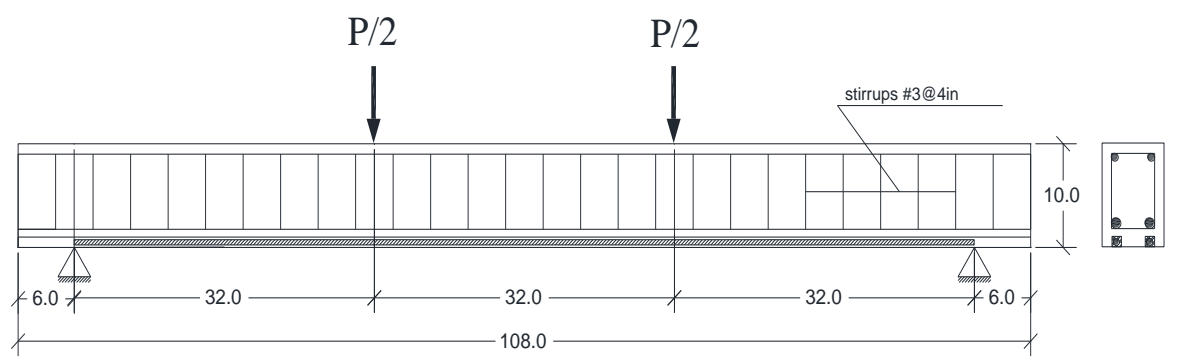

Figure 3-13 Control specimens of set $A$ and $B$. 

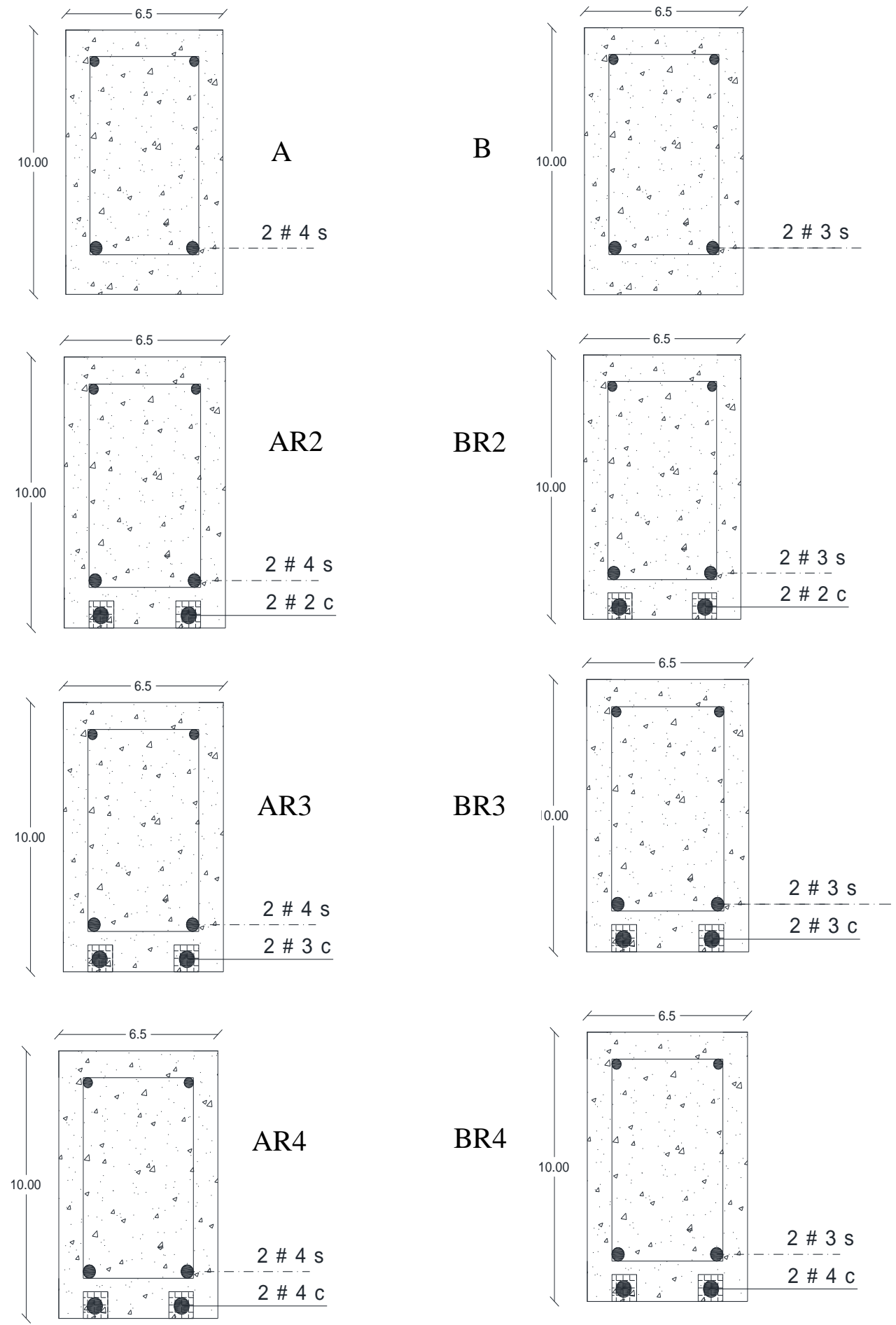

Figure 3-14 Details of set $A$ and set $B$. 
The materials used in this projects were concrete, steel, CFRP, and epoxy. All the material were tested according ASTM in iSTAR lab and in South Green House Lab at Portland State University.

\subsubsection{Concrete}

A compressive strength of concrete at 4000 psi was selected for both the flexural and pullout tests. The concrete was supplied by Miller's Mini Mix Concrete. Cement type II was used, and the aggregates were supplied by The Willamette River bed. The gravel and sand gradation was as follows: $100 \%$ passing the $25 \mathrm{~mm}$ sieve (1.0 in.), $48.34 \%$ passing the $12.7 \mathrm{~mm}$ (1/2 in.), $26.16 \%$ passing $9.5 \mathrm{~mm}$ (3/8in.), and $0.66 \%$ passing $4.75 \mathrm{~mm}(\# 4)$. For the sand, the gradation was as follows: $97.81 \%$ passing $4.75 \mathrm{~mm}$ sieve (\#4), $84.67 \%$ passing $2.00 \mathrm{~mm}$ (\#10), $72.99 \%$ passing $0.85 \mathrm{~mm}$ (\#20), 49.64\% passing $0.425 \mathrm{~mm}$ (\#40), 5.11\% passing 0.150 mm (\#100), and 0.73\% passing 0.075 mm (\#200). The slump of 4 in was achieved by reducing the added water to the mix. As shown in Figure 3-23, the concrete compressive strength was performed on the cylinders. The average compressive strength was (3.72 ksi). Splitting and flexure tests were also conducted according to the ASTM to obtain the mechanical properties of plain concrete. The table provided below describes the mechanical properties of the concrete at twenty-eight days. 
Table 3-2 Concrete properties.

\begin{tabular}{|c|c|c|}
\hline $\begin{array}{c}\text { Compressive } \\
\text { strength(ksi) }\end{array}$ & $\begin{array}{c}\text { Tensile strength } \\
(\mathrm{ksi})\end{array}$ & Modulus of rupture(ksi) \\
\hline 3.72 & 0.342 & 0.55 \\
\hline
\end{tabular}

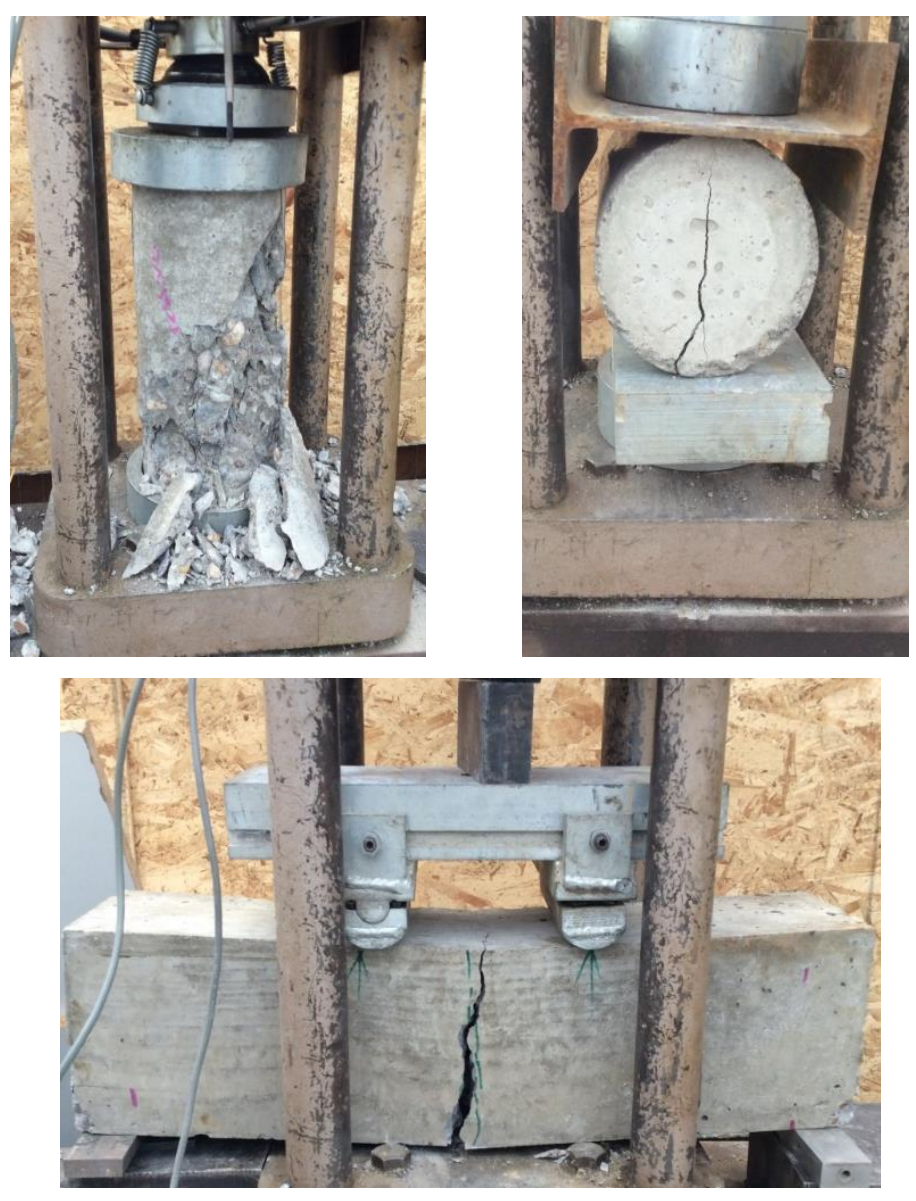

Figure 3-15 Concrete mechanical tests. 


\subsubsection{Epoxy}

The epoxy was used in this research was Sika AnchorFix ${ }^{\circledR}-1$. It is a fast curing anchoring adhesive, which consisted of two parts: adhesive and hardening. The mechanical properties were provided by the manufacture as shown in the Table 3-3 below.

\section{Table 3-3 Epoxy properties.}

\begin{tabular}{|c|c|c|c|c|c|c|}
\hline Epoxy & $\begin{array}{c}\text { Compressive } \\
\text { Strength } \\
\mathrm{MPa}\end{array}$ & $\begin{array}{c}\text { Flexural } \\
\text { Strength } \\
\mathrm{MPa}\end{array}$ & $\begin{array}{c}\text { Tensile } \\
\text { Strength } \\
\mathrm{MPa}\end{array}$ & $\begin{array}{c}\text { Compressive } \\
\text { E-Modulus } \\
\mathrm{MPa}\end{array}$ & $\begin{array}{c}\text { Tensile } \\
\text { E-Modulus } \\
\mathrm{MPa}\end{array}$ & $\begin{array}{c}\text { Curing } \\
\text { time }\end{array}$ \\
\hline Sika & 60 & 28 & 12 & 3500 & 4500 & 7 days \\
\hline
\end{tabular}

\subsubsection{Steel}

Steel bars \# 3 and \#4 were used as flexural and shear reinforcement. The tensile strength and modulus of elasticity were obtained by testing $3 \mathrm{ft}$. specimens according to ASTM. The prepared specimens were provided with strain gages at the middle to obtain the tensile stress-strain diagram. The test was performed in the MTS machine in the iSTAR laboratory. Figures 3-16 and Figure 3-17 below are the steel stress-strain diagrams that constructed based on the collected results. 


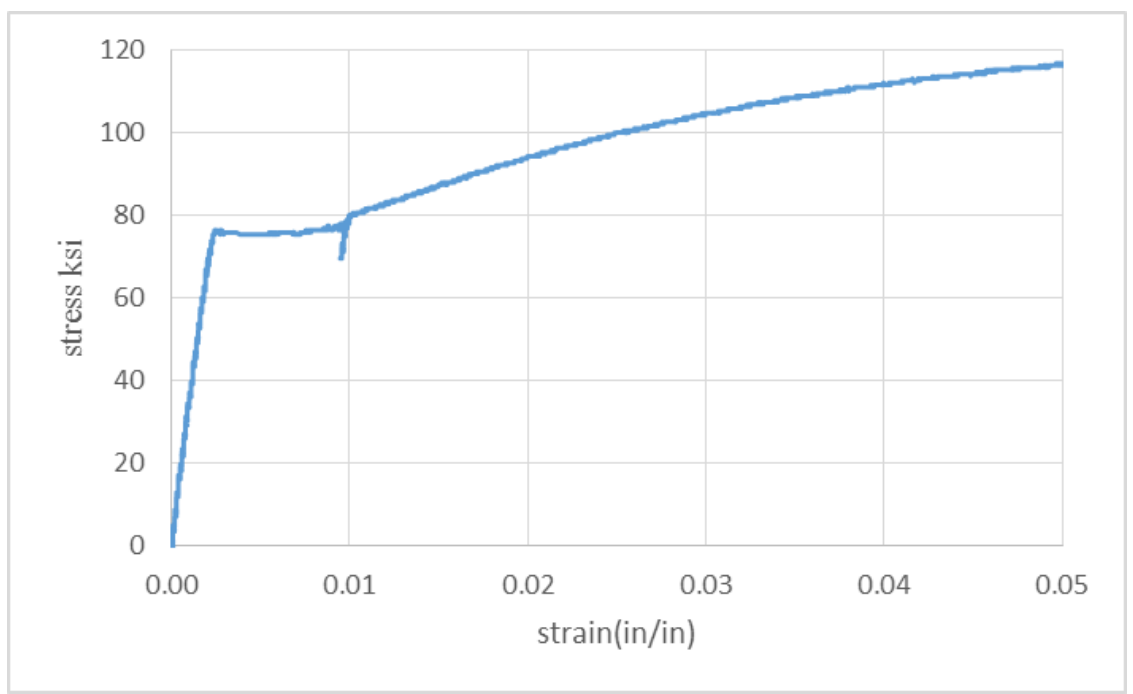

Figure 3-16 \#3 steel strain stress diagram.

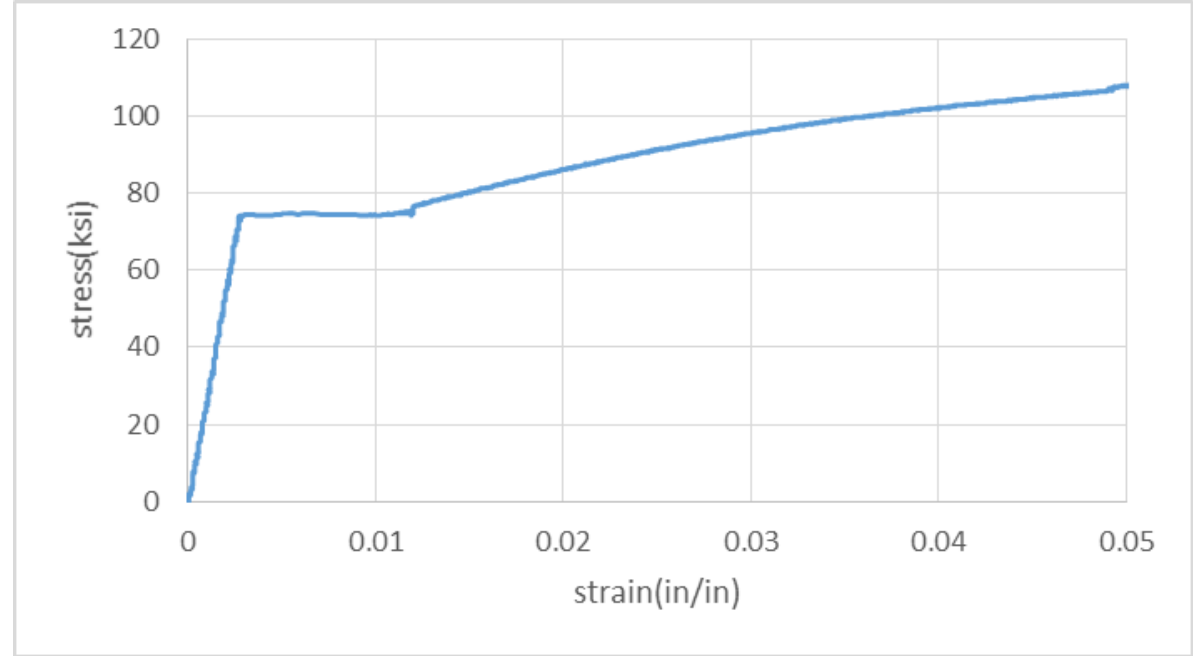

Figure 3-17 \#4 steel strain stress diagram. 


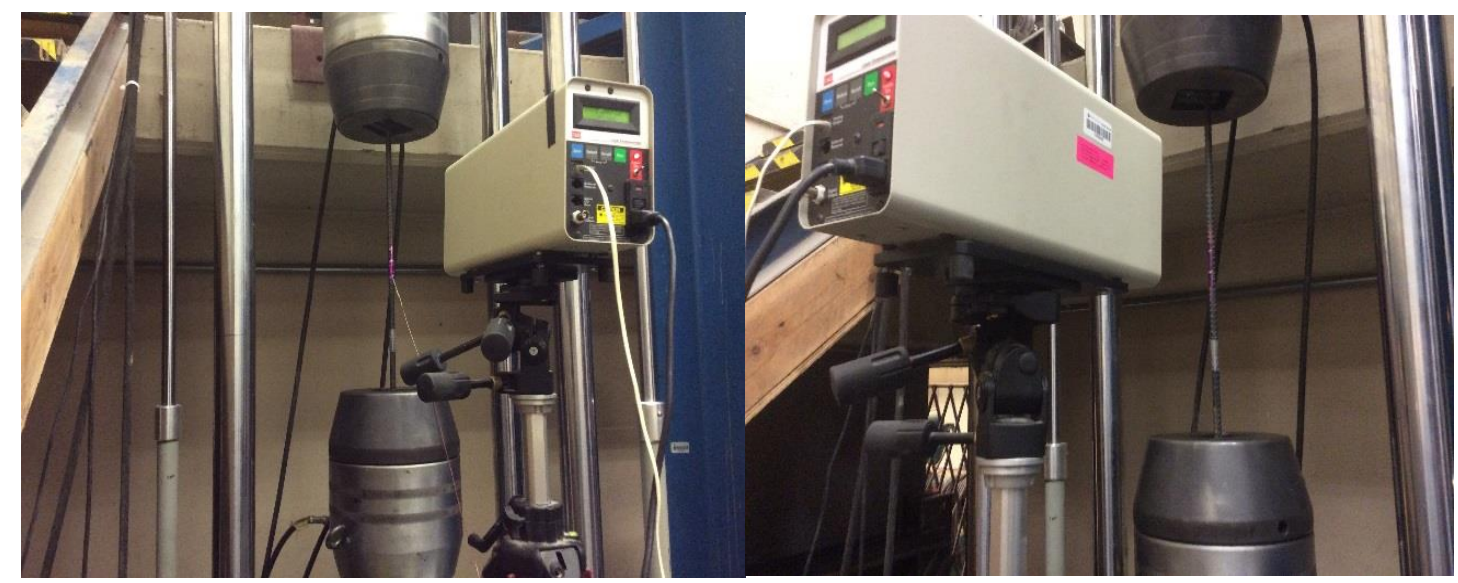

Figure 3-18 Tensile test of steel.

From graphs above the following results have been obtained.

Table 3-4 Steel tensile properties.

\begin{tabular}{|c|c|c|}
\hline$f_{y}(\mathrm{ksi})$ & $\varepsilon_{y}($ strain $)$ & Modulus of elasticity(ksi) \\
\hline $74 \mathrm{ksi}$ & 0.0027 & 27407 \\
\hline
\end{tabular}

\subsubsection{Specimens' Analysis and Design}

ACI 318-11 and ACI 440.2R-08 were adopted to perform flexural analysis and design of rectangular reinforced concrete beams and NSM-CFRP reinforced concrete beams. ACI 440.2R-08 has some preliminary assumptions, such as full bonding between the CFRP rod and the concrete. The section is assumed plane before and after loading. The 
maximum service strain in concrete is 0.003 . Finally, the CFRP rod has elastic tensile properties until the rupture.

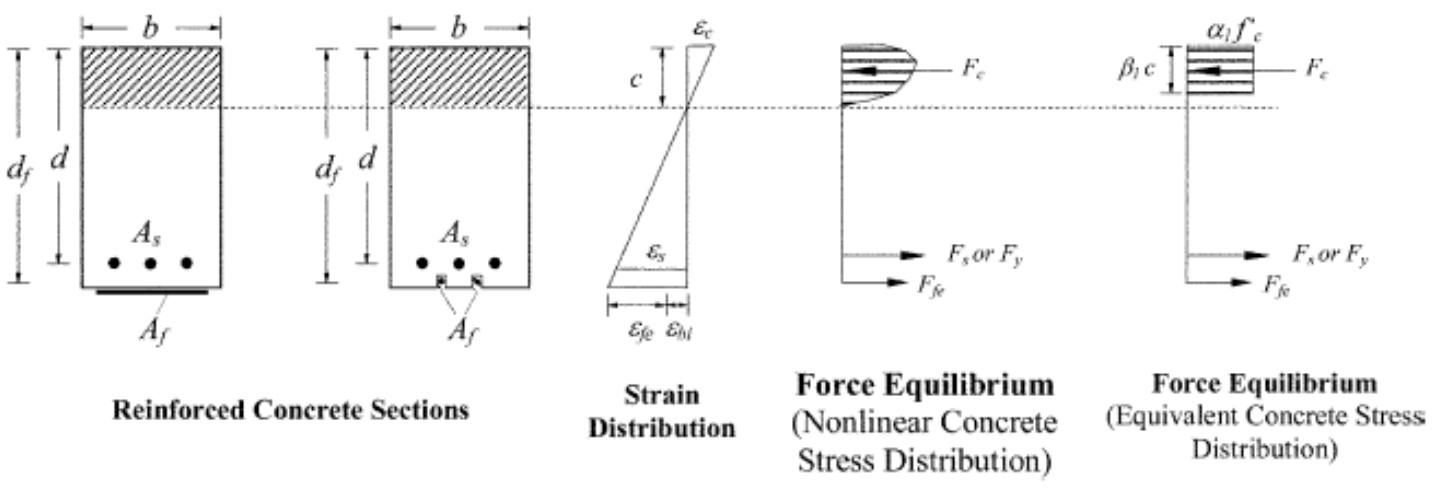

Figure 3-19 Strain and stress distribution (ACI-440-2R-08).

As shown in figure above, strain compatibility and equilibrium condition of the cross section will be satisfied to induce the capacity of the section.

$$
\begin{array}{ll}
f_{f u}=C_{E} f_{f u}^{*} & \text { ACI 440.2R-08 (9-3) } \\
\varepsilon_{f u}=C_{E} \varepsilon_{f u}^{*} & \text { ACI 440.2R-08 (9-4) } \\
\varepsilon_{f e}=k_{e} \varepsilon_{f u} & \text { ACI 440.2R-08 (12-5) }
\end{array}
$$

$\mathrm{CE}$ is the environmental reduction factor, which is available in table 9.1in ACI 440.2R-08 for variety of cases.

$\mathrm{k}_{\mathrm{e}}(0.6-0.9)$, it is bonding coefficient that depends on many characters its such as the internal reinforcement, member dimensions, and the surface texture of CFRP bars. 
An assumption was made on whether the concrete crushing or CFRP rod rupture is controlled based on the following equations. An iterative solution was guided by assuming a value for $\mathrm{C}$, the distance from the concrete block to the neutral axis. This assumption was checked by using the equilibrium condition as explained in equation (1012) of ACI 440.2R-08.

$$
\begin{aligned}
& \varepsilon_{f e}=\varepsilon_{c u}\left(\frac{d_{f}-c}{c}\right) \text { ACI 440.2R-08 (10-3) when concrete crushing failure governs } \\
& \varepsilon_{f e}=\varepsilon_{b i}+\varepsilon_{f d} \text { ACI 440.2R-08 (10-3) when CFRP rod failure governs }
\end{aligned}
$$

From strain compatibility, the strain at the steel and the concrete was determined from the following relationships.

$$
\begin{array}{ll}
\varepsilon_{s}=\left(\varepsilon_{f e}+\varepsilon_{b i}\right)\left(\frac{d-c}{d_{f-c}}\right) & \text { ACI 440.2R-08 (10-10) } \\
f_{f e}=E_{f} \varepsilon_{f e} & \text { ACI 440.2R-08 (10-9) } \\
f_{s}=E_{s} \varepsilon_{s} \leq f_{y} & \text { ACI 440.2R-08 (10-11) } \\
c=\frac{A_{s} f_{s}+A_{f} f_{f e}}{\alpha_{1} f_{c}^{\prime} \beta_{1} b} & \text { ACI 440.2R-08 (10-12) }
\end{array}
$$

After the strain compatibility and equilibrium condition were satisfied, the following equation was used to obtain the section flexural capacity.

$$
M_{n}=A_{s} f_{s}\left(d-\frac{\beta_{1} c}{2}\right)+\psi_{f} A_{f} f_{f e}\left(d_{f}-\frac{\beta_{1} c}{2}\right) \text { ACI 440.2R-08 (10-13) }
$$


$\Psi_{\mathrm{f}}=$ is a reduction factor of 0.85 statistically suggested to account for CFRP strength contribution.

The procedure described above was followed to analyze the specimen's flexural capacity.as explained in appendix A. Tables 3-5 and 3-6 below show the strain levels, the flexural capacity, and the theoretical mode of failure for each specimen.

Table 3-5 NSM-CFRP flexural cross section analysis for set A.

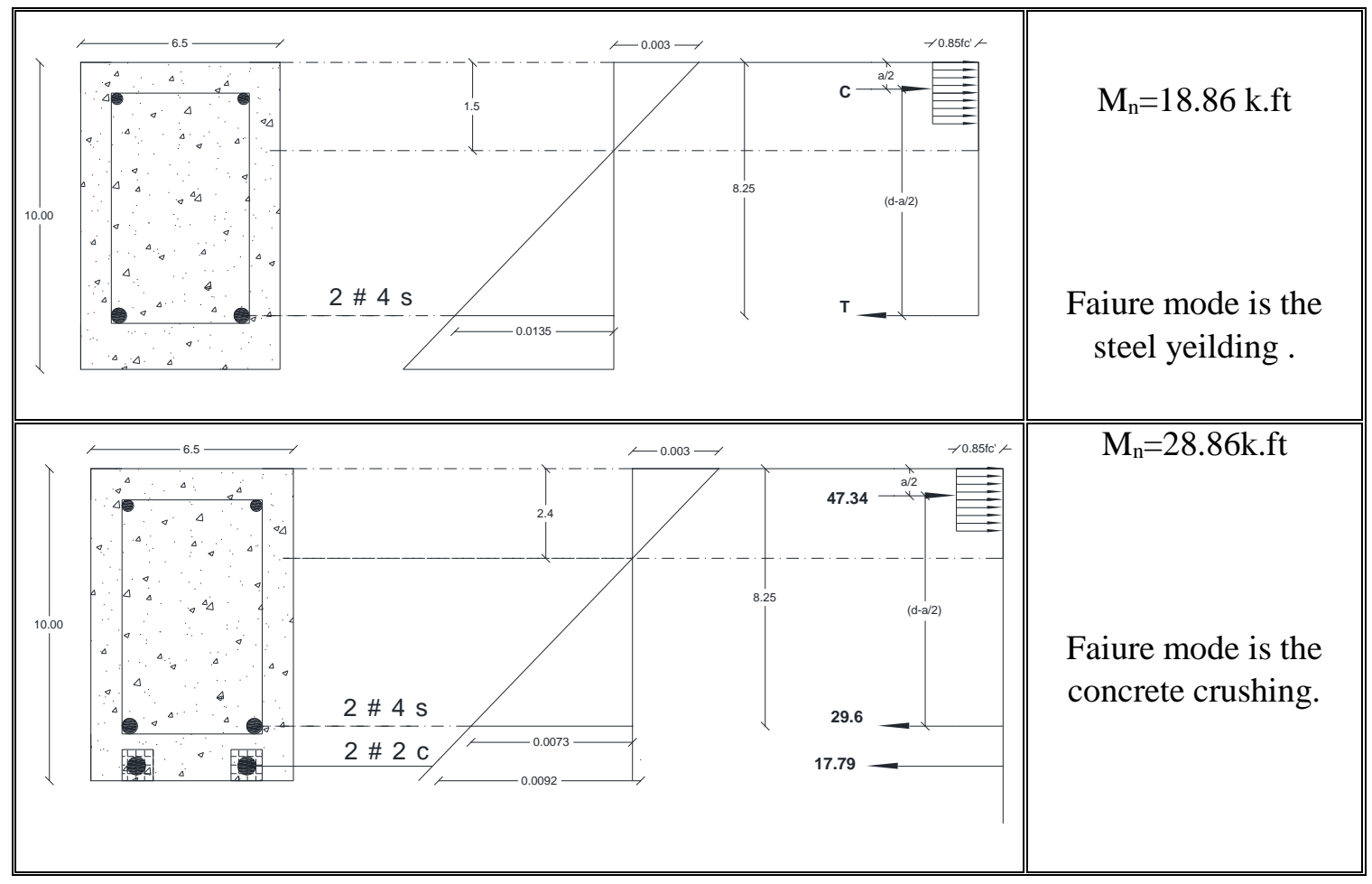


Table 3-4 (cont.)

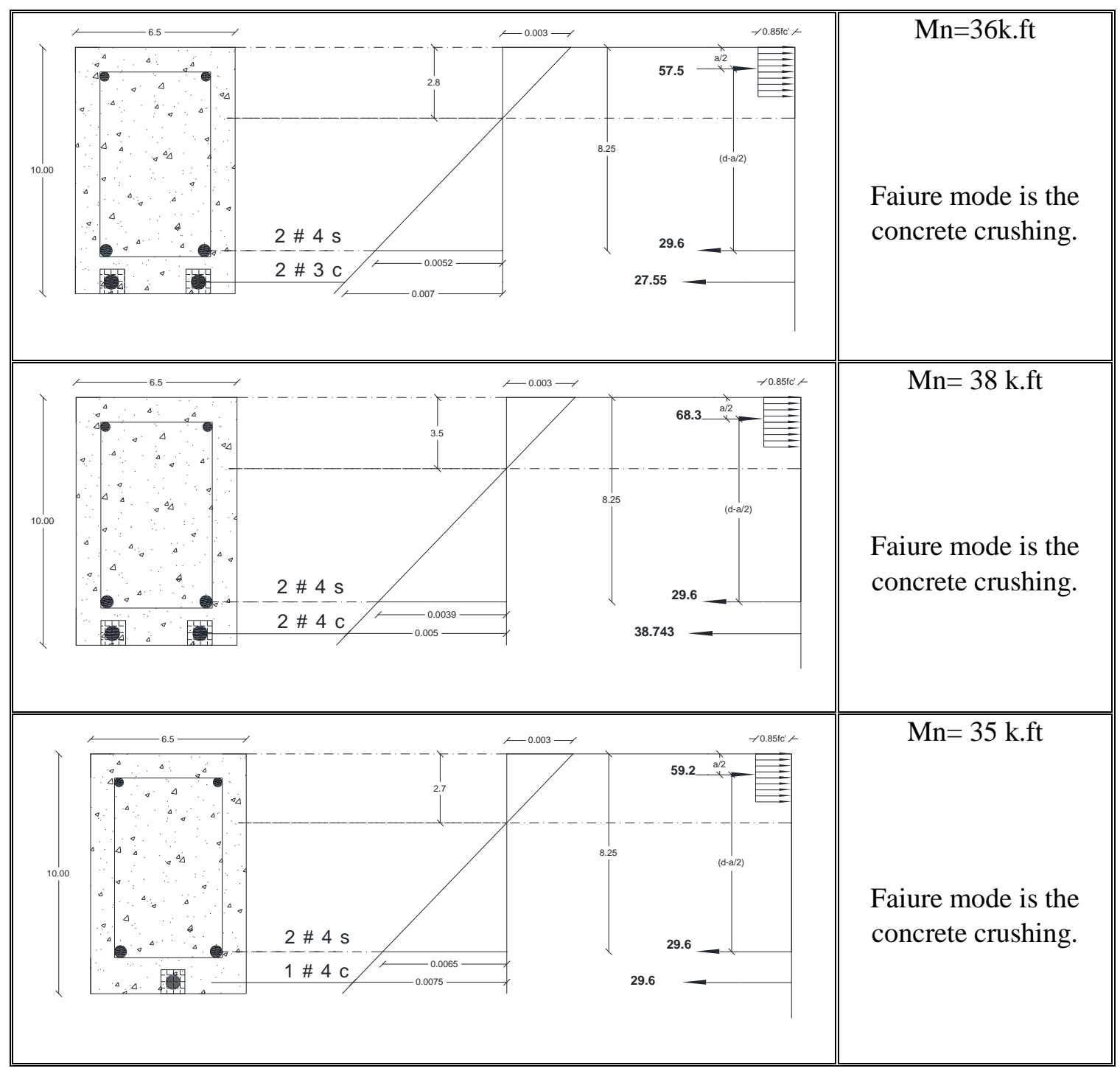


Table 3-6 NSM-CFRP flexural cross section analysis for set B.

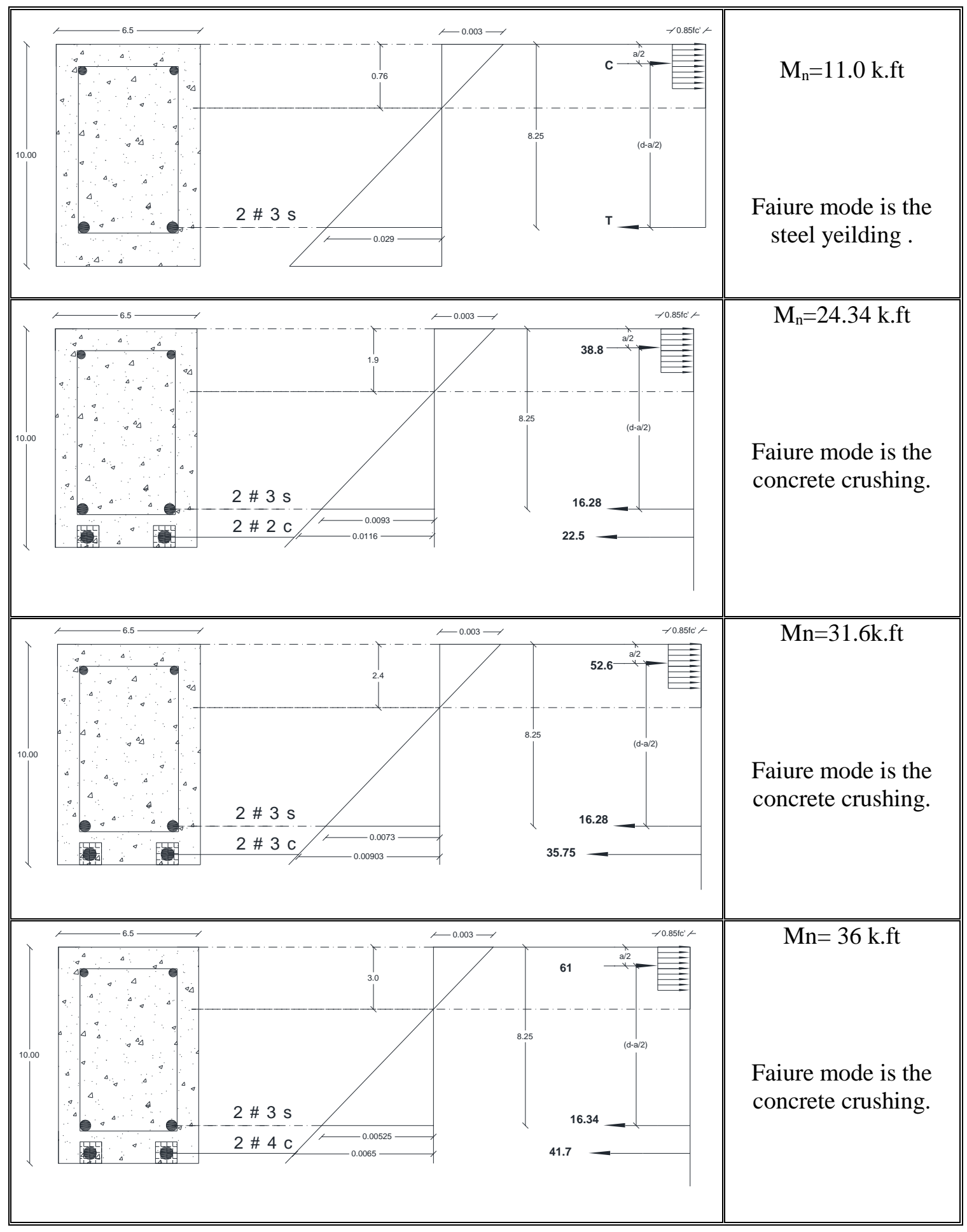




\subsubsection{Specimens Preparation}

The fabrication of the beams' steel gages and the wood molds were fabricated and made at the South Green House. Four plastic spacers were used for each beam to provide the required cover. The inside surface of wood molds were also finished with oil to provide a smooth surface and to easily disassemble the forms. The figures below show the steel cages and the forms.
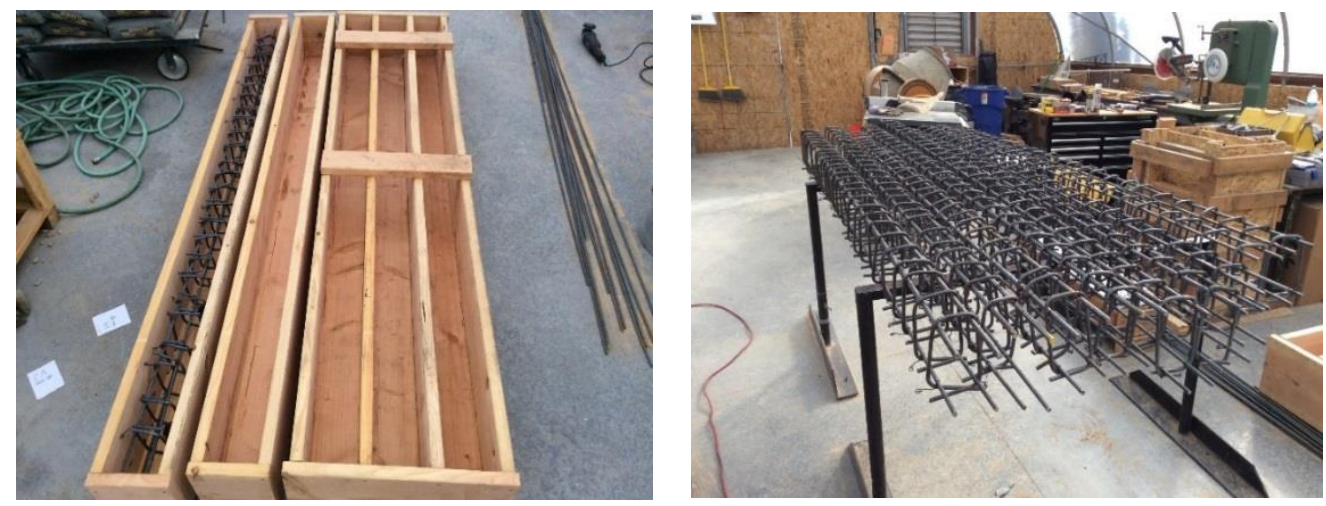

Figure 3-20 Steel cage and mold fabrication.
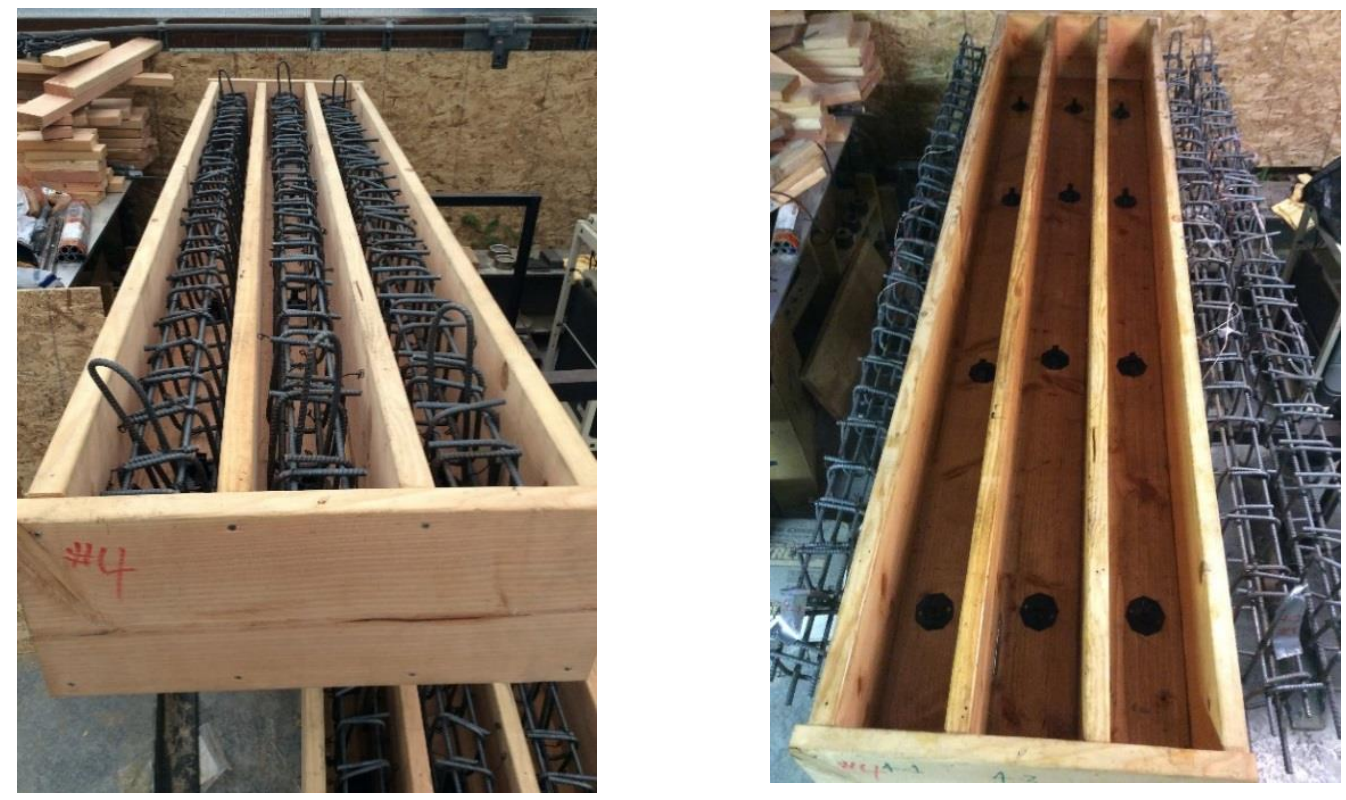

Figure 3-21 Steel cage inside the molds with the required cover. 


\subsubsection{Concrete Casting and Curing}

The casting of the concrete beams was done outside of the Hoop house. Therefore, the fresh concrete was directly poured into the wood forms. The forms were then properly leveled and covered with plastic cover after curing. Forty plastic cylinders were prepared and casted to find the mechanical properties of the hardened concrete. Concrete casting and curing are showing in the figure provided below.
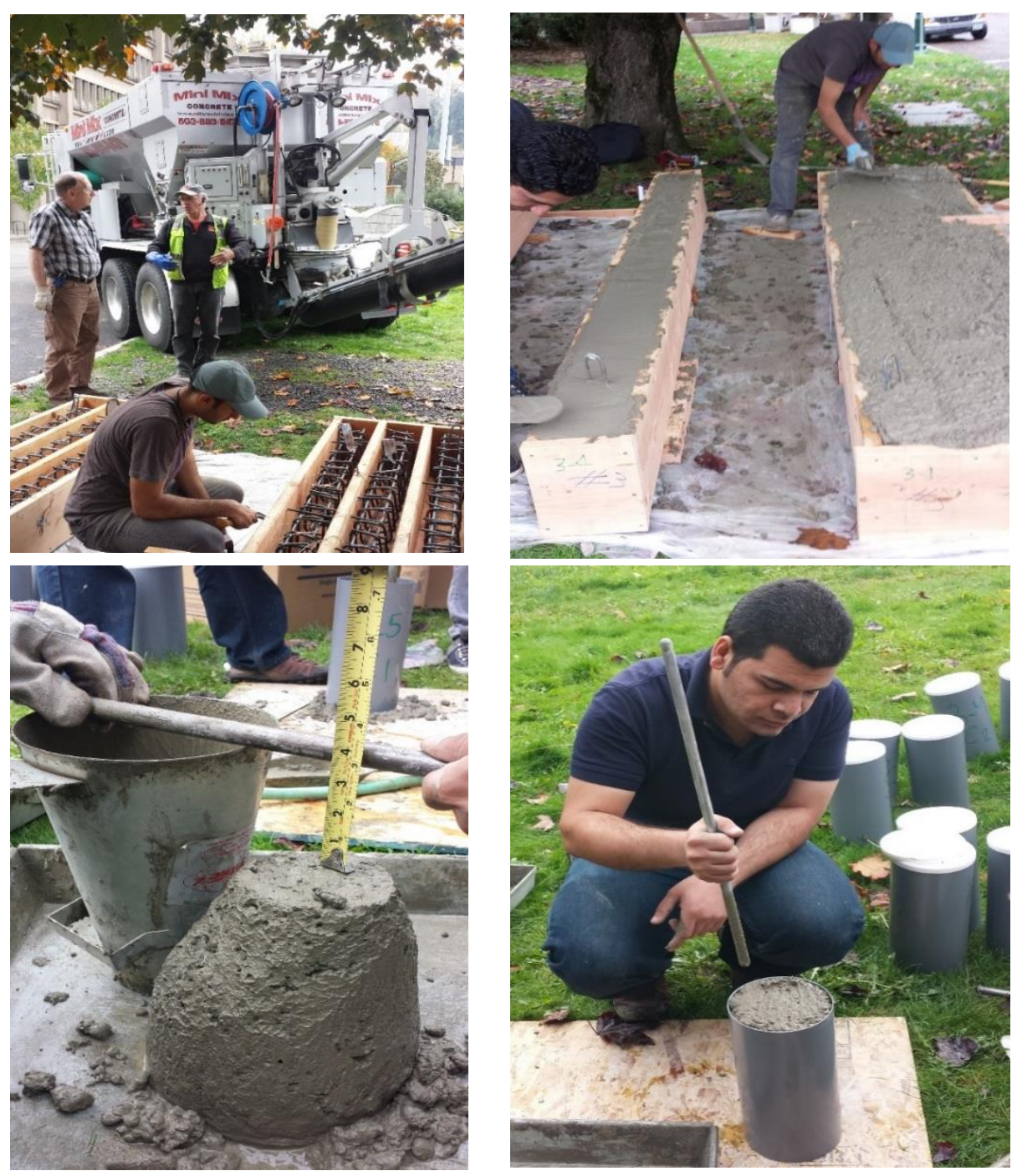

Figure 3-23 Concrete casting. 

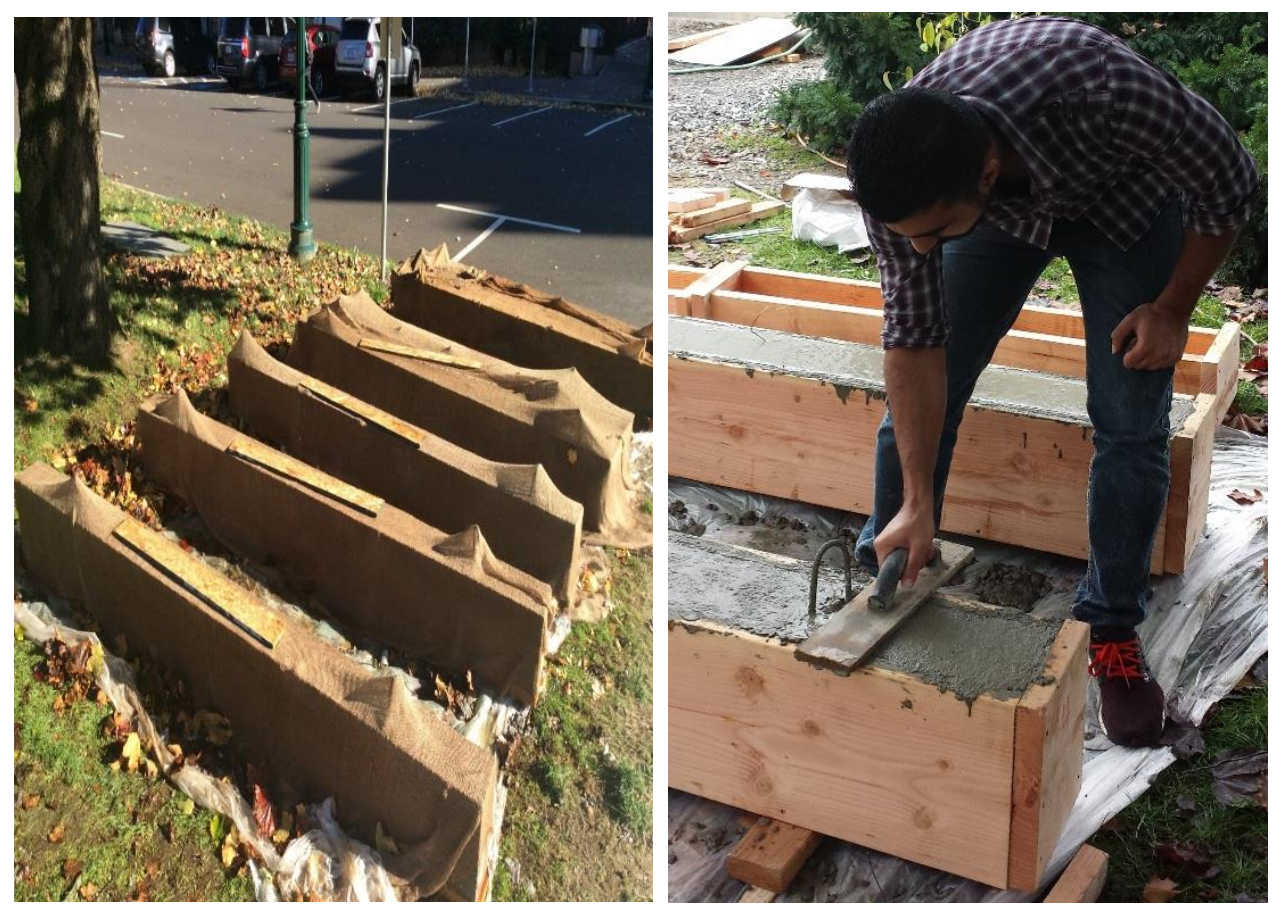

Figure 3-24 Concrete finishing and curing.

\subsubsection{Instrumentations}

Steel strain gages were posted on both the flexural steel rebars and the NSM CFRP rods. Three steel strain gages were placed on steel rebars. Steel strain gages were placed at the pure bending moment region to capture the flexural strain. For the CFRP rods, four strain gages were distributed at $1 / 6^{\text {th }}$ of the development length. The strain gage of "KFH-20120-C1-11L1M2R" was purchased from Omega Engineering, Inc. Steel and CFRP rod's surface preparation were done to ensure the proper bonding of the strain gage as shown in figures below. Three concrete strain gauges were mounted on the top of each beam to record the compression strain at concrete mid span. The concrete strain gauges were type PL-30-11from TML. An LVDT of $100 \mathrm{~mm}$ (4 in) stroke was placed at the middle of the beam to record the deflection. 

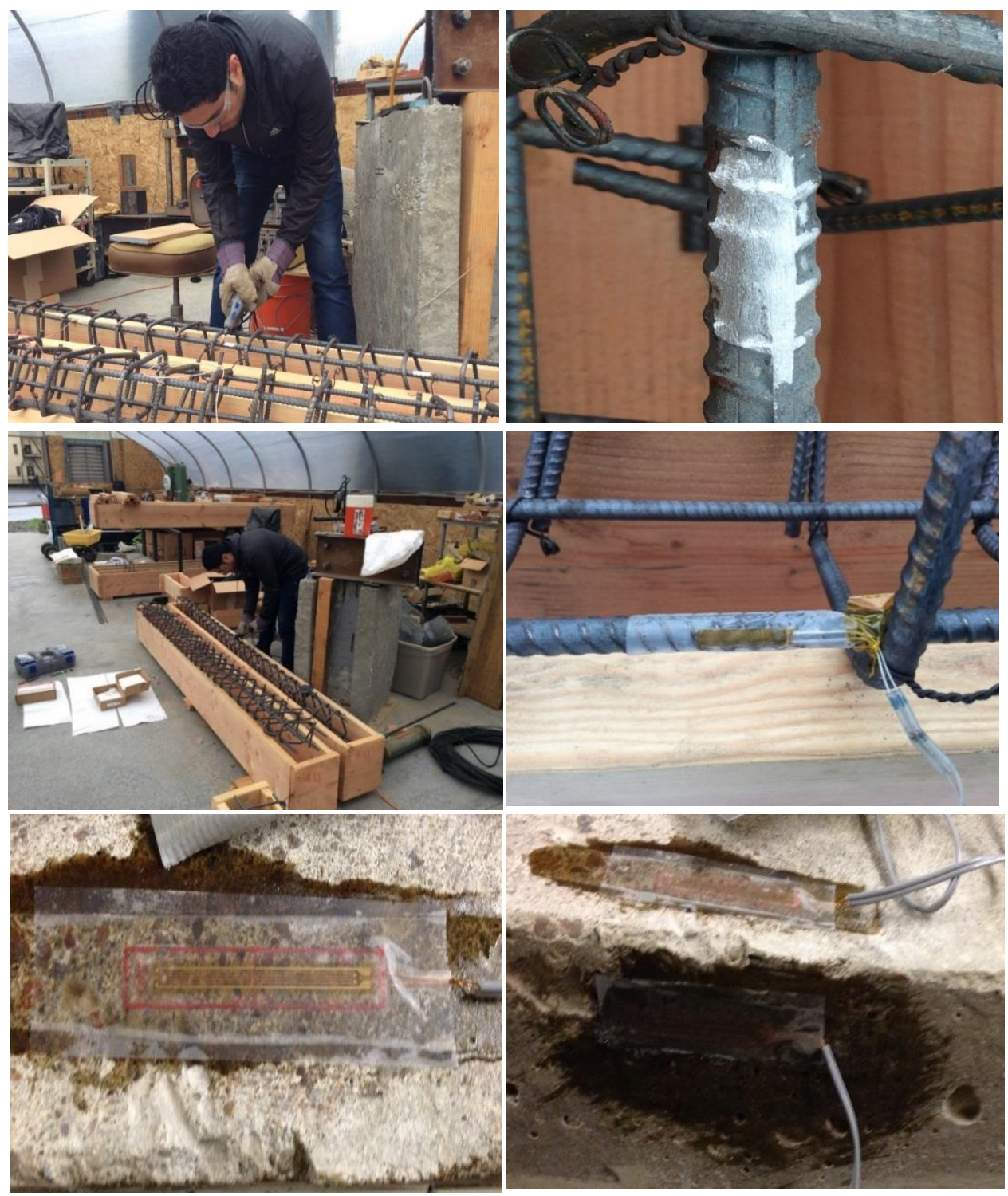

Figure 3-25 Strain gages preparation and posting. 


\subsubsection{Preparation of the Groove}

The grooves were made by a saw with a diamond blade to form two parallel cuts, then a manual hammer with chisel was used to finalize the grooves. The groove's size was $2 \mathrm{D}_{\mathrm{b}}$, that is 0.5 in $x 0.5$ in for \#2 CFRP rod, 0.75 in $x 0.75$ in for \#3 CFRP rod, and 1.0 in x 1.0 in for \#4 CFRP rod. The distance of the longitudinal grooves was 1.0' 'from the edge, and the spacing between the lateral grooves was 3 in as shown in figures below. The grooves were cleaned with an air compressor to eliminate of the concrete dust before inserting the CFRP rods.
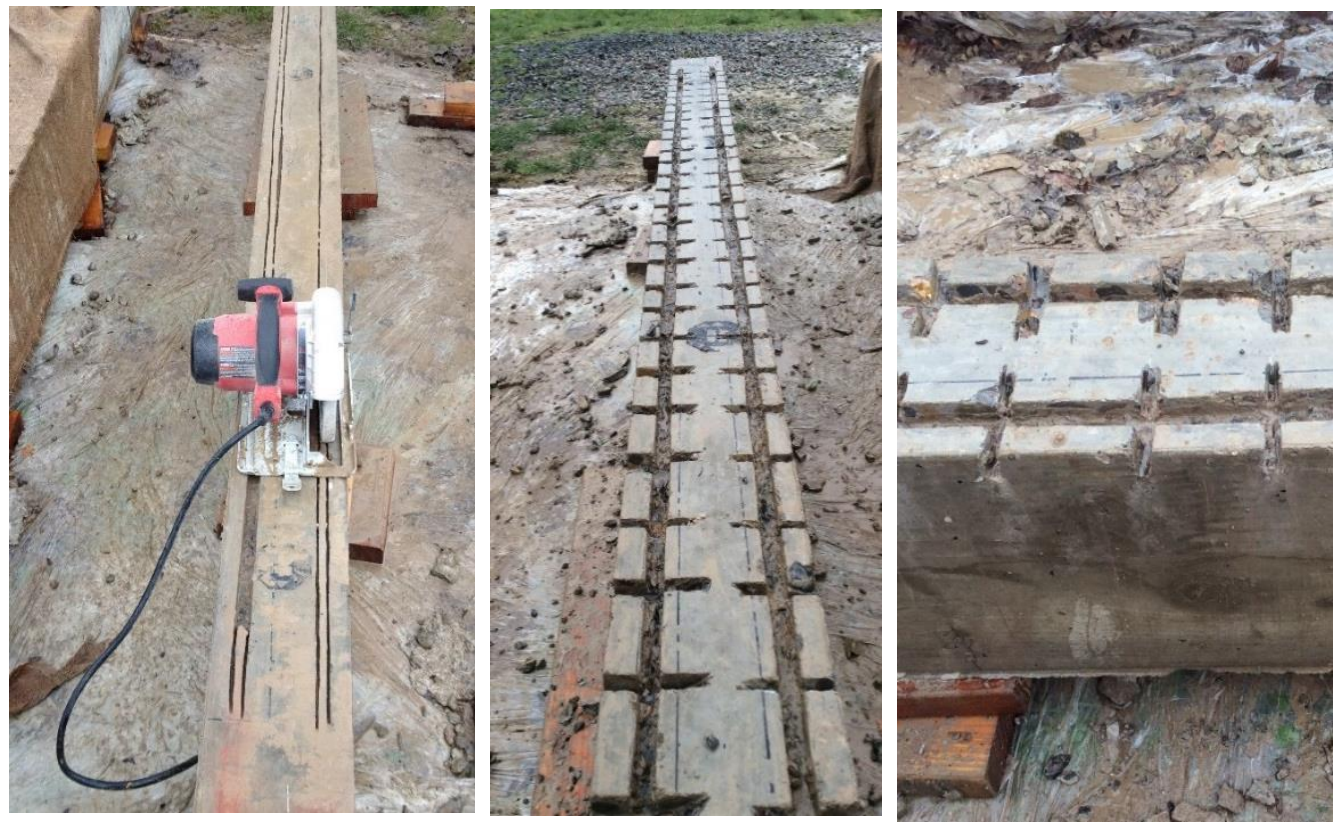

Figure 3-26 Making grooves in the tension side of the strengthened beams. 


\subsubsection{Inserting the CFRP Bars.}

In order to post the CFRP rods, a first layer of epoxy was applied to the grooves. The first layer's thickness was almost half of the grooves' depth. The CFRP rod then was pressed in the groove. After that, a second layer of adhesive was applied at the top of the CFRP rod. The excessive adhesive was leveled and removed as shown in figures below. The adhesive was left for at least seven days for curing at temperature of $17.0 \mathrm{C}^{0 .}$
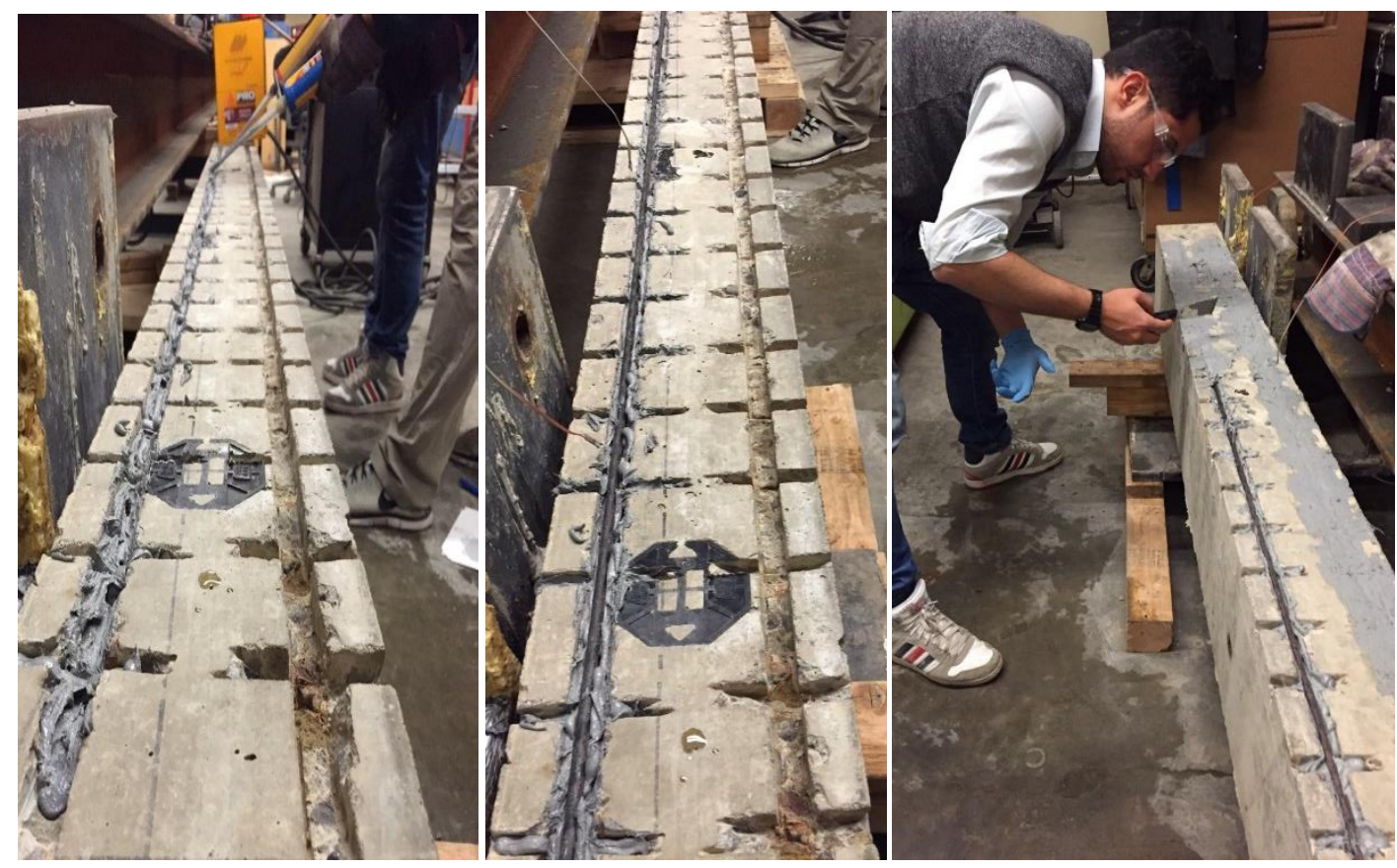

Figure 3-27 Inserting CFRP Rods.

\subsubsection{Instrumentations and Procedure}

The flexural tests for beams were tested in iSTAR laboratory at Portland State University. All beams were tested under four-point loads by using a 50-kip hydraulic cylinder that connected to a manual pump. The test setup is shown in Figure 3-28. The specimens 
were supported on a plate that rested on a 4-in wide bearing plate. A spreader beam of W8x35 was attached to the hydraulic ram. The spreader beam had a flexural span of 32 in that was supported by two plates. The specimens were tested under a monotonically increasing load until failure. The cracks width and paths were observed, and marked at specific load stage.

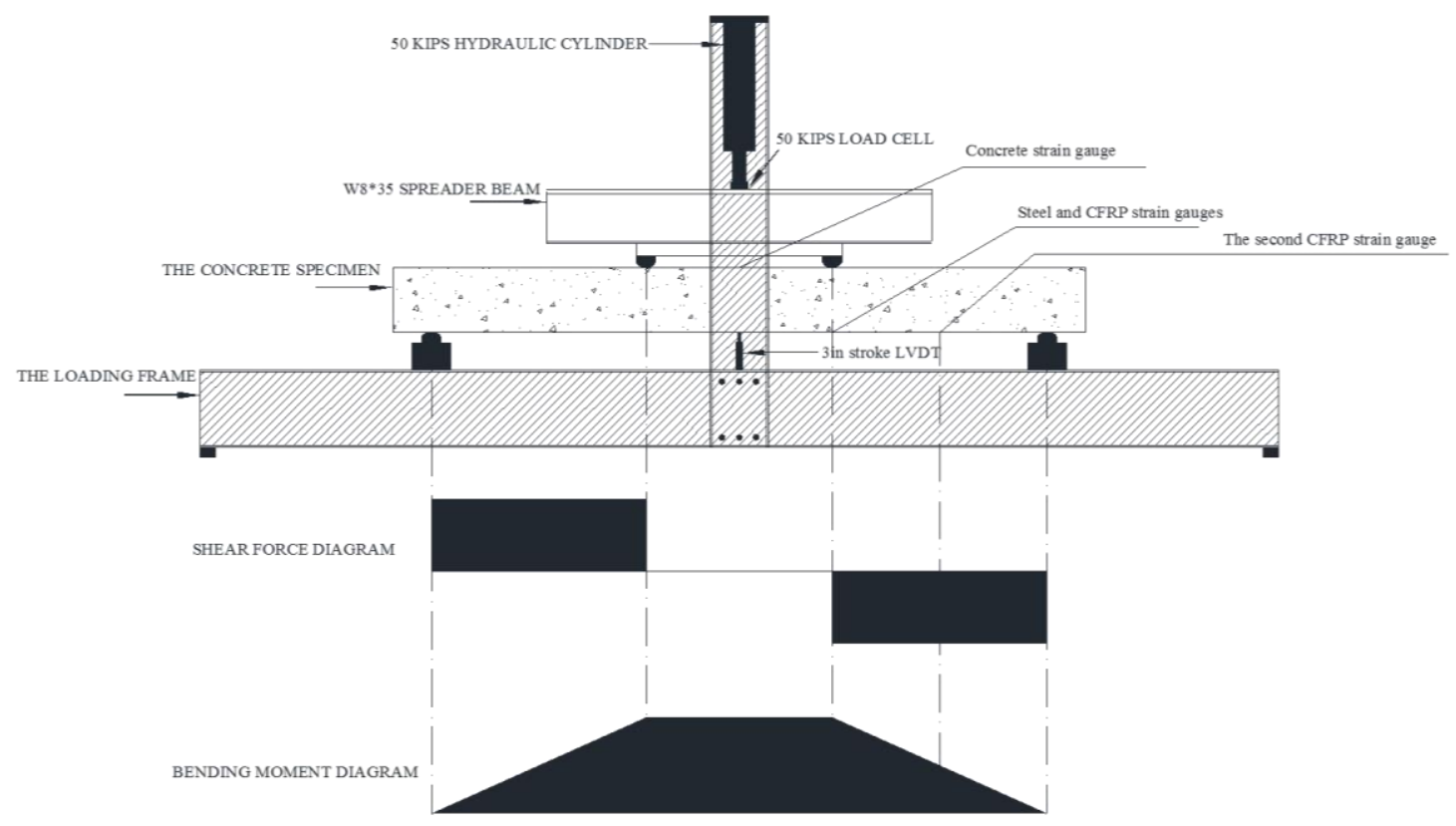

Figure 3-28 Four-point load test setup. 


\section{Chapter 4: $\quad$ The Results}

\subsection{Pullout Test}

The pullout test system shown in Figure 3-12 was adopted in this study. Three sizes of CFRP rods were tested: \#2 (0.25 in diameter), \#3 (0.375 in diameter), and \#4 (0.5 in. diameter). The development length was selected as 60 times the diameter of the CFRP rod. The bonded length was 15 in for the \#2 CFRP rod, 23 in for the \#3 rod, and 30 in for the \#4 rod. The first test was done for the \#2 CFRP rod. In this test two concrete cuts were made at the concrete surface, then the chisel and a manual hammer were used to make the grooves. The failure mode was de-bonding at the concrete-epoxy interface where the CFRP and the epoxy separated from the concrete surfaces as one block. Epoxy-concrete interface de-bonding was the failure mode for this specimen as it seen in Figure 4-1. From Figure 4-2, it is apparent that the failure load was about $40 \%$ of the bar ultimate strength.

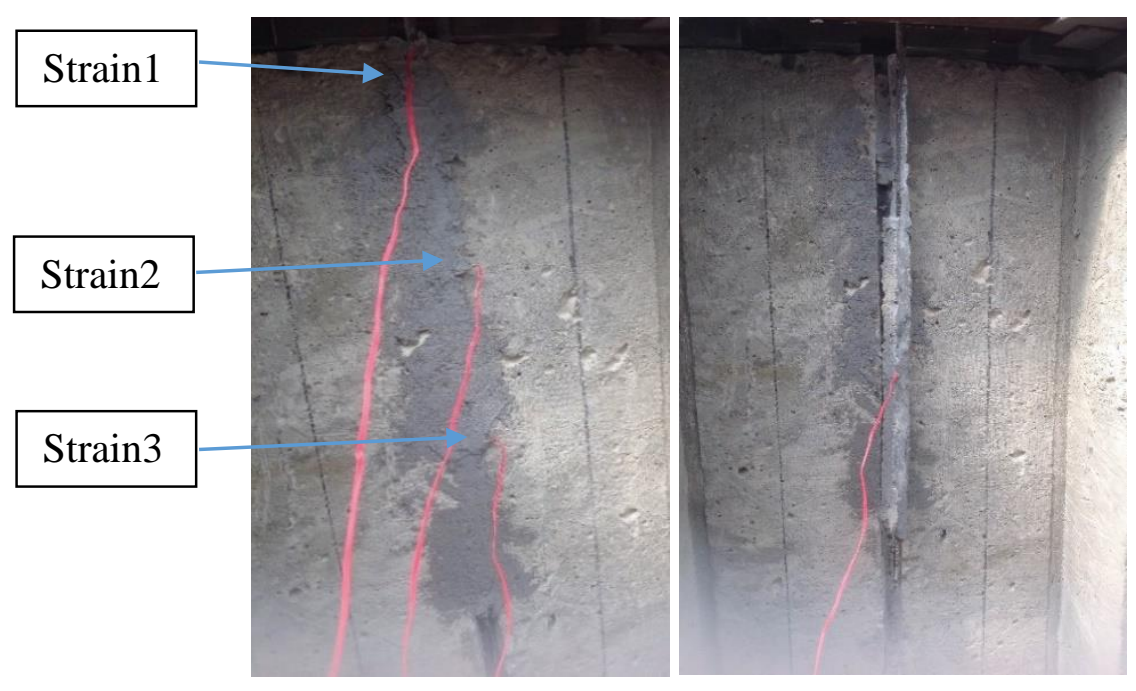

Figure 4-1 Pull out test failure without lateral grooves. 


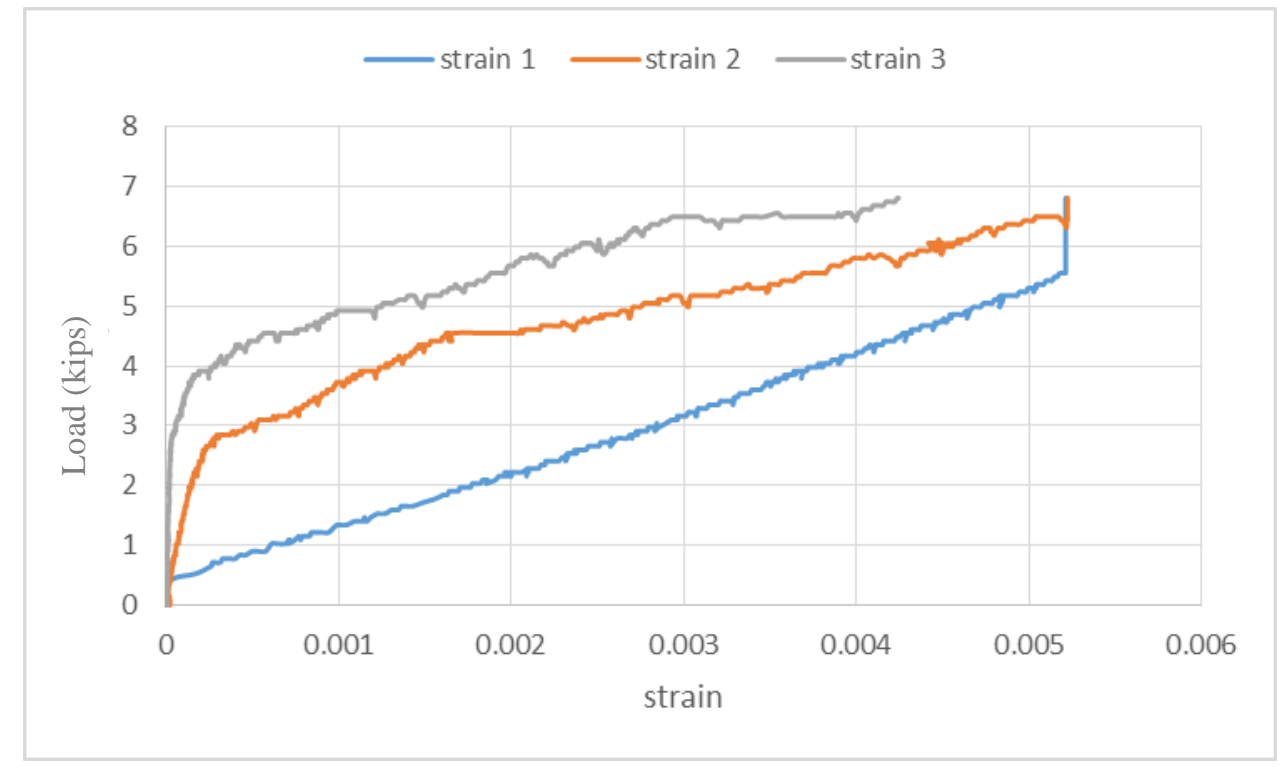

Figure 4-2 Load-strain diagram for \#2with out lateral grooves.

This low bonding capacity was insufficient since it did not utilize more than $40 \%$ of the rod capacity. Therefore, it was decided to enhance the bonding by using lateral grooves of 0.25 inch in width and about 1.0 inch in length. The distance between the grooves was about 3 in. The details for the lateral grooves were adopted from Sharaky, I. A. et al. (2013). The layout of the lateral grooves are shown in Figure 4-3 below. 


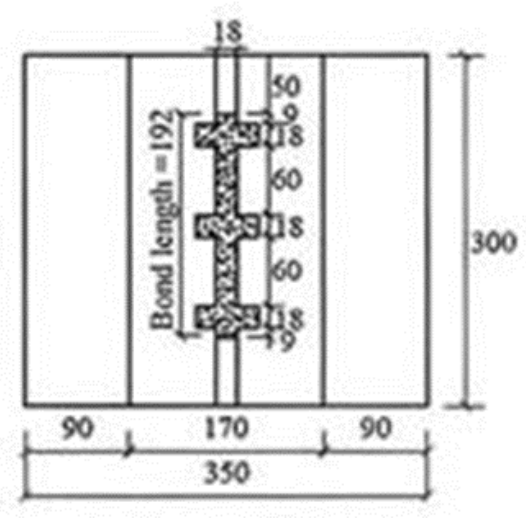

Specimens with mechanical interlocking (Sharaky, I. A. et al. 2013).

\#2\&\#4 lateral grooves details

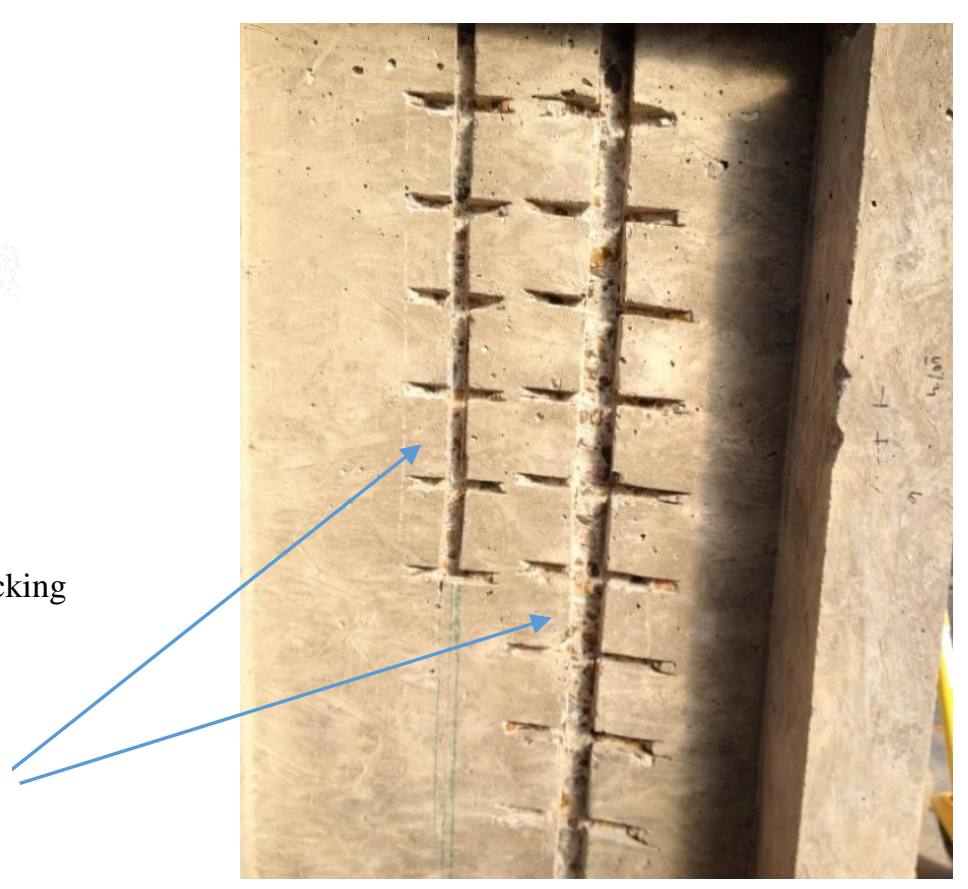

Figure 4-3 Lateral grooves details.

Using the lateral grooves, the result in bonding capacity was $100 \%$ for the \#2 rods, $60 \%$ for \#3 rods, and about $50 \%$ for \#4 rods. It was concluded that the lateral grooves enhanced the bonding by providing an interlocking bond between the epoxy and the concrete. This interlocking force allowed the bonding to resist additional forces by transferring the load to the concrete. Figures 4-4, 4-6, and 4-7 show the strain distribution along the CFRP rods. Strain readings were recorded by strain gages that had been posted along the CFRP rod. Strain gage no.1 was posted at the top of the bonding length. Strain gages no. 2 and no. 3 were posted at third points of the embedment length. For \#2 rod and the \#3 rod CFRP pullout test, the middle strain gauges were damaged and stopped recording after certain level of load. In general, the graph shows that the strain along the 
CFRP is maximum at the loaded end and minimum at strain gages no. 3, which is close to free end. As the pullout load increased, the strain increased along the CFRP rod.

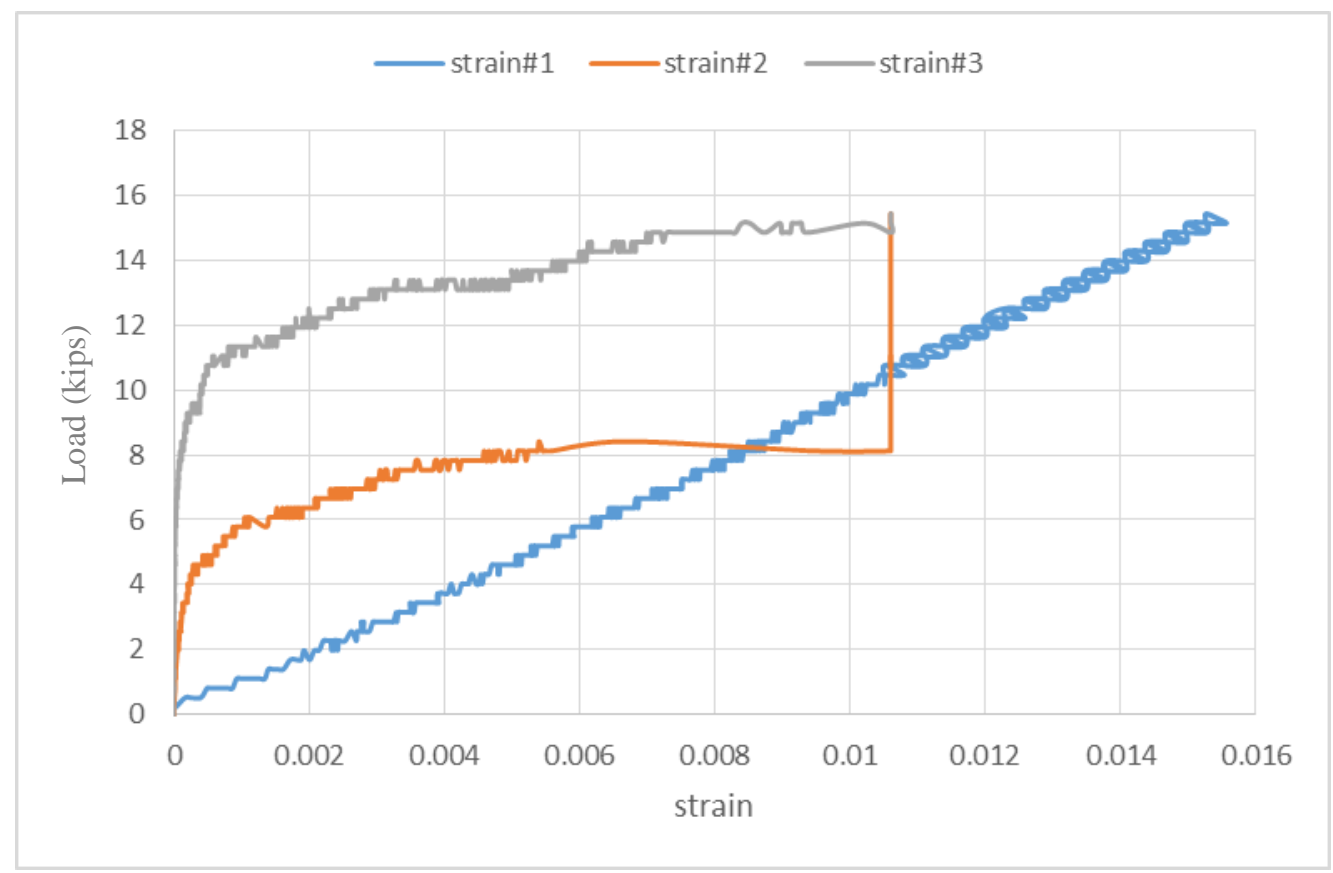

Figure 4-4 Strain load diagram for\#2 CFRP with lateral grooves.
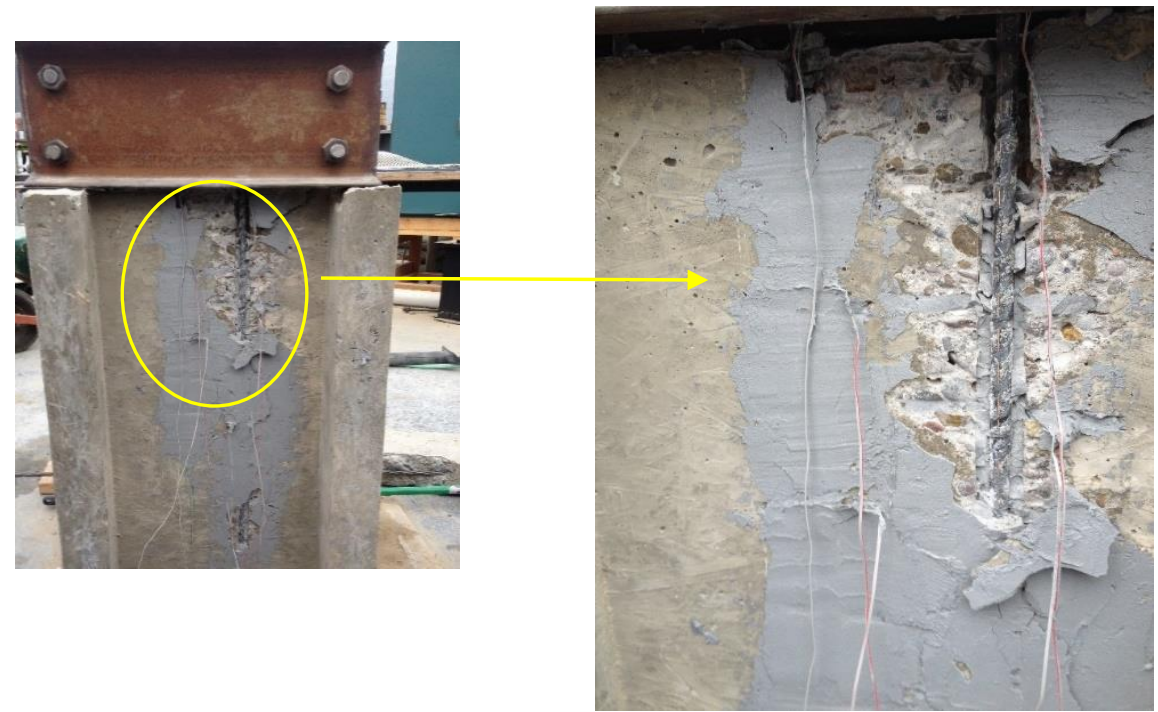

Figure 4-5 Pullout-test-failure for \#2 with lateral grooves. 
Figure 4-5 shows \# 2 and \#4 pullout failure mode. It was observed that \#2 failure did not involve any damage for the surface of the concrete before it ruptured. On the other hand, the failure of the \#4 CFRP rods caused serious damage to the surface of the concrete. The crushing of the concrete introduced the de-bonding failure. For the \#3 CFRP rod, the failure mode was exactly the same mode of failure as the \#4 CFRP rod. These failure modes reduced the bonding capacity of the \#3 and the \#4 CFRP rod to $60 \%$ and $50 \%$ respectively as shown in load-strain curves below. It is apparent from the results above that the interlocking mechanism shifted the failure from the concrete-epoxy interface to the rupture of the CFRP rod for the size \#2 rods, and concrete crushing for the \#3and the \#4 CFRP rods.

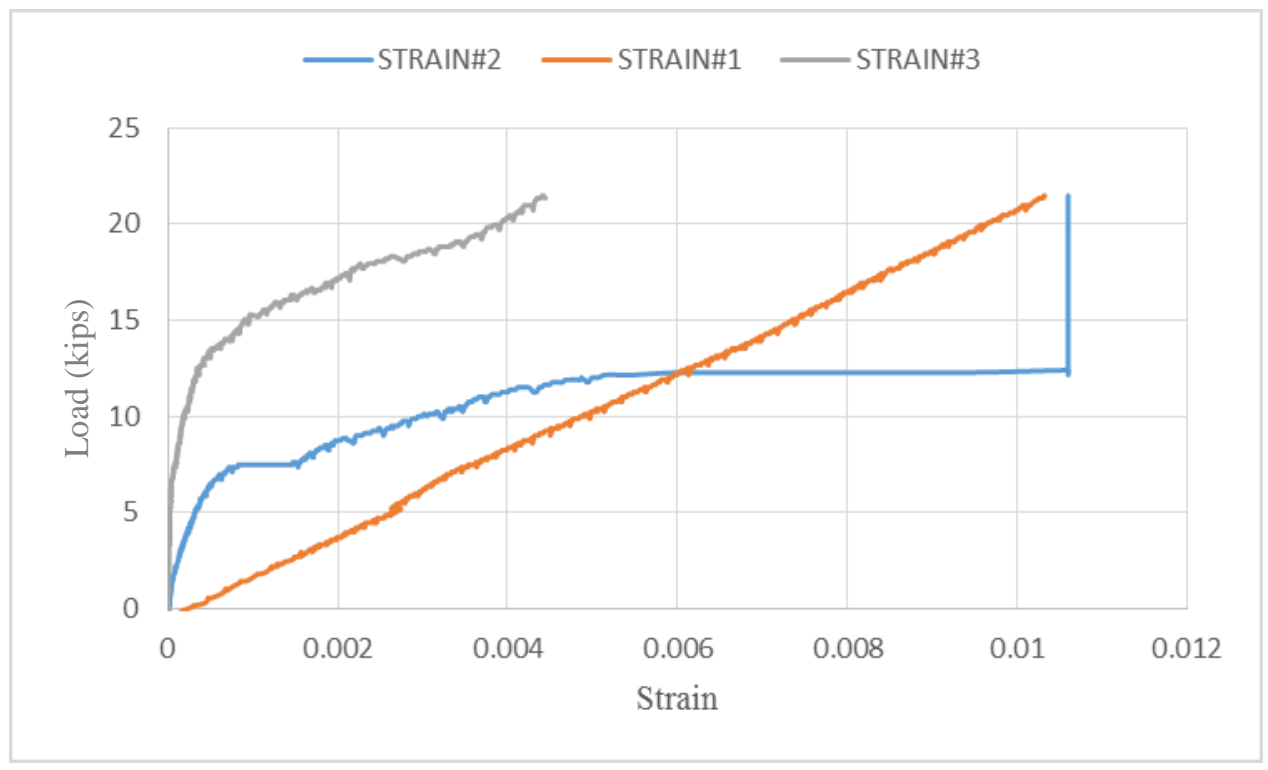

Figure 4-6 Strain load diagram for\#3 CFRP with lateral grooves.

As Figure 4-5 shows, the failure of the \#3 and the \#4 CFRP rods mainly occurred at the loaded end. This indicates that the stress at the loaded end position is significant. 


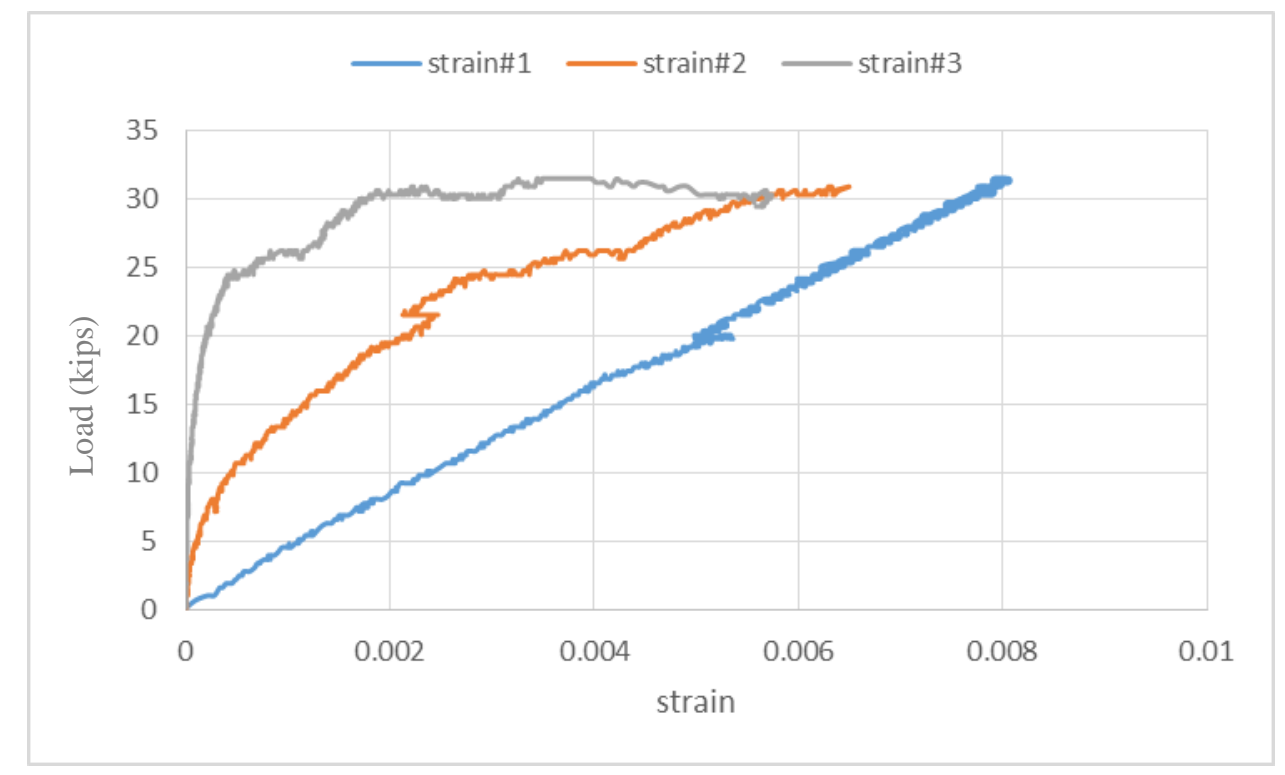

Figure 4-7 Strain load diagram for\#4 CFRP with lateral grooves.

The load-slippage curve was also constructed from the LVDT reading that is explained in Figure 3-13. Figure 4-8 shows the load-slippage relationships for \#2, 3, AND 4 CFRP rods. It was observed that the relationship between the load-slippage was reasonably linear for the \#2 and \#3 rods. However, for \#4 rod, the relationship is linear until about $50 \%$ of the capacity, then the curve started to behave in a nonlinear manner due to the concrete and epoxy deformation surrounding the CFRP rod. 


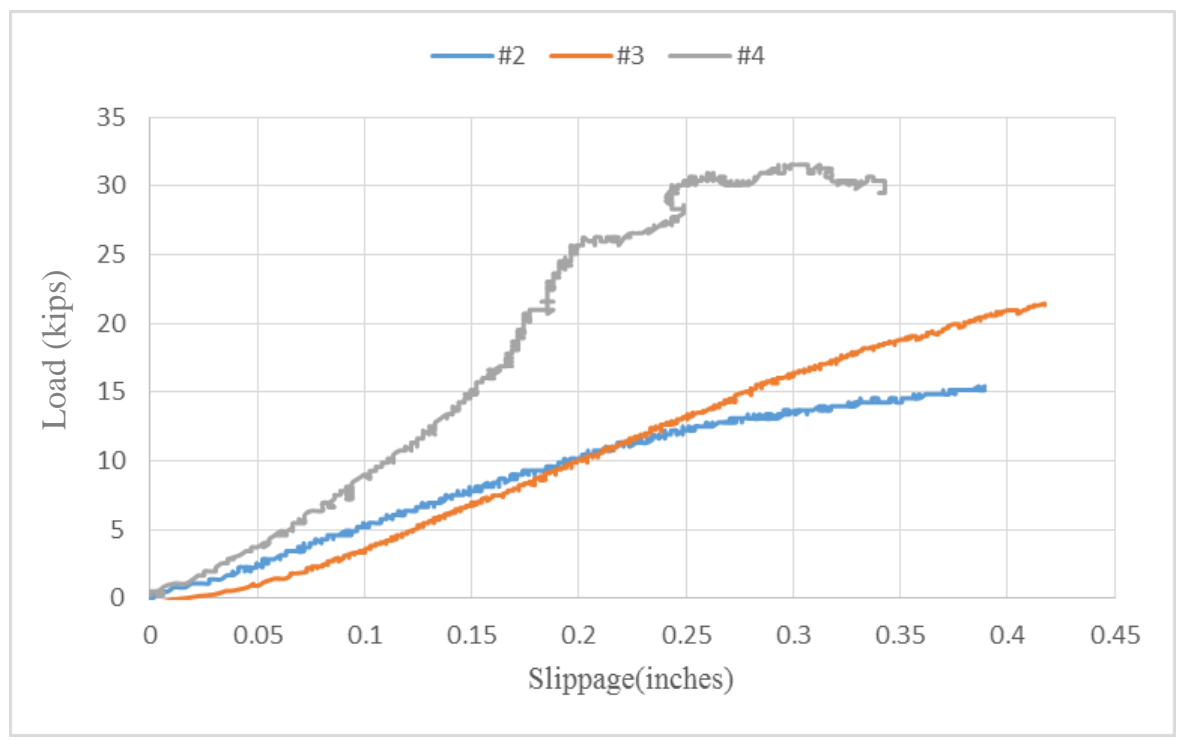

Figure 4-8 Pullout load slippage curves.

\subsection{Discussing the Pullout Results.}

In order to understand the distribution of the pullout stress along the CFRP rod, the figures shown below were constructed. At each load level, the strains were multiplied by the modulus of elasticity for each rod and positioned at the same location of the strain gauges. A, B, and C are the locations of the strain gauges. D is the free end point where the stress was zero. 


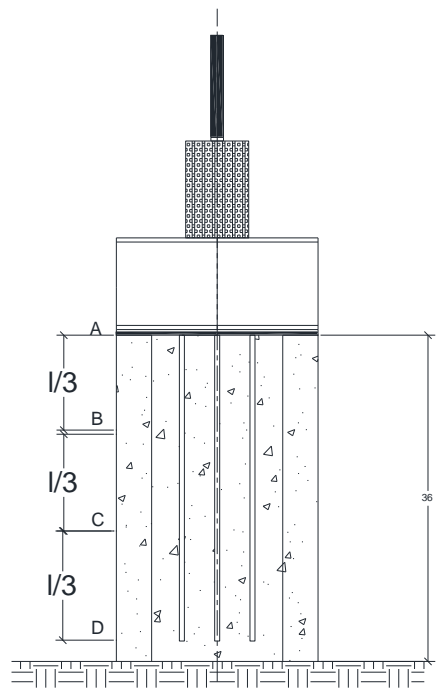

Front view

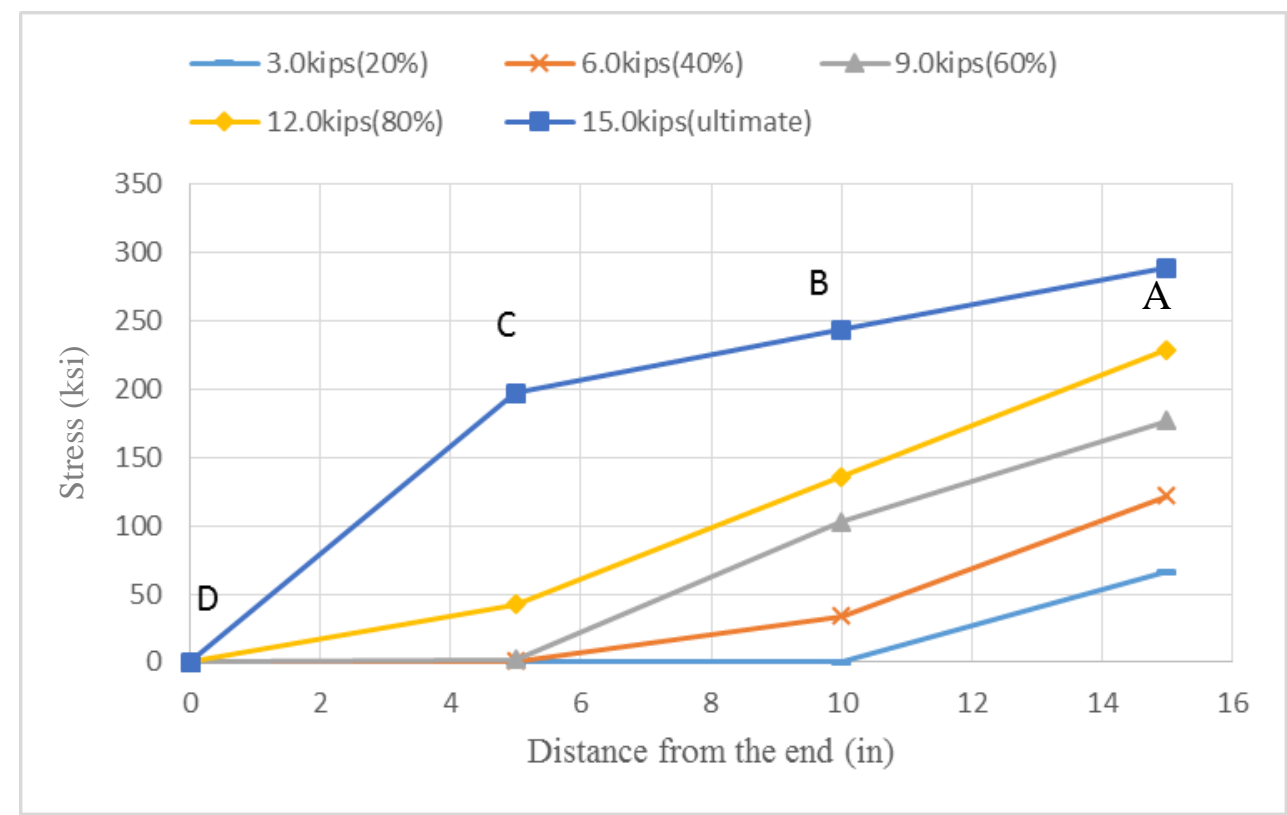

Figure 4-9 \#2 CFRP pullout stress distribution.

It was concluded that the stress variations along the CFRP rods of the stress were uniform for all the bar sizes. Rods \#2 and \#4 had some of discrepancies of strain variation at the early load stages. Nevertheless, the strain adjusted at the ultimate load when more stress 
was transferred to the lower portion of the development length. That indicated that the bonding was adequate to transfer the stress along the bonded length.

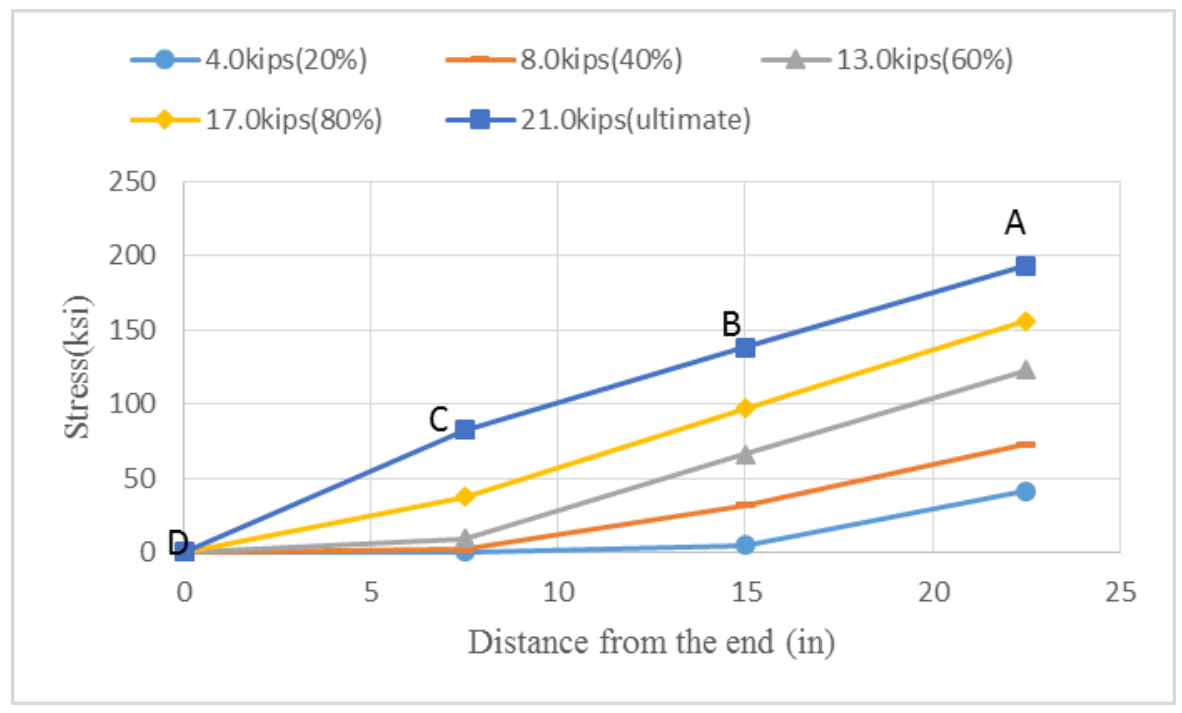

Figure 4-10 \#3 CFRP pullout stress distribution.

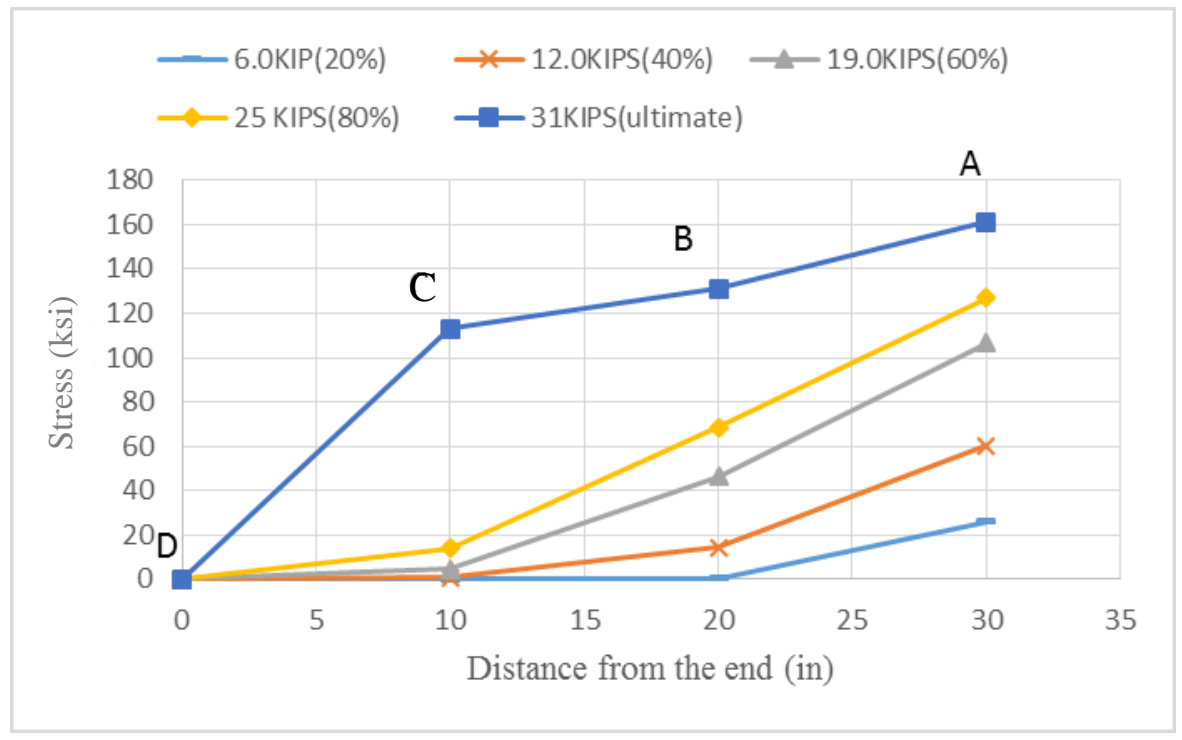

Figure 4-11 \# 4 CFRP pullout stress distribution.

Table 4-1 shows the summery of the pullout tests. Shear stresses at the CFRP-epoxy interface and at epoxy-concrete interface were calculated and referred to as $\tau_{\text {r-e. }}$ and $\tau_{\text {e-c }}$ 
respectively. These stresses were calculated based on the maximum load of the pullout and according to ACI 440.2R-08 equation shown below:

$$
\begin{aligned}
\tau_{r-e} & =\frac{P_{u}}{\left(\Pi D L_{d b}\right)} \\
\tau_{e-c} & =\frac{P_{u}}{\left((a+2 b) L_{d b}\right)}
\end{aligned}
$$

B. $\mathrm{R}=$ Bar Rupture. $\quad$ C. $\mathrm{C}=$ Concrete Crushing.

\begin{tabular}{|c|c|c|c|c|c|c|c|c|c|}
\hline CFRP & $L_{d b}$ & $f_{c}^{\prime}$ & $\mathrm{P}_{\mathrm{u}}$ & $\sigma_{\mathrm{u}}$ & $\tau_{r-e}$ & $\tau_{e-c}$ & $\varepsilon_{\mathrm{u}}$ & Slippage & Failure \\
rod\# & inches & $\mathrm{ksi}$ & $\mathrm{kips}$ & $\mathrm{ksi}$ & $\mathrm{ksi}$ & $\mathrm{ksi}$ & $\mathrm{strain}$ & $(\mathrm{in})$ & mode \\
\hline$\# 2$ & 15.0 & 4.5 & 15.0 & 288.7 & 1.2 & 0.63 & 0.0155 & 0.39 & B.R \\
\hline$\# 3$ & 22.5 & 4.0 & 21.0 & 193.5 & 0.8 & 0.42 & 0.01 & 0.41 & C.C \\
\hline$\# 4$ & 30 & 4.5 & 31.0 & 161.14 & 0.67 & 0.35 & 0.008 & 0.34 & C.C \\
\hline
\end{tabular}

Table 4-1 pullout results summery.

ACI 440.2R-08 assumes a linear distribution for the shear stresses along the bonded length, with a peak near the middle of the embedment. The max stress starts at the loaded end or the maximum bending moment region, and assuming a uniform bond stress, the bar stress gradually decreases until it reaches the support or the free end.

Figure 4-12 shows the assumed bond distribution according to ACI440.2R-08

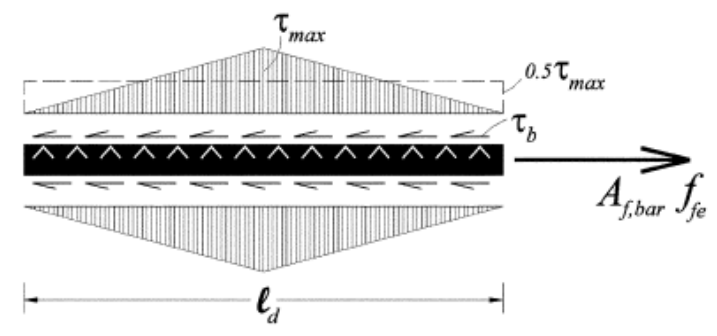

Figure 4-12 Bond stress distribution (ACI 440.2R-08, p 40). 
From the force equilibrium, ACI 440.2R-08 derived the following equation to calculate the development length. ACI 440.2R-08 reported an average shear stress from500-3000 psi based on previous studies. However, the 1000 psi was recommended as the average shear strength for NSM.

$$
L_{d b}=\frac{d_{b}}{4\left(\tau_{b}\right)} \sigma_{b} \quad \mathrm{ACI} 440.2 \mathrm{R}-08(13-3)
$$

By comparing, the bond shear stress results from the pullout results with the ones that were presented by ACI 440. 2R-08, the obtained results were reasonably close to the average shear stress that was recommended by ACI 440.2R-08 as shown in figure 4-13.

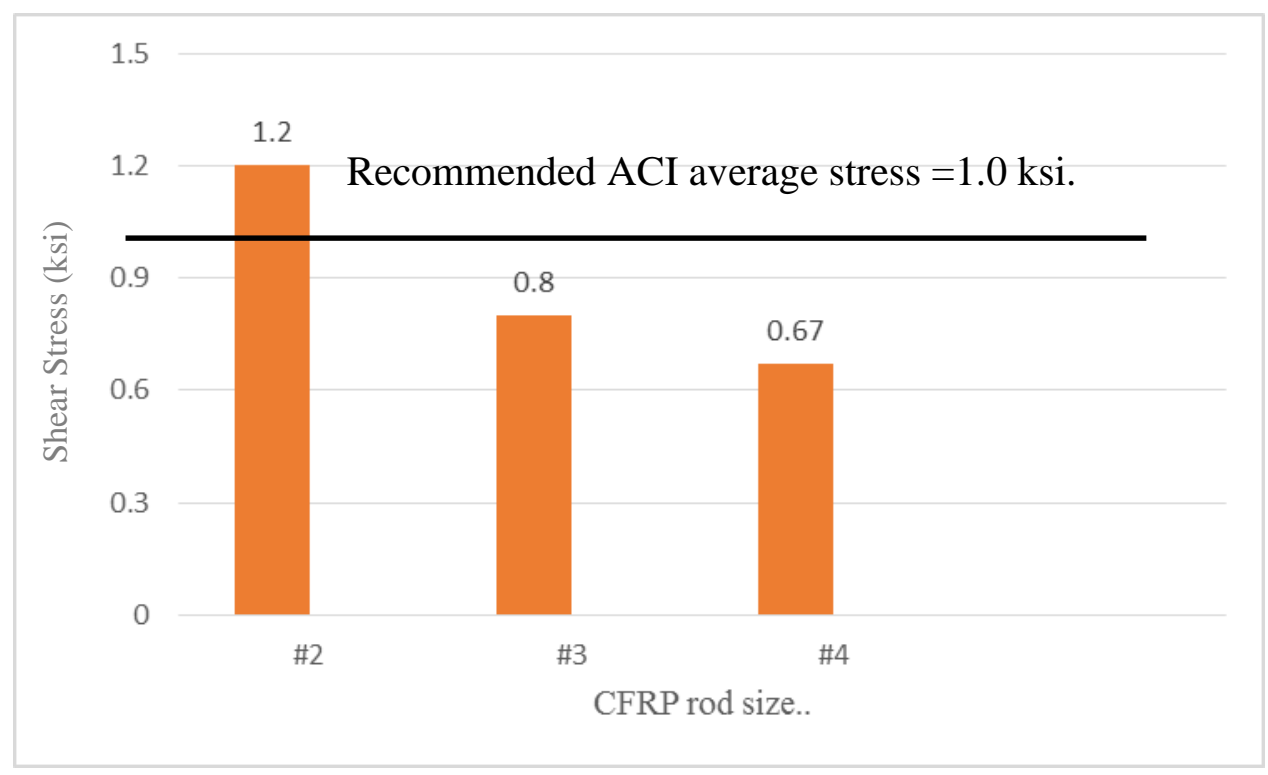

Figure 4-13 Average shear stress for NSM CFRP rod. 


\subsection{Beam Test}

For the flexural test, nine beams were tested under a two-point load as shown schematically in Figure 4-14 below.

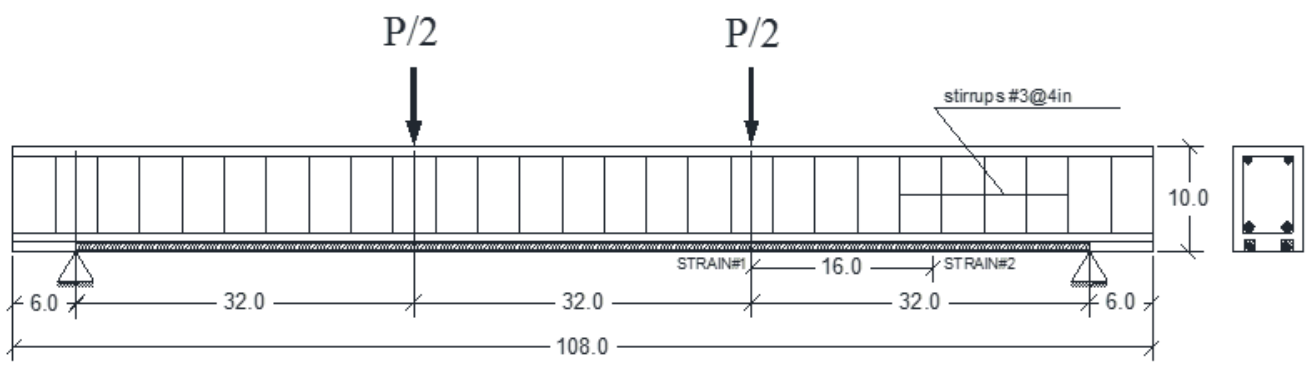

Figure 4-14 Two point load flexural test.

All beams had dimensions $b x h=6.5 \times 10$ inches. The beams were classified into two sets. The steel reinforcement for Set A was selected to be a "medium-low" amount to reflect a portion of actual beams that may need to be retrofitted. The beams in set A had a $0.7 \%$ steel ratio, which is two \#4 steel rebars. The steel reinforcement for Set B was selected to be a "low" amount to reflect a portion of actual beams that will more likely to be retrofitted. The beams in Set B had a $0.4 \%$ steel ratio, which is two \#3 steel rebar. For each set, the beams were additionally reinforced with two CFRP rods as described in Table 4-2 below. The load was recorded by a load cell and the mid-span deflection was recorded by a Linear Variable Differential Transformer (LVDT). The strains in the steel bar, concrete, and CFRP bar were also recoded. The load was applied gradually in 3-kip intervals. The crack propagation and crack width were inspected, marked, and recorded manually by crack width measuring device. Strains were measured in the concrete in compression (top surface), in the steel and in CFRP bars at two locations. 


\subsubsection{Set (A) Specimens}

Table 4-2 Set A specimens results summery.

\begin{tabular}{|c|c|c|c|c|c|c|c|}
\hline $\begin{array}{l}\text { Beam } \\
\text { label }\end{array}$ & $\begin{array}{c}\text { Reinforcement } \\
\text { details }\end{array}$ & $\mathrm{f}_{\mathrm{c}}{ }^{\prime}(\mathrm{psi})$ & $\mathrm{P}_{\mathrm{u}}(\mathrm{Kips})$ & $\Delta_{\mathrm{u}}($ inches $)$ & Ductility & $\begin{array}{l}\text { Increase in } \\
\text { capacity } \\
\text { beyond AC }\end{array}$ & $\begin{array}{l}\text { Failure } \\
\text { Mode }\end{array}$ \\
\hline $\mathrm{AC}$ & $\begin{array}{c}\text { 2\#4 steel bars. } \\
\text { No CFRP }\end{array}$ & 4200 & 17.0 & 2.0 & 3.75 & - & $\begin{array}{l}\text { Concrete } \\
\text { crushing }\end{array}$ \\
\hline AR2 & $\begin{array}{c}\text { 2\#4 steel bars } \\
\text { 2\#2 CFRP } \\
\text { bars }\end{array}$ & 4200 & 29.0 & 1.5 & 2.5 & $70 \%$ & $\begin{array}{l}\text { Concrete } \\
\text { peeling off }\end{array}$ \\
\hline AR3 & $\begin{array}{c}\text { 2\#4steel bars } \\
\text { 2\#3 CFRP } \\
\text { bars }\end{array}$ & 4372 & 23.4 & 1.1 & 1.6 & $38 \%$ & $\begin{array}{l}\text { Concrete } \\
\text { peeling off }\end{array}$ \\
\hline AR4 & $\begin{array}{c}\text { 2\#4 steel bars } \\
\text { 2\#4 CFRP } \\
\text { bars }\end{array}$ & 4000 & 27.5 & 0.8 & 0 & $62 \%$ & $\begin{array}{l}\text { CFRP de- } \\
\text { bonding }\end{array}$ \\
\hline AR4-S & $\begin{array}{l}\text { 2\#4 steel bars } \\
\text { 1\#4CFRP bars }\end{array}$ & 4600 & 26.5 & 1.1 & 1.7 & $56 \%$ & $\begin{array}{l}\text { CFRP de- } \\
\text { bonding }\end{array}$ \\
\hline
\end{tabular}

\subsubsection{The Control Beam (AC)}

The first tested beam in set A was the control beam (AC), which had two \#4 steel rebars.

According to ACI318-12 (shown in Figure 4-15), the flexural capacity of this beam is $18.9 \mathrm{k}-\mathrm{ft}$. which corresponds to a load of $14.2 \mathrm{kips}$. Figure 4-16 shows the experimental load-deflection relationships. 


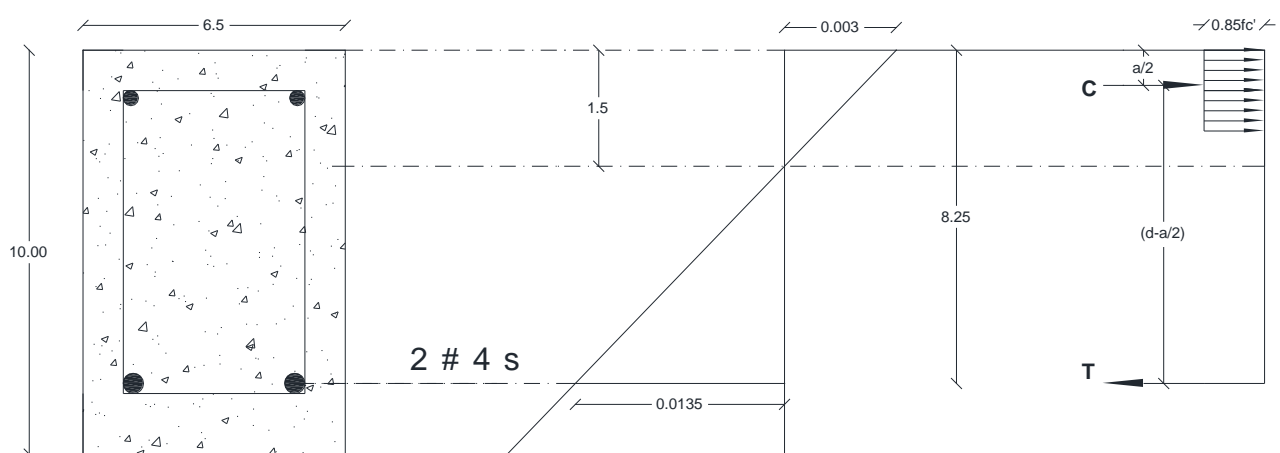

Figure 4-15 Specimen AC strain and stress profile according to ACI.

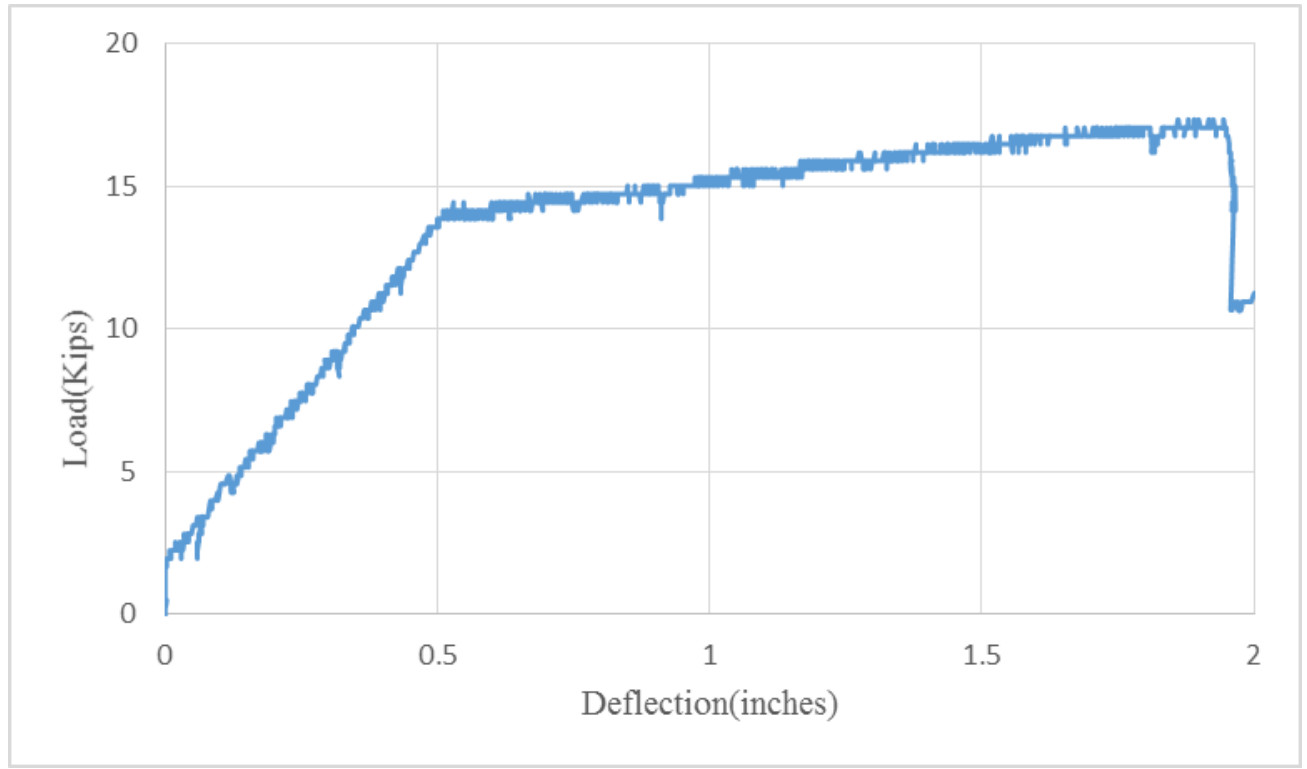

Figure 4-16 Specimen AC load deflection-curve.

The strain profile measured at the maximum bending moment region is shown in Figure 4-17. The strain profile showed that the pure bending moment section experienced a significant strain increase when the load increased from 15.0 kips to 17.0 kips. At 17 kips, the steel and concrete strain was about 0.015 and 0.005 respectively. After this point, concrete crushed and the capacity decreased. 


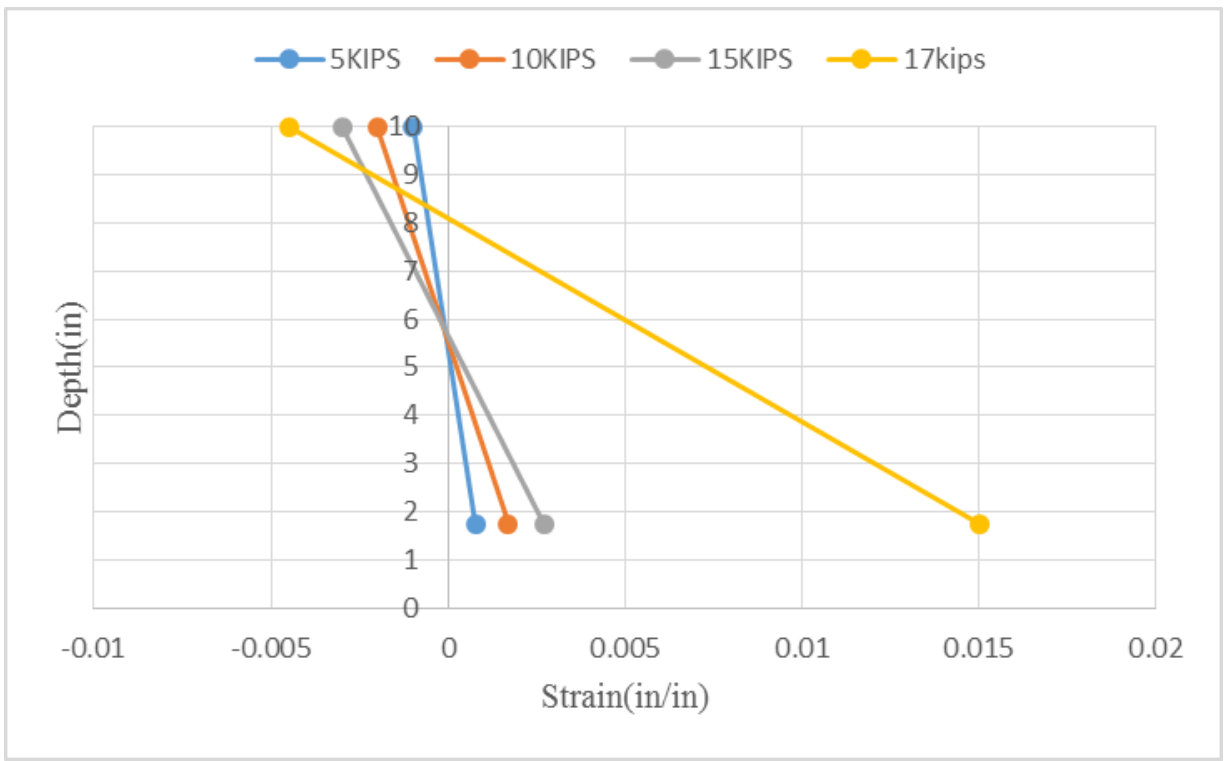

Figure 4-17 Specimen AC strain profile at different load level.

Cracks propagated at the pure positive bending moment regions. As the load increased, the cracks widened. The load was then increased until the concrete crashing occurred at about 17.0 kips as shown in Figure 4-18. 

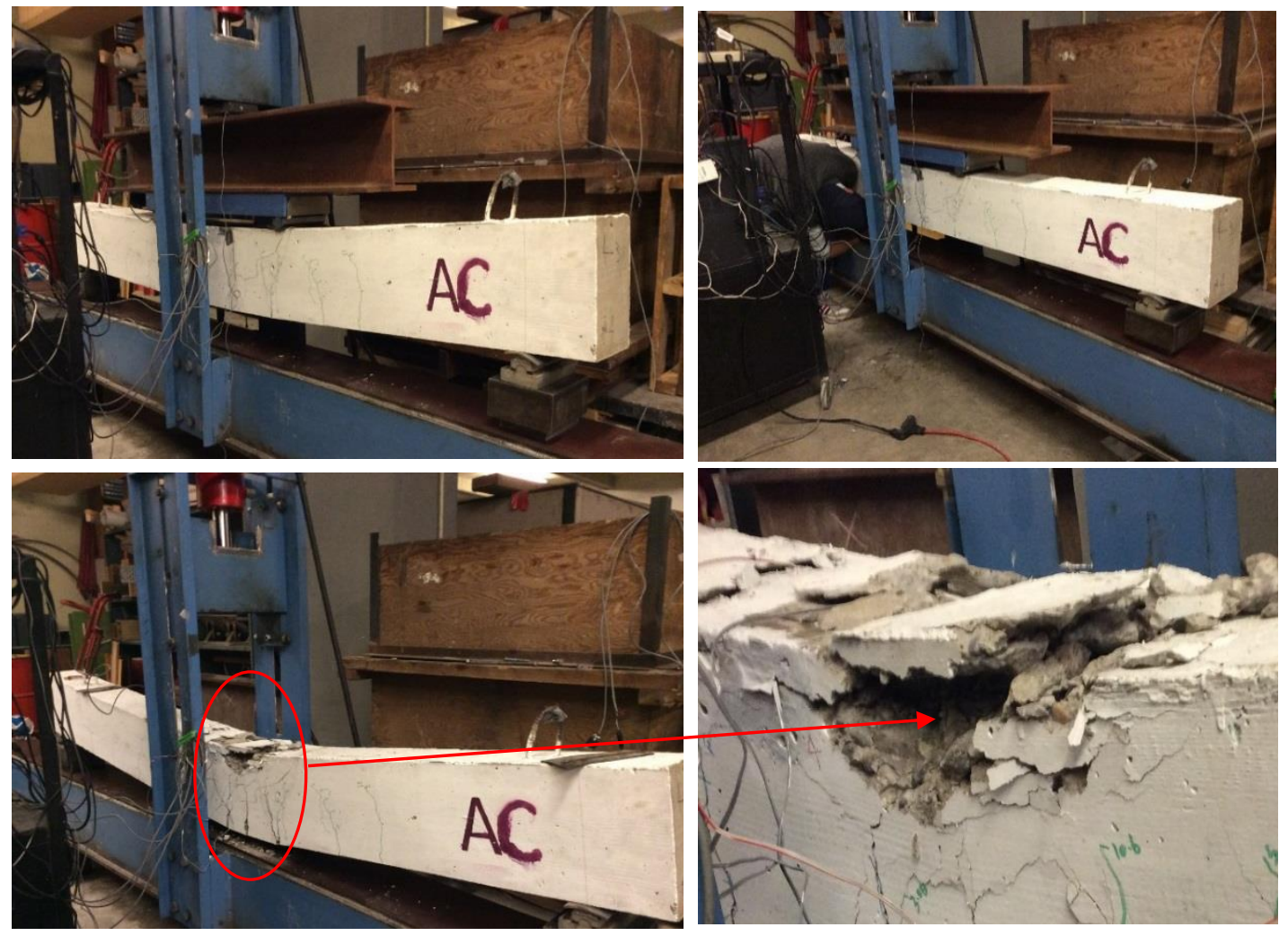

Figure 4-18 Failure mode of specimen AC.

\subsubsection{Beam Retrofitted with Two \#2 CFRP Rods (AR2)}

The second beam tested in set A was AR2. This beam had the same properties as the AC beam, but was additionally reinforced (retrofitted) with two \#2 CFRP rods at the tension side. According to ACI 440-2R-08, the maximum capacity of this beam is $29.0 \mathrm{k}-\mathrm{ft}$ that leads to a load of about 21.6 kips. Strain and stress profile according to ACI is shown in Figure 4-19. 


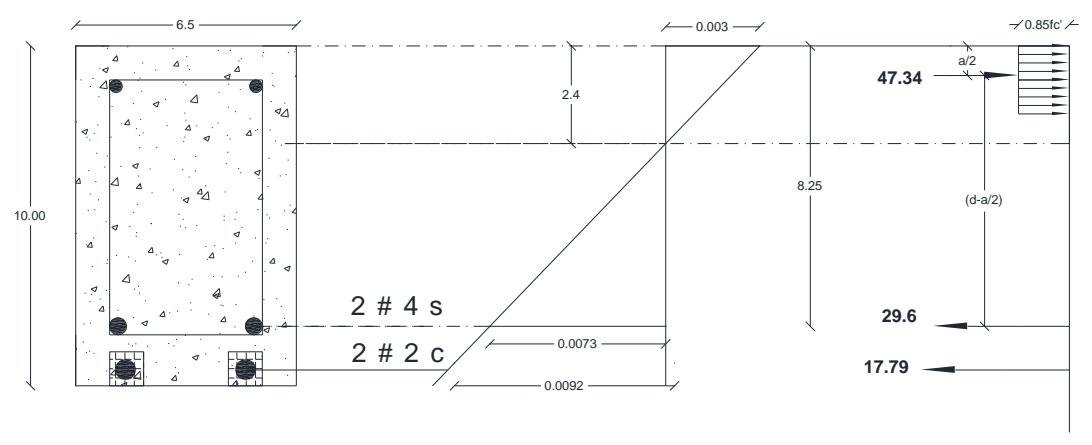

Figure 4-19 ACI strain and stress analysis of specimen AR2.

From the measured load deflection curve shown in Figure 4-20, three distinct regions were observed: the first region was where the first crack of $0.05 \mathrm{~mm}$ occurred at about 3 kips. That is where the beam lost some of its flexural stiffness. The second region was where the steel and the CFRP rods behaved elastically; and the third region was where the steel reinforcement yielded. In this stage, more of flexural stiffness was lost and more cracks were initiated and widened at the positions of the lateral grooves. This observation was reported by Al-Mahmoud, F.et al. (2010) where the authors categorized the momentdeflection curve into three stages: first zone is the elastic stage, second zone is concrete crack to steel yielding stage, and the third Zone is steel yielding to failure stage as shown in Figure 2-9. As the load increased, the measured cracks increased. The load was then increased until the de-bonding occurred at about 29 kips. 


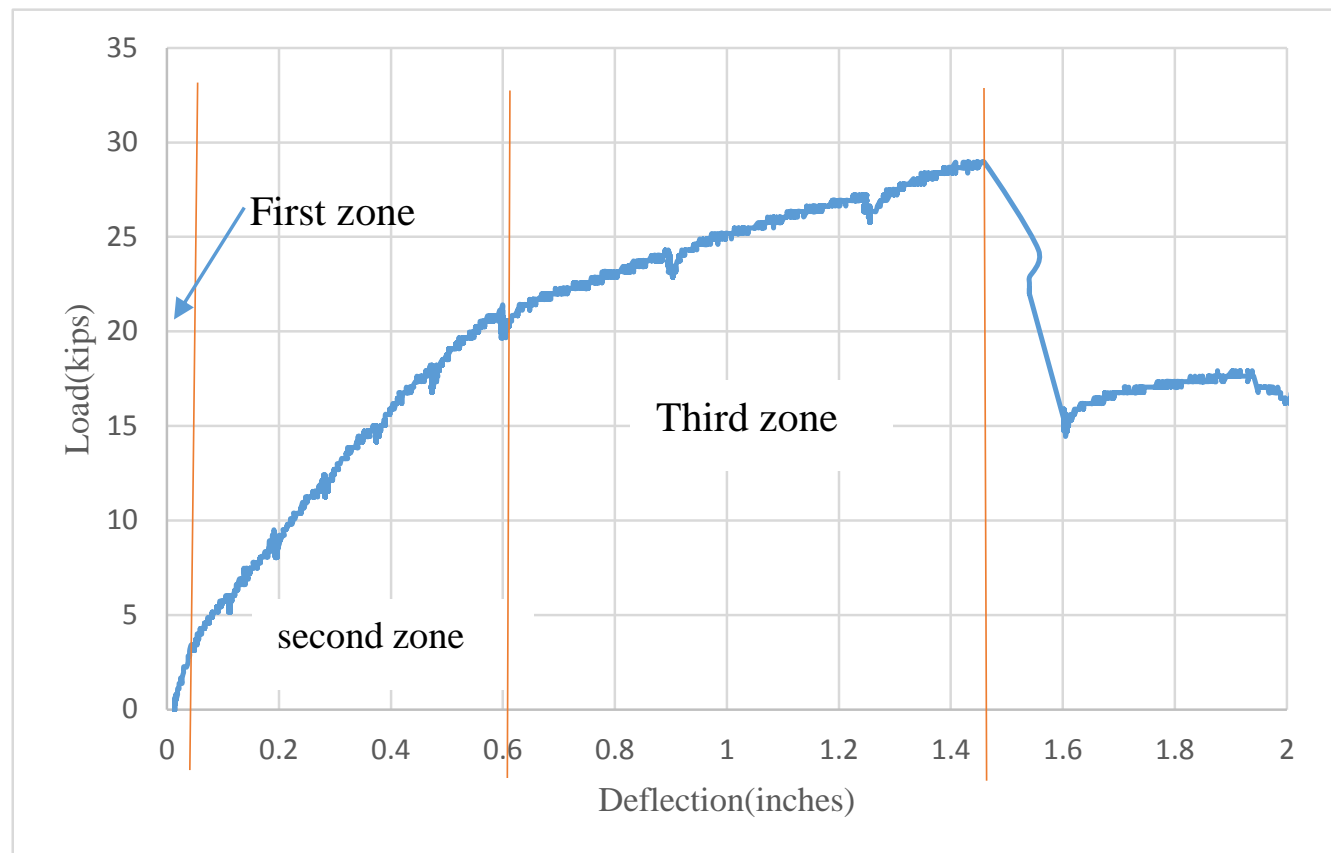

Figure 4-20 Specimen AR2 load-deflection curve.

The increased capacity was about $70 \%$ over the control beam. Before deboning occurred, some diagonal cracking occurred at the maximum bending moment region. These cracks were initiated at the middle and extended to the ends of the beam.

From the CFRP, steel, and concrete's strain gauges, the strain profile at the maximum moment section was constructed as shown in Figure 4-21. It was observed that the strain in the section was linear up to 20 kips. After that, the strain profile behaved nonlinearly, especially prior to the de-bonding when the strain in the CFRP material was less than the steel bars. 


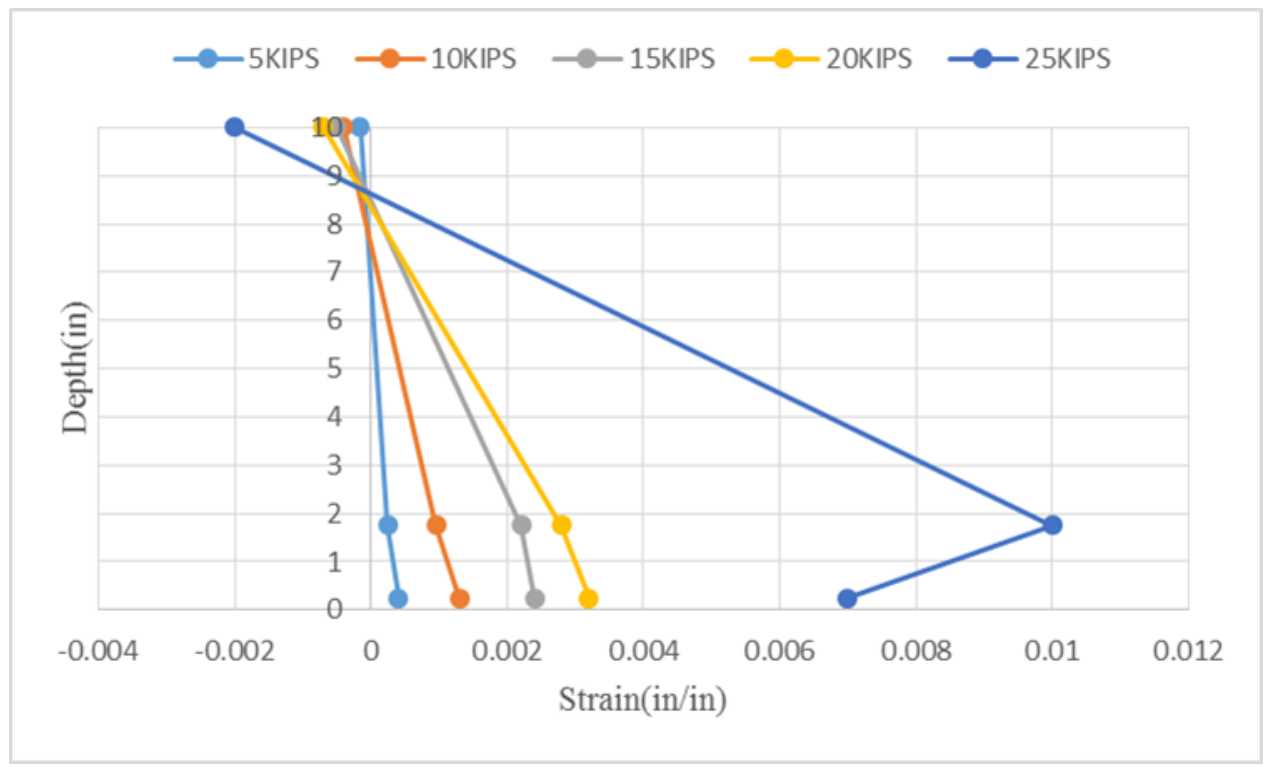

Figure 4-21 Section strain profile for specimen AR2 at different load levels.

This phenomenon is described in ACI 440-2R-08 as the "delamination of the concrete layer caused by the tension failure of the concrete cover" as shown in Figure 4-22 below.
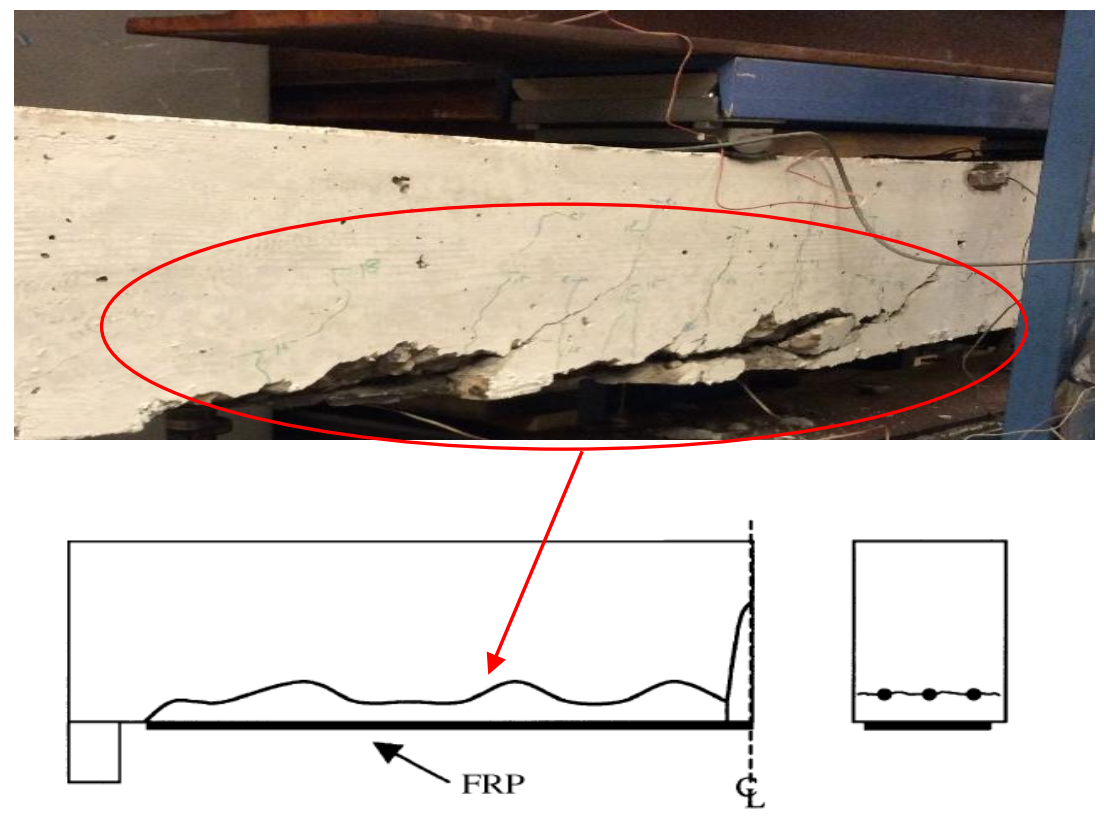

Figure 4-22 Tension layer delamination (ACI440.2R-08, p 38). 
Figure 4-23 shows the load-strain relationship at two points along the CFRP rods. The first strain gauge was located at the beginning of the pure moment region, directly under the point load, and the second strain gauge was located at 16 inches away from the first guage. The strain distribution shows that the strain was larger at the pure moment region and increased as the load increased, as expected. The maximum strain in the first and the second strain gauge was about $70 \%$ and $40 \%$ of the ultimate strain.
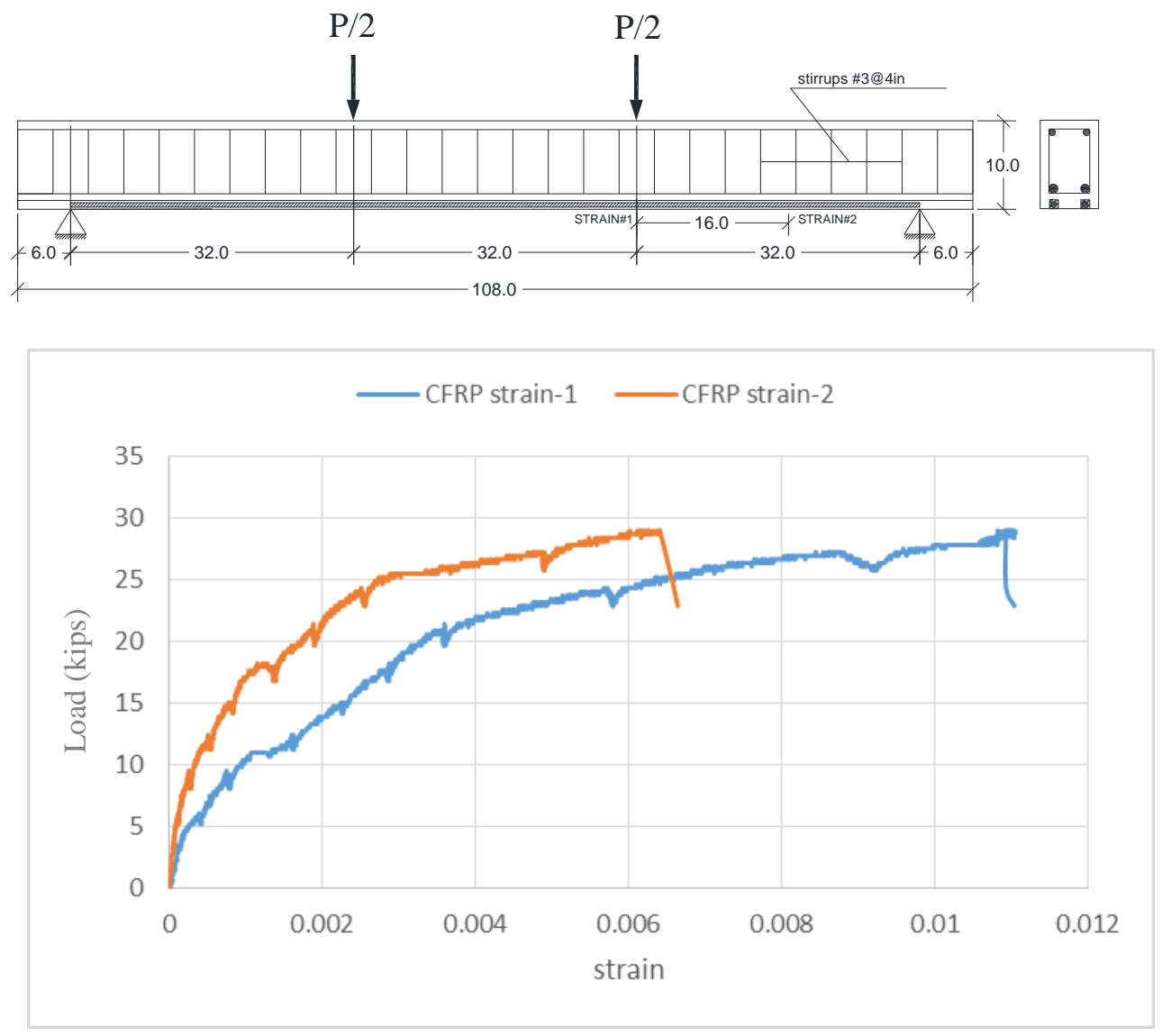

Figure 4-23 CFRP load-strain relationship for specimen AR2.

Figure 4-24 shows the failure mode for specimen AR2. 


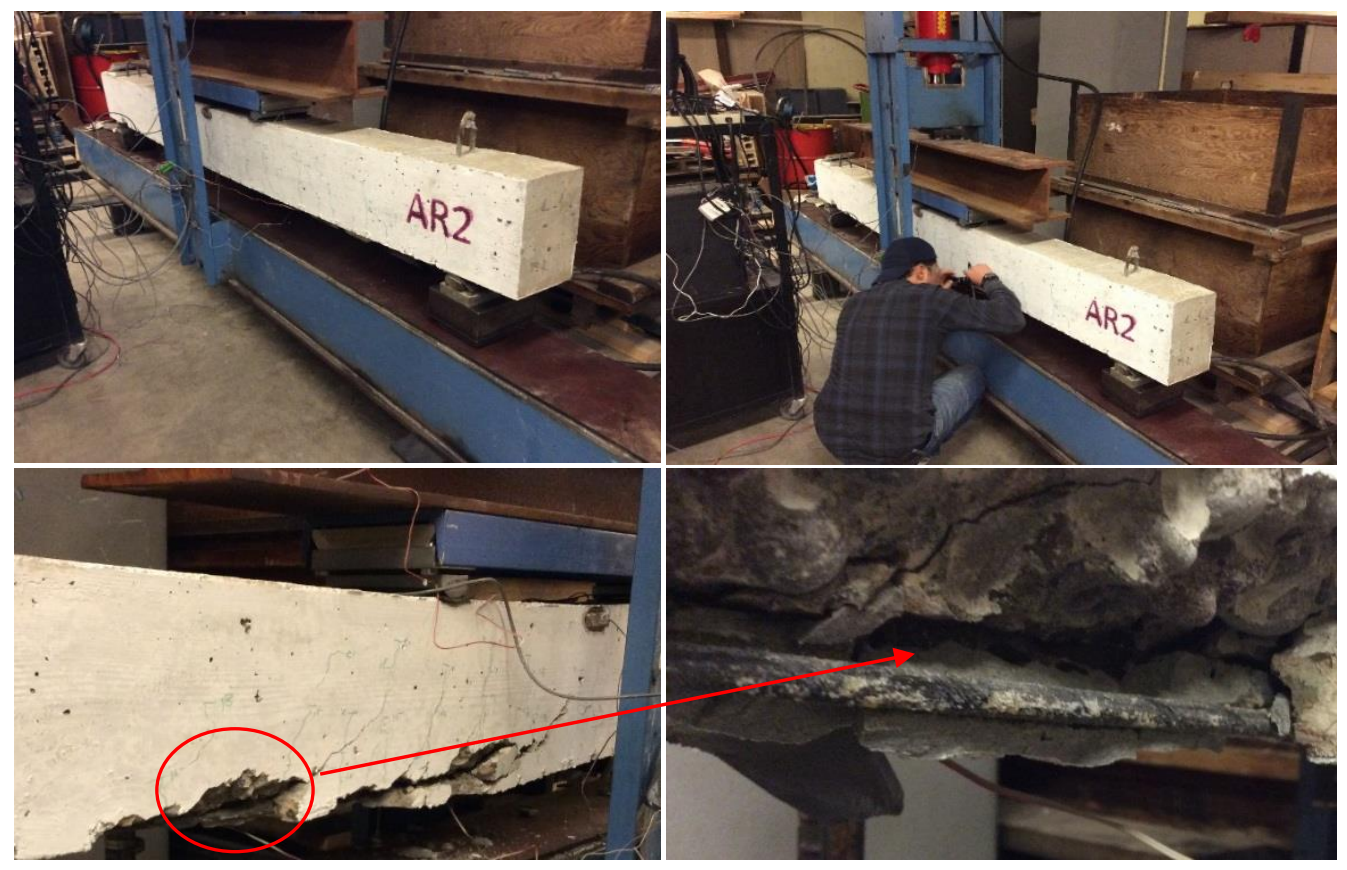

Figure 4-24 Specimen AR2 failure mode.

\subsubsection{Beam Retrofitted with Two \#3 CFRP Rods (AR3)}

The third beam tested in set A was AR3. This had the same properties of the AC beam, but was additionally reinforced with two \#3 CFRP rods at the tension side. According to ACI 440-2R-08, the maximum capacity of this beam is $36.0 \mathrm{k}-\mathrm{ft}$. that is corresponded to 27.0 kips. Stress analysis of AR3 is shown in Figure 4-25.

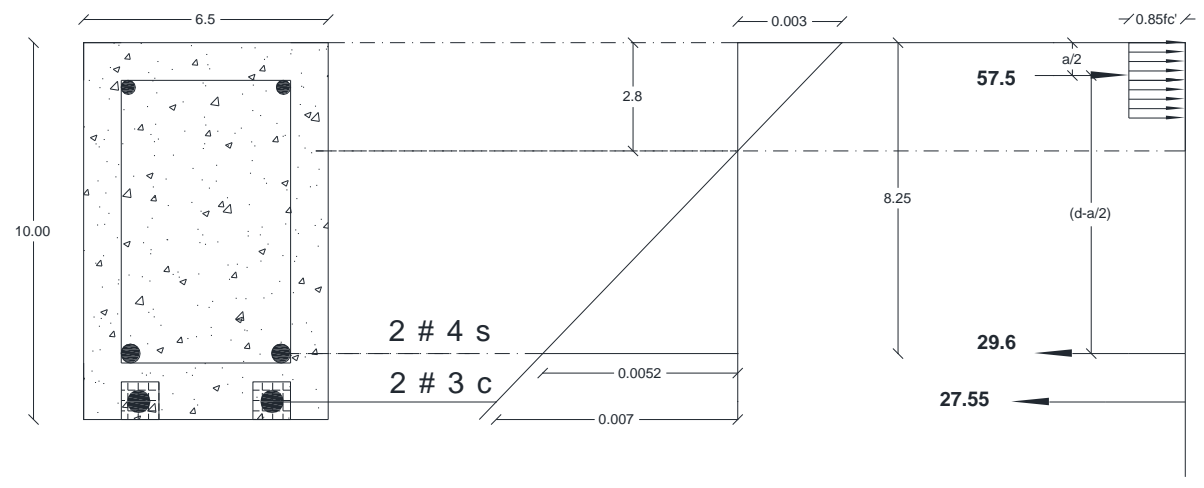

Figure 4-25 stress and strain analysis of specimen AR3 
In general, the same three zones were exhibited in the load-deflection curve as shown in Figure 4-26. The first region was where the first cracking of $0.05 \mathrm{~mm}$ occurred at 3.44 kips. The second region was at about 18 kips. As the load increased, the selected cracks increased as shown in Figure 4-27. The load was then increased until the de-bonding occurred at about 24 kips, and that was where the third region of the curve was shaped.

The increased capacity was about $38 \%$ over the control beam.

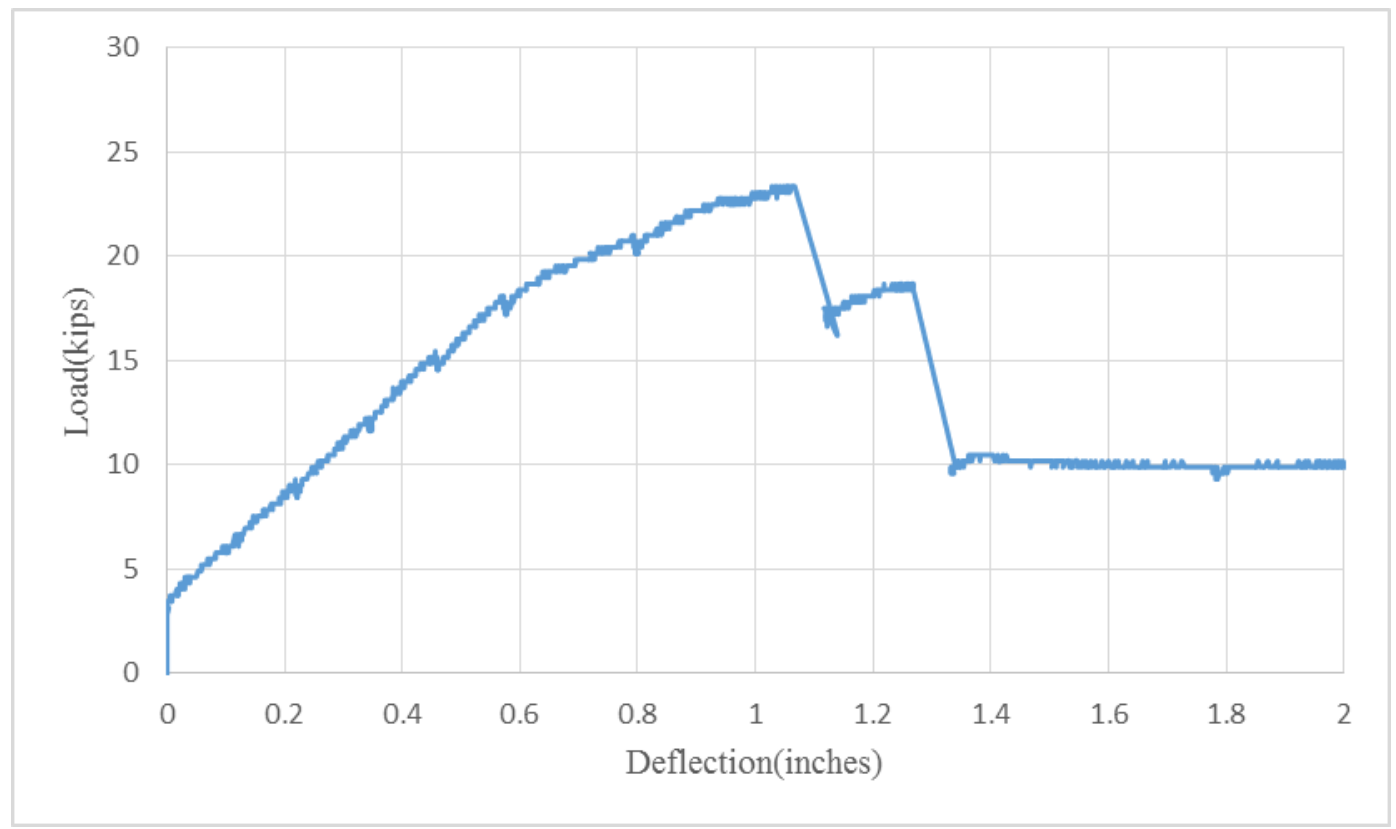

Figure 4-26 Load deflection curve for specimenAR3.

Figure 4-27 shows the failure mode of specimen AR3. The de-bonding in this specimen occurred in two stages. The first stage occurred when one of the CFRP rods de-bonded at the middle. That is where the load dropped from 24.0 kips to 17.0 kips. The second debonding occurred when the load was increased up to 19.0 kips after that the load dropped to 10.0 kips. The expected capacity of this specimen was more than AR2. However, some 
bonding issues in one of the CFRP rod caused the first de-bonding, and that reduced the capacity of the specimen
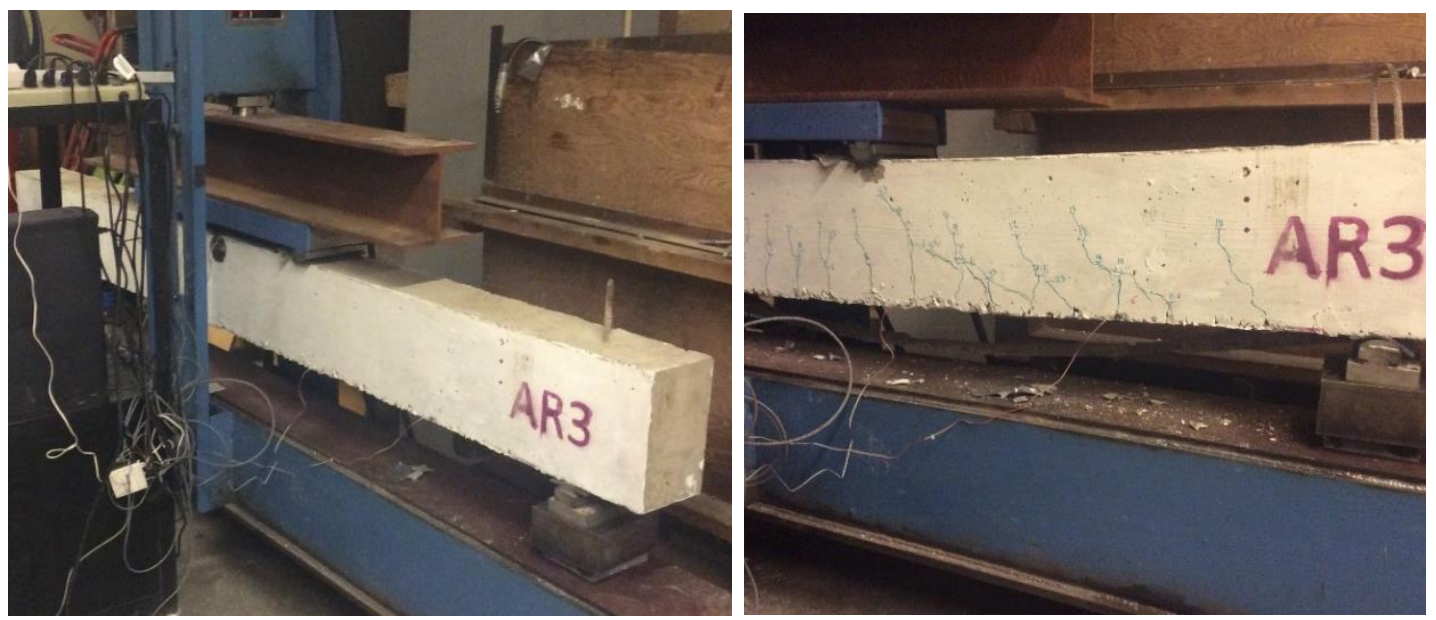

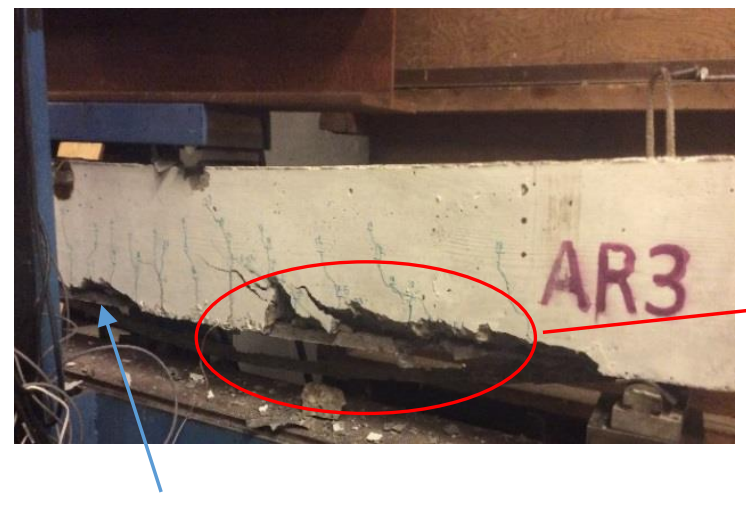

First de-bonding

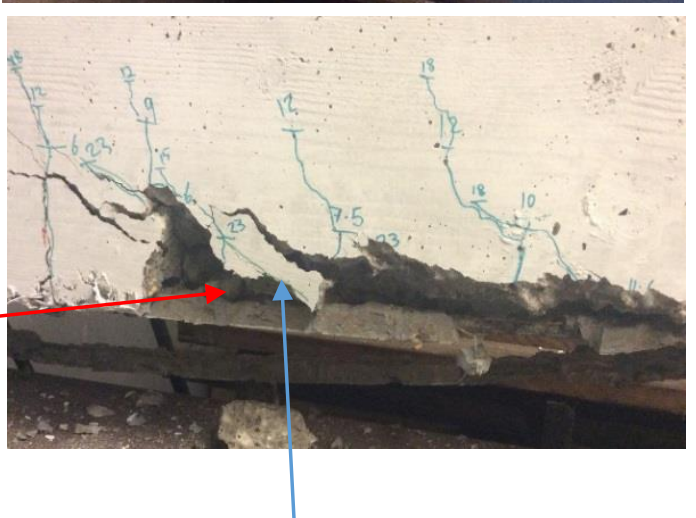

Second de-bonding

Figure 4-27 Failure mode of specimen AR3.

From the CFRP, steel, and concrete's strain gauges, the strain profile was constructed as shown in Figure 4.28 below. It was observed that the strain in the section was linear up to 
15.0 kips. After that point the strain profile behaved nonlinearly, especially prior to the de-bonding where the strain in the CFRP was less than the steel.

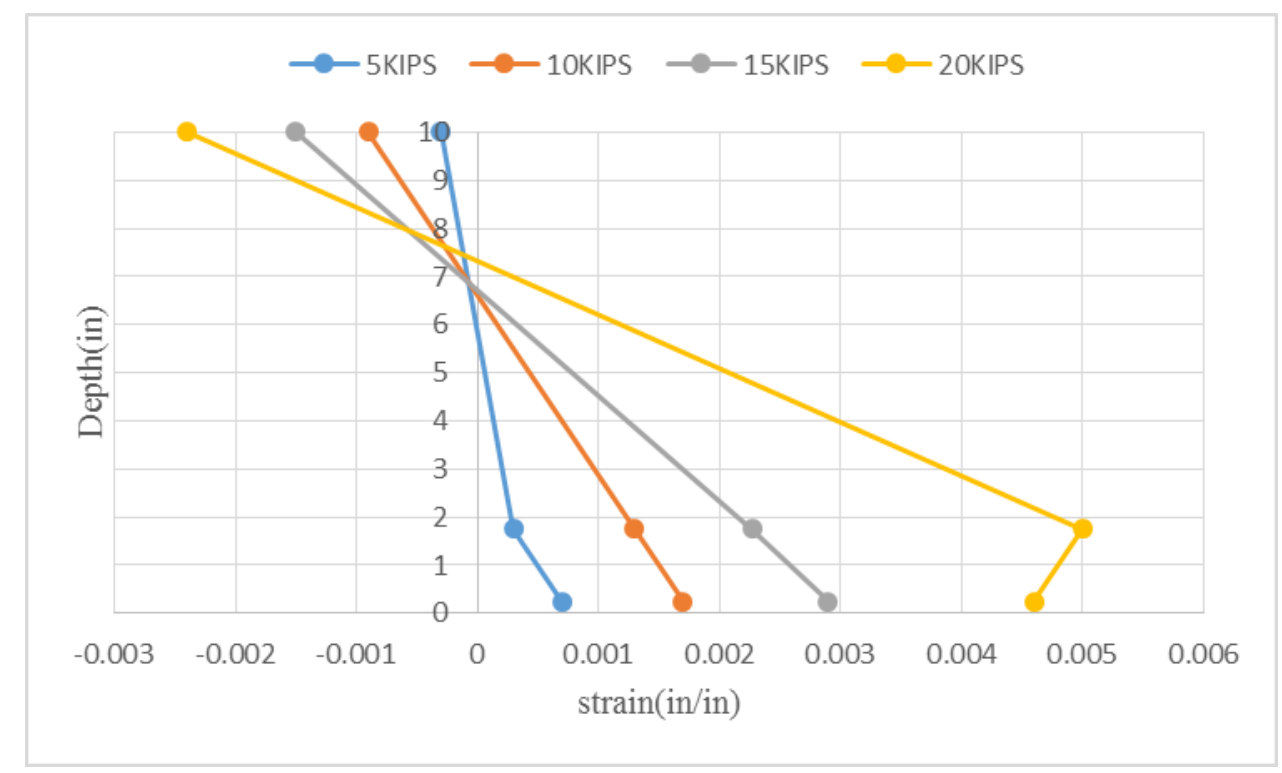

Figure 4-28 Strain profile for specimen AR3 at different load level.

Figure 4-29 shows the load-strain relationship at two points along the CFRP rods. The first strain gauge was located at the start of the pure moment region under the point load, and the second strain gauge was located at 16 inches away from the first gauge. As expected, the strain distribution shows that the strain was larger at the pure moment region and increased as the load increased. The maximum strain in the first and the second strain gauges were about $30 \%$ and $20 \%$ of the ultimate strain. These low values indicate the deficiency of bonding. 


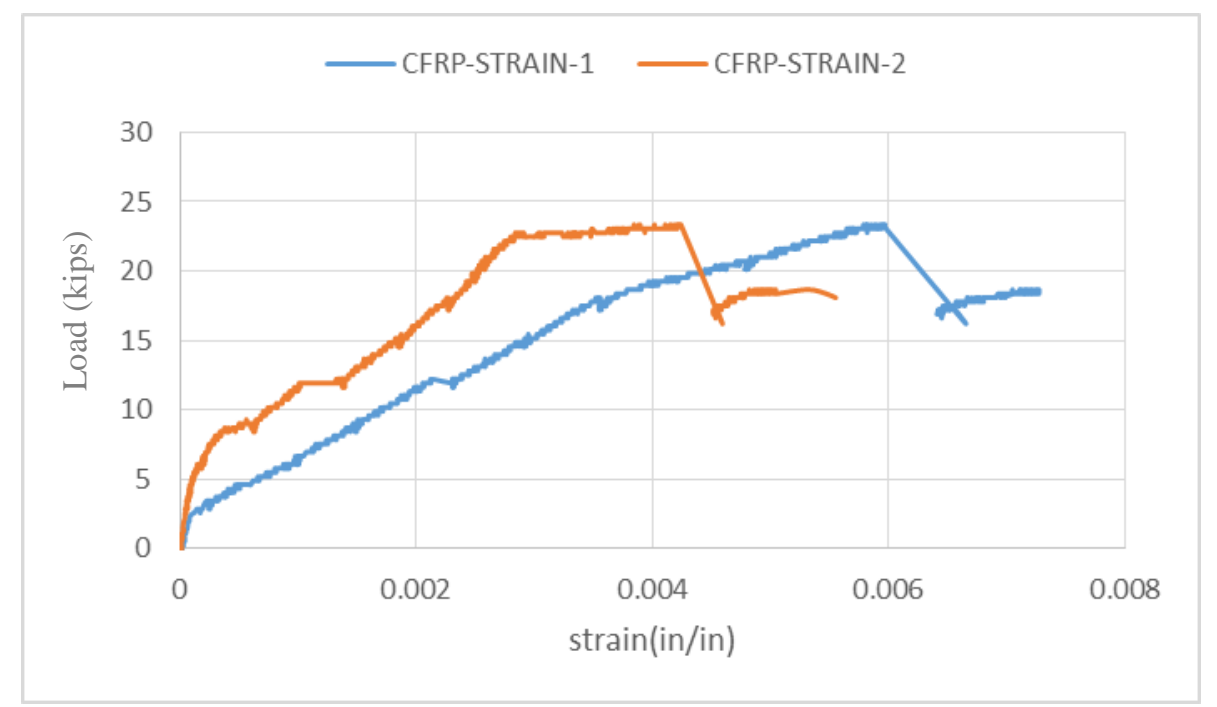

Figure 4-29 CFRP load-strain relationship for specimen AR3.

\subsubsection{Beam Retrofitted with Two \#4 CFRP Rods (AR4)}

The fourth tested beam in set A was AR4. This had the same properties as the AC beam, but was additionally reinforced with two \#4 CFRP rods at the tension side. According to ACI 440.2R-08, shown in Figure 4-30, the maximum capacity of this beam was $38.0 \mathrm{k}-\mathrm{ft}$. that resulted in a load of about 8.5 kips.

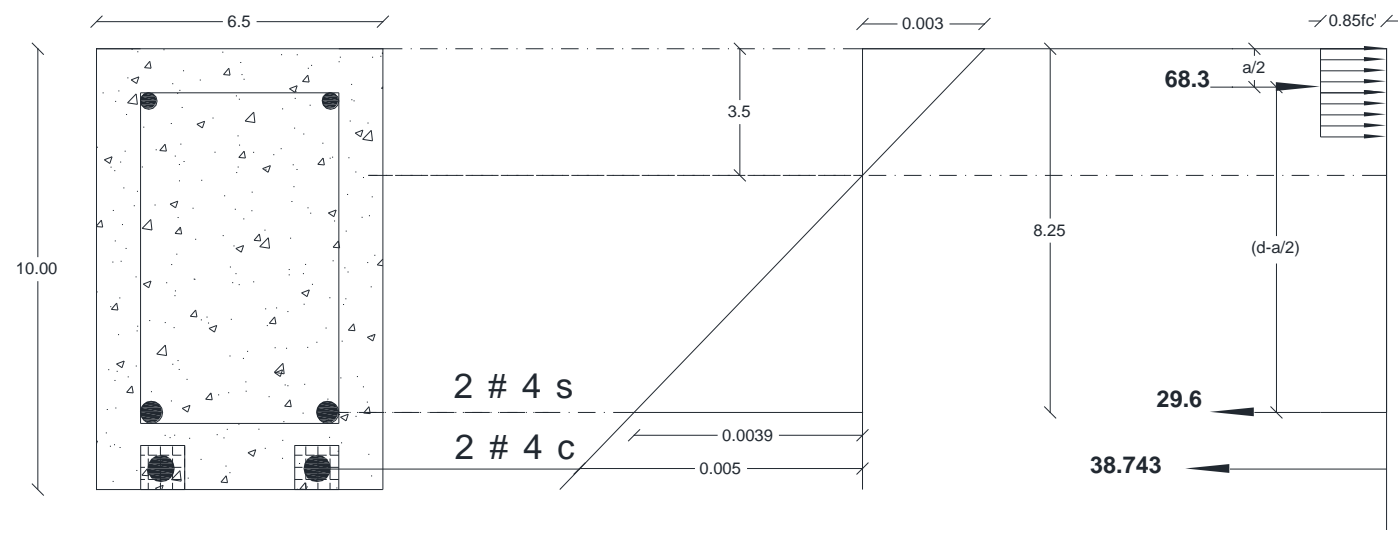

Figure 4-30 Strain and stress analysis of specimen AR4. 
Figure 4-31 shows the load deflection curve and two distinct regions can be observed. The first region is where the first cracking of $0.04 \mathrm{~mm}$ occurred at about $5 \mathrm{kips}$. That is where the beam lost some of its flexural stiffness as shown in the load deflection curve. The load was increased until the de-bonding occurred at about $28 \mathrm{kips}$, and that is where the second region of the curve was exhibited by a significant drop in the load. The increased capacity over the control beam was about $64 \%$. However, this specimen had a brittle behavior, which indicated the over reinforcement of the system.

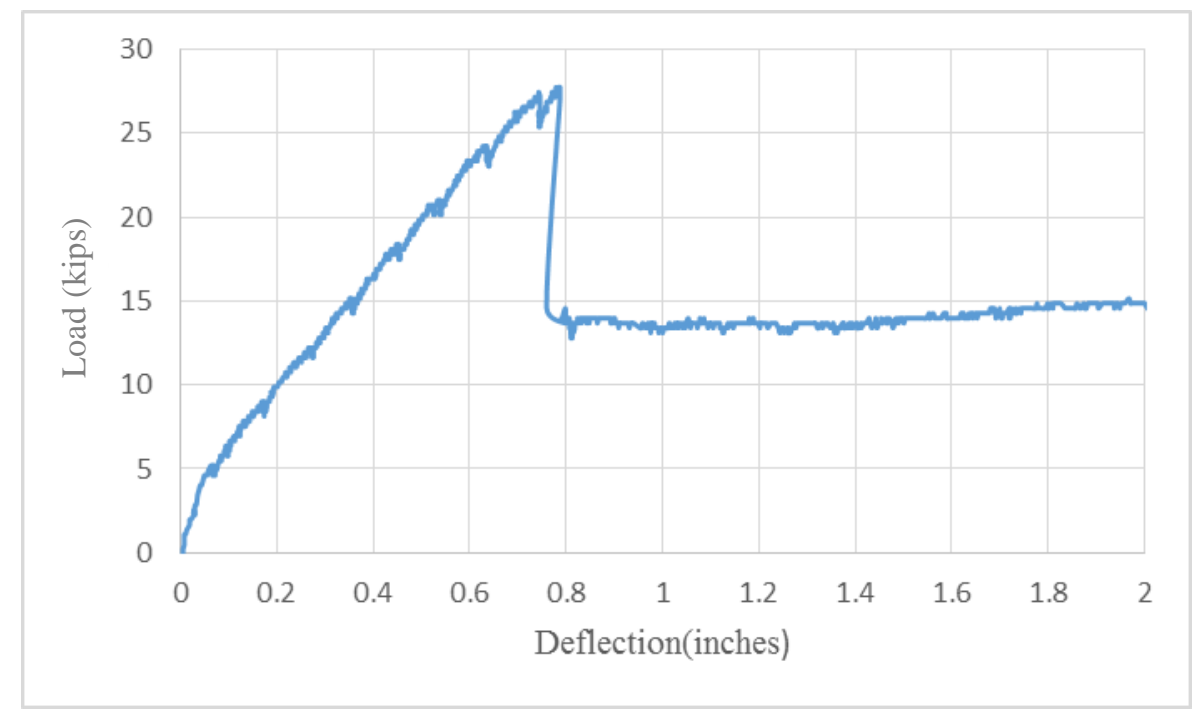

Figure 4-31 Load deflection curve of specimen AR4.

Before the de-bonding occurred, some diagonal cracking occurred in the shear spans. These cracks initiated at the beginning of the shear span and extended to the ends of the beam. The de-bonding was due to the over stress of the cover layers where the edge concrete cracked and spalled, initiating the de-bonding as shown in Figure 4-32. 


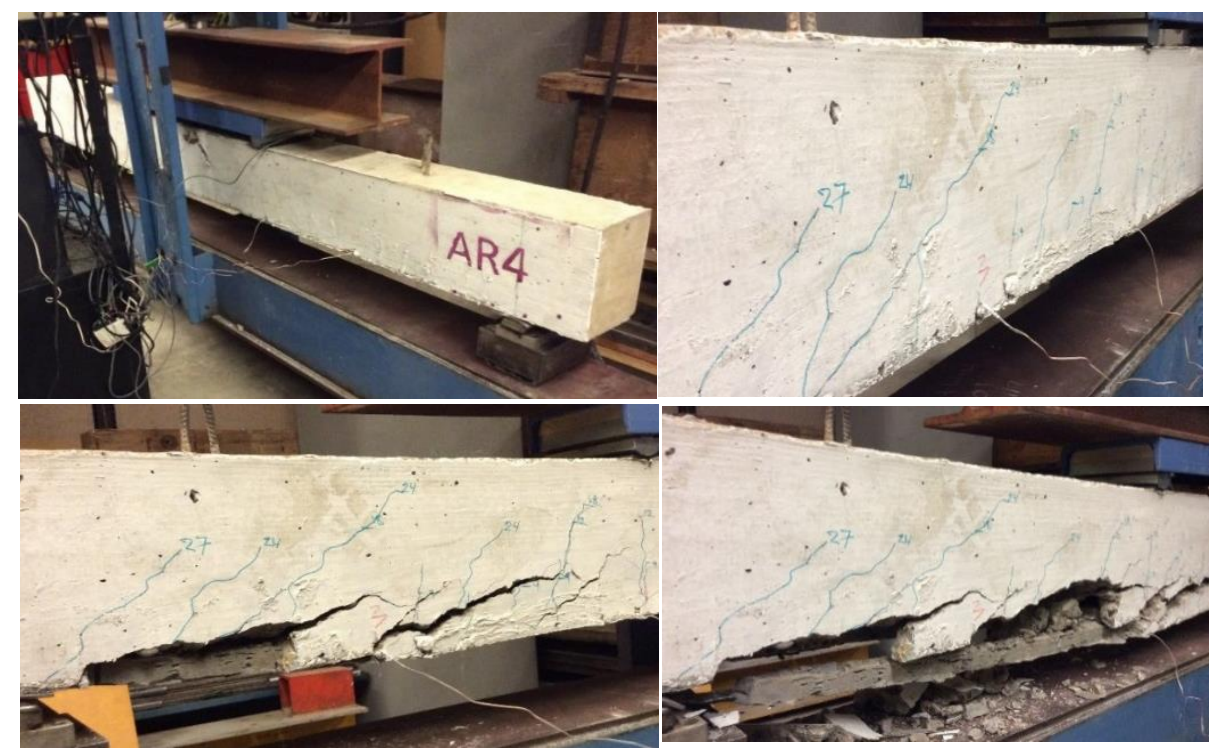

Figure 4-32 Failure mode of specimen AR4.

From the CFRP, steel, and concrete's strain gauges, the strain profile was constructed as shown in Figure4-33 below. It can be observed that the strain in the maximum bending moment section is reasonably linear up to the failure and the steel reinforcement did not yield.

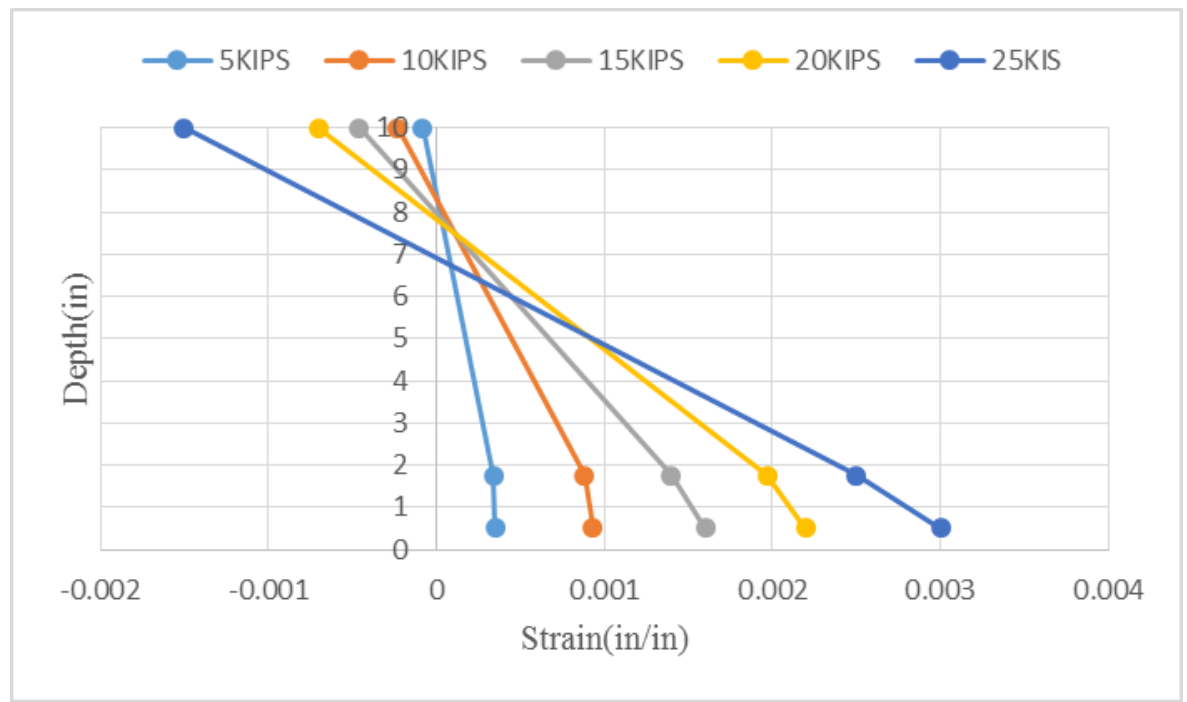

Figure 4-33 Strain profile of specimenAR4 at different load levels. 
Figure 4-34 shows the load-strain relationship at two points along the CFRP rods. The first strain gauge was located at the start of the pure moment region, under the point load, and the second strain gauge was located at 16 inches away from the first one. The strain distribution showed that the strain was larger at the pure moment region and increased as the load increased, as expected. The maximum CFRP strain before de-bonding was about $20 \%$ of the ultimate strain. That indicates the poor performance of the composite action.

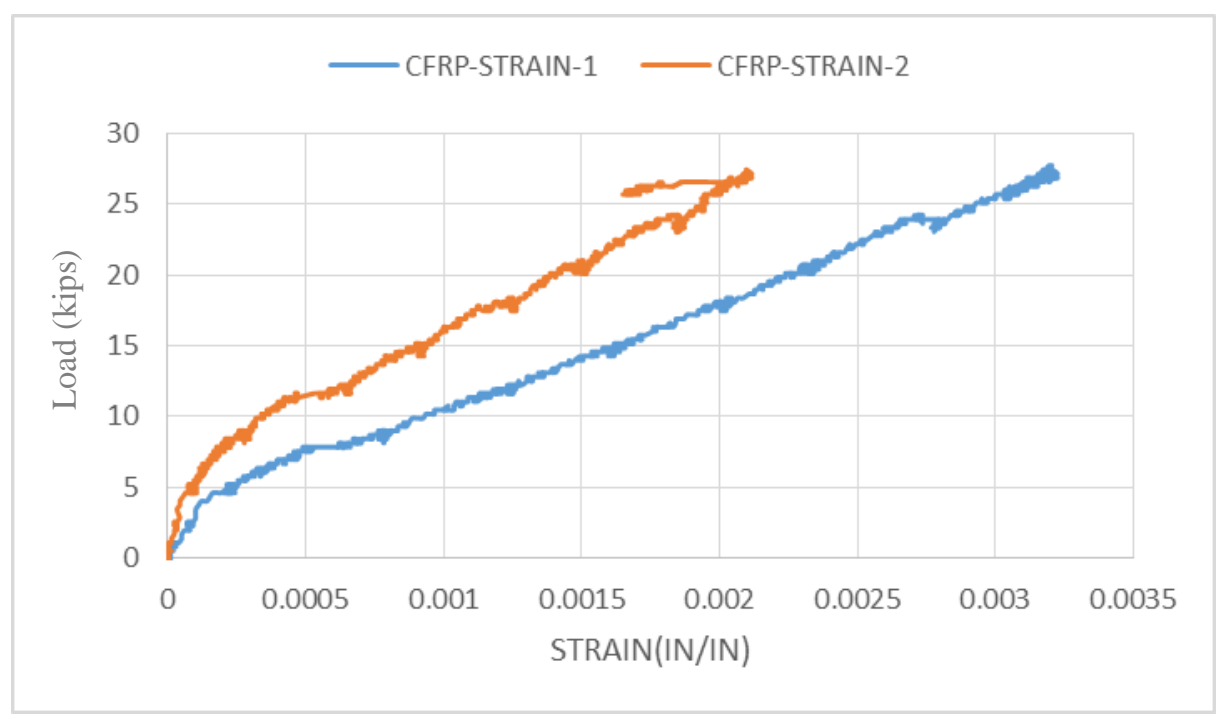

Figure 4-34 CFRP load-strain relationship for specimen AR4. 


\subsubsection{Beam Retrofitted with One \#4 CFRP Rod (AR4-S)}

The fifth beam tested in set A was AR4-S. This specimen had the same properties as the AC beam, but was additionally reinforced with a single \#4 CFRP rod on the tension side. The purpose of testing this specimen was to minimize the stress at the bonding area by increasing the edge distance According to ACI 440.2R-08, the maximum capacity of this beam is about $35 \mathrm{k}-\mathrm{ft}$. leading to a load of about 27kips. Figure 4-35 shows the strain and stress analysis of the specimen according to ACI 440.2R-08.

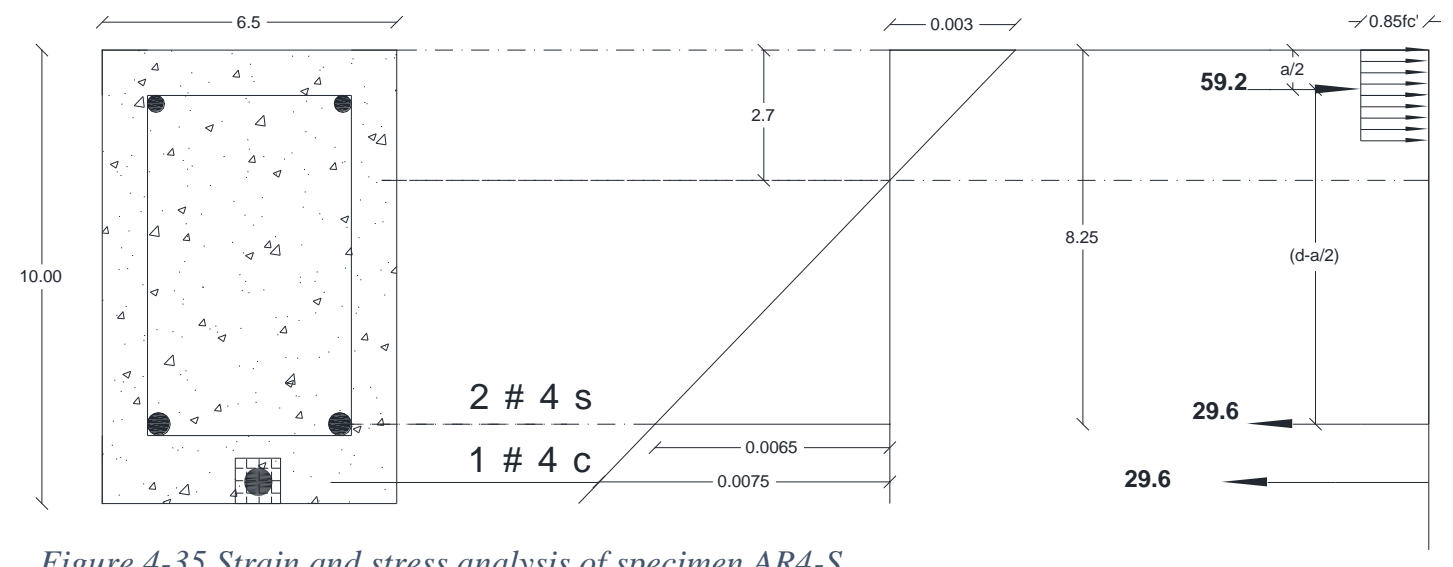

Figure 4-35 Strain and stress analysis of specimen AR4-S.

Figure 4-36 shows the load deflection curve, with three distinct regions. As the load increased, the selected cracks increased. The load was then increased until the de-bonding occurred at about 26 kips. 


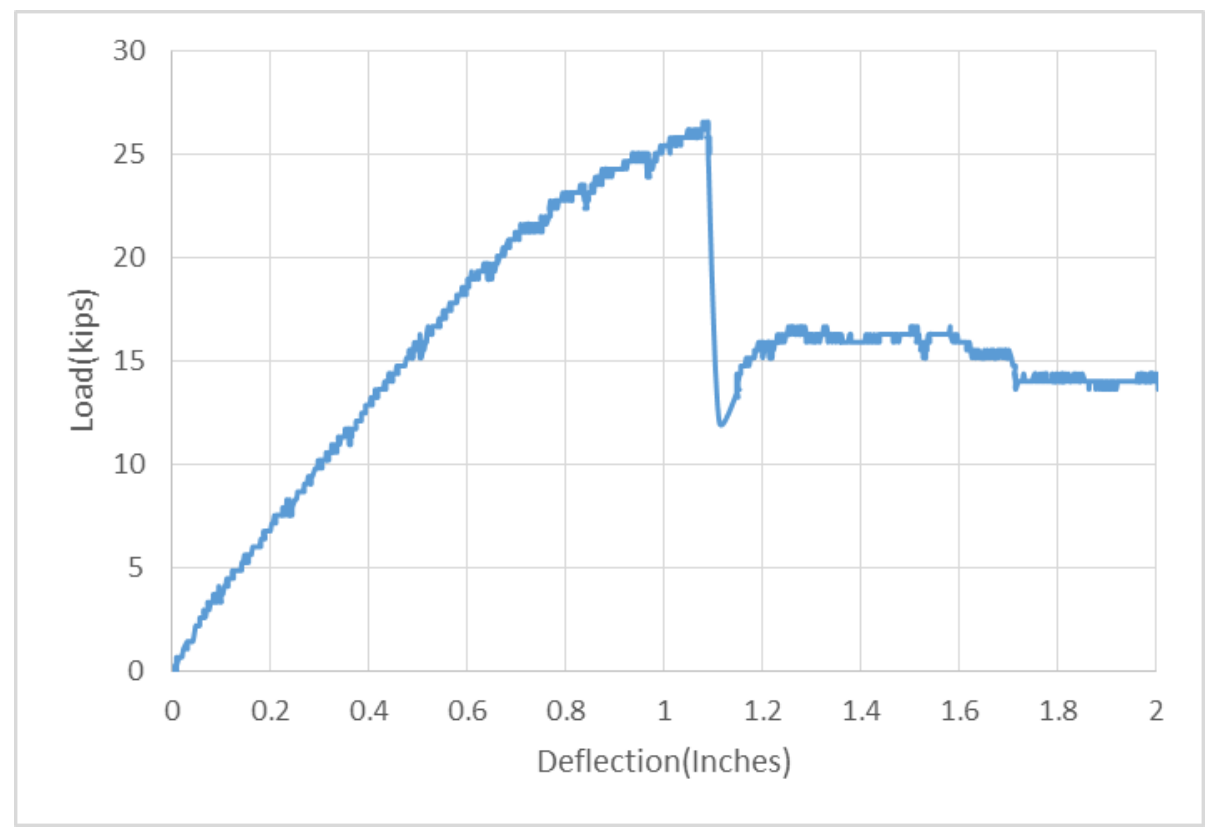

Figure 4-36 Load deflection curve for specimen AR4-S.

The increased capacity was about $52 \%$ over the control beam. Before the de-bonding occurred, some diagonal cracking occurred at the maximum bending moment region. These cracks initiated at the middle, and did not extend to the ends of the beam. The debonding was due to the over stress of the cover layer where the edge concrete cracked and spalled, initiating the de-bonding. Figure 4-37 shows the failure mode of specimen AR4-S. 


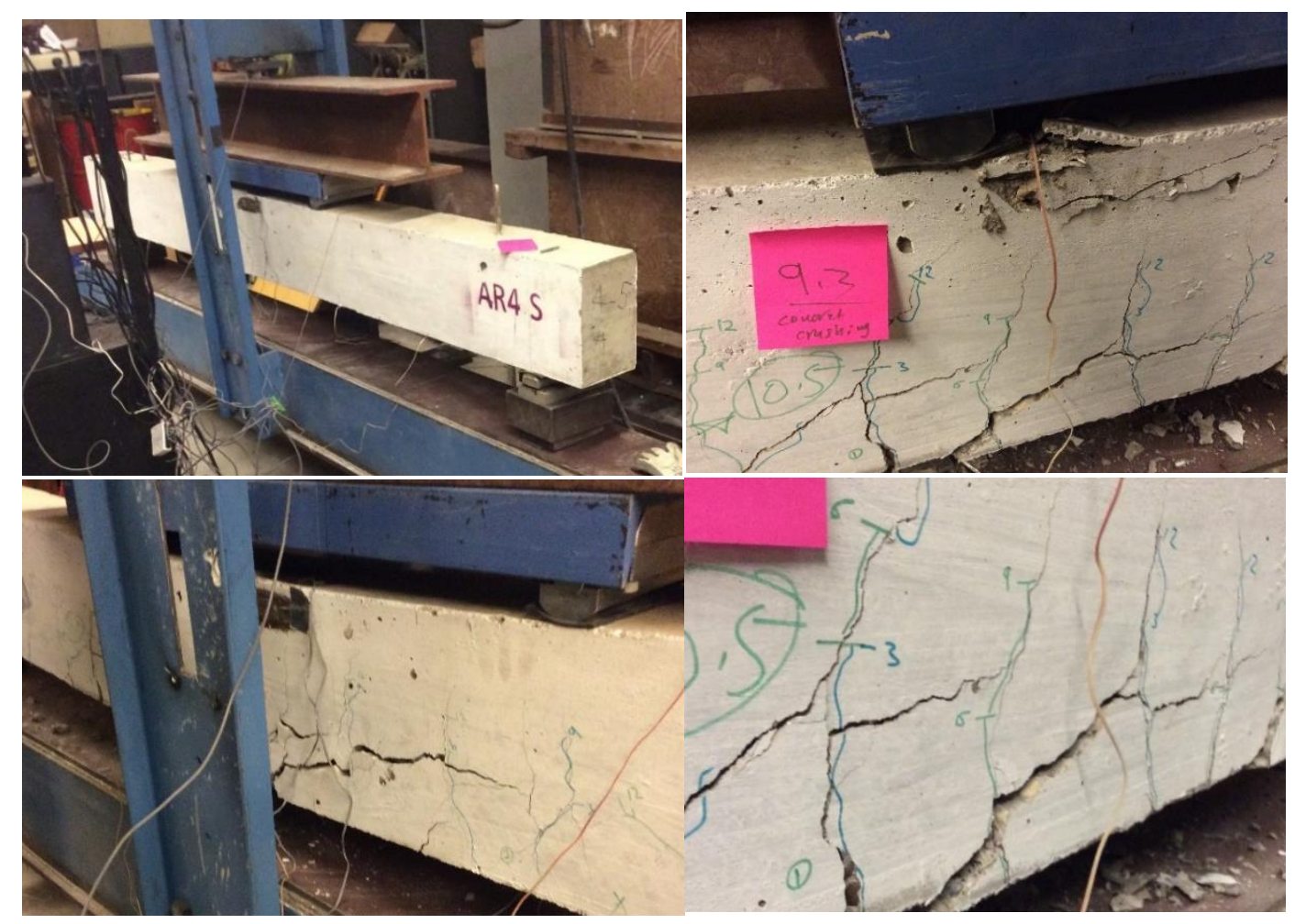

Figure 4-37 Failure mode of specimen AR4-S.

From the CFRP, steel, and concrete's strain gauges, the strain profile was constructed as shown in Figure 4-38 below. It can be observed that the strain in the concrete, steel and CFRP bars in the section are compatible, i.e., forming reasonable straight lines up to the failure. 


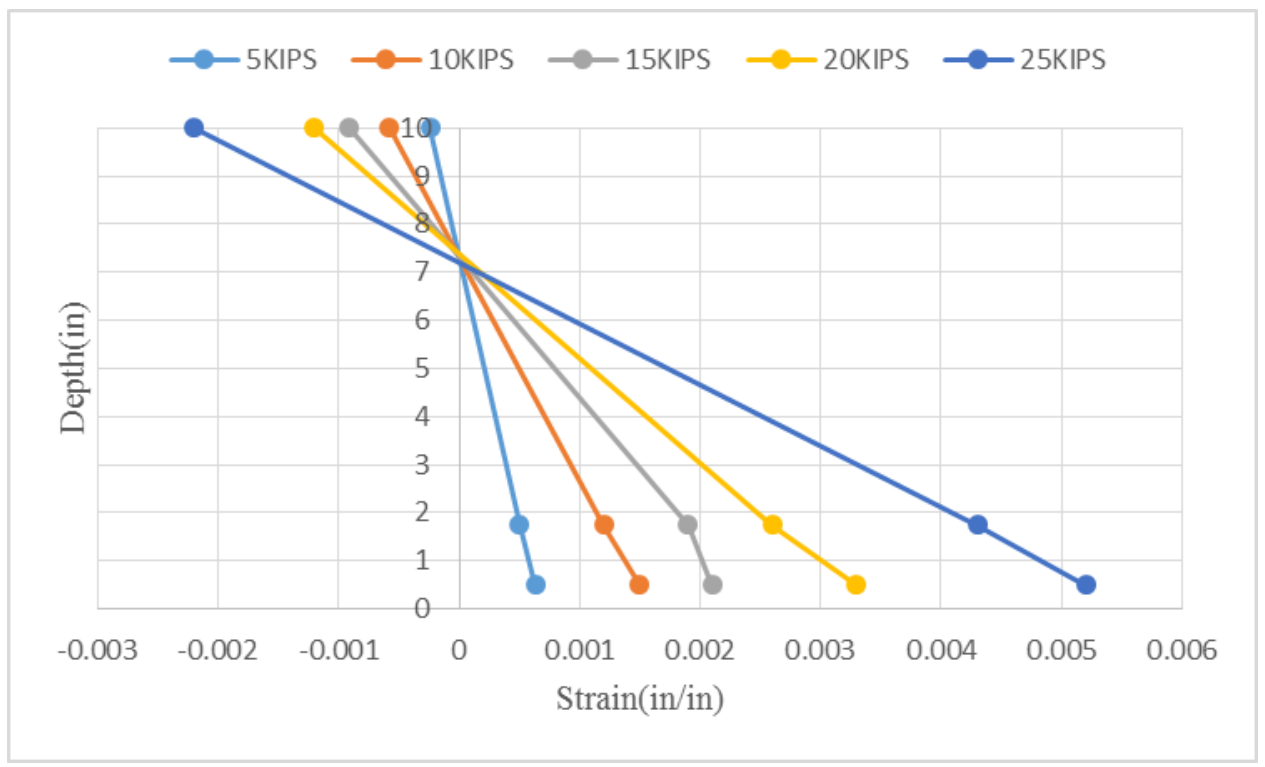

Figure 4-38 Strain profile for specimen AR4-S at different load levels.

Figure 4-39 shows the load-strain relationship at two points along the CFRP rods. The first strain gauge was located at the edge of pure moment region (under the concentrated load), and the second strain gauge was located at 16 inches away from the first gauge. The strain distribution shows that the strain was larger at the pure moment region, and increased as the load increased, as expected. The maximum strain in the first and the second strain gauges was about $31 \%$ and $18 \%$ of the ultimate strain. This indicated that the maximum strain for the \#4 CFRP was about $31 \%$ before the de-bonding occurred. This value does not agree with the pullout test result where the maximum strain in \#4CFRP rod was about $50 \%$ of the ultimate strain. This difference could be because of the flexural action and flexural cracking that raises the bond stress, the so called in-and out bond stress that occurs between flexural cracks. 


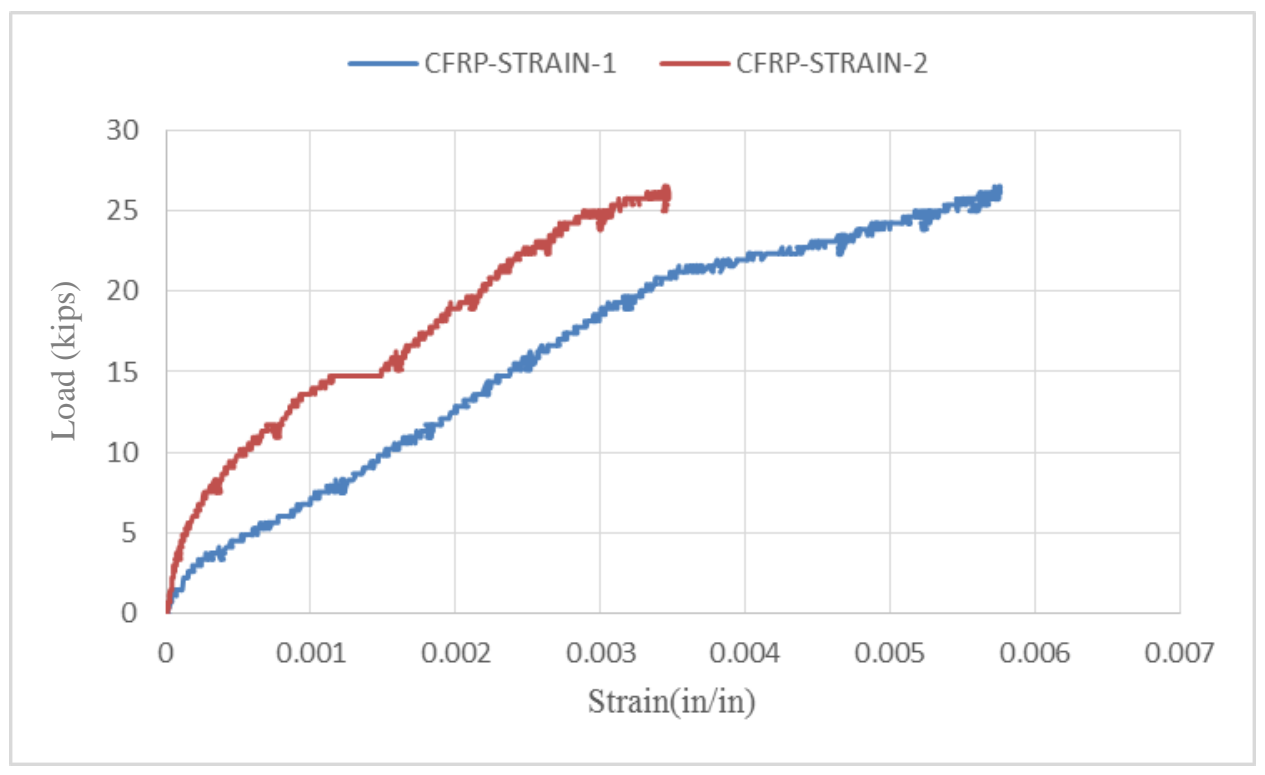

Figure 4-39 CFRP load-strain relationship for specimen AR4-S.

In ACI 440.2R-08, there is guidance for the distribution of the CFRP rod in tensile layer. The edge distance should be four times the depth of the grooves and the spacing between the bars should be at least two times the depth of the groove. For all specimens, the minimum spacing was 2.5 inches and the edge distance was1.0 inch with the exception of specimen AR4-S where the edge distance was 3in. The purpose of testing this specimen was to minimize the stress at the bonding area by increasing the edge distance. However, specimens AR2 and AR3 showed better performance in composite action than AR4-S. 


\subsubsection{Set (B) specimens}

Table 4-3 Set B results summery.

\begin{tabular}{|c|c|c|c|c|c|c|c|}
\hline $\begin{array}{l}\text { Beam } \\
\text { label }\end{array}$ & $\begin{array}{c}\text { Reinforcement } \\
\text { details }\end{array}$ & $\mathrm{f}_{\mathrm{c}}{ }^{\prime}(\mathrm{psi})$ & $\mathrm{P}_{\mathrm{u}}(\mathrm{Kips})$ & $\Delta_{\mathrm{u}}($ inches $)$ & Ductility & $\begin{array}{c}\text { Increase in } \\
\text { capacity } \\
\text { beyond BC. }\end{array}$ & $\begin{array}{l}\text { Failure } \\
\text { Mode }\end{array}$ \\
\hline $\mathrm{BC}$ & $\begin{array}{c}\text { 2\#3steel bars } \\
\text { No CFRP }\end{array}$ & 4560 & 11.6 & 2.5 & 5 & - & $\begin{array}{l}\text { Concrete } \\
\text { crushing }\end{array}$ \\
\hline BR2 & $\begin{array}{c}\text { 2\#3steel bars } \\
\text { 2\#2 CFRP } \\
\text { bars }\end{array}$ & 4348 & 18.0 & 1.8 & 3.5 & $60 \%$ & $\begin{array}{c}\text { CFRP } \\
\text { de- } \\
\text { bonding }\end{array}$ \\
\hline BR3 & $\begin{array}{c}\text { 2\#3steel bars } \\
\text { 2\#3 CFRP } \\
\text { bars }\end{array}$ & 4676 & 25.4 & 1.37 & 2.3 & $130 \%$ & $\begin{array}{c}\text { CFRP } \\
\text { de- } \\
\text { bonding }\end{array}$ \\
\hline BR4 & $\begin{array}{c}\text { 2\#3 steel bars } \\
\text { 2\#4 CFRP } \\
\text { bars }\end{array}$ & 4400 & 25.6 & 1.12 & 0 & $130 \%$ & $\begin{array}{c}\text { Concrete } \\
\text { peeling } \\
\text { off }\end{array}$ \\
\hline
\end{tabular}

\subsubsection{Control Beam (BC)}

The first beam tested in set B was the control beam, which had two \#3 steel bars in the tension side. As shown in figure 4-40 according to ACI318-12, the flexural capacity of this beam is about $11 \mathrm{k}-\mathrm{ft}$, which results in a load of 8.25 kips. 


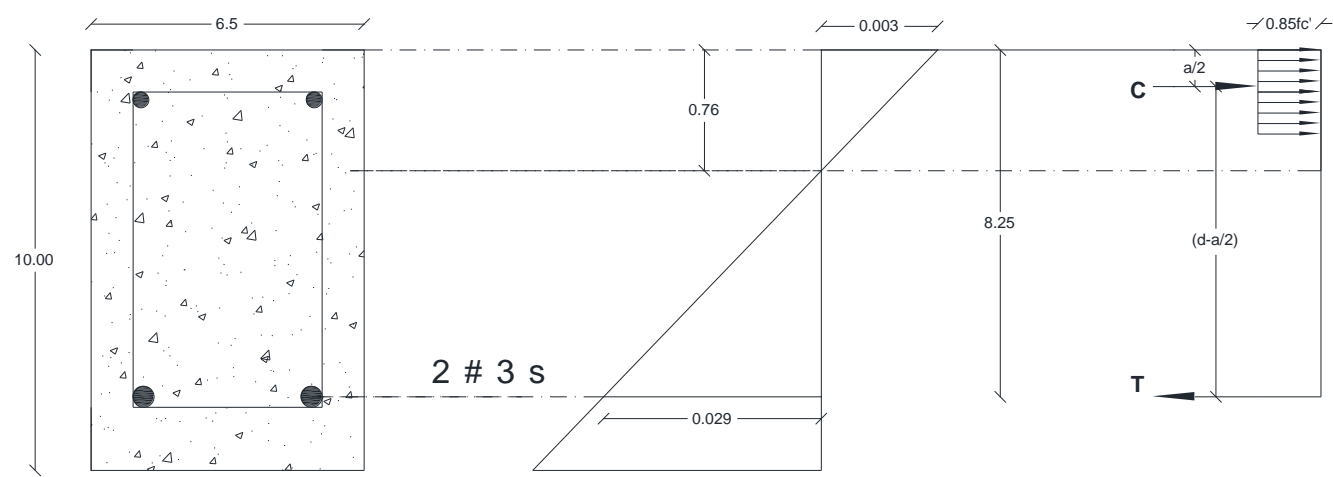

Figure 4-40 ACI 318 strain and strain profile for specimen BC.

Figure 4-41 shows the measured load-deflection relationship. The first observed cracking was $0.2 \mathrm{~mm}$ at $3 \mathrm{kips}$. The load deflection curve showed that the reduced stiffness begins at about 2 kips. That was where the beam lost a significant amount of its flexural stiffness. It appears that steel yielding happened at about $8 \mathrm{kips}$, which is reasonably close to the nominal capacity computed according to ACI code.

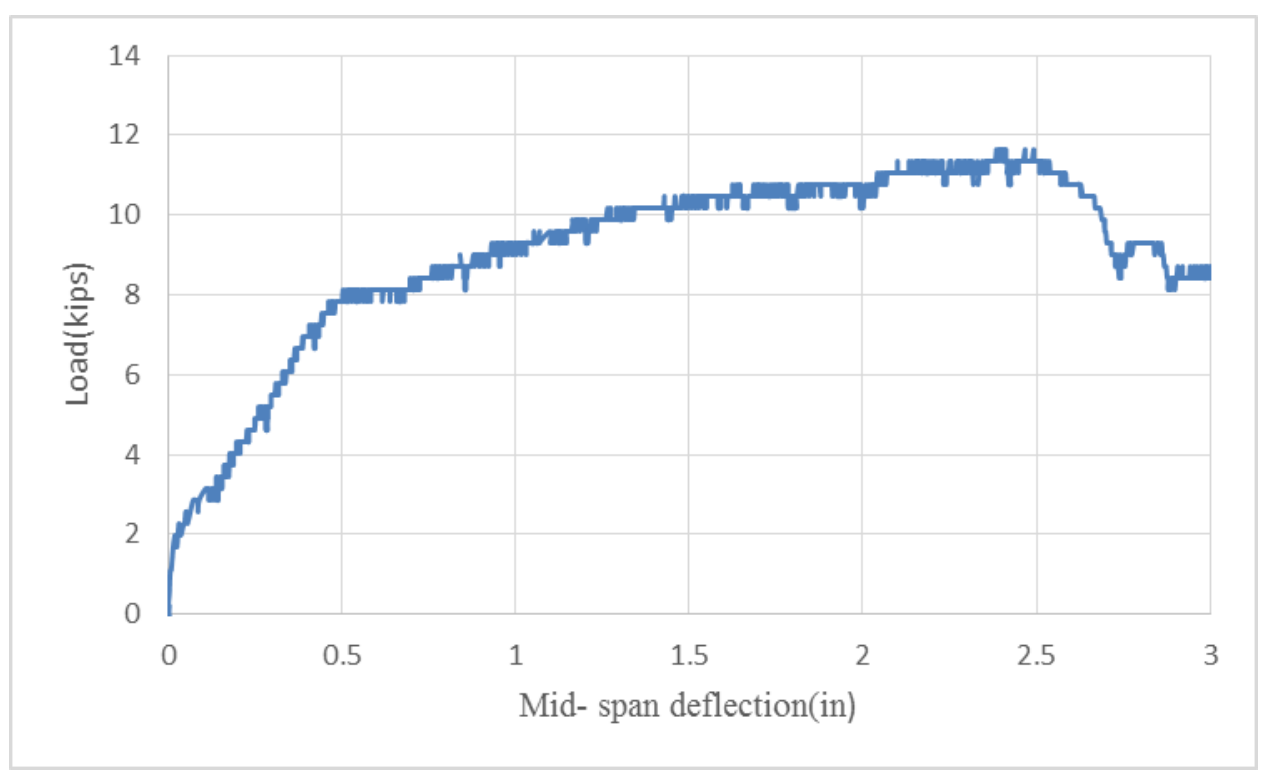

Figure 4-41 Load deflection curve of specimen BC. 
Cracks propagated at the pure positive bending moment regions. As the load increased, the selected measured cracks widened. The load was then increased until the concrete crashing occurred at about 11.3 kips. The measured load capacity of the beam was about $37 \%$ higher than computed. Figure 4-42 shows the cracks pattern and the failure mode of specimen BC.

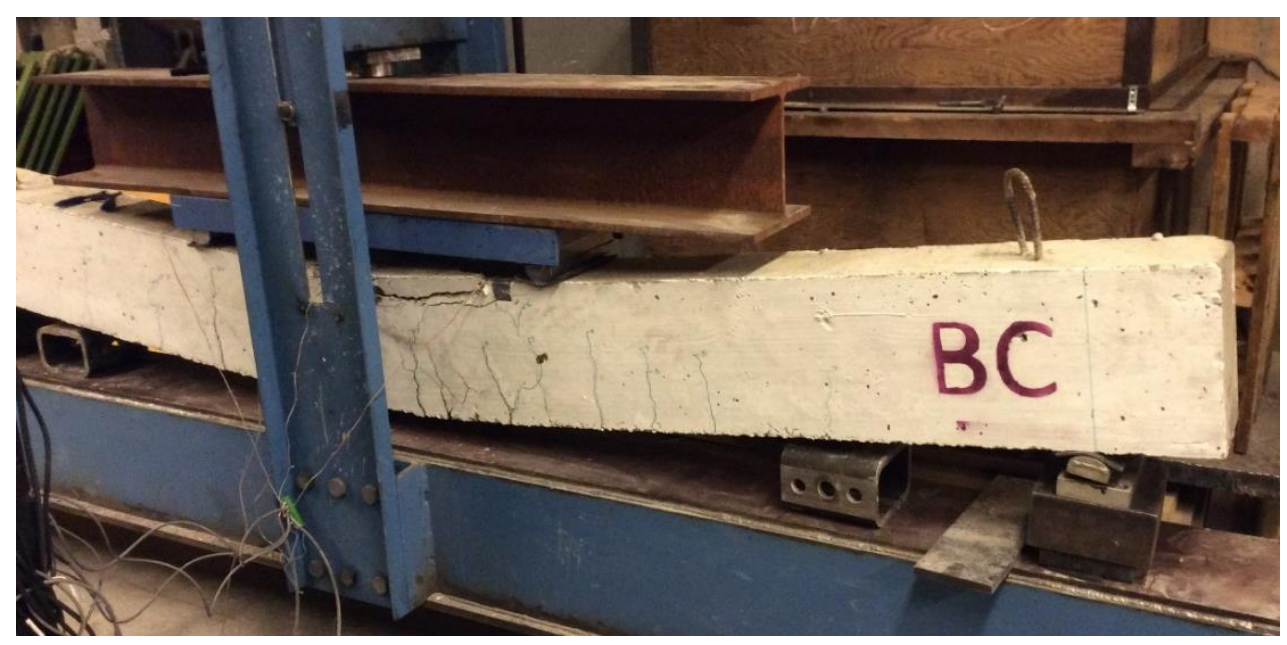

Figure 4-42 Failure mode of specimen BC.

The strain profile measured at the maximum bending moment region is shown in Figure 4-43.The strain profile showed that the pure bending section experienced a significant strain increase when the load was raised from 9.0 kips to 11.0 kips. At 11.0 kips, the steel and concrete strains were about 0.02 and 0.0033 respectively. After this point, concrete crushed and the load dropped. 


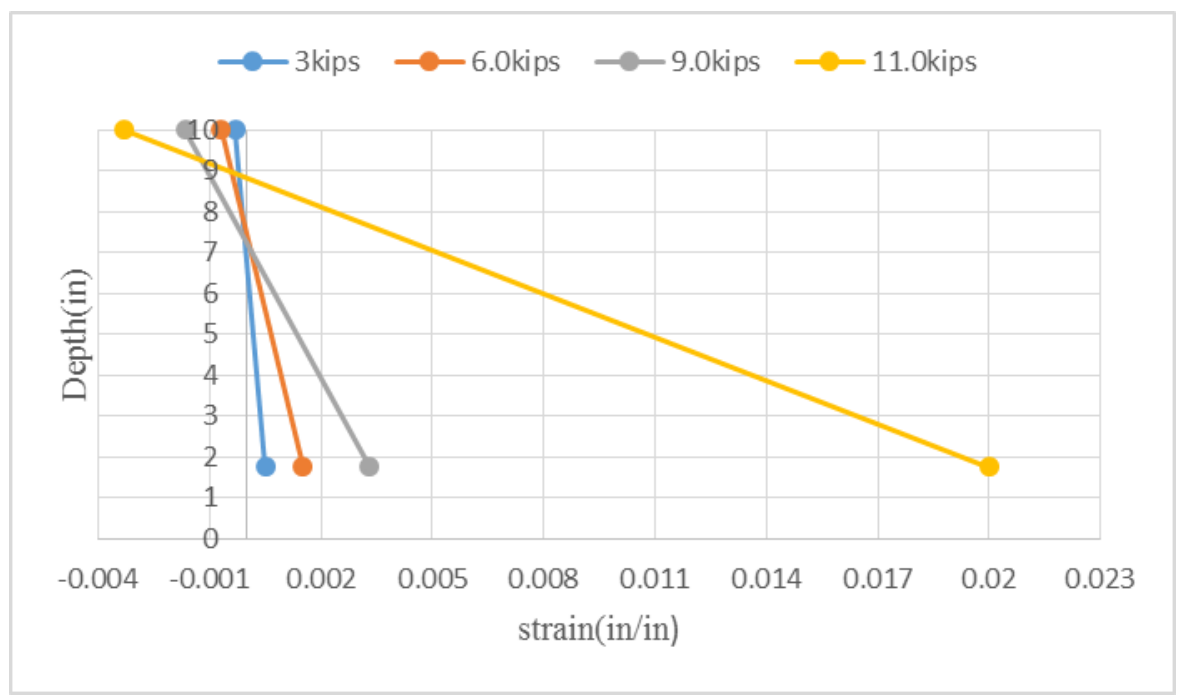

Figure 4-43 Strain profile for specimen BC at different load levels.

\subsubsection{Beam Retrofitted with Two \#2 CFRP Rods (BR2)}

The second beam tested in set B was BR2. This beam had the same properties as the AC beam, and was additionally reinforced with two \#2 CFRP rods at the tension side.

According to ACI 440-2R-08, Figure 4-44 shows the maximum flexural capacity of this beam is about $24.3 \mathrm{k}-\mathrm{ft}$, which leads to a load value of 18 kips.

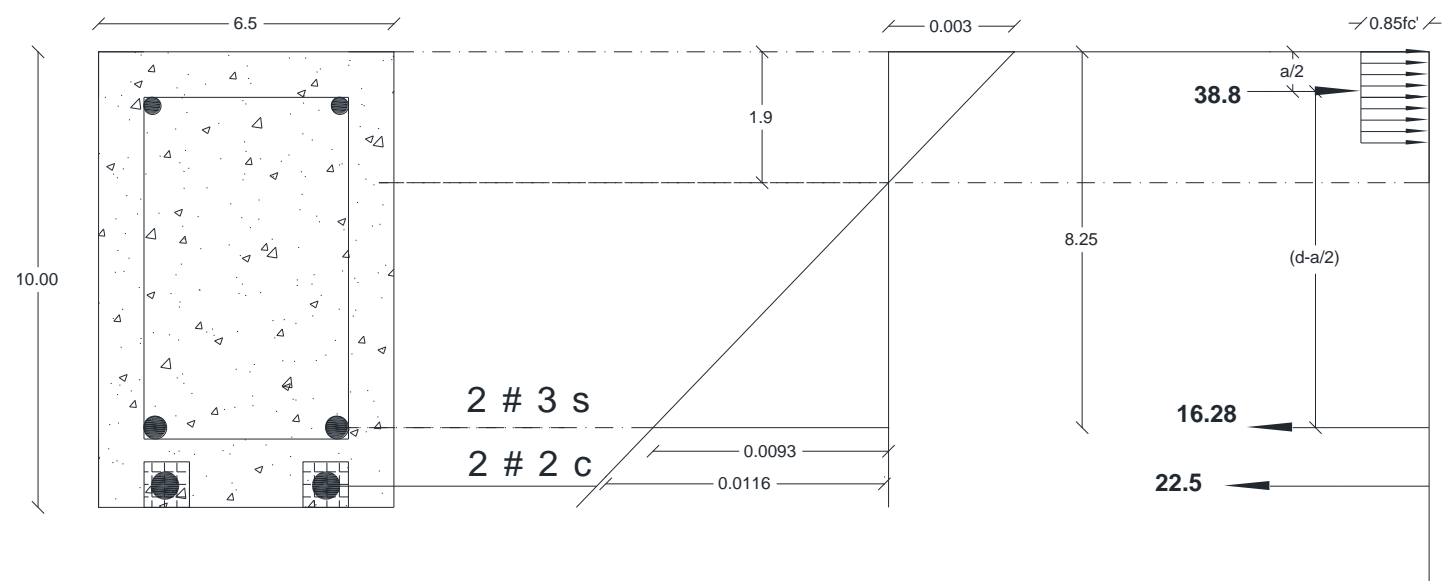

Figure 4-44 Strain and stress analysis of specimen BR2. 
As shown in Figure 4-45, three distinct regions can be observed: the first region was where the first crack of $0.05 \mathrm{~mm}$ occurred at about 2 kips. That was when the beam lost some of its flexural stiffness; the second region was where the steel and the CFRP rods behave elastically; and the third region was where the steel reinforcement yielded. In this stage, more of the flexural stiffness was lost, and more cracks were initiated and widened at the positions of the lateral grooves. As the load increased, the selected measured cracks increased. The load was then increased until the de-bonding occurred at about 18 kips. which is the same value as given by ACI 440.2R-08 design formula. The increased capacity was about $55 \%$ over the control beam. Figure 4-46 shows the specimen after reaching failure.

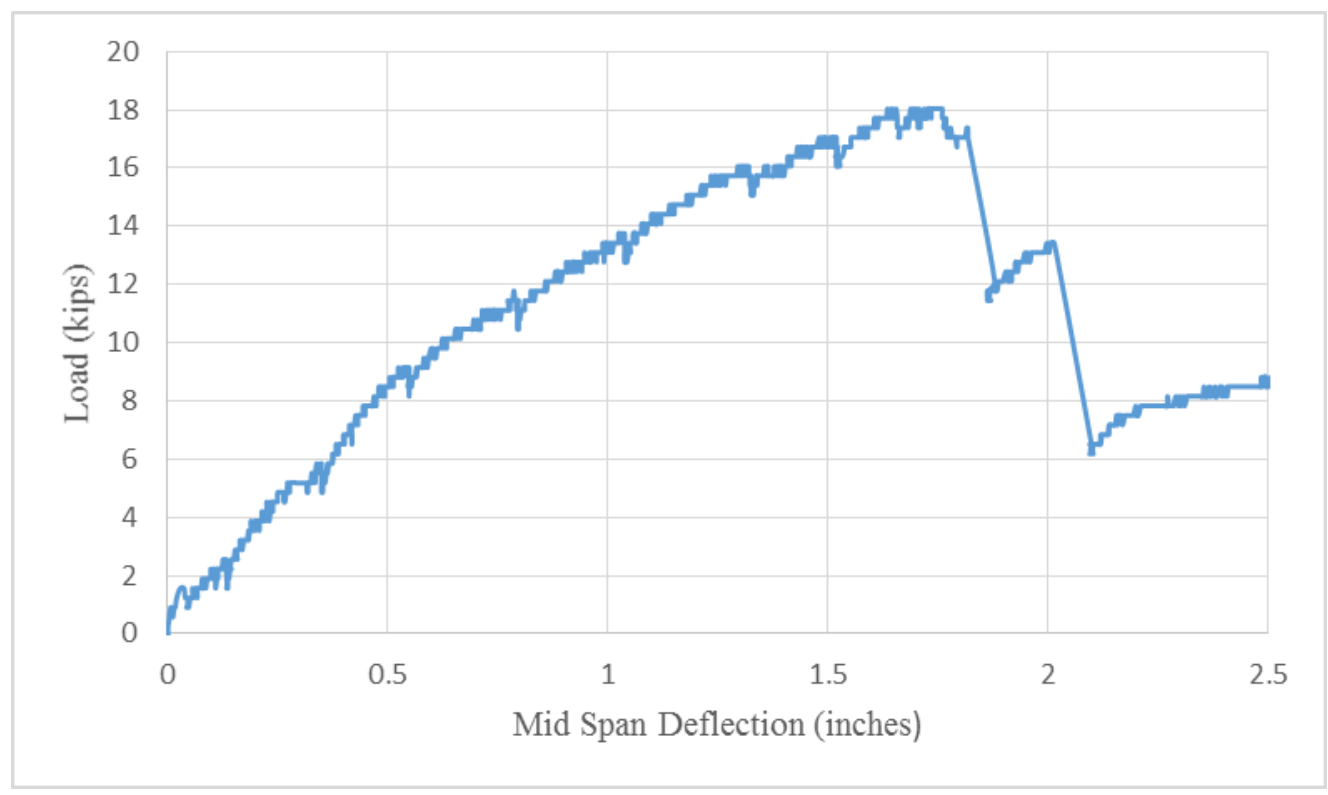

Figure 4-45 Load deflection curve of specimen BC. 


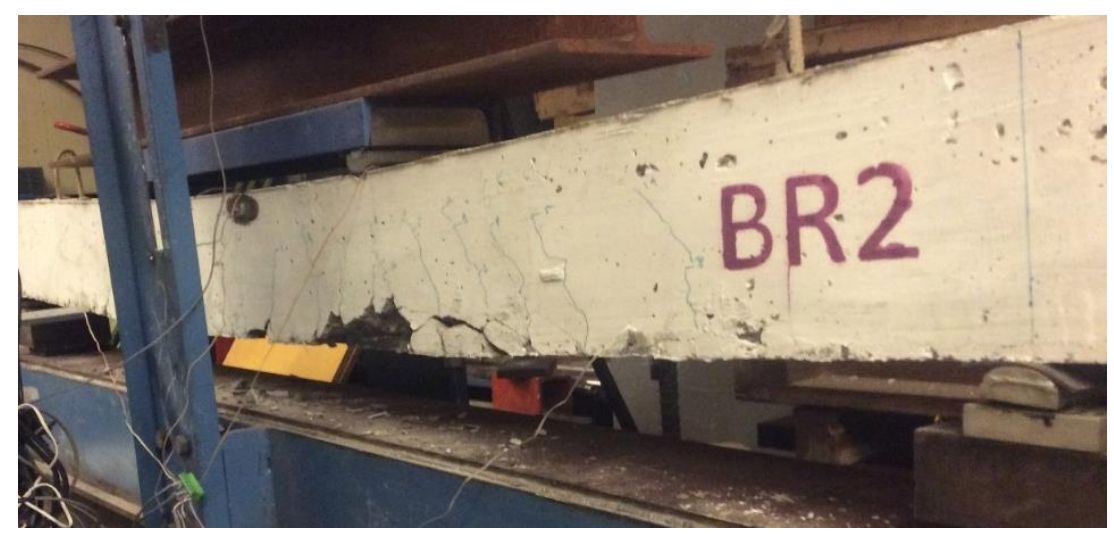

Figure 4-46 Failure mode of specimen BR2.

From the CFRP, steel, and concrete's strain gauges, the strain profile was constructed as shown in Figure 4-47. There appears to be some incongruity between the steel and the CFRP strains for the loads at 5 and 10 kips values. The variation of the strain profile from the linear strain distribution seems excessive. However, the section strain distribution at higher loads (15 and 18 kips) are as expected.

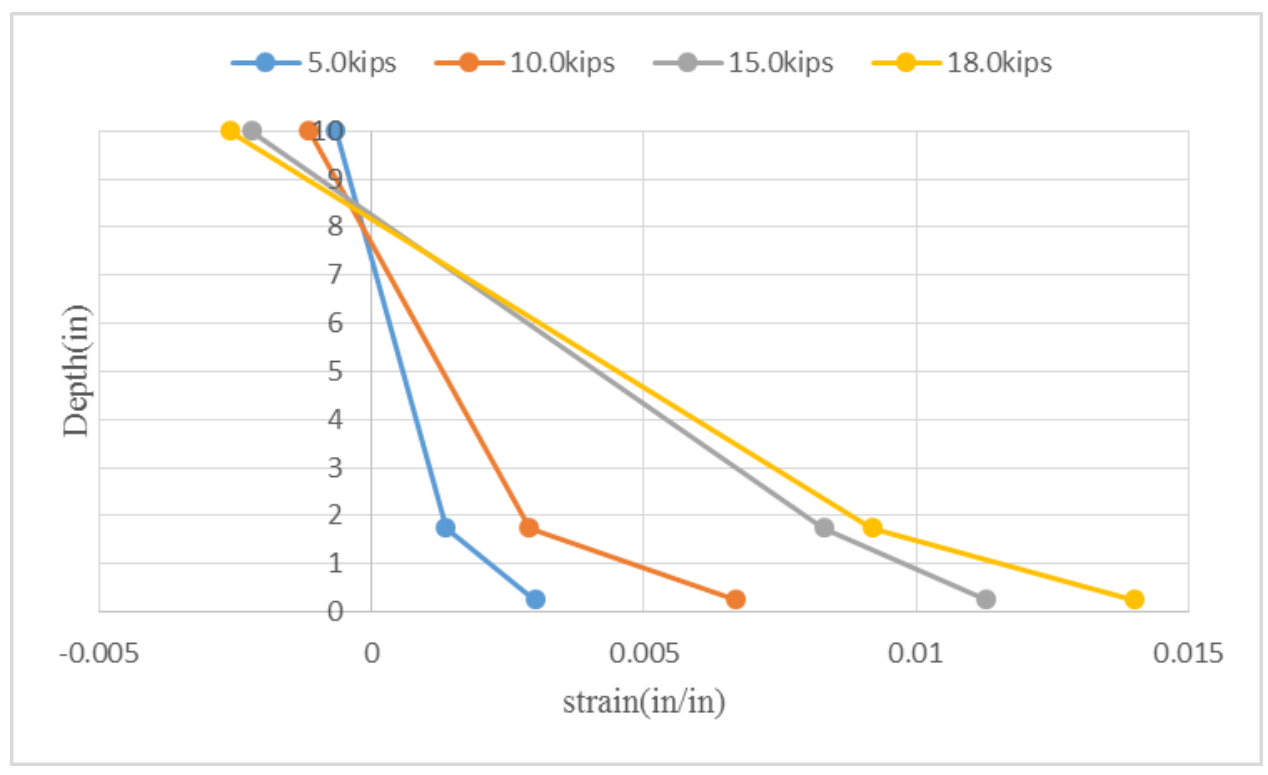

Figure 4-47 Strain profile for specimen BR2 at different load levels. 
Figure 4-48 shows the load strain relationship for the two gauges in a CFRP rod. The first strain gauge was located at the pure moment region under the concentrated load, and the second strain gauge was located at 16in away from the first gauge. The load- strain diagram shows that the strain was larger at the pure moment region, and increased more rapidly as the load increased, as expected. It can be observed that the maximum strain in CFRP rod located in the pure moment region was about 0.014 which is close to the rupture strain of the CFRP rods. That means that the bonding of the CFRP rods in this system was utilized reasonably well. The strain in the second location reached about $50 \%$ of the ultimate strain. This is as expected since the moment at the second location was smaller than (about half as much) the moment at the first location. The compatibility of the steel and CFRP strain distribution at higher loads, shown in figure 4-47 indicates that the section had good composite behavior.

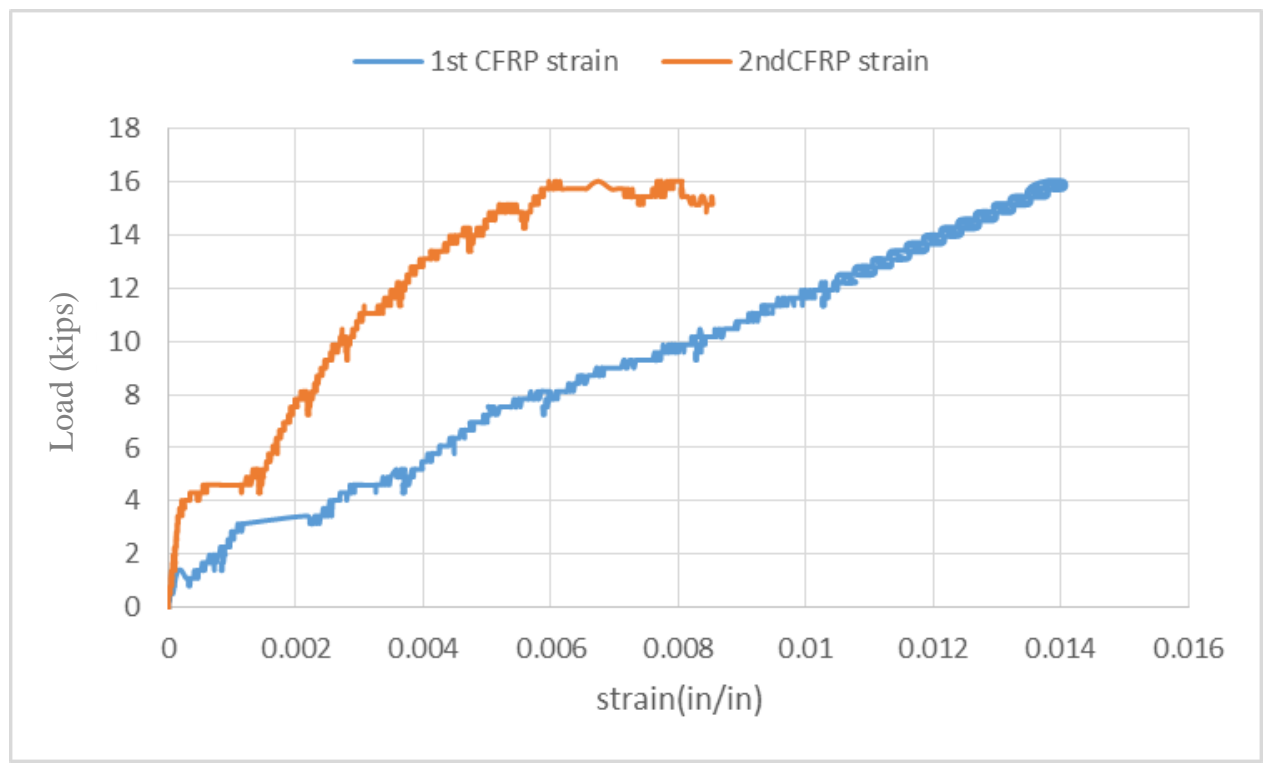

Figure 4-48 CFRP load-strain relationship for specimen BR2. 


\subsubsection{Beam Retrofitted with Two \#3 CFRP Bars (BR3)}

The third beam tested in set B was BR3. This specimen had the same properties as the BC beam, and was additionally reinforced with two \#3 CFRP rods at the tension side. According to ACI 440-2R-08, Figure4-49 shows that the maximum capacity of this beam was $31.6 \mathrm{k}-\mathrm{ft}$. which corresponds to a load of about $23.7 \mathrm{kips}$.

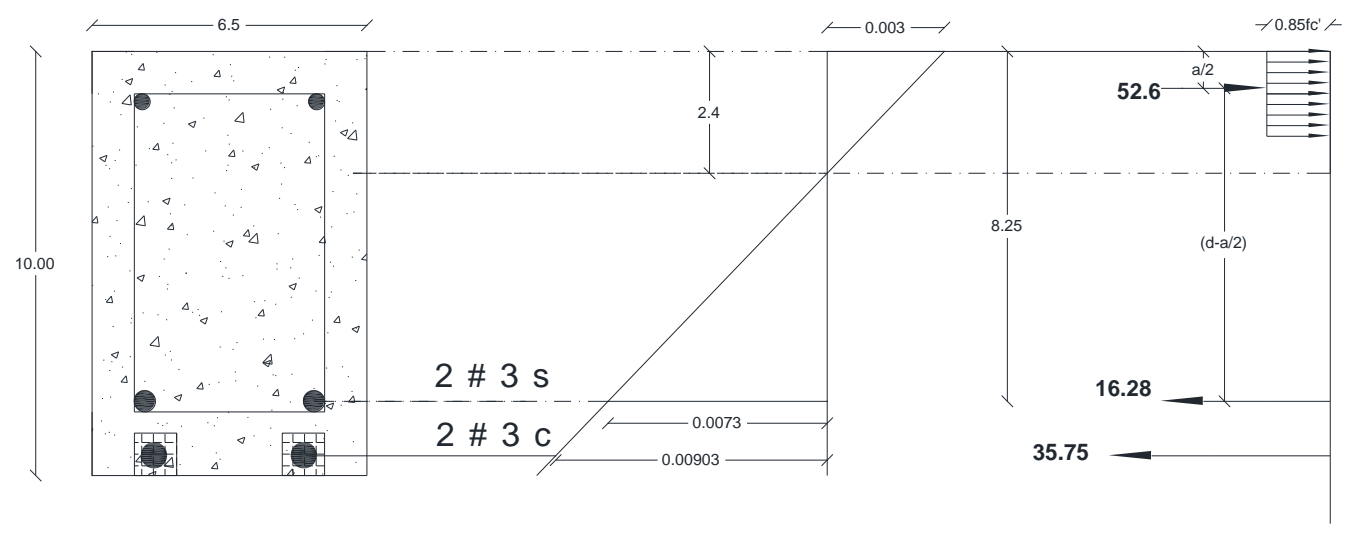

Figure 4-49 Strain and stress analysis of specimen BR3.

From the load deflection curve shown in Figure 4-50, three distinct regions can be observed: the first region was when the first crack of $0.05 \mathrm{~mm}$ occurred at a load of about 3 kips. That was when the beam lost some of its flexural stiffness; the second region was where the steel and the CFRP rods behave elastically; and the third region was where the steel reinforcement yielded. In this stage, more of flexural stiffness was lost, and more cracks were initiated and widened at the positions of the lateral grooves. 


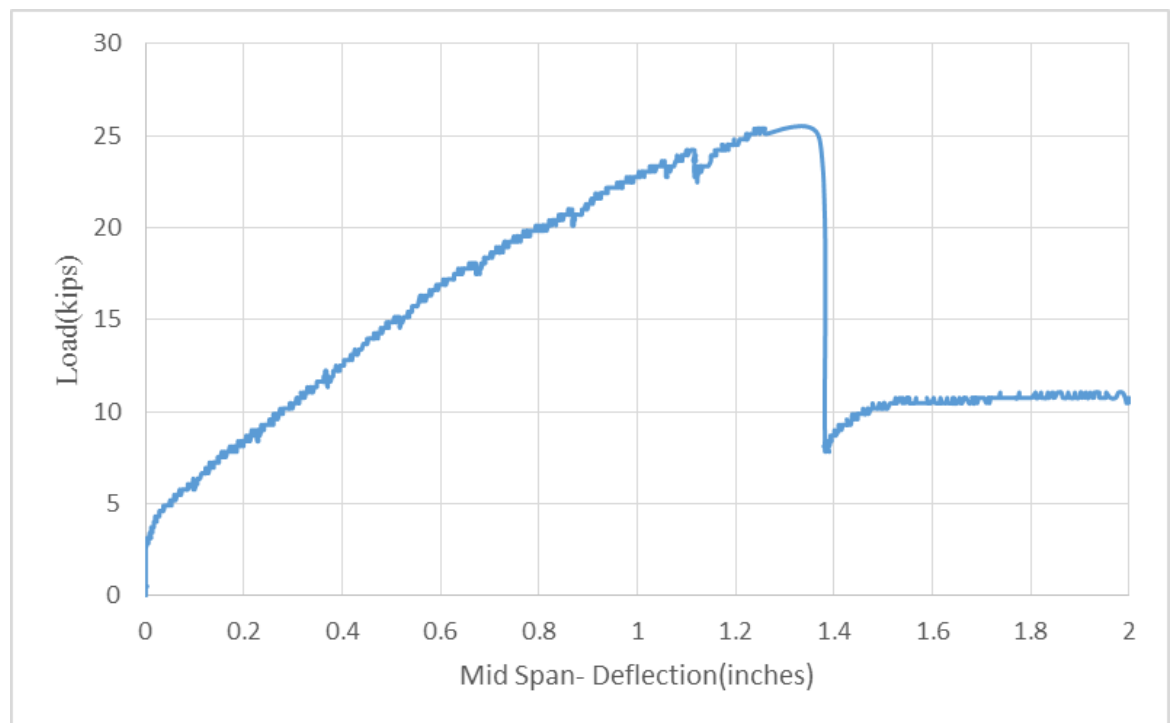

Figure 4-50 Load deflection curve of specimen BR3.

As the load increased, the selected crack widths increased. The load was then increased until the de-bonding occurred at about 25 kips. The increased capacity was about $119 \%$ over the control beam. Before the de-bonding occurred, some diagonal cracking occurred in the shear span. These cracks initiated at the positions of the lateral grooves, and extended to the middle sections of the beam. The de-bonding was due to the over stress of the beam's tensile layer where the edge concrete cracked and spalled, initiating the debonding. Figure 4-51 shows the failure mode of the specimen. 

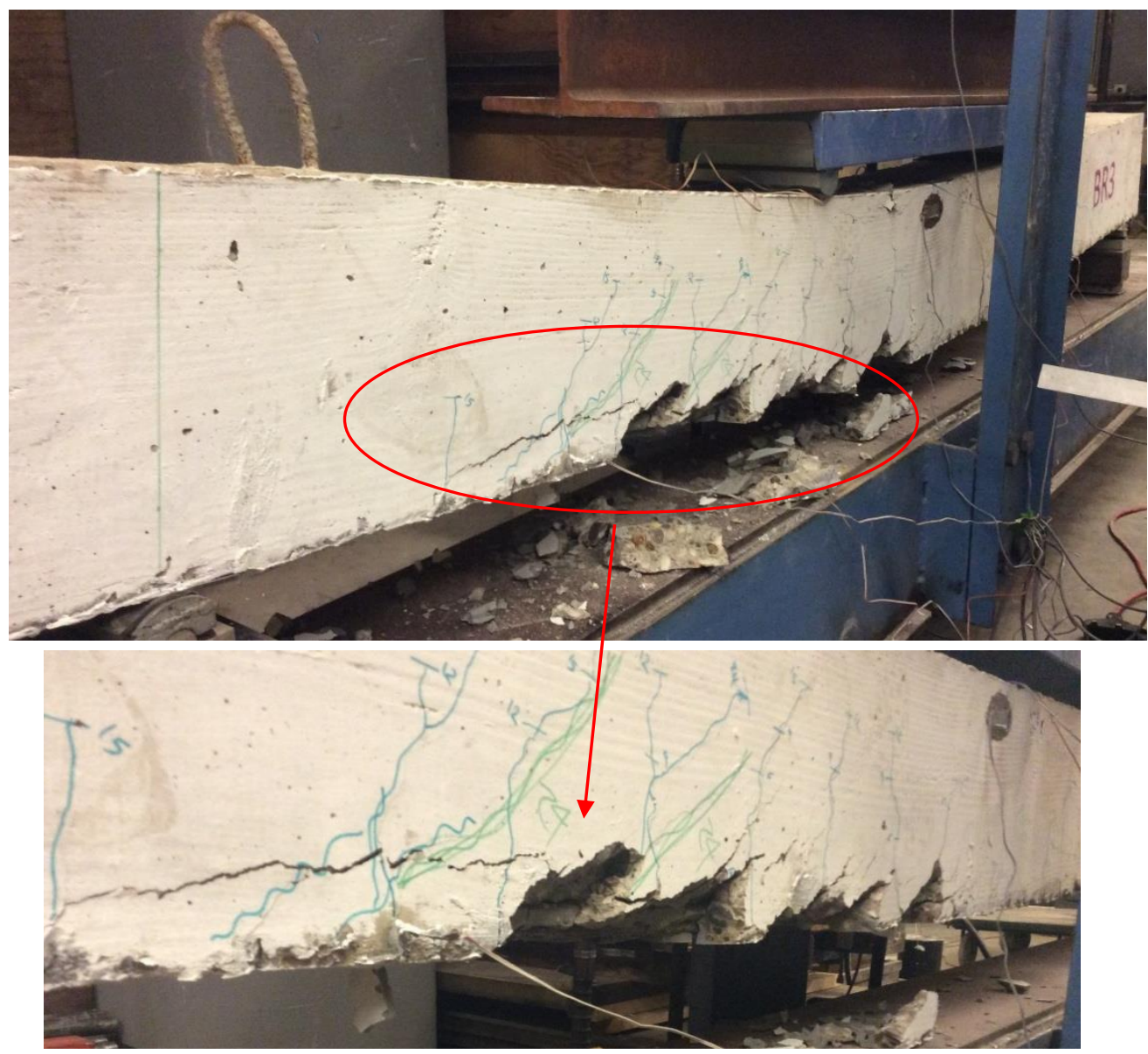

Initiation of the lateral grooves that caused the de-bonding.

Figure 4-51 Failure mode of specimen BR3.

From the CFRP, steel, and concrete's strain gauges, the strain profile was constructed as shown in Figure 4-52. It can be observed that the strain in the section was linear up to 15 kips. At 16 kips, the steel strain gauges at the maximum bending moment region stopped recording data. They might have been damaged during testing or had some other technical issues in data acquisition. Therefore, the data for strain profile up to $15 \mathrm{kips}$ only are available. 


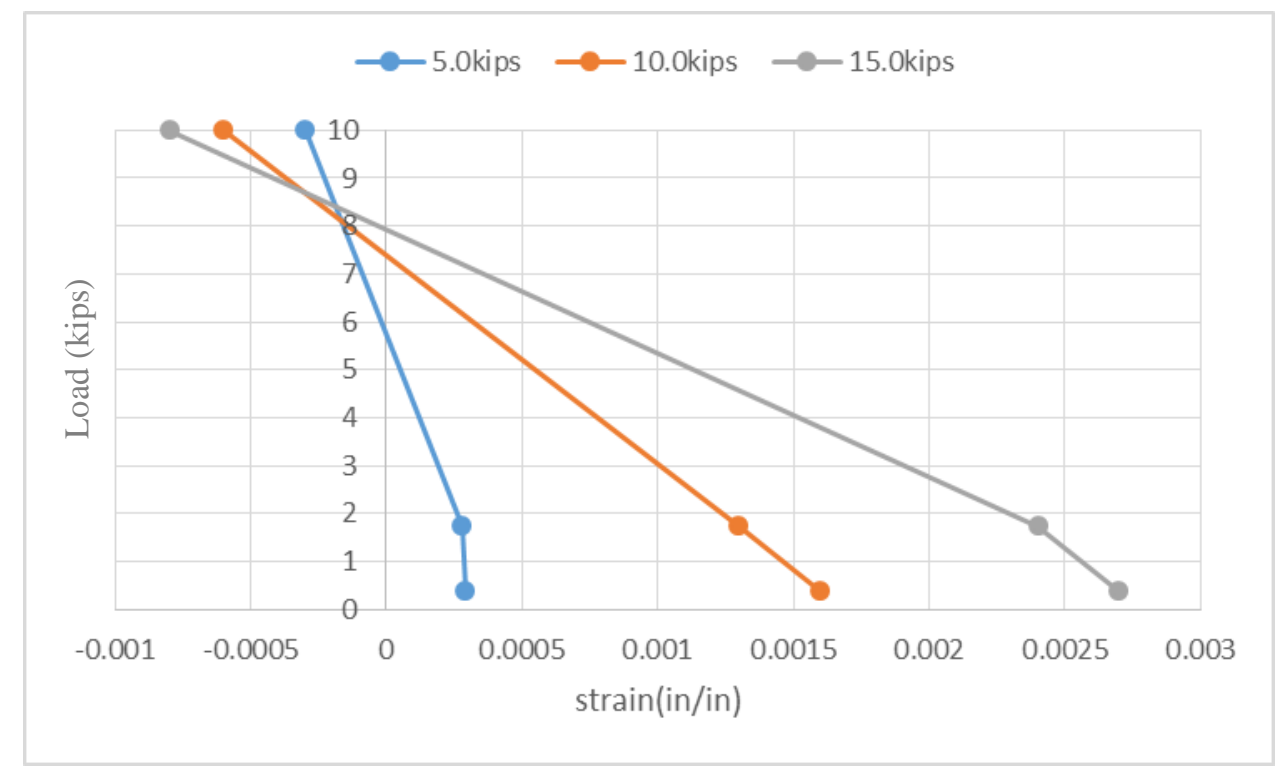

Figure 4-52 Strain profile for specimen BR3 at different load levels.

Figure 4-53 shows the load-strain relationship at two points along the CFRP rods. The first strain gauge was located at the pure moment region, and the second strain was located at 16 in away from the pure moment region. The strain distribution showed that the strain was larger at the pure moment region, and increased as the load increased, as expected. The maximum strain in the first and the second strain gauge was about $36 \%$ and $30 \%$ of the FRP ultimate strain respectively. This shows that the variation of the stress at the maximum moment region, and 16 inches away from the maximum moment region, was small. 


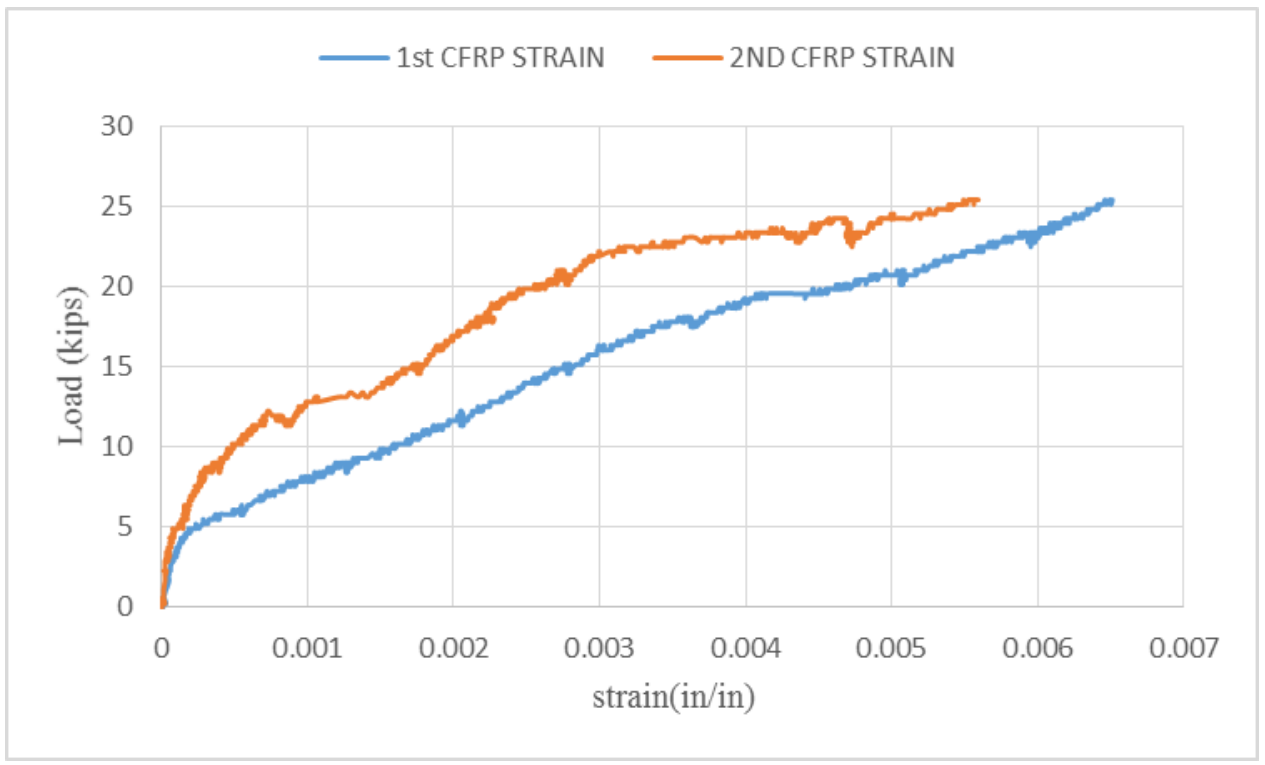

Figure 4-53 CFRP load-strain relationship for specimen BR3.

\subsubsection{Beam Retrofitted with Two \#4 CFRP (BR4)}

The fourth beam tested in set B was BR4. This had the same properties as the BC beam, and was additionally retrofitted with two \#4 CFRP rods on the tension side. According to ACI 440-2R-08(Figure 4-54 below), the maximum capacity of this beam was about $36 \mathrm{k}$ $\mathrm{ft}$, which corresponds to a load of 27.0 kips.

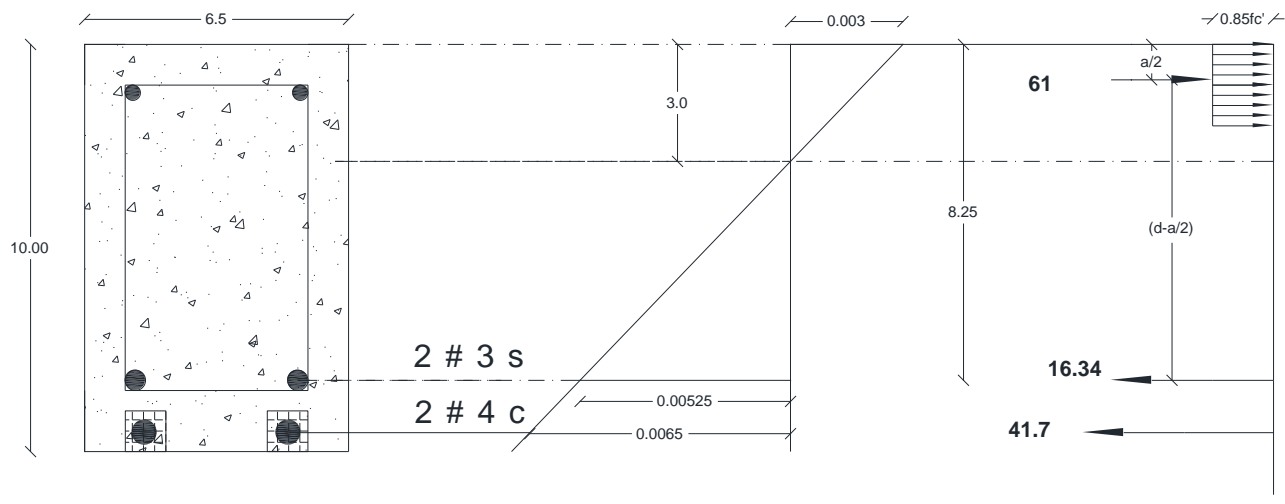

Figure 4-54 Strain and stress analysis of specimen BR4. 
From the load deflection curve shown in Figure 4-55, two distinct regions can be observed. The first region was when the first cracking of $0.04 \mathrm{~mm}$ occurred at 5 kips. That was when the beam lost some of its flexural stiffness as shown in load deflection curve below. The load was then increased until the de-bonding occurred at about 26 kips, and that was where the second region of the curve was shaped. The increased capacity was about $121 \%$ over the control beam. However, this specimen had a brittle behavior. That indicated the over reinforcement of the system.

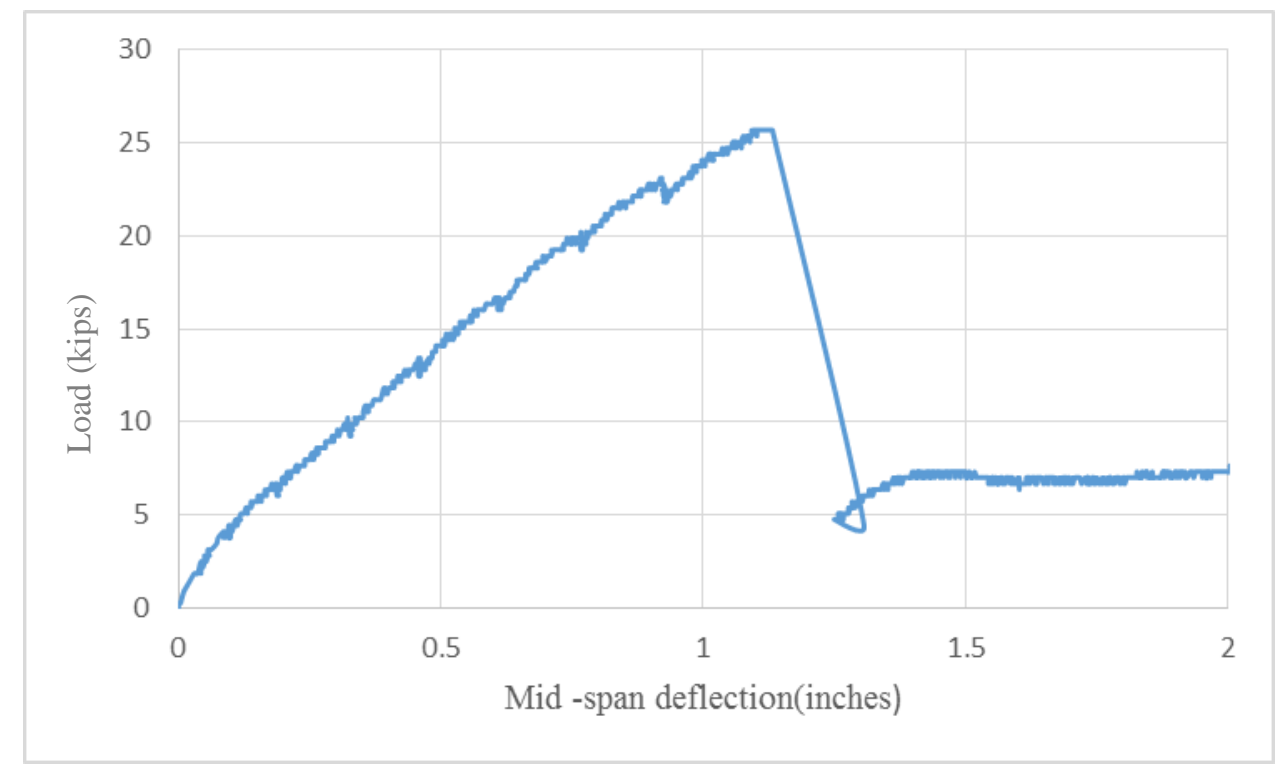

Figure 4-55 Load deflection curve of specimen BR4.

Before the de-bonding occurred, some diagonal cracking occurred in the shear spans. These cracks initiated at the beginning of the shear span, and extended to the ends of the beam. The de-bonding was due to the over stress of the cover layers where the edge concrete cracked and fell off, initiating the de-bonding. Figure 4-56 shows the failure mode of the specimen. 


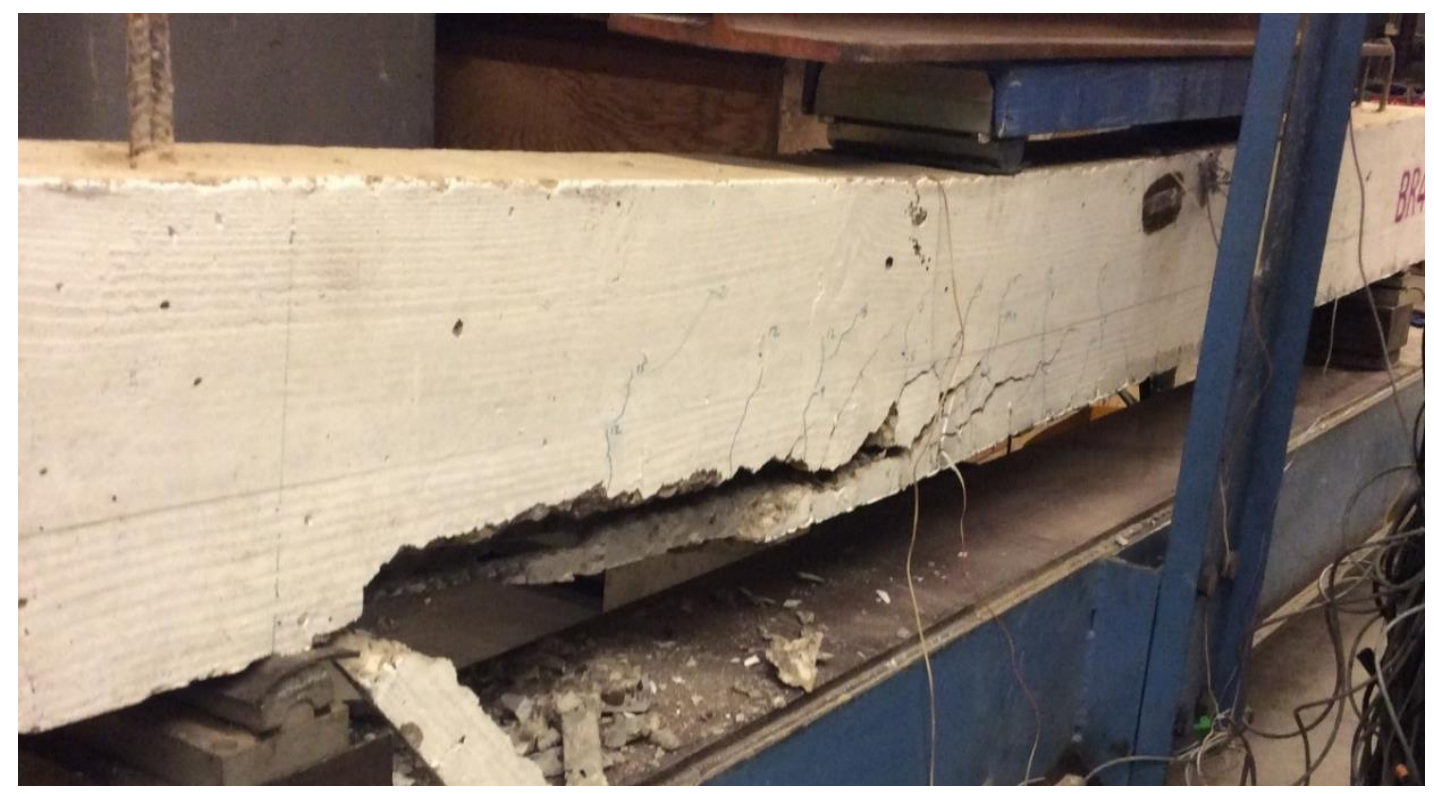

Figure 4-56 Failure mode of specimen BR4.

From the CFRP, steel, and concrete's strain gauges, the strain profile was constructed for the section under the concentrated load as shown in Figure 4-57 below. It can be observed that the strain in the section was linear up to the failure, and that the steel reinforcement did not yield. 


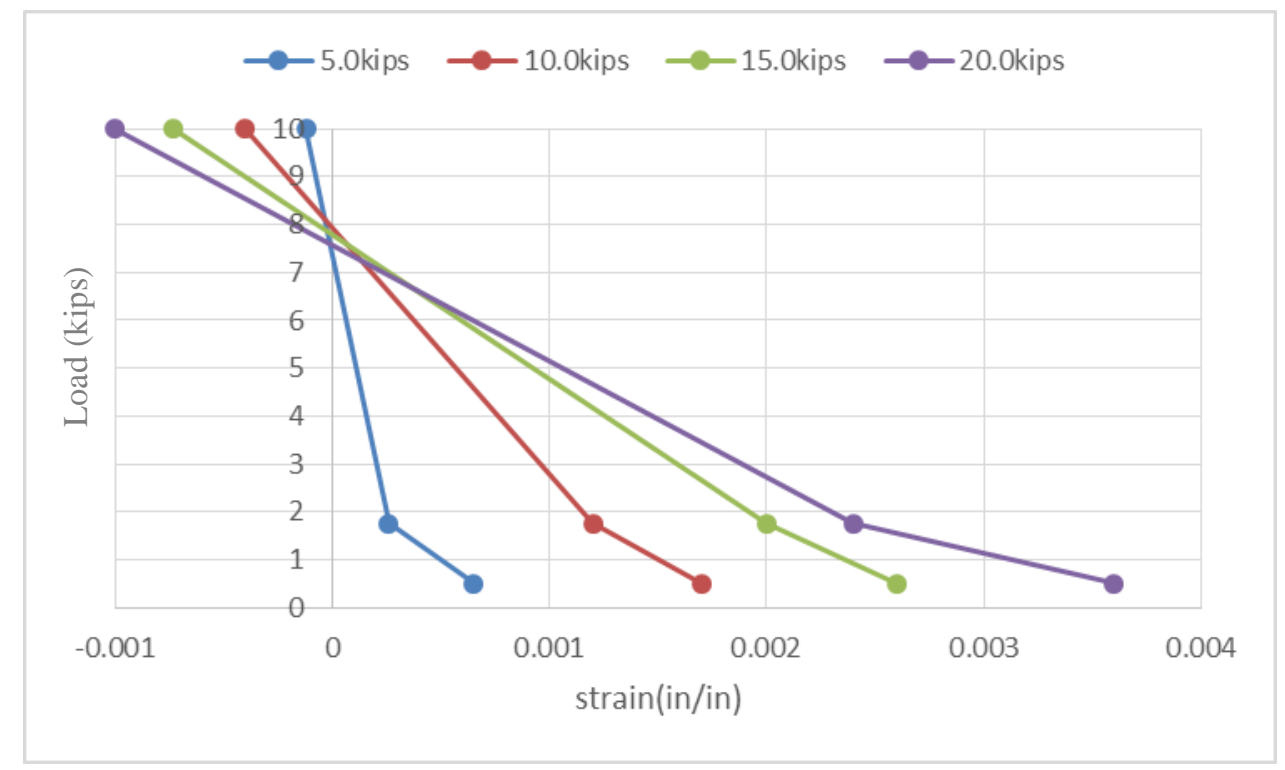

Figure 4-57 Strain profile for specimen BR4 at different load levels.

Figure 4-58 shows the load-strain relationship at two points along the CFRP rods. The first strain was located at the pure moment region, and the second strain was located at 16in away from the pure moment region. The strain distribution shows that the strain was larger at the pure moment region, and increased as the load increased. The maximum strains in the first and the second strain gauges was about $24 \%$ and $15 \%$ of the CFRP ultimate strain respectively. These low strain values indicate the poor performance of the composite action due to the over reinforcement of the system. 


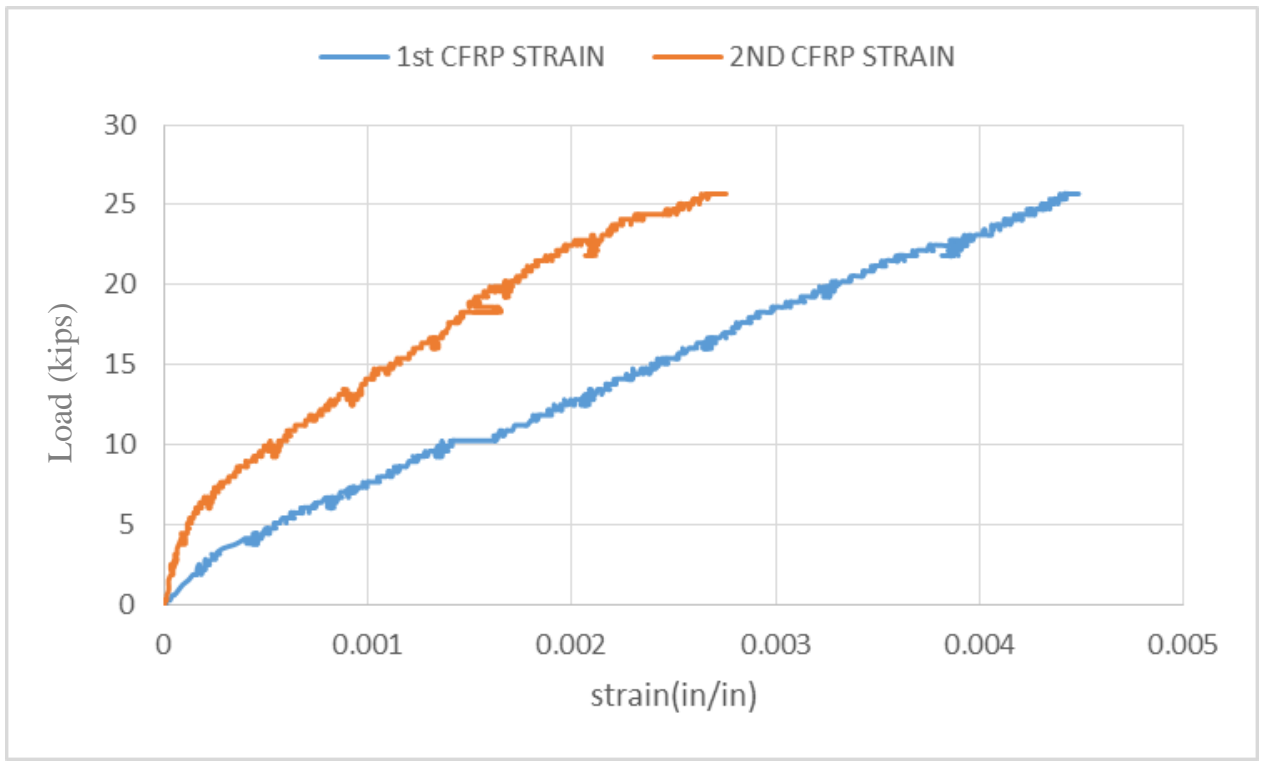

Figure 4-58 CFRP load-strain relationship for specimen BR4. 


\subsubsection{Set A and B Results Comparison}

Figure 4-59 shows the measured load-deflection curves for beam specimens in set A.

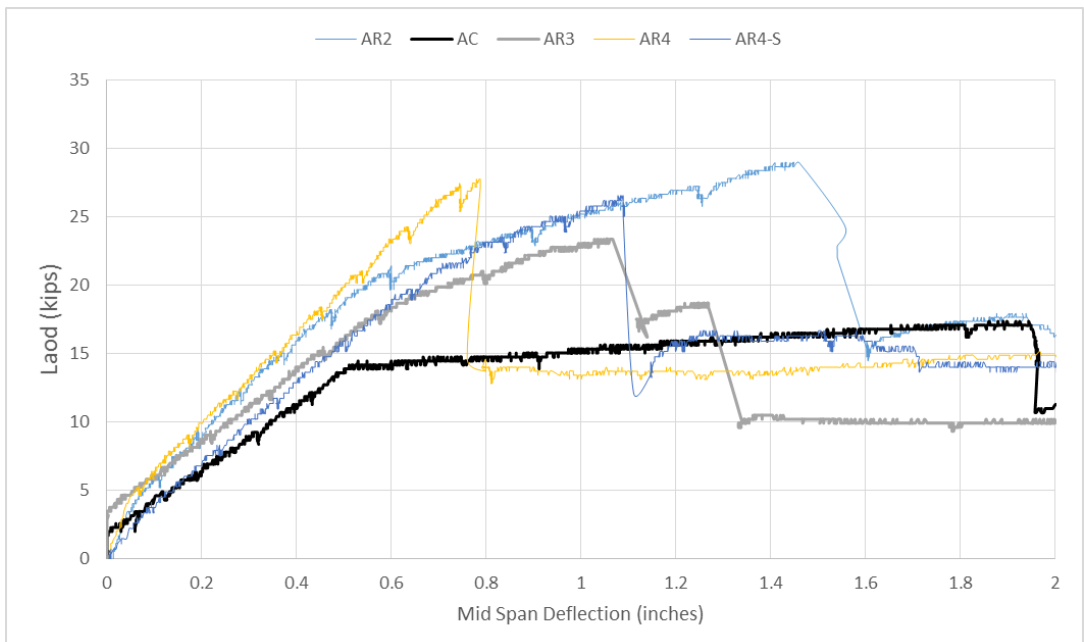

Figure 4-59 Set A load deflection curves.

Figure 4-60 shows the normalized load-deflection curves for beam specimens in set A.

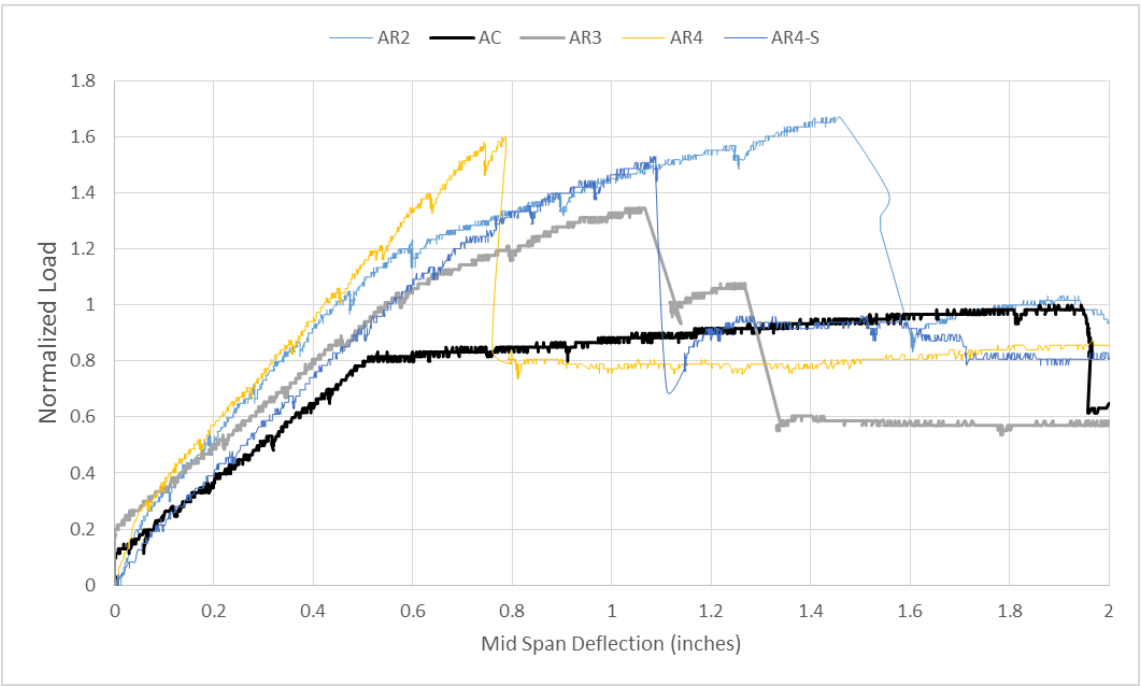

Figure 4-60 Set A normalized load deflection curves.

Figure 4-61 shows the measured load-deflection curves for beam specimens in set B. 


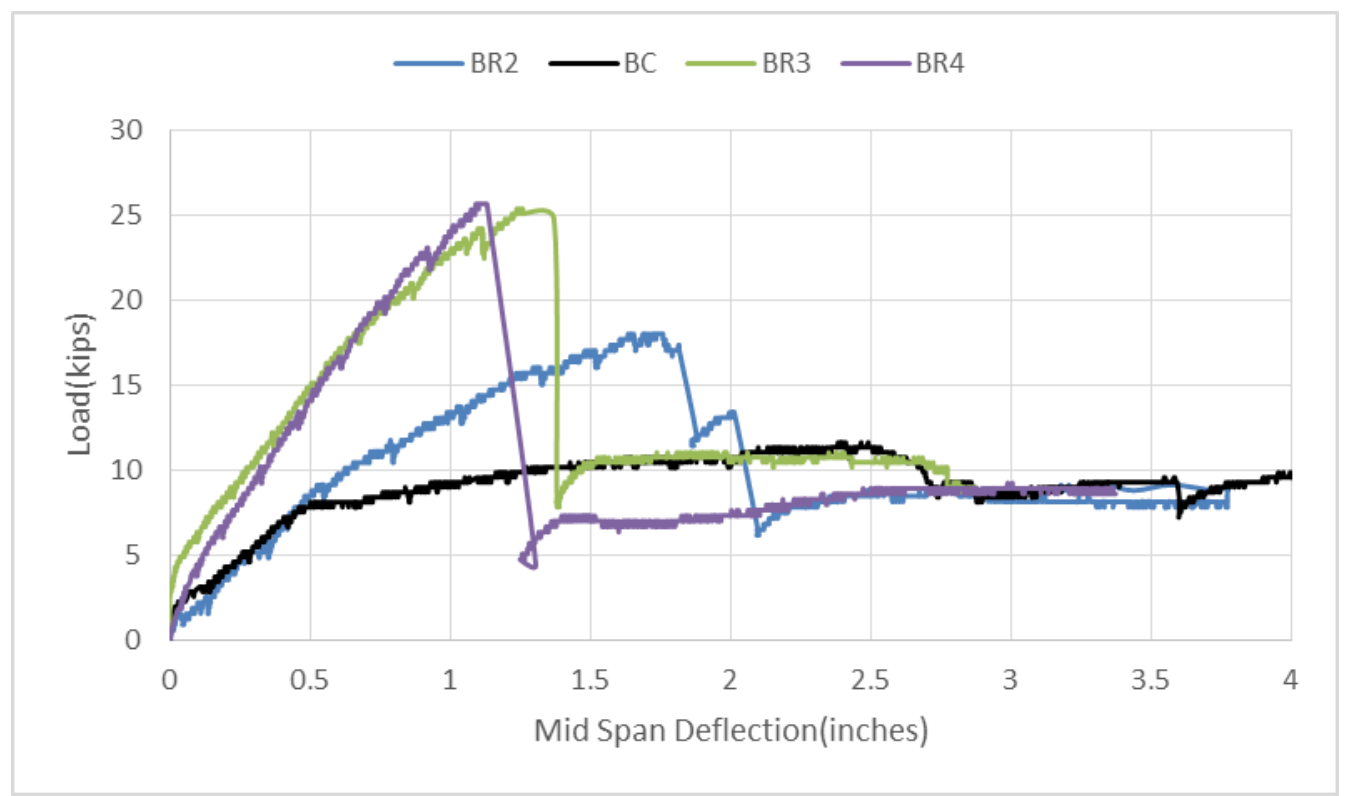

Figure 4-61 Set B load deflection curves.

Figure 4-62 shows the normalized load-deflection curves for beam specimens in set B.

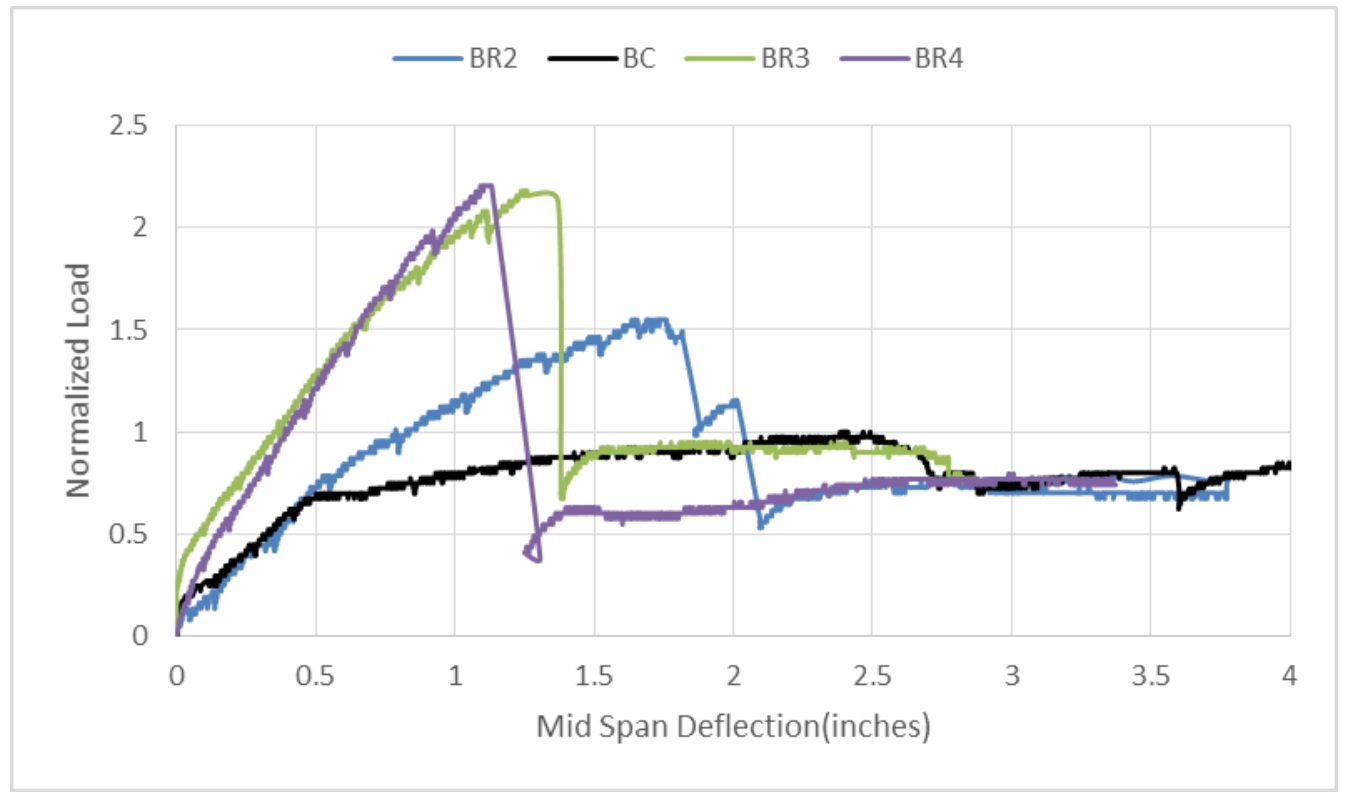

Figure 4-62 Set B normalized load deflection curves. 
From the data in the figures above, it is apparent that adding CFRP rods increased the flexural capacity and the stiffness of the retrofitted beams. Another interesting fact was that as the sizes of CFRP rod increased, the ductility decreased.

In comparing set $\mathrm{A}$ and set $\mathrm{B}$ results, it is observed that adding CFRP rods to set $\mathrm{B}$ specimens works more efficiently than adding the CFRP bar sizes to set A specimens. Soliman, S. M. et al. (2010) reported that $0.4 \%$ is the optimum steel reinforcement ratio to increase the capacity by adding the CFRP rods. Tables 4-4 and 4-5 shown below reveal that the optimum reinforcement ratio for this section was within the range of 0.9$0.6 \%$. A reinforcement ratio larger than $0.9 \%$ would result in prematurely de-bonding CFRP rods with sharp drop in load. On the other hand, a reinforcement ratio smaller than $0.6 \%$ would result in smaller added capacity. As the reinforcement ratio ranged between $(0.9-0.6 \%)$, the maximum capacity of the beam ranged between 18.0-29.0 kips. However, this value was obtained at a different ultimate deflection levels. For example, AR2 had a maximum capacity of 28.7 kips and deflection of 1.5 inches. On the other hand, BR2 had a maximum capacity of 18.0 kips at ultimate deflection of 1.76 inches. Therefore, the deflection in AR2 was compromised over the capacity, and the capacity in BR2 was compromised over the deflection. From tables 4-4 and 4-5, we can see that the ultimate CFRP strain in set B was larger than the corresponding ones in set A. Therefore, he composite mechanism in set B beams was more efficient than set A beams. 
Table 4-4 Set A results comparison.

\begin{tabular}{|c|c|c|c|c|c||}
\hline Specimens & Reinforcement & Ultimate & Normalized & Ultimate & Ultimate \\
No. & ratio & $\begin{array}{c}\text { capacity } \\
\text { (kips) }\end{array}$ & $\begin{array}{c}\text { Ultimate } \\
\text { Capacity }\end{array}$ & deflection(in) & CFRP \\
strain \\
\hline \hline AC & $0.73 \%$ & 17.0 & 1.0 & 1.93 & ---- \\
\hline AR2 & $0.92 \%$ & 28.7 & 1.7 & 1.5 & 0.011 \\
\hline AR3 & $1.1 \%$ & 23.0 & 1.35 & 1.0 & 0.006 \\
\hline AR4-S & $1.12 \%$ & 26.5 & 1.55 & 1.1 & 0.0057 \\
\hline AR4 & $1.4 \%$ & 27.5 & 1.6 & 0.78 & 0.003 \\
\hline
\end{tabular}

Table 4-5 Set B results comparison.

\begin{tabular}{|c|c|c|c|c|c|}
\hline $\begin{array}{c}\text { Specimens } \\
\text { No. }\end{array}$ & $\begin{array}{c}\text { Reinforcement } \\
\text { ratio }\end{array}$ & $\begin{array}{c}\text { Ultimate } \\
\text { capacity } \\
\text { (kips) }\end{array}$ & $\begin{array}{l}\text { Normalized } \\
\text { Ultimate } \\
\text { Capacity }\end{array}$ & $\begin{array}{c}\text { Ultimate } \\
\text { deflection(in) }\end{array}$ & $\begin{array}{l}\text { Ultimate } \\
\text { CFRP } \\
\text { strain }\end{array}$ \\
\hline$\overline{\mathrm{BC}}$ & $0.4 \%$ & 11.0 & 1.0 & 2.5 & ---- \\
\hline$\overline{\text { BR2 }}$ & $0.6 \%$ & 18.0 & 1.6 & 1.76 & 0.014 \\
\hline$\overline{\text { BR3 }}$ & $0.82 \%$ & 25.0 & 2.3 & 1.37 & 0.0065 \\
\hline$\overline{\text { BR4 }}$ & $1.2 \%$ & 25.6 & 2.33 & $\begin{array}{l}1.128 \\
\end{array}$ & $\begin{array}{l}0.0044 \\
\end{array}$ \\
\hline
\end{tabular}




\subsubsection{Measured Crack Width}

Figures 4-63 and 4-64 show the normalized measured load crack width curves for specimens in set $\mathrm{A}$ and set $\mathrm{b}$ respectively.

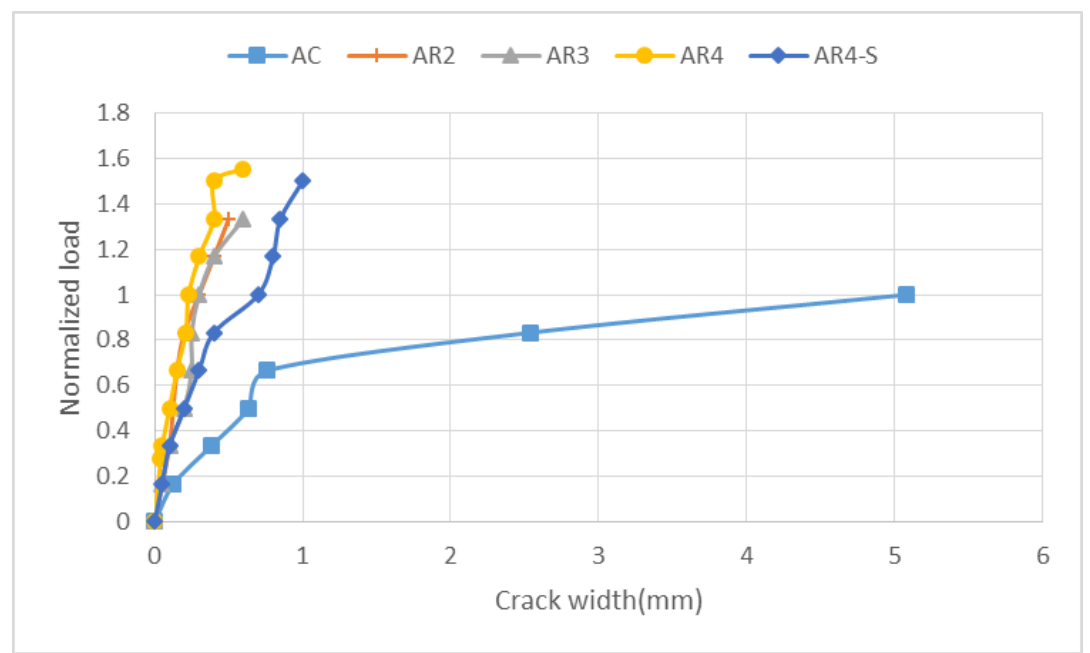

Figure 4-63 Set A normalized load crack-width curve.

It is apparent from the Figures that adding the CFRP reinforcement limited the crack width to less than $1.0 \mathrm{~mm}$ as shown in the graphs 4-63 and 4-64. For the retrofitted beams, the cracks were distributed along the entire length of the beams specifically at the position of the lateral grooves. However, for the control beams, the cracks were concentrated at the region of the pure bending moment. 


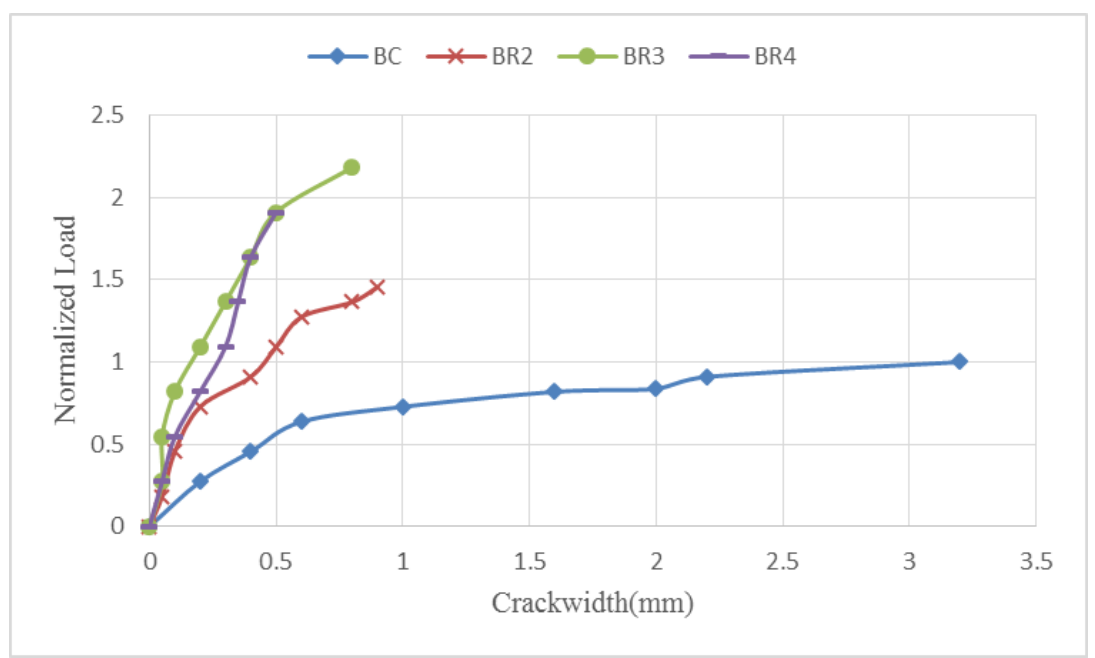

Figure 4-64 Set B Normalized load crack-width curves.

\subsubsection{Theoretical Analysis}

An analytical study was done and compared to the experimental results. The analysis was based on the developing moment curvature relationship for reinforced concrete beam section. The load deflection curve was then established from the moment curvature relationship. A Mathcad code was programmed by Anas Yosefani, a graduate student at Portland State University. This program allows the user to input material and section properties. By incrementally increasing the strain in the concrete, the program uses the equilibrium and strain compatibility to find the moment and the curvature of the section at any strain level. Deflection was then derived from the curvature by moment - area method. For each specimen, the load - deflection curve was established based on three points: concrete cracking point, steel yielding point, and concrete crushing point. As described in appendix $\mathrm{B}$, the steel yielding point and the concrete crushing point were found based on the properties of each section. 
Table 4-6 shows ultimate loads for each specimen based on a) ACI prediction, b) experimental values, c) theoretical value assuming $\varepsilon_{c u}=0.003$, and d) theoretical value assuming $\varepsilon_{c u}=0.004$. the ratio of $\mathrm{ACI} /$ Experimental and theoretical $(0.003) /$ experimental are also shown.

\section{Table 4-6 Ultimate loads comparison.}

\begin{tabular}{|c|c|c|c|c|c|c|}
\hline & \multicolumn{3}{|c|}{ Ultimate load ( kips) } & \multicolumn{2}{c|}{ Ratio } \\
\hline Specimen & ACI & Experimental & Theoretical & Theoretical & $\frac{A C I}{E X P .}$ & $\frac{0.003 \text { Theo }}{E X P .}$ \\
& Prediction & & $\begin{array}{c}\varepsilon_{c u} \\
=0.003\end{array}$ & $\begin{array}{c}\varepsilon_{c u} \\
=0.004\end{array}$ & & \\
\hline AC & 14.14 & 17.0 & 15.73 & 16.8 & 0.83 & 0.92 \\
\hline AR2 & 21.64 & 29.0 & 26.2 & 30.56 & 0.75 & 0.9 \\
\hline AR3 & 27.0 & 23.4 & 32 & 36.15 & 1.2 & 1.4 \\
\hline AR4 & 28.5 & 27.5 & 37.4 & 42.2 & 1.0 & 1.4 \\
\hline AR4-S & 26.6 & 26.5 & 30.4 & 34.42 & 1.0 & 1.1 \\
\hline BC & 8.25 & 11.6 & 9.8 & 10.395 & 0.7 & 0.85 \\
\hline BR2 & 18.0 & 18.0 & 23.0 & 23.9 & 1.0 & 1.3 \\
\hline BR3 & 23.7 & 25.4 & 29.5 & 35.43 & 0.9 & 1.2 \\
\hline BR4 & 27.0 & 25.6 & 40.725 & 35.5 & 1.1 & 1.6 \\
\hline
\end{tabular}

From table 4-6, it can be observed that ACI prediction and the experimental results are in reasonable agreement. On the other hand, the ultimate loads according to the theoretical analysis seemed to be generally higher than the experimental results especially for specimens with high CFRP reinforcement ratio. Nonetheless, the bonding and epoxy deformation were not considered in the theoretical analysis which result in the higher 
values. Figures 4-65 through 4-68 demonstrate the theoretical performance of each specimen, and the locations of the experimental de-bonding points. It can be concluded from the figures that the de-bonding at set A specimens occurred between 25-30 kips. On the other hand, set B specimens had a slightly larger range where the de-bonding occurred between 18-24 kips.

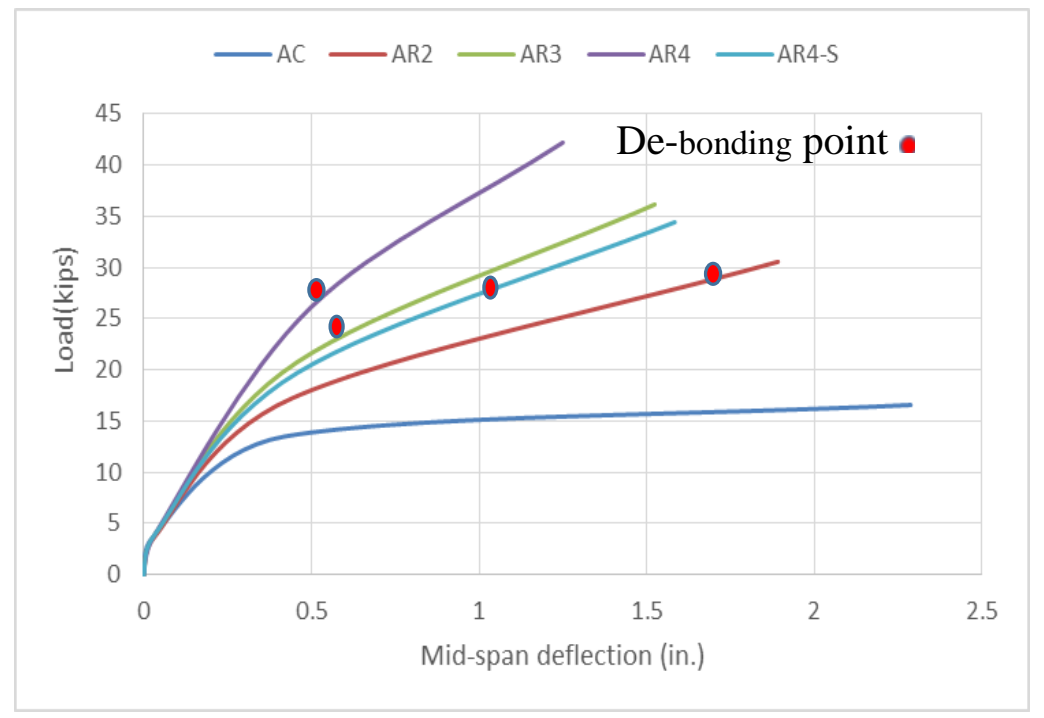

Figure 4-65 Theoretical load deflection curves for set A.

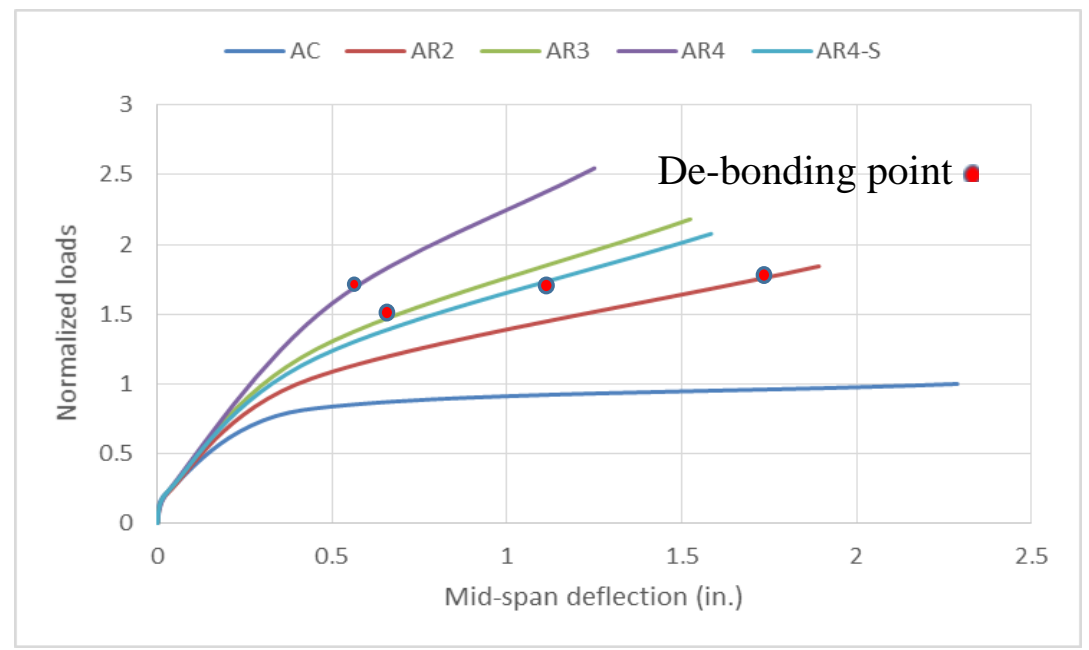

Figure 4-66 Normalized theoretical load deflection curves for set A 


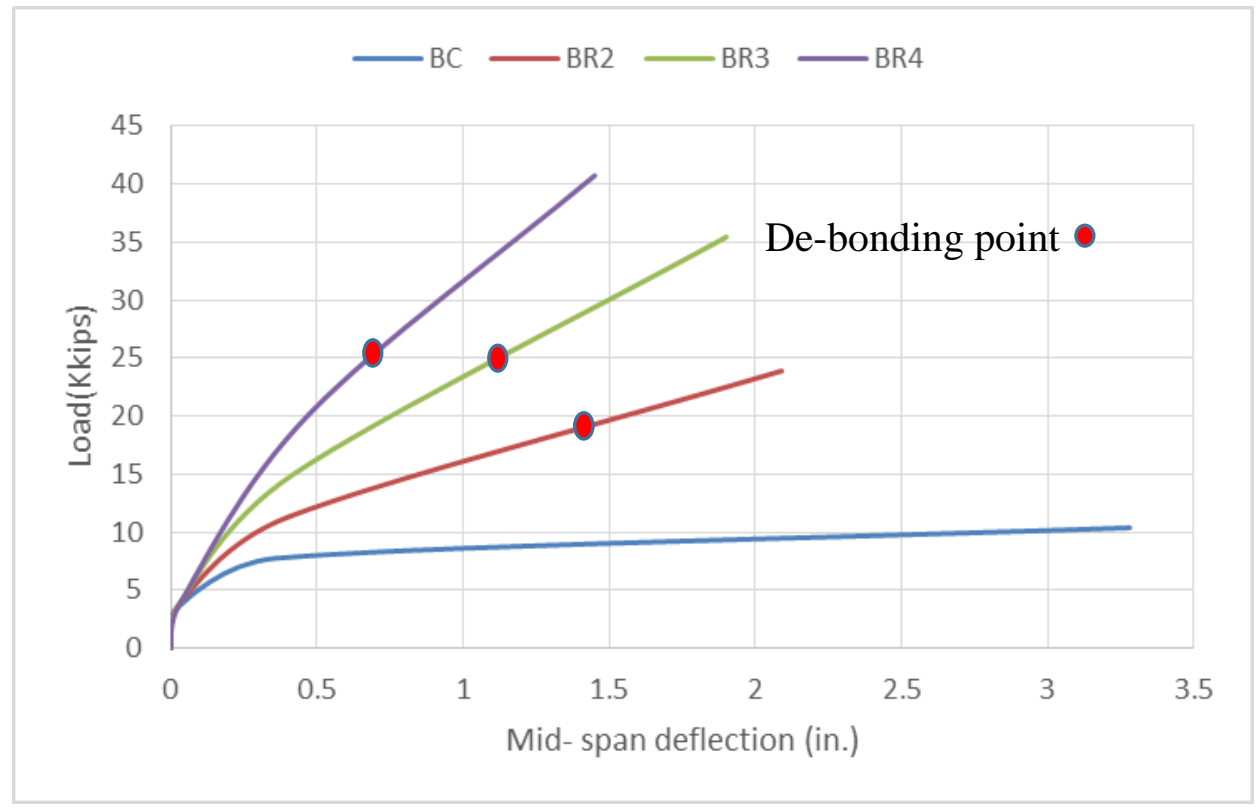

Figure 4-67 Theoretical Load deflection curves for set B.

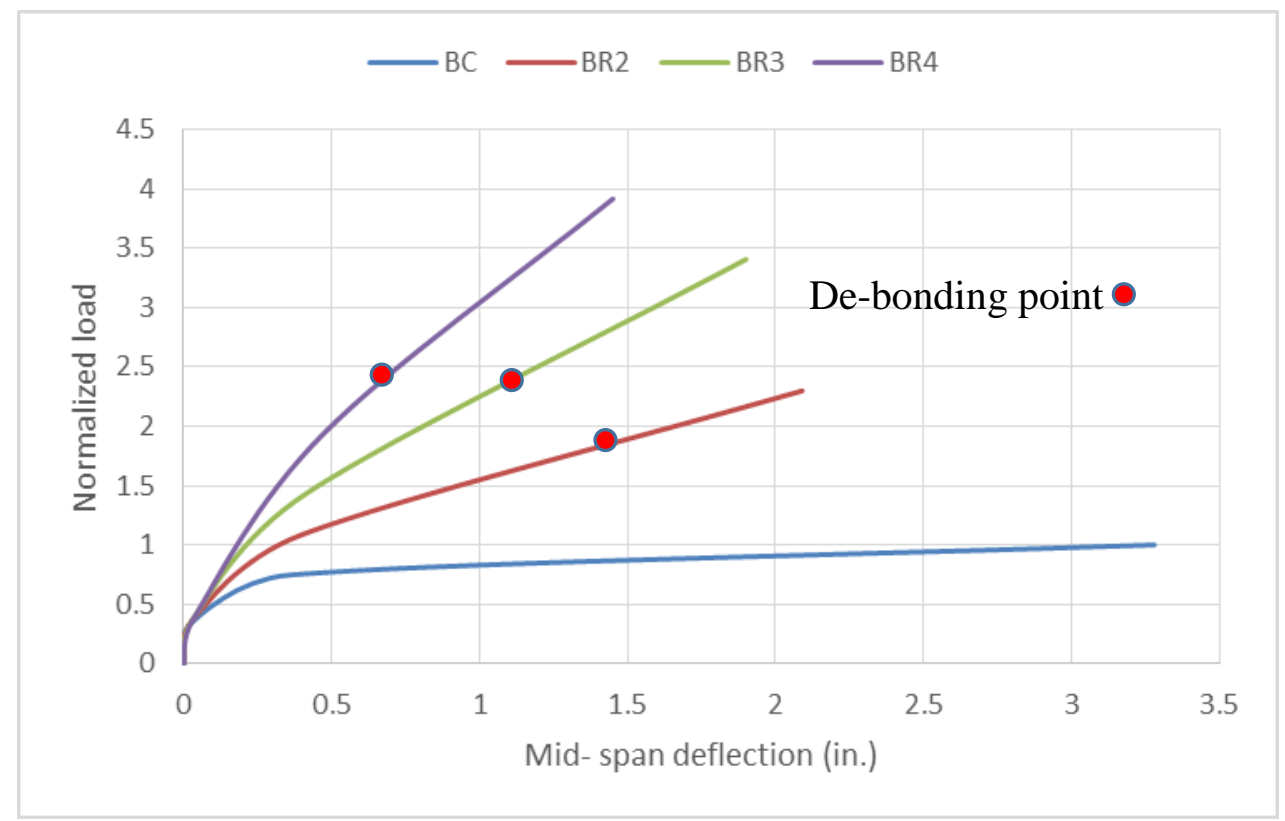

Figure 4-68 Normalized load deflection curves for set B. 
Figures 4-69 through 4-77 below are the theoretical and experimental load- deflection curve comparison for all specimens. In general, the theoretical load deflection curves were comparable to the experimental results as shown in figures below. For all retrofitted specimens, the experimental mode of failure was the de-bonding of the CFRP rods. However, for the theoretical specimens, the mode of failure was the crushing of concrete. Therefore, the theoretical analysis always reached a larger ultimate capacity than the experimental results. The derivation of the theoretical curves are described in appendix B.

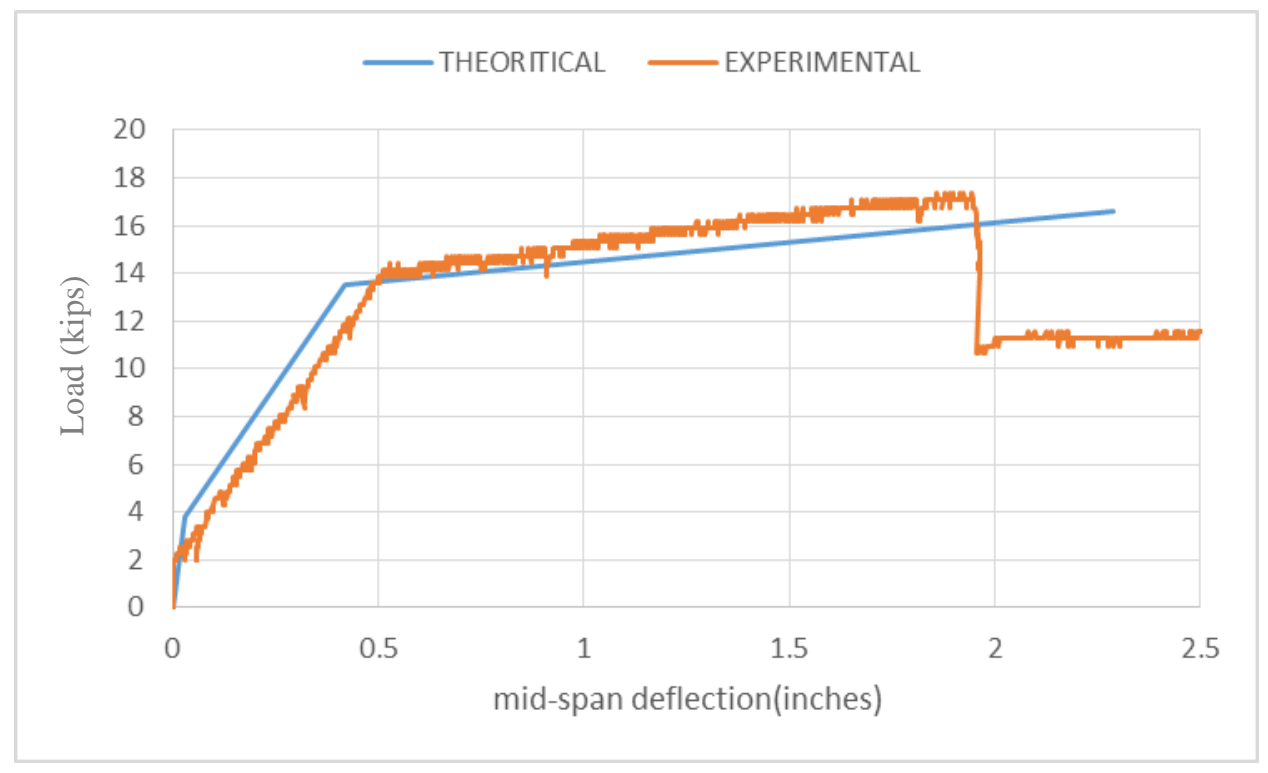

Figure 4-69 Specimen AC theoretical and experimental load deflection comparison. 


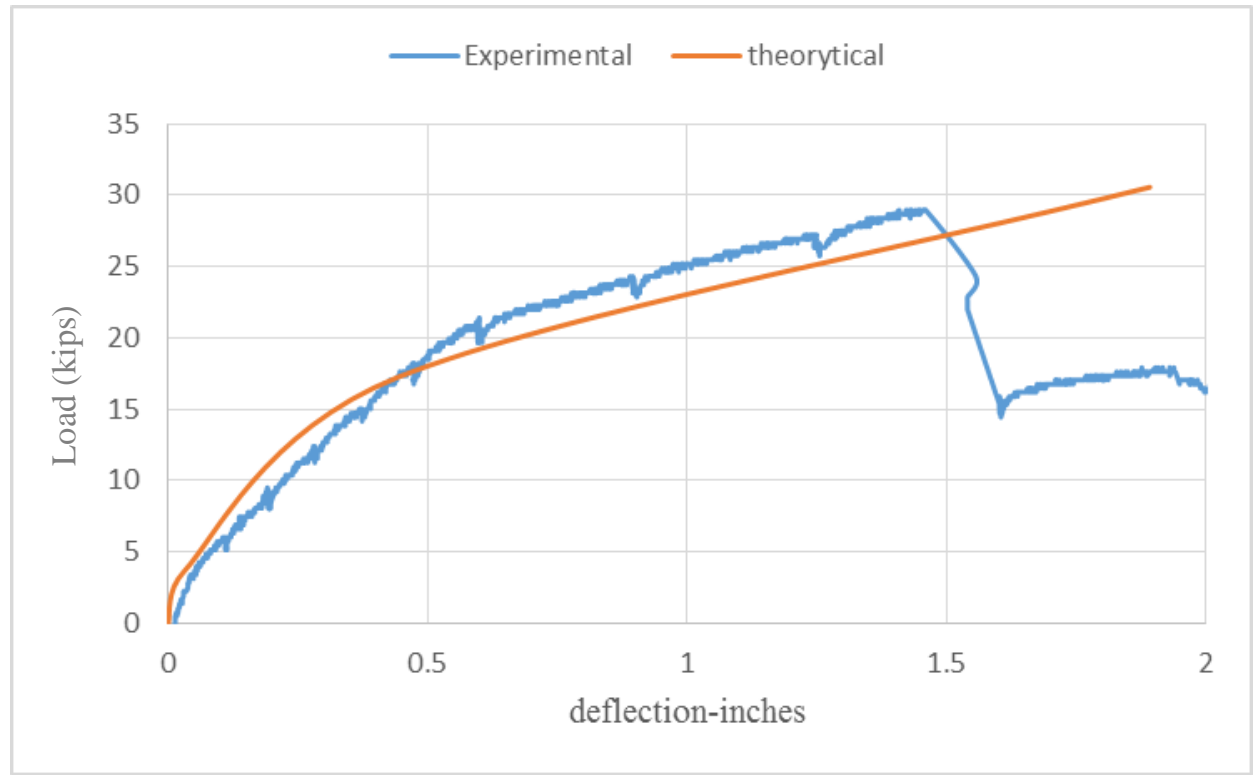

Figure 4-70 Specimen AR2 theoretical and experimental load deflection comparison.

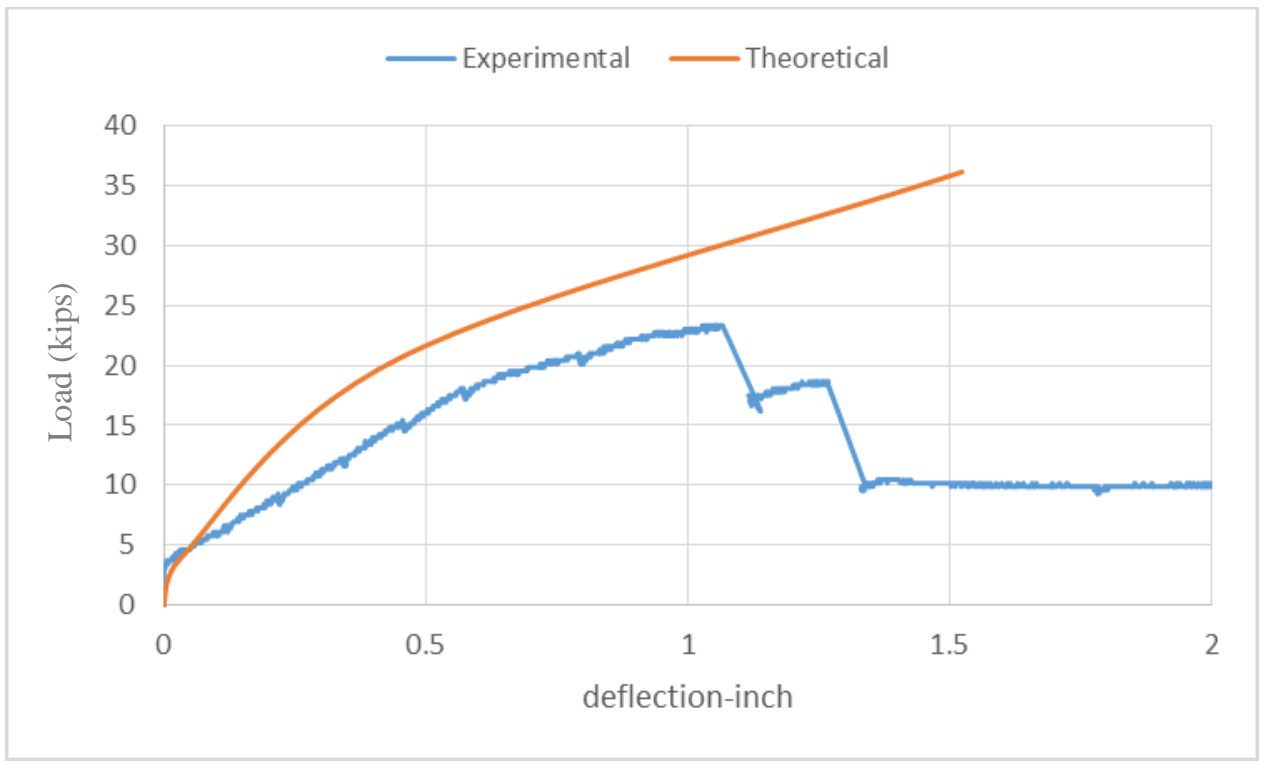

Figure 4-71 Specimen AR3theoretical and experimental load deflection comparison. 


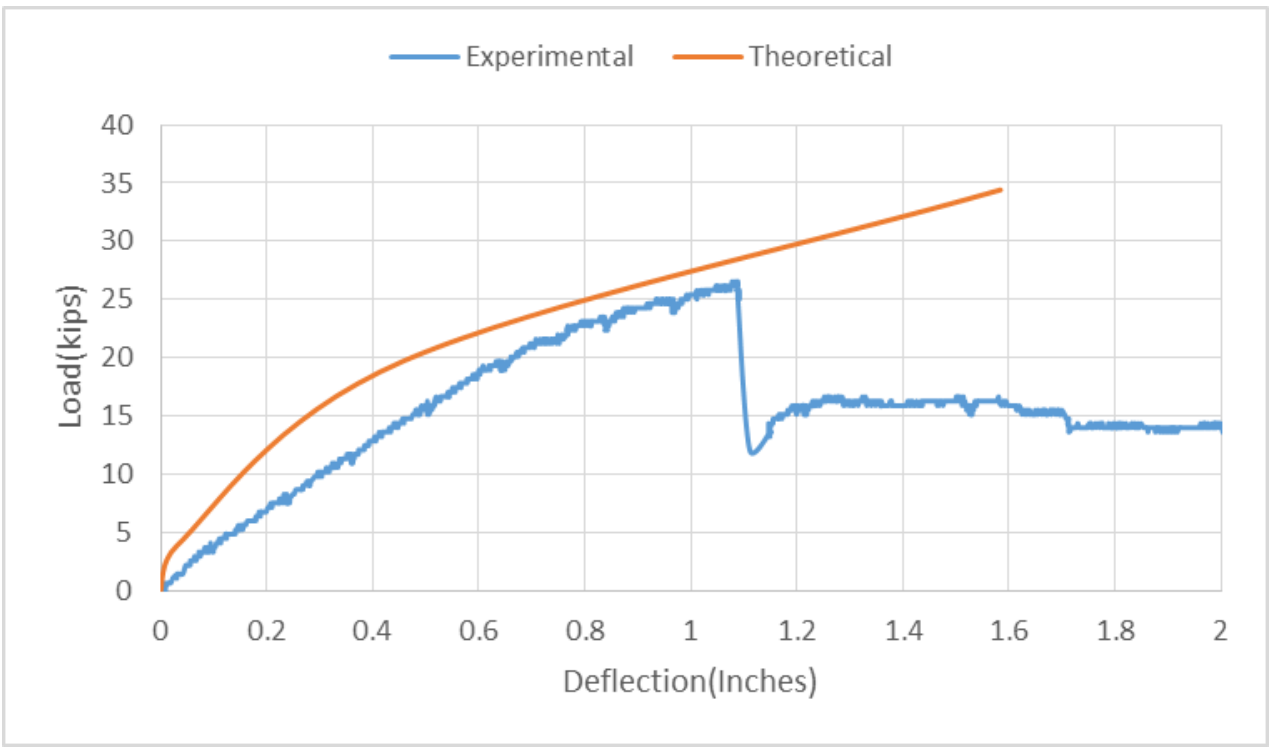

Figure 4-72 Specimen AR4-S theoretical and experimental load deflection curves.

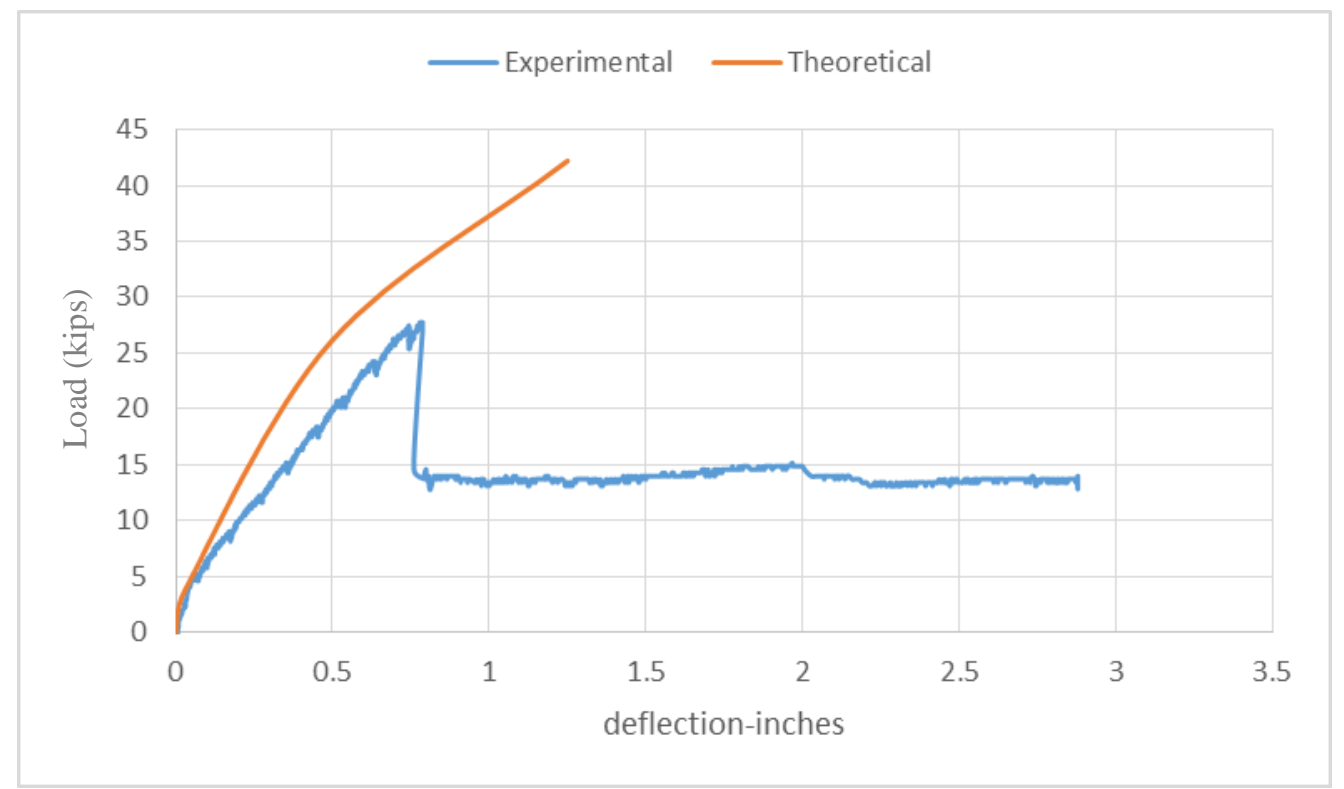

Figure 4-73 Specimen AR4 theoretical and experimental load deflection comparison. 


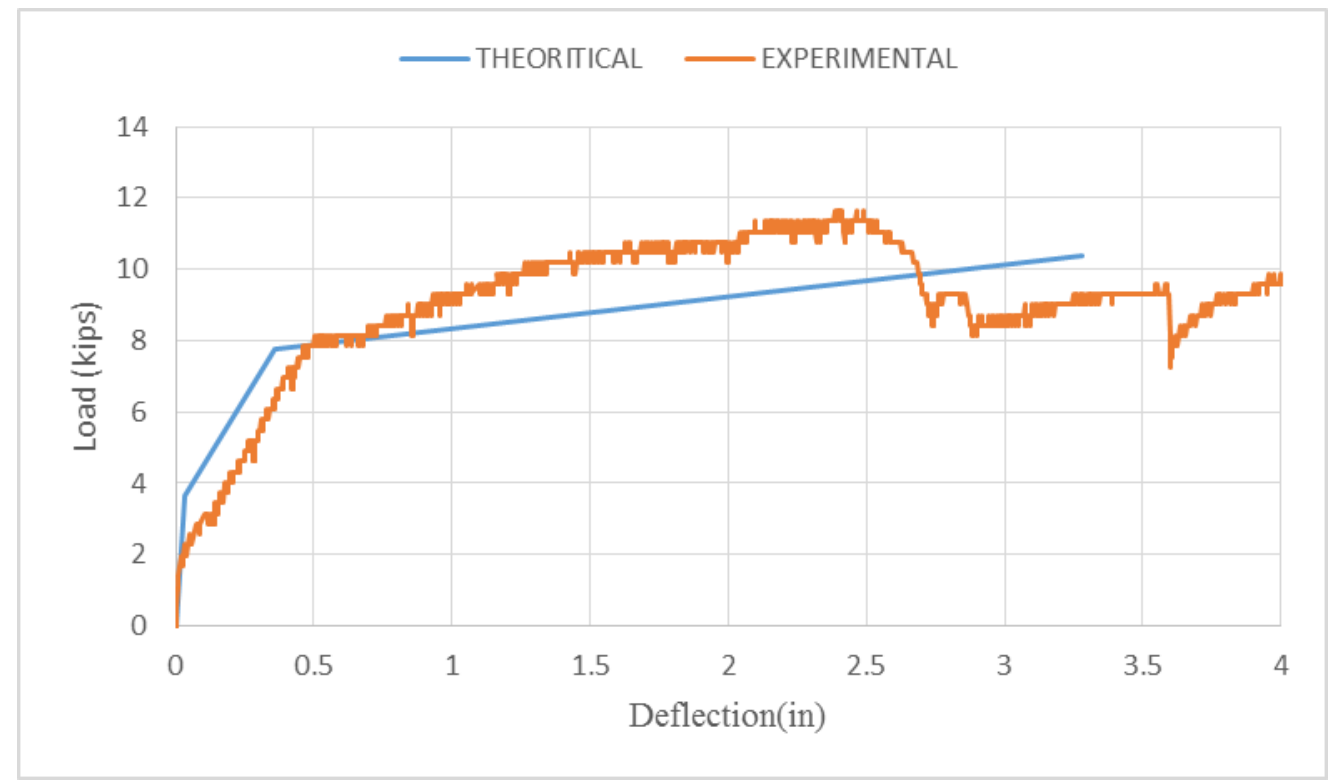

Figure 4-74 Specimen BC theoretical and experimental load deflection comparison.

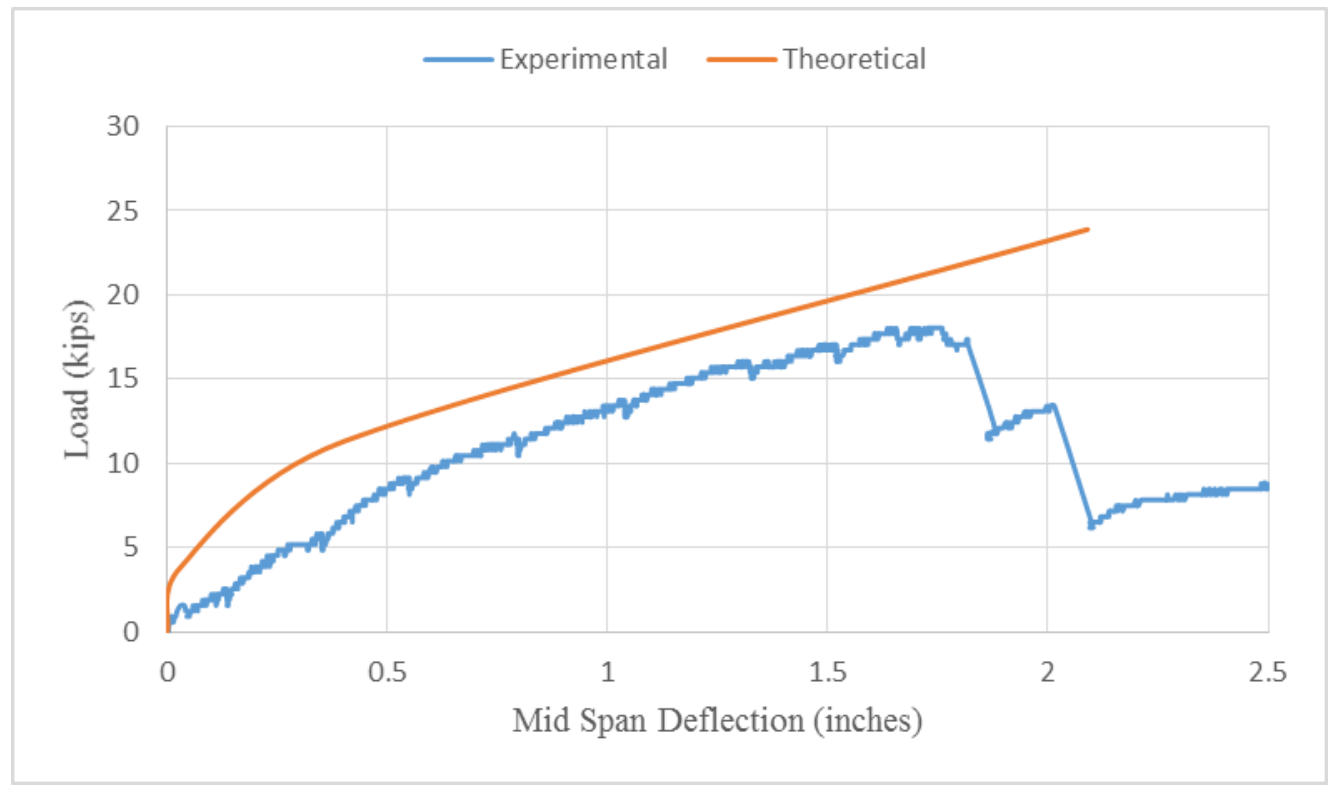

Figure 4-75 Specimen BR2 theoretical and experimental load deflection comparison. 


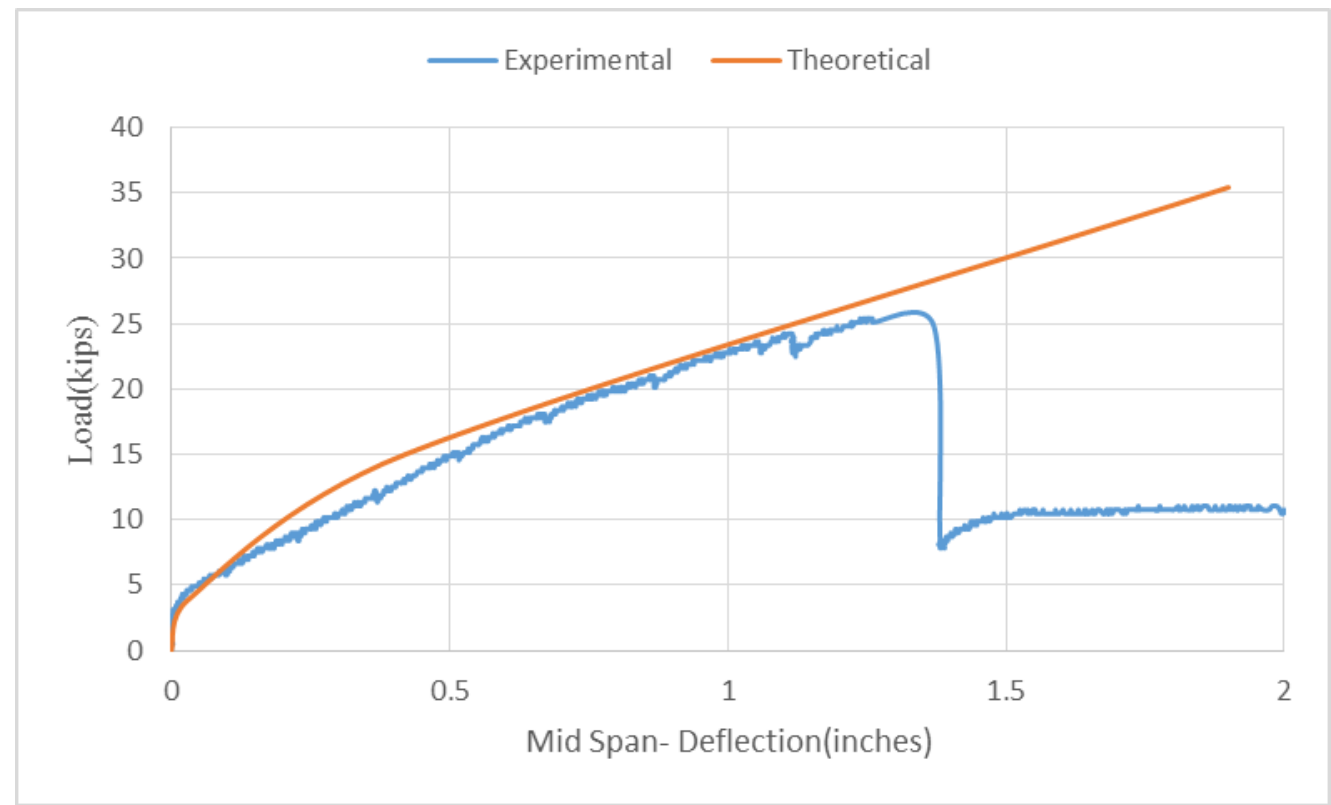

Figure 4-76 Specimen BR3Theoretical and experimental load deflection comparison.

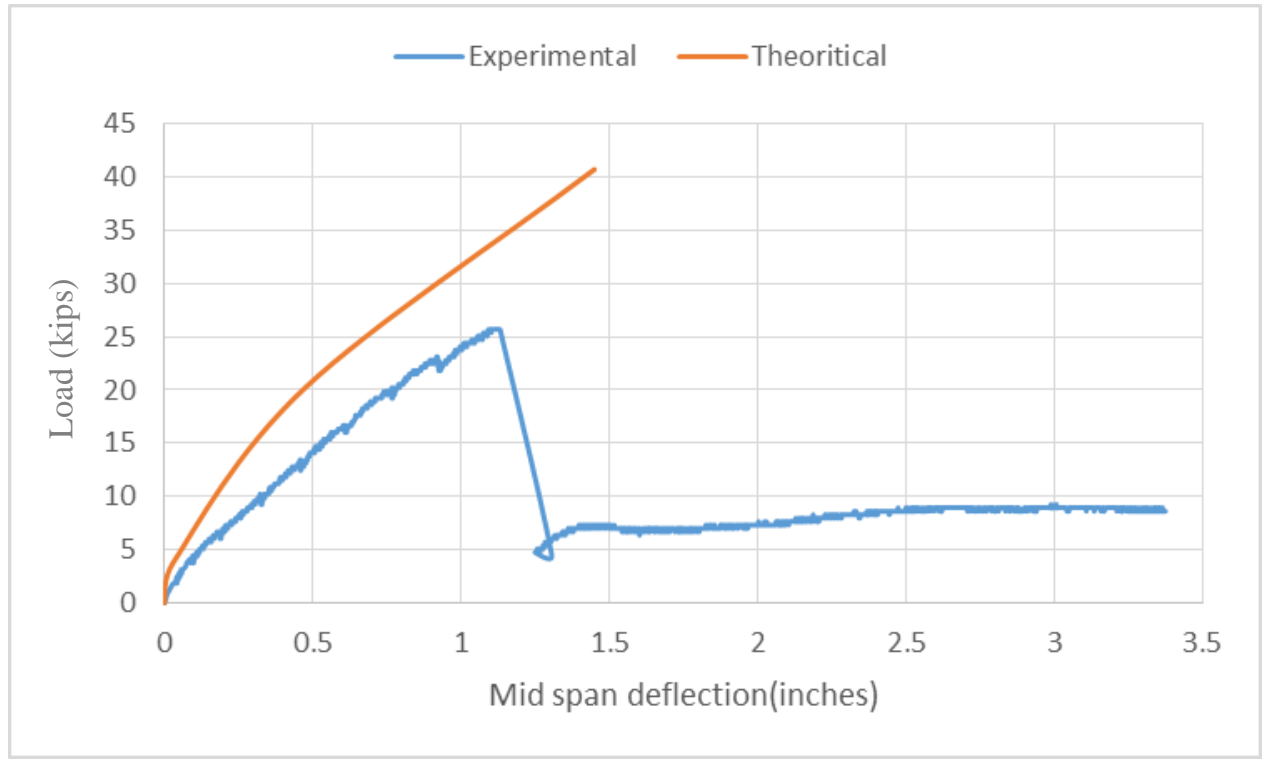

Figure 4-77 Specimen BR4 Theoretical and experimental load deflection. 


\section{Chapter 5: Summery Conclusions and Recommendations}

\subsection{Summery}

Pullout tests of the \#2, \#3, and \#4 CFRP rods were carried out to investigate the bonding characteristics of CFRP rods. Nine beams with different steel reinforcement ratio were retrofitted with different sizes of CFRP rods. Each beam was tested in flexure under twopoint load. Analytical computations were carried out for each specimens and compared to the experimental results. From the obtained results the following conclusion can be drawn:

\subsection{Conclusions}

- NSM CFRP application increased the flexural capacity and the stiffness of tested specimens.

- The failure mode of retrofitted specimen was mainly the de-bonding of the CFRP materials and peeling of the concrete cover.

- Retrofitting the specimens that had a low steel ratio appeared to be more effective than retrofitting specimens that had a high steel ratio.

- Bonding length of $60 \mathrm{D}_{\mathrm{b}}$ appeared to perform an excellent composite action for the \#2 CFRP rod, and a reasonable composite action for the \#3 CFRP rod.

- The measured maximum bond shear stress of the pullout tests appeared to be within the range as specified by the ACI440.2R-08. 
- ACI 440.2R-08 reasonably predicted the flexural capacity of the NSM CFRP beams.

- The lateral grooves played a significant role in the composite action by enhancing the bond between the concrete and the epoxy.

- Since the bonding characteristic was not involved in the analytical calculations, the theoretical load deflection curves were calculated based on the moment curvature method and appeared stiffer than the experimental results.

\subsection{Recommendations}

Based on the experimental results, the following recommendations are made.

- Investigate the influence of the fatigue and long-term loading on beams retrofitted with NSM-CFRP.

- Create a reliable analytical FEM model to predict the flexural performance of beams retrofitted with NSM-CFRP.

- Further investigate the bonding behavior of CFRP rods especially size \# 4.

- Investigate the performance of the NSM-CFRP applications on beams that have a deteriorated cover.

- Investigate adding CFRP fabric to the NSM-CFRP beams to limit the de-bonding due to concrete spalling off and delamination. 


\section{References}

Al-Mahmoud, F., Castel, A., François, R., \& Tourneur, C. (2010). RC beams strengthened with NSM CFRP rods and modeling of peeling-off failure-Composite structures 92.

American concrete institute (2008). ACI 440.2R -08:Guid for the Design and Construction of Externally Bonded FRP Systems for Strengthening Concrete Structures. ACI Manual of Concrete Practice, Farmington Hills, Michigan.

American concrete institute (2011). ACI 318 -11 : Building Code Requirements for Structural Concrete and Commentary. ACI Manual of Concrete Practice, Farmington Hills, Michigan.

ASCE ( American Society of Civil Engineering), 2013a, ASCE report card for America's infrastructure.http:// www.infrastructurereportcard.org/ (accessed on March 29,2013).

ASTM D7205 / D7205M - Standard Test Method for Tensile Properties of Fiber

Reinforced Polymer Matrix Composite Bars. American Society of Testing and Materials: West Conshohocken, PA.2006, 12.

Bilotta, A., Ceroni, F., Di Ludovico, M., Nigro, E., Pecce, M., \& Manfredi, G. (2011). Bond efficiency of EBR and NSM FRP systems for strengthening concrete members. Journal of Composites for Construction, 15(5), 757-772. 
De Lorenzis, L., \& Nanni, A. (2002). Bond between near-surface mounted fiberreinforced polymer rods and concrete in structural strengthening. ACI structural Journal, 99(2).

De Lorenzis, L., \& Teng, J. G. (2007). Near-surface mounted FRP reinforcement: An emerging technique for strengthening structures. Composites Part B: Engineering, 38(2), 119-143.

De Lorenzis, L., Rizzo, A., \& La Tegola, A. (2002). A modified pull-out test for bond of near-surface mounted FRP rods in concrete. Composites Part B: Engineering, 33(8), 589603.

Hassan, T. K., \& Rizkalla, S. H. (2004). Bond mechanism of near-surface-mounted fiberreinforced polymer bars for flexural strengthening of concrete structures. ACI Structural Journal, 101(6).

Jung, W. T., Park, Y. H., Park, J. S., Kang, J. Y., \& You, Y. J. (2005). Experimental investigation on flexural behavior of RC beams strengthened by NSM CFRP reinforcements. ACI Special Publication, 230.

Kent, D.C., and Park, R. (1971). "Flexural members with confined concrete." Journal of the Structural Division, Proc. of the American Society of Civil Engineers, 97(ST7), 19691990

Micelli, F., \& De Lorenzis, L. (2012). Near surface mounted flexural strengthening of reinforced concrete beams with low concrete strength. Proceedings of the ICEConstruction Materials, 166(5), 295-303. 
Novidis, D. G., \& Pantazopoulou, S. J. (2008). Bond tests of short NSM-FRP and steel bar anchorages. Journal of Composites for Construction, 12(3), 323-333.

Parretti, R., \& Nanni, A. (2004). Strengthening of RC members using near-surface mounted FRP composites: Design overview. Advances in Structural Engineering, 7(6), $469-483$.

Sharaky, I. A., Torres, L., Baena, M., \& Vilanova, I. (2013). Effect of different material and construction details on the bond behaviour of NSM FRP bars in concrete. Construction and Building Materials, 38, 890-902.

Soliman, S. M., El-Salakawy, E., \& Benmokrane, B. (2010). Bond performance of nearsurface-mounted FRP bars. Journal of Composites for Construction, 15(1), 103-111.

Soliman, S. M., El-Salakawy, E., \& Benmokrane, B. (2010). Flexural behaviour of concrete beams strengthened with near surface mounted fibre reinforced polymer bars. Canadian Journal of Civil Engineering, 37(10), 1371-1382.

Täljsten, B., Carolin, A., \& Nordin, H. (2003). Concrete structures strengthened with near surface mounted reinforcement of CFRP. Advances in structural engineering, 6(3), 201213.

Tang, W. C., Balendran, R. V., Nadeem, A., \& Leung, H. Y. (2006). Flexural strengthening of reinforced lightweight polystyrene aggregate concrete beams with nearsurface mounted GFRP bars. Building and environment, 41(10), 1381-1393. 


\section{Appendix A}

Flexural Design Example of NSM_CFRP Rods based on ACI440.2R-08

Concrete properties: $f_{c}^{\prime}=4.676 \mathrm{ksi}$ (normal weight concrete)

Steel reinforcement properties: $f_{y}=74.0 \mathrm{ksi}$ and $\varepsilon_{c}=0.0027$

Carbon fire rods properties: $E_{f}=18000 k s i, \varepsilon_{f u}^{*}=0.0175$

It is required to find the flexural capacity of the section shown in figure below.
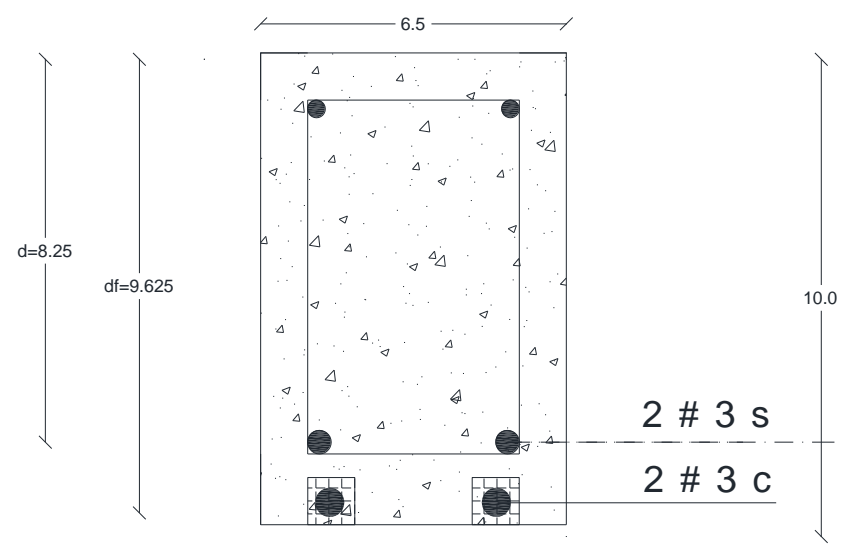

The environmental reduction factor of 0.9 shall be apply based on table 9.1 in ACI440.2R-08.

$f_{f u}=C_{E} f_{f u}^{*} \quad$ ACI 440.2R-08 (9-3)

$f_{f u}=0.9(0.0175)=0.01575 k s i$ 
Bond dependent coefficient $\mathrm{k}_{\mathrm{e}}$ shall be apply to limit the strain in the FRP reinforcement.

A value of 0.7 will be apply as bond coefficient factor.

$\varepsilon_{f e}=k_{e} \varepsilon_{f u} \quad$ ACI 440.2R-08 (12-5)

$\varepsilon_{f e}=0.7(0.01575)=0.011$

The section was assumed to be controlled by concrete crushing failure. The strain in the FRP and the steel was calculated as following

$\varepsilon_{f e}=\varepsilon_{c u}\left(\frac{d_{f}-c}{c}\right) \quad$ ACI $440.2 \mathrm{R}-08(10-3)$

The value of $\mathrm{C}$ was found after an iterative trials. The value of 2.4 was found to satisfy the equation of equilibrium and compatibility conditions as explain in the following steps.

$\varepsilon_{f e}=0.003\left(\frac{9.625-2.4}{2.4}\right)=0.009<0.01575 .0 . k$ no CFRP rod failure .

$\varepsilon_{s}=\left(\varepsilon_{f e}+\varepsilon_{b i}\right)\left(\frac{d-c}{d_{f-c}}\right) \quad$ ACI 440.2R-08 (10-10)

Since the section is not under load, the pre-existing strain was assumed zero.

$$
\begin{aligned}
& \varepsilon_{f e}=0.009\left(\frac{8.25-2.4}{9.625-2.4}\right)=0.0073>0.0027 . \text { the steel reinforcement has yeilded } . \\
& f_{f e}=E_{f} \varepsilon_{f e} \quad \text { ACI 440.2R-08 (10-9) } \\
& f_{f e}=18000(0.009)=162 \mathrm{ksi} \\
& f_{s}=f y=74 \mathrm{ksi}
\end{aligned}
$$


$c=\frac{A_{s} f_{s}+A_{f} f_{f e}}{\alpha_{1} f_{c}^{\prime} \beta_{1} b}$

ACI 440.2R-08 (10-12)

$\alpha_{1}$ and $\beta_{1}$ are the cocnrete stress block coefficient and can be taken as 0.85

for cocncrte crushing failure mode.

$c=\frac{0.22(74)+0.22(162)}{0.85(4.67)(0.85)(6.6)}=2.36 \sim 2.4 \mathrm{in}$.

ACI 440.2R-08 (10-13)

$M_{n}=A_{s} f_{s}\left(d-\frac{\beta_{1} c}{2}\right)+\psi_{f} A_{f} f_{f e}\left(d_{f}-\frac{\beta_{1} c}{2}\right)$

$M_{n}=0.22(74)\left(8.28-\frac{0.85(2.4)}{2}\right)+0.85(0.22)(162)\left(9.625-\frac{0.85(2.4)}{2}\right)$

$M_{n}=117.7+260.7=378.4 \mathrm{k} . \mathrm{in}=31.53 \mathrm{k} . \mathrm{ft}$

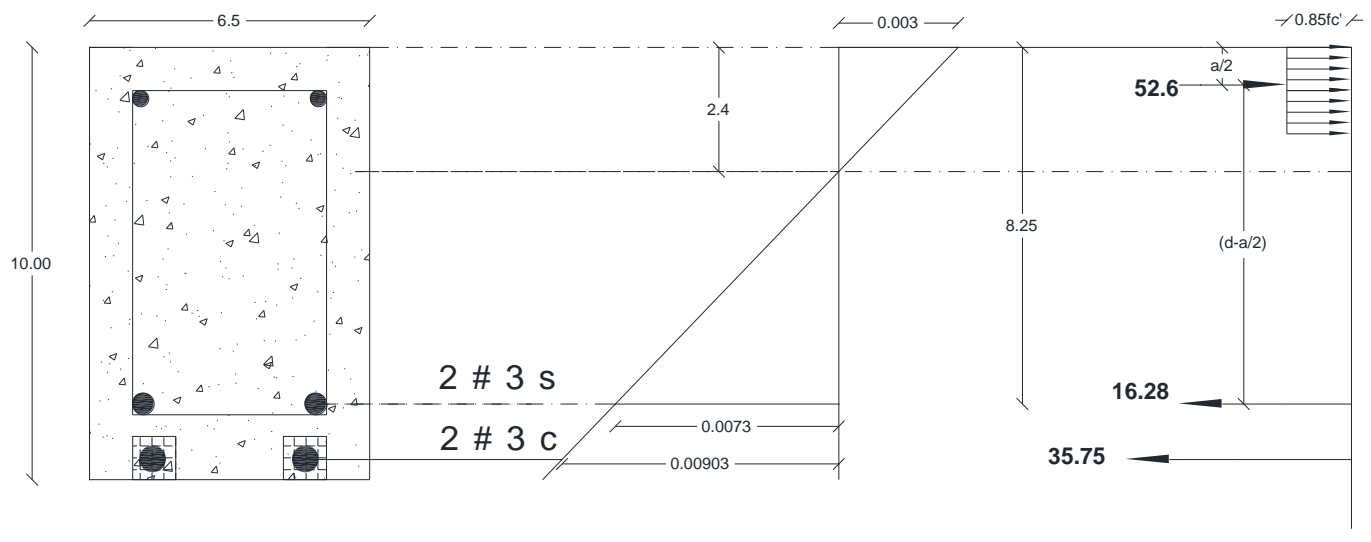




\section{Appendix B}

\section{Theoretical Load Deflection Relationship}

The analytical program was done to verify the results. This program was based on the developing moment curvature relationship for the reinforced concrete beam section. The load deflection curve was then established from the moment curvature relationship, which was done by following the procedure that described in the lecture notes of Dr. Caesar Abi Shadid (2008). A Mathcad code was programmed by Anas Yosefani, a graduate student at Portland State University. This program allows the user to input material and section properties. By incrementally increasing the strain in the concrete, the program uses the equilibrium and strain compatibility to find the flexural capacity and the curvature of the section at any strain level.

Strain and stress properties of the materials were input as formula to account for the nonlinear behavior. As shown in figure B-1, the steel strain diagram has three distinct regions.

For $\varepsilon_{\mathrm{s}} \leq 0.0027$ (elastic region)

$$
\mathrm{f}_{\mathrm{s}}=\mathrm{E} \varepsilon_{\mathrm{s}}
$$

For $\varepsilon_{\mathrm{y}} \leq \varepsilon_{\mathrm{s}} \leq 0.012$ (perfectly plastic region)

For $0.012 \leq \varepsilon_{\mathrm{s}} \leq 0.05$ (strain hardening region) 
Regression analysis was done to find the formula that best defined the strain-hardening trend, which turned out to be as follows

$$
f_{s}=22.79 \ln \left(\varepsilon_{s}\right)+175.88
$$

The steel properties were defined for both the top (As') and bottom reinforcement (As)

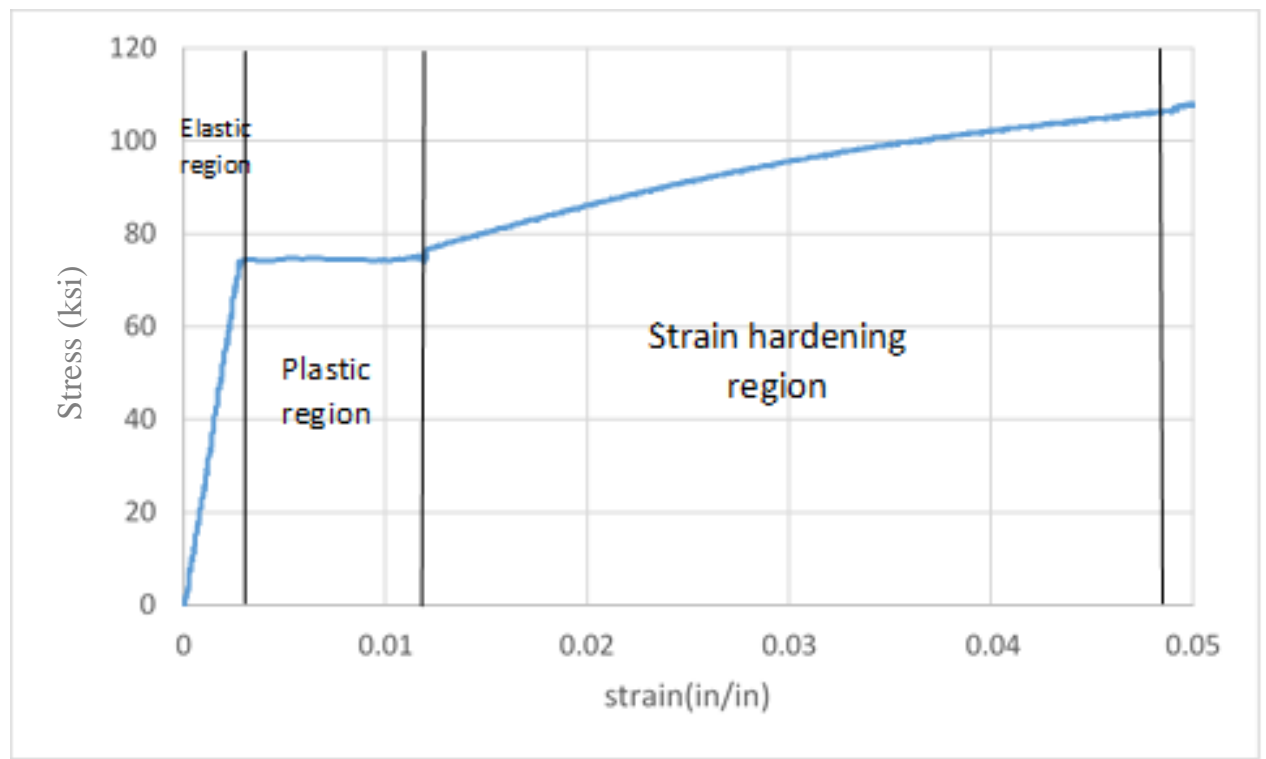

Figure B-0-1 steel strain-stress curve.

For concrete material properties, a compression strain-stress diagram was defined by some of the concrete parameters. This concrete parametric diagram was adopted from Kent and Park (1971). Where the ascending branch of concrete compressive strain diagram is defined by equation (16) and the descending branch is defined by equation (17) as explained in figure(B-2). 


$$
\begin{aligned}
& f_{c}=f_{c}^{\prime}\left[\frac{2 \varepsilon_{c}}{\varepsilon_{c o}}-\left(\frac{\varepsilon_{c}}{\varepsilon_{c o}}\right)^{2}\right] \\
& f_{c}=f_{c}^{\prime}\left[1-Z\left(\varepsilon_{c}-\varepsilon_{c o}\right)\right]
\end{aligned}
$$

Where $\quad \varepsilon_{c o}=0.002$ and $\quad Z=\frac{0.5}{\varepsilon_{50 u}-\varepsilon_{c o}} \quad$ in which $\quad \varepsilon_{50 u}=\frac{3+0.002 f_{c}^{\prime}}{f_{c}^{\prime}-1000}\left(f_{c}^{\prime}\right.$ in psi)

For $f_{c}^{\prime}=4500$ psi. $\varepsilon_{50 u}=0.003$. Therefore $\mathrm{Z}=350$.

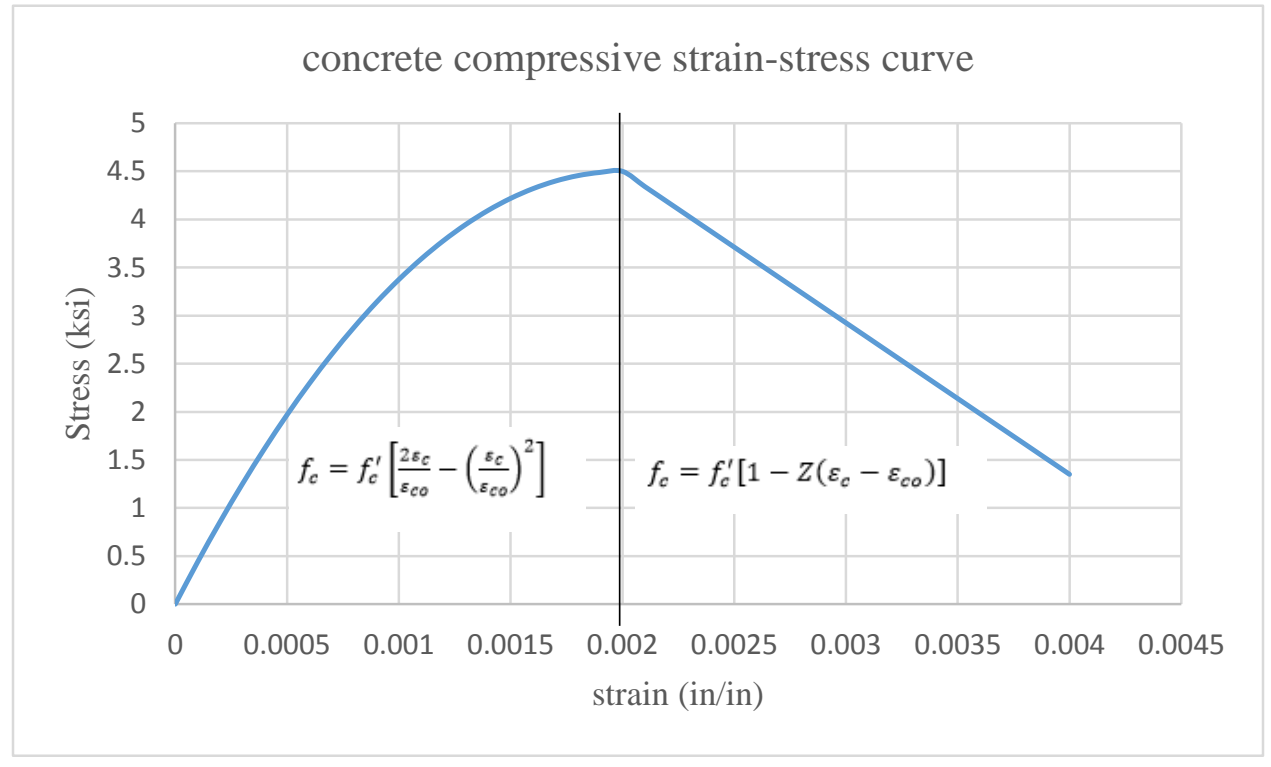

Figure B-2 Concrete strain stress curve.

For the CFRP material properties, the tensile stress-strain diagram for the \#2 CFRP rod was tested, and the obtained results indicated that the tensile behavior was linear up to the rupture of the bar. As shown in figure (B-3). 


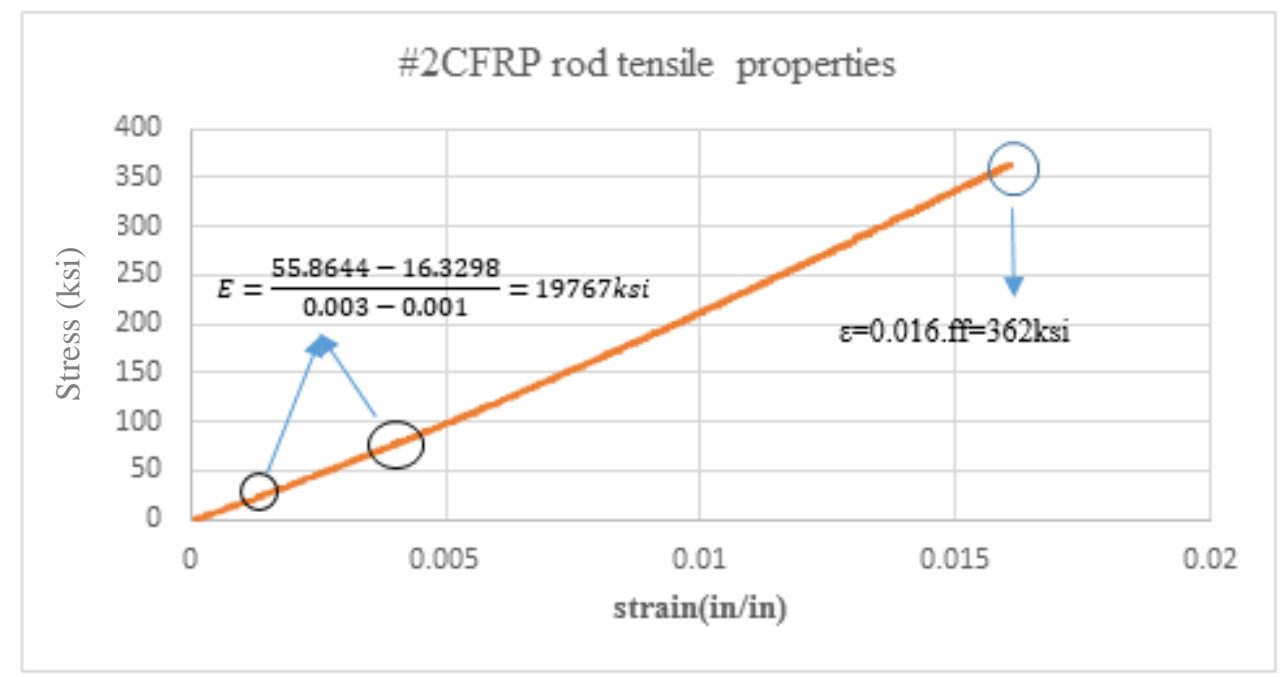

Figure B-3 \#2CFRP strain-stress curve.

\section{Analysis of Section AC}

In order to draw the load deflection diagram, the moment curvature diagram was constructed for the section. Three points can define the moment curvature diagram: the first point is before concrete cracking; the second point is before steel yielding, and the third point was selected when the strain in concrete $\left(\varepsilon_{c}\right)$ is 0.004 .

1) The cracking moment.

$y^{\prime}=\frac{6.5(10)(5)+2.56(8.25)}{6.5(10)+2.56}=5.123 \mathrm{in}$.

$I_{\text {transformed }}=\frac{I_{g}}{0.88}=\frac{10^{3}(6.5)}{12 * 0.88}=615 \mathrm{in}^{4}$

$y_{t}=10-5.12=4.8 \mathrm{in}$

$f_{\text {rupture }}=\frac{7.5 \sqrt{4200}}{1000}=0.48 \mathrm{ksi}$. 


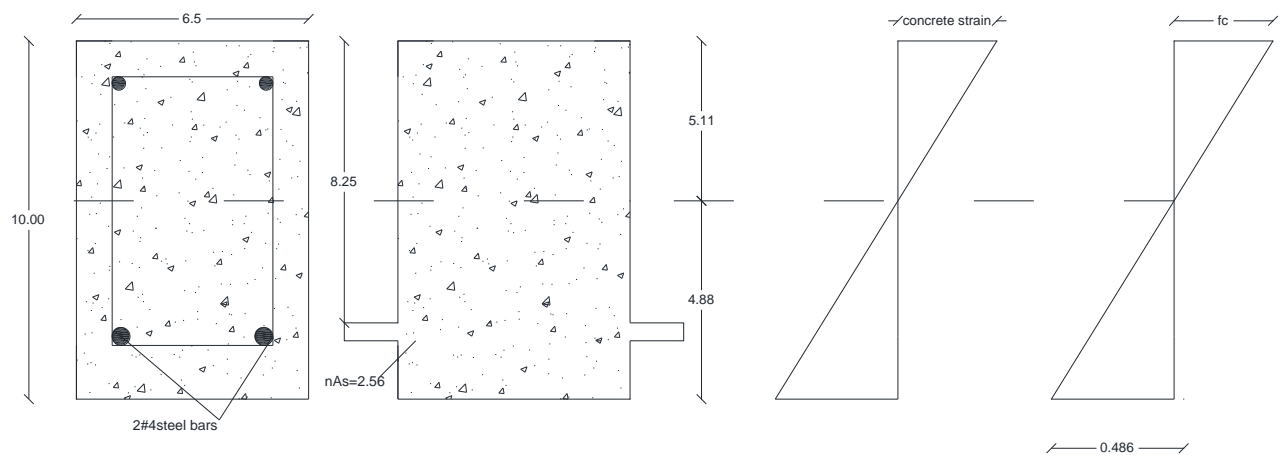

$m_{\text {crack }}=\frac{f_{\text {rupture }} I_{\text {transformed }}}{y_{t}}=\frac{0.48(615)}{5.12}=5.11 k . f t$

$\Phi_{\text {crack }}=\frac{m_{\text {crack }}}{E_{c} I_{\text {transformed }}}=\frac{5.11 * 12}{3694(615)} \cong 3 * 10^{-5}$

\section{2) The Steel Yielding Point.}

At this point, the concrete cracked and it was assumed that the strain in the concrete was still less than 0.002.Therfore, the force in the concrete can be found from the first equation (16).

$F_{c}=\int_{0}^{\varepsilon_{c}} b f_{c} d_{c} \quad, f_{c}=f_{c}^{\prime}\left[\frac{2 \varepsilon_{c}}{\varepsilon_{c o}}-\left(\frac{\varepsilon_{c}}{\varepsilon_{c o}}\right)^{2}\right]$ 


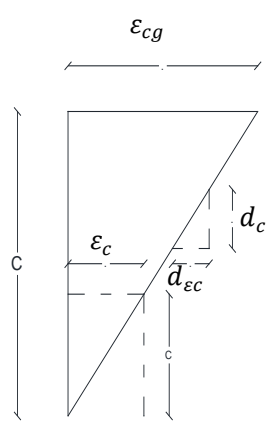

STRAIN DISTRIBUTION

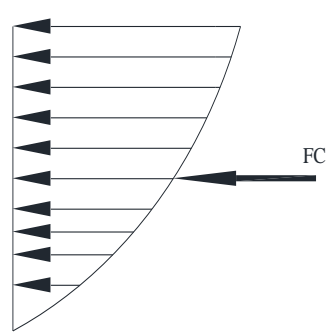

STRESS DISTRIBUTION

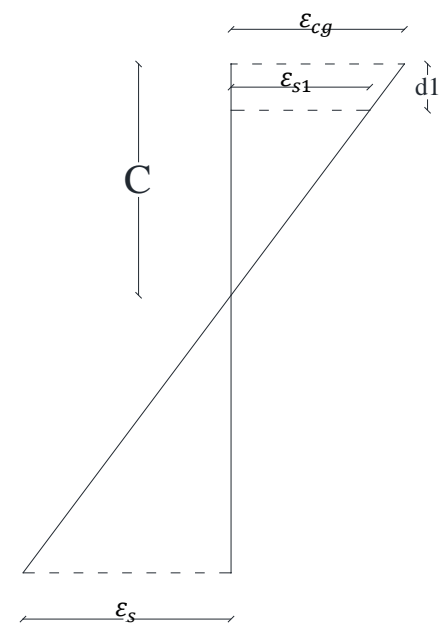

From the strain triangle, one can find that $d_{c}=\frac{C}{\varepsilon_{c g}} d_{\varepsilon c}$

$F_{c}=\frac{C b}{\varepsilon_{c g}} f_{c}^{\prime} \int_{0}^{\varepsilon_{c g}}\left[\frac{2 \varepsilon_{c}}{\varepsilon_{c o}}-\left(\frac{\varepsilon_{c}}{\varepsilon_{c o}}\right)^{2}\right] d_{\varepsilon c} \quad \rightarrow F_{c}=C b f_{c}^{\prime}\left[\frac{\varepsilon_{c g}}{\varepsilon_{c o}}-\frac{1}{3}\left(\frac{\varepsilon_{c g}}{\varepsilon_{c o}}\right)^{2}\right]$

From the strain compatibility, one can find that $\frac{\varepsilon_{c g}}{C}=\frac{\varepsilon_{s y}}{d-C} \quad \rightarrow \varepsilon_{c g}=\frac{C\left(\varepsilon_{s y)}\right.}{(d-C)}$

$F_{s}=E_{s} \varepsilon_{s y} A_{s} \quad \rightarrow \quad F_{s}=27407.4(0.0027)(0.4)=29.6$ kips.

$F_{s 1}=E_{s} \varepsilon_{s 1} A_{s 1} \quad$ From the strain compatibility, one can find that $\frac{\varepsilon_{c g}}{C}=\frac{\varepsilon_{s 1}}{C-d 1}$

$\varepsilon_{s 1}=\frac{\varepsilon_{c g}}{C}\left(C-d_{1}\right)$

From equilibrium, $F_{s}=F_{c}+F_{s 1}$

$$
29.6=C(6.5)(4.2)\left[\frac{\varepsilon_{c g}}{0.002}-\frac{1}{3}\left(\frac{\varepsilon_{c g}}{0.002}\right)^{2}\right]+27407.4(0.22)\left[\frac{\varepsilon_{c g}}{C}\left(C-d_{1}\right)\right]
$$


$\varepsilon_{c g}=\frac{C(0.0027)}{(d-C)}, \mathrm{d}=8.25 \mathrm{in}, d_{1}=1.0 \mathrm{in}$ apply in eq.18 above and solve for $\mathrm{C}$.

$\mathrm{C}=2.26$

Check for $\varepsilon_{c g}=\frac{C(0.0027)}{(d-C)} \cdot \varepsilon_{c g}=\frac{2.26(0.0027)}{(8.25-2.26)}=0.001 \leq 0.002 \mathrm{ok}$

To calculate the bending moment of each element about the neutral axis, the level arm of the concrete parabola should be integrated as shown.

$M_{c}=\int_{0}^{\varepsilon_{c}} b c f_{c} d_{c} \quad, f_{c}=f_{c}^{\prime}\left[\frac{2 \varepsilon_{c}}{\varepsilon_{c o}}-\left(\frac{\varepsilon_{c}}{\varepsilon_{c o}}\right)^{2}\right]$

From strain triangle, one can find that $d_{c}=\frac{C}{\varepsilon_{c g}} d_{\varepsilon c}, c=\frac{C}{\varepsilon_{c g}} \varepsilon_{c}$

$$
\begin{gathered}
M_{c}=\frac{C^{2} b}{\varepsilon_{c g}^{2}} f_{c}^{\prime} \int_{0}^{\varepsilon_{c g}} \varepsilon_{c}\left[\frac{2 \varepsilon_{c}}{\varepsilon_{c o}}-\left(\frac{\varepsilon_{c}}{\varepsilon_{c o}}\right)^{2}\right] d_{\varepsilon c} \rightarrow M_{c}=c^{2} b f_{c}^{\prime} \frac{\varepsilon_{c g}}{\varepsilon_{c o}}\left[\frac{2}{3}-\frac{1}{4} \frac{\varepsilon_{c g}}{\varepsilon_{c o}}\right] \\
M_{c}=c^{2} b f_{c}^{\prime} \frac{\varepsilon_{c g}}{\varepsilon_{c o}}\left[\frac{2}{3}-\frac{1}{4} \frac{\varepsilon_{c g}}{\varepsilon_{c o}}\right] \\
M_{s t}=F_{s t}(d-C) \\
M_{s t 1}=F_{s t 1}\left(C-d_{1}\right)
\end{gathered}
$$

Apply the values of C, $\mathrm{d}$ and d1 in eqs.19,20,and 21 above.

$$
\begin{aligned}
& M_{c}=37.75 \mathrm{k} . \mathrm{in}, \quad M_{s t}=174.1 \mathrm{k} . \mathrm{in}, \quad M_{s t 1}=4.23 \mathrm{k} . \mathrm{in} \\
& M_{T}=M_{C}+M_{s t}+M_{s t 1}=18.0 \mathrm{k} . \mathrm{ft} \\
& \Phi_{y}=\frac{\varepsilon_{c}}{C}=\frac{0.001}{2.26}=4.425 * 10^{-4}
\end{aligned}
$$




\section{3) Concrete Crushing Point.}

At this point, the concrete has reached the limit of crushing, which was assumed as 0.004. Therfoe; the force in the concrete can be integrated based on both concrete equations.

$$
\begin{aligned}
& F_{c}=\int_{0}^{\varepsilon_{o}} b f_{c 1} d_{c}+\int_{\varepsilon o}^{\varepsilon c g} b f_{c 2} d_{c} \\
& f_{c 1}=f_{c}^{\prime}\left[\frac{2 \varepsilon_{c}}{\varepsilon_{c o}}-\left(\frac{\varepsilon_{c}}{\varepsilon_{c o}}\right)^{2}\right], f_{c 2}=f_{c}^{\prime}\left[1-Z\left(\varepsilon_{c}-\varepsilon_{c o}\right)\right], \quad d_{c}=\frac{C}{\varepsilon_{c g}} d_{\varepsilon c}
\end{aligned}
$$

By integrating both terms of the above equation, the result is the total force in concrete.

$$
\begin{aligned}
& F_{c}=\frac{C b}{\varepsilon_{c g}}\left[\frac{2}{3} f_{c}^{\prime} \varepsilon_{o}+\left[2 f_{c}^{\prime}-z\left(\varepsilon_{c g}-\varepsilon_{o}\right)\right]\left(\frac{\varepsilon_{c g}-\varepsilon_{o}}{2}\right)\right] \\
& F_{s 1}=E_{s} \varepsilon_{s 1} A_{s 1} \quad, F_{s}=\left(22.79 \ln \varepsilon_{s}+175.88\right) A_{s} \quad, \frac{\varepsilon_{c g}}{C}=\frac{\varepsilon_{s}}{d-C}, \frac{\varepsilon_{c g}}{C}=\frac{\varepsilon_{s 1}}{C-d 1}
\end{aligned}
$$

From equilibrium equation $\rightarrow F_{s}=F_{c}+F_{s 1}$

$$
\left(22.79 \ln \varepsilon_{s}+175.88\right) A_{s}=\frac{C b}{\varepsilon_{c g}}\left[\frac{2}{3} f_{c}^{\prime} \varepsilon_{o}+\left[2 f_{c}^{\prime}-z\left(\varepsilon_{c g}-\varepsilon_{o}\right)\right]\left(\frac{\varepsilon_{c g}-\varepsilon_{o}}{2}\right)\right]+E_{s} \varepsilon_{s 1} A_{s 1}
$$

$\varepsilon_{S}=\frac{0.004(d-C)}{C}, \varepsilon_{s 1}=\frac{0.004(C-d 1)}{C} \mathrm{~d}=8.25 \mathrm{in}, d_{1}=1.0 \mathrm{in} \varepsilon_{c g}=0.004$ apply in eq. 22 above and solve for $\mathrm{C}$.

$\mathrm{C}=1.29$ in. check for $\varepsilon_{s}=\frac{0.004(8.25-1.29)}{1.29}=0.0215 \geq 0.012$ the hardining region . 
For moment capacity, the same previous process was done by integrating the concrete force multiplied by the lever arm to the neutral axis and the resulted equation is as shown below.

$$
\begin{aligned}
& M_{c}=\frac{b C^{2}}{12 \varepsilon_{c g}^{2}}\left[f_{c}^{\prime}\left(6 \varepsilon_{c g}^{2}-\varepsilon_{o}^{2}\right)-2 z\left(\varepsilon_{c g}-\varepsilon_{o}\right)^{2} 2\left(\varepsilon_{c g}-\varepsilon_{o}\right)\right] \\
& M_{s t}=F_{s}(d-C) \\
& M_{s t 1}=F_{s 1}\left(C-d_{1}\right)
\end{aligned}
$$

Apply the values of $\mathrm{C}, \mathrm{d}$ and $\mathrm{d} 1$ in eqs.23,24,and 25 above.

$$
\begin{aligned}
& M_{c}=22.364 \mathrm{k} . \mathrm{in}, \quad M_{s t}=246.293 \mathrm{k} . \mathrm{in}, M_{s t 1}=1.57 \mathrm{k} . \mathrm{in} \\
& M_{T}=M_{c}+M_{s t}+M_{s t 1}=22.519 \mathrm{k} . \mathrm{ft} \\
& \Phi_{y}=\frac{\varepsilon_{c}}{C}=\frac{0.004}{1.29}=3.1 * 10^{-3}
\end{aligned}
$$

These three values were used to establish the load deflection curve by using the moment area method as explained below.

\begin{tabular}{|c|c|c|}
\hline Point \# & Moment (K.ft) & Curvature \\
\hline 1 & 0 & 0 \\
\hline 2(cracking moment) & 5.0 & $3 * 10^{-5}$ \\
\hline 3(yielding moment) & 18.0 & $4.43 * 10^{-4}$ \\
\hline 4(concrete crushing moment ) & 22.5 & $3.0 * 10^{-3}$ \\
\hline
\end{tabular}




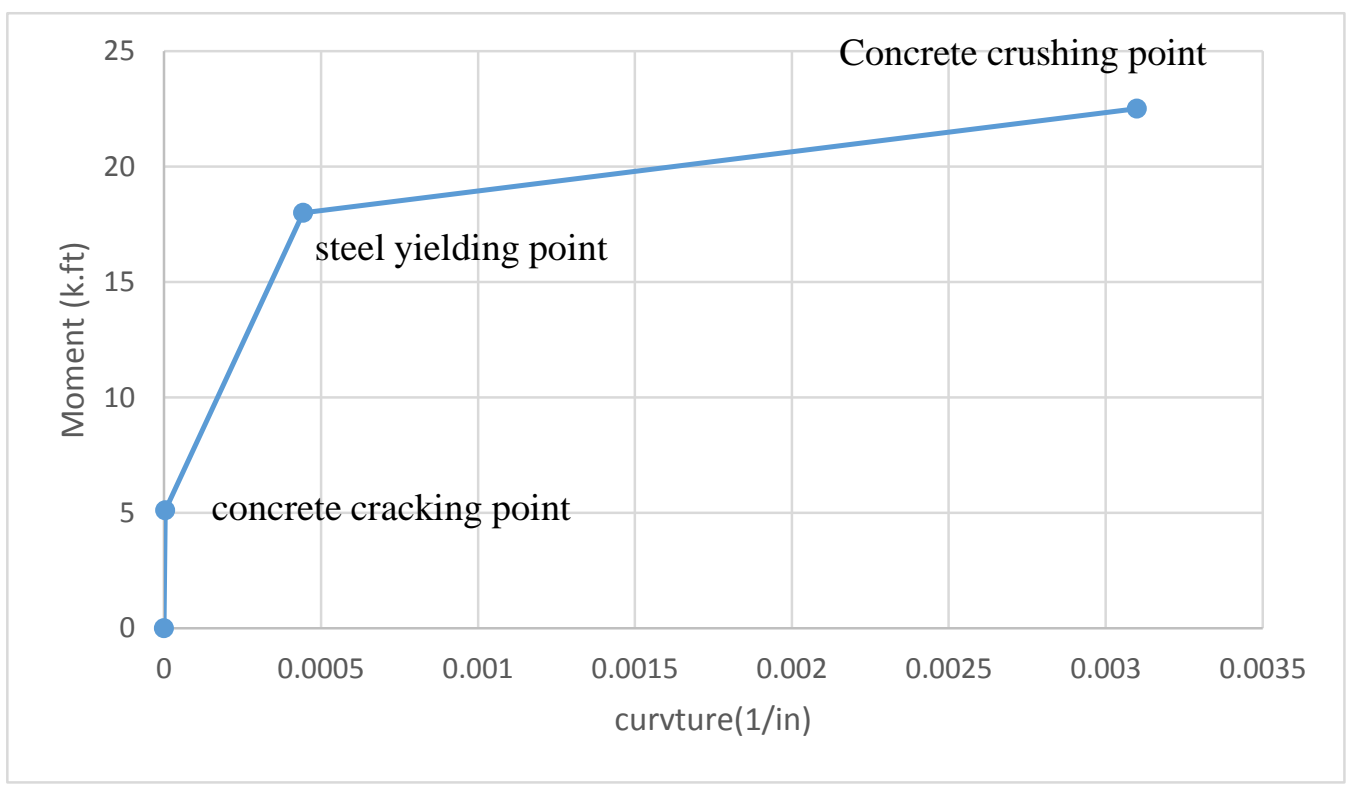

\section{Deflection Calculation}

\section{1) At Cracking Point.}

$\Delta=$ the moment of curvature diagram about $\mathrm{A}$.

$\Delta=6.42 * 10^{-4} \frac{f t^{2}}{i n}$

$\delta=$ half of the moment of curvature diagram about the center point.

$$
\begin{aligned}
& \delta=1.158 * 10^{-4} \frac{f t^{2}}{i n} \\
& \Delta_{c r .}=\frac{6.42 * 10^{-4}}{2}-1.158 * 10^{-4}=2.05 * 10^{-4} \frac{f t^{2}}{\text { in }} * 144=0.03 \mathrm{in} .
\end{aligned}
$$




\section{2) At Yielding Point.}

$$
\begin{aligned}
& \Delta=8.515 * 10^{-3} \frac{f t^{2}}{i n} \\
& \delta=1.36 * 10^{-3} \frac{f t^{2}}{i n} \\
& \Delta_{y i .}=0.42 \mathrm{in} .
\end{aligned}
$$

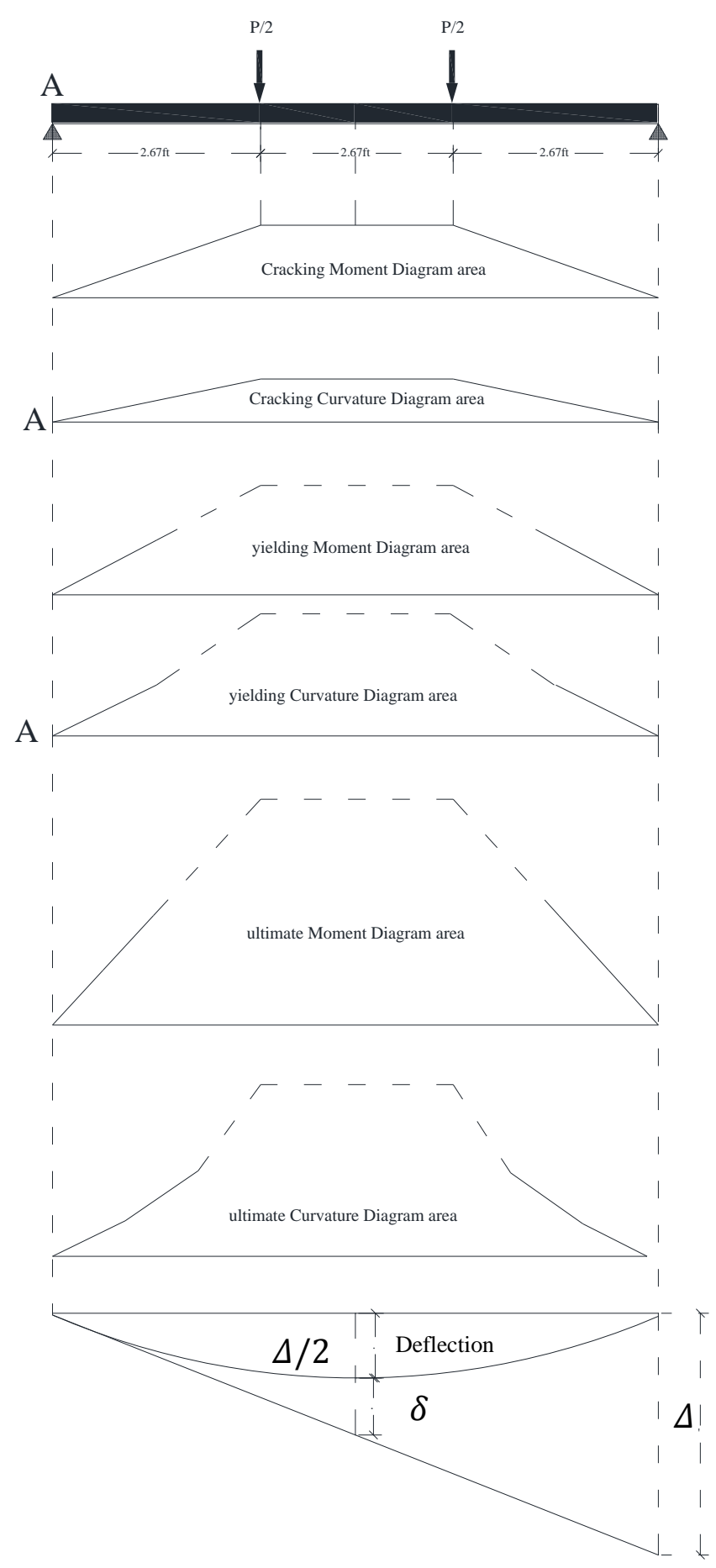

\section{3) At Ultimate Point.}

$$
\begin{aligned}
& \Delta=0.0415 \frac{f t^{2}}{i n} \\
& \delta=4.86 * 10^{-3} \frac{f t^{2}}{i n} \\
& \Delta_{u l .}=2.288 i n .
\end{aligned}
$$




\section{Analysis of Section AR2}

For the specimen AR2, the analysis was basically the same steps that have been done with specimen AC. However, the contribution of two \#2 CFRP rods in the beam cover is going to be added to the flexural analysis and the concrete compressive strength is now $4.5 \mathrm{ksi}$.

\section{1) The Cracking Moment.}

Since the concrete properties of specimen AR2 is slightly different from concrete properties of specimen $\mathrm{AC}$, the cracking moment and curvature can be assumed the same.

\section{2) The Steel Yielding Point.}

At this point, the concrete has cracked and it assumed that the strain in the concrete is still less than 0.002.Therfoe, the force in the concrete can be find from the first equation (1).

$F_{c}=\int_{0}^{\varepsilon_{c}} b f_{c} d_{c} \quad, f_{c}=f_{c}^{\prime}\left[\frac{2 \varepsilon_{c}}{\varepsilon_{c o}}-\left(\frac{\varepsilon_{c}}{\varepsilon_{c o}}\right)^{2}\right]$

From strain triangle, one can find that $d_{c}=\frac{C}{\varepsilon_{c g}} d_{\varepsilon c}$

$F_{c}=\frac{C b}{\varepsilon_{c g}} f_{c}^{\prime} \int_{0}^{\varepsilon_{c g}}\left[\frac{2 \varepsilon_{c}}{\varepsilon_{c o}}-\left(\frac{\varepsilon_{c}}{\varepsilon_{c o}}\right)^{2}\right] d_{\varepsilon c} \quad \rightarrow F_{c}=C b f_{c}^{\prime}\left[\frac{\varepsilon_{c g}}{\varepsilon_{c o}}-\frac{1}{3}\left(\frac{\varepsilon_{c g}}{\varepsilon_{c o}}\right)^{2}\right]$

From strain compatibility, one can find that $\frac{\varepsilon_{c g}}{C}=\frac{\varepsilon_{s y}}{d-C} \quad \rightarrow \varepsilon_{c g}=\frac{C\left(\varepsilon_{s y)}\right.}{(d-C)}$ 


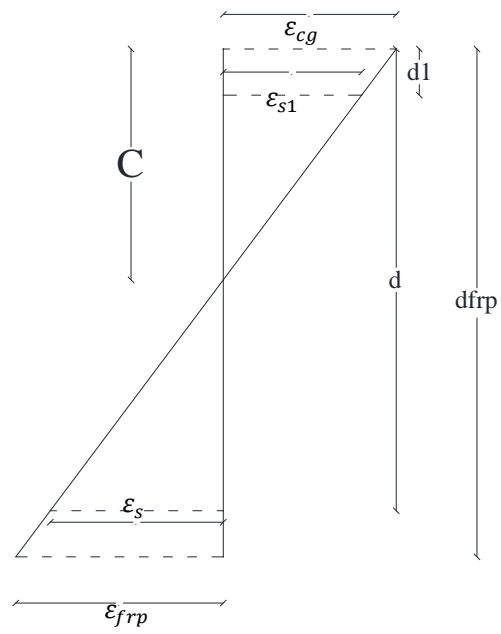

$\frac{\varepsilon_{c g}}{C}=\frac{\varepsilon_{f r p}}{d_{f r p}-C} \rightarrow \varepsilon_{c g}=\frac{C\left(\varepsilon_{f r p}\right)}{\left(d_{f r p}-C\right)}$, where $\varepsilon_{f r p}$ and $d_{f r p}$ are the strain and the depth of CFRP.

$F_{s}=E_{s} \varepsilon_{s y} A_{s} \quad \rightarrow \quad F_{s}=27407.4(0.0027)(0.4)=29.6$ kips.

$F_{f r p}=E_{f r p} \varepsilon_{f r p} A_{f r p} \quad \rightarrow \varepsilon_{f r p}=\frac{\varepsilon_{c g}\left(d_{f r p}-C\right)}{c}$

$F_{s 1}=E_{s} \varepsilon_{s 1} A_{s 1} \quad$ From strain compatibility, one can find that $\frac{\varepsilon_{c g}}{C}=\frac{\varepsilon_{s 1}}{C-d 1}$

$\varepsilon_{s 1}=\frac{\varepsilon_{c g}}{C}\left(C-d_{1}\right)$

From equilibrium, $F_{S}+F_{\text {frp }}=F_{c}+F_{s 1}$

$$
\begin{gathered}
29.6+E_{f r p} \varepsilon_{f r p} A_{f r p}=C(6.5)(4.2)\left[\frac{\varepsilon_{c g}}{0.002}-\frac{1}{3}\left(\frac{\varepsilon_{c g}}{0.002}\right)^{2}\right]+27407.4(0.22)\left[\frac{\varepsilon_{c g}}{c}\left(C-d_{1}\right)\right] \\
\varepsilon_{c g}=\frac{C(0.0027)}{(d-C)}, \mathrm{d}=8.25 \mathrm{in}, d_{1}=1.0 \mathrm{in}, d_{f r p}=9.75 \mathrm{in} . A_{f r p}=0.098 \mathrm{in}^{2}, \text { and }
\end{gathered}
$$


$E_{f r p}=19767 k s i$ apply in eq.26 above and solve for C.

$\mathrm{C}=2.466$ in.

Check for $\varepsilon_{c g}=\frac{C(0.0027)}{(d-C)} \cdot \varepsilon_{c g}=\frac{2.466(0.0027)}{(8.25-2.466)}=0.00115 \leq 0.002 \mathrm{ok}$

$\varepsilon_{f r p}=\frac{0.00115(9.75-2.466)}{2.466}=0.0034$

To calculate the bending moment of each element about the neutral axis, the level arm of the concrete parabola should be integrated as shown.

$M_{c}=\int_{0}^{\varepsilon_{c}} b c f_{c} d_{c} \quad, f_{c}=f_{c}^{\prime}\left[\frac{2 \varepsilon_{c}}{\varepsilon_{c o}}-\left(\frac{\varepsilon_{c}}{\varepsilon_{c o}}\right)^{2}\right]$

From strain triangle, one can find that $d_{c}=\frac{C}{\varepsilon_{c g}} d_{\varepsilon c}, c=\frac{C}{\varepsilon_{c g}} \varepsilon_{c}$

$$
\begin{gathered}
M_{c}=\frac{c^{2} b}{\varepsilon_{c g}{ }^{2}} f_{c}^{\prime} \int_{0}^{\varepsilon_{c g}} \varepsilon_{c}\left[\frac{2 \varepsilon_{c}}{\varepsilon_{c o}}-\left(\frac{\varepsilon_{c}}{\varepsilon_{c o}}\right)^{2}\right] d_{\varepsilon c} \rightarrow M_{c}=c^{2} b f_{c}^{\prime} \frac{\varepsilon_{c g}}{\varepsilon_{c o}}\left[\frac{2}{3}-\frac{1}{4} \frac{\varepsilon_{c g}}{\varepsilon_{c o}}\right] \\
M_{c}=c^{2} b f_{c}^{\prime} \frac{\varepsilon_{c g}}{\varepsilon_{c o}}\left[\frac{2}{3}-\frac{1}{4} \frac{\varepsilon_{c g}}{\varepsilon_{c o}}\right] \\
M_{s t}=F_{s t}(d-C) \\
M_{s t 1}=F_{s t 1}\left(C-d_{1}\right) \\
M_{f r p}=F_{f r p}\left(d_{f r p}-C\right)
\end{gathered}
$$

Apply the values of $\mathrm{C}, \mathrm{d}$ and $\mathrm{d} 1$ in eqs27,28,29, and 30. above. 


$$
\begin{aligned}
& M_{c}=51.103 \mathrm{k} . \mathrm{in}, \quad M_{s t}=171.03 \mathrm{k} . \mathrm{in}, M_{s t 1}=6.04 \mathrm{k} . \mathrm{in} \quad M_{f r p}=47.97 \mathrm{k} . \mathrm{in} . \\
& M_{T}=M_{c}+M_{s t}+M_{s t 1}+M_{f r p}=23.013 \mathrm{k} . \mathrm{ft} \\
& \Phi_{y}=\frac{\varepsilon_{c}}{C}=\frac{0.00115}{2.466}=4.66 * 10^{-4}
\end{aligned}
$$

\section{3) Concrete Crushing Point or CFRP Rupture Point}

At this point, an assumption have to be made whether the concrete will reach the strain of 0.004 or the CFRP will reach the strain of 0.016 . Therefore, the assumptions are going to be that the concrete will reach the crushing limit of 0.004 and the steel is within the perfectly plastic region.

$$
\begin{aligned}
& F_{c}=\int_{0}^{\varepsilon_{o}} b f_{c 1} d_{c}+\int_{\varepsilon o}^{\varepsilon c g} b f_{c 2} d_{c} \\
& f_{c 1}=f_{c}^{\prime}\left[\frac{2 \varepsilon_{c}}{\varepsilon_{c o}}-\left(\frac{\varepsilon_{c}}{\varepsilon_{c o}}\right)^{2}\right], f_{c 2}=f_{c}^{\prime}\left[1-Z\left(\varepsilon_{c}-\varepsilon_{c o}\right)\right], \quad d_{c}=\frac{c}{\varepsilon_{c g}} d_{\varepsilon c}
\end{aligned}
$$

By integrating both terms of the above equation, the result is the total force in concrete.

$$
\begin{aligned}
& F_{c}=\frac{C b}{\varepsilon_{c g}}\left[\frac{2}{3} f_{c}^{\prime} \varepsilon_{o}+\left[2 f_{c}^{\prime}-z\left(\varepsilon_{c g}-\varepsilon_{o}\right)\right]\left(\frac{\varepsilon_{c g}-\varepsilon_{o}}{2}\right)\right] \\
& F_{s 1}=E_{s} \varepsilon_{s 1} A_{s 1}, F_{s}=29.6 \text { kips, } F_{f r p}=E_{f r p} \varepsilon_{f r p} A_{f r p 1} .
\end{aligned}
$$

From equilibrium equation $\rightarrow F_{s}+F_{f r p}=F_{c}+F_{s 1}$

$$
E_{f r p} \varepsilon_{f r p} A_{f r p 1 .}+29.6=\frac{C b}{\varepsilon_{c g}}\left[\frac{2}{3} f_{c}^{\prime} \varepsilon_{o}+\left[2 f_{c}^{\prime}-z\left(\varepsilon_{c g}-\varepsilon_{o}\right)\right]\left(\frac{\varepsilon_{c g}-\varepsilon_{o}}{2}\right)\right]+E_{s} \varepsilon_{s 1} A_{s 1}
$$


$\varepsilon_{f r p}=\frac{\left(\varepsilon_{c g}\right)\left(d_{f r p}-C\right)}{C} \varepsilon_{s 1}=\frac{\varepsilon_{c g}(C-d 1)}{C}, \varepsilon_{c g}=0.004$ apply in eq.31 above and solve for $\mathrm{C}$.

$\mathrm{C}=2.064$ in. check for $\varepsilon_{s}=\frac{0.004(8.25-2.064)}{2.064}=0.0119 \leq 0.012$ the plastic region.

check for $\varepsilon_{f r p}=\frac{\left(\varepsilon_{c g}\right)\left(d_{f r p}-C\right)}{C}=\frac{(0.004)(9.75-2.064)}{2.064}=0.015 \leq 0.0160 . k$.

For moment capacity, the same previous process was done by integrating the concrete force multiplied by the lever arm to the neutral axis and the resulted equation is as shown below.

$$
\begin{aligned}
& M_{c}=\frac{b C^{2}}{12 \varepsilon_{c g}^{2}}\left[f_{c}^{\prime}\left(6 \varepsilon_{c g}^{2}-\varepsilon_{o}^{2}\right)-2 z\left(\varepsilon_{c g}-\varepsilon_{o}\right)^{2} 2\left(\varepsilon_{c g}-\varepsilon_{o}\right)\right] \\
& M_{s t}=F_{s}(d-C) \\
& M_{s t 1}=F_{s 1}\left(C-d_{1}\right) \\
& M_{f r p}=F_{f r p}\left(d_{f r p}-C\right)
\end{aligned}
$$

Apply the values of $\mathrm{C}, \mathrm{d}$ and $\mathrm{d} 1$ in eqs.32,33,34,and35 above.

$$
\begin{aligned}
& M_{c}=56.25 k . i n, \quad M_{s t}=196.19 k . i n, \quad M_{s t 1}=13.22 \mathrm{k} . \mathrm{in} \quad M_{f r p}=223.33 \mathrm{k} . \mathrm{in} . \\
& M_{T}=M_{c}+M_{s t}+M_{s t 1}+M_{f r p}=40.751 \mathrm{k} . \mathrm{ft} \\
& \Phi_{c}=\frac{\varepsilon_{c}}{C}=\frac{0.004}{2.064}=1.93 * 10^{-3}
\end{aligned}
$$




\begin{tabular}{|c|c|c|}
\hline Point \# & Moment (K.ft) & Curvature \\
\hline Starting point & 0 & 0 \\
& & $3 * 10^{-5}$ \\
\hline 2( concrete cracking moment) & 5.11 & $4.66 * 10^{-4}$ \\
\hline 3( steel yielding moment) & 23.013 & $1.93 * 10^{-3}$ \\
\hline 4(concrete crushing moment ) & 40.75 & \\
\hline
\end{tabular}

The same process of calculating the deflection of $\mathrm{AC}$ was done to calculate the deflection of AR2. The result are as shown below.

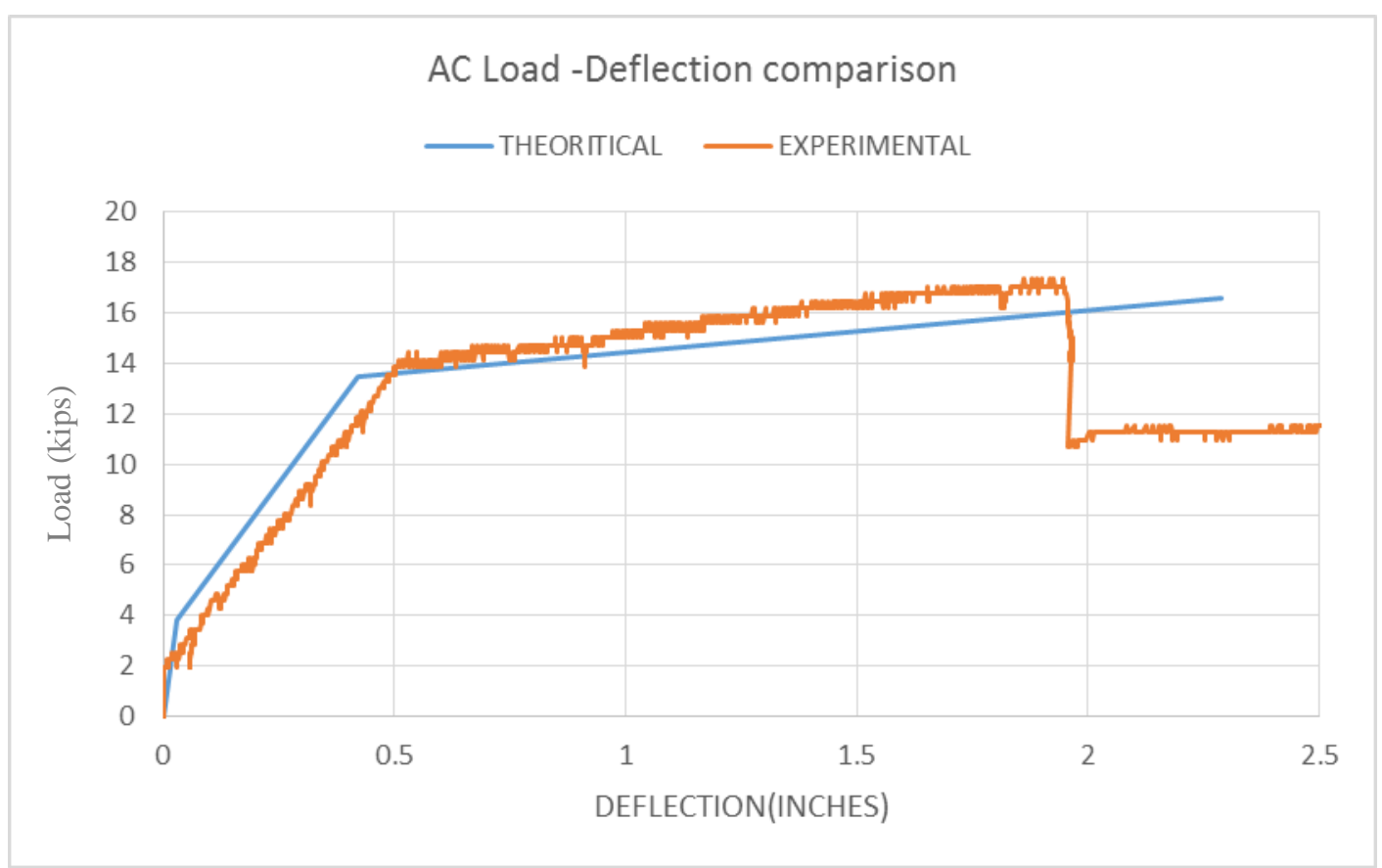



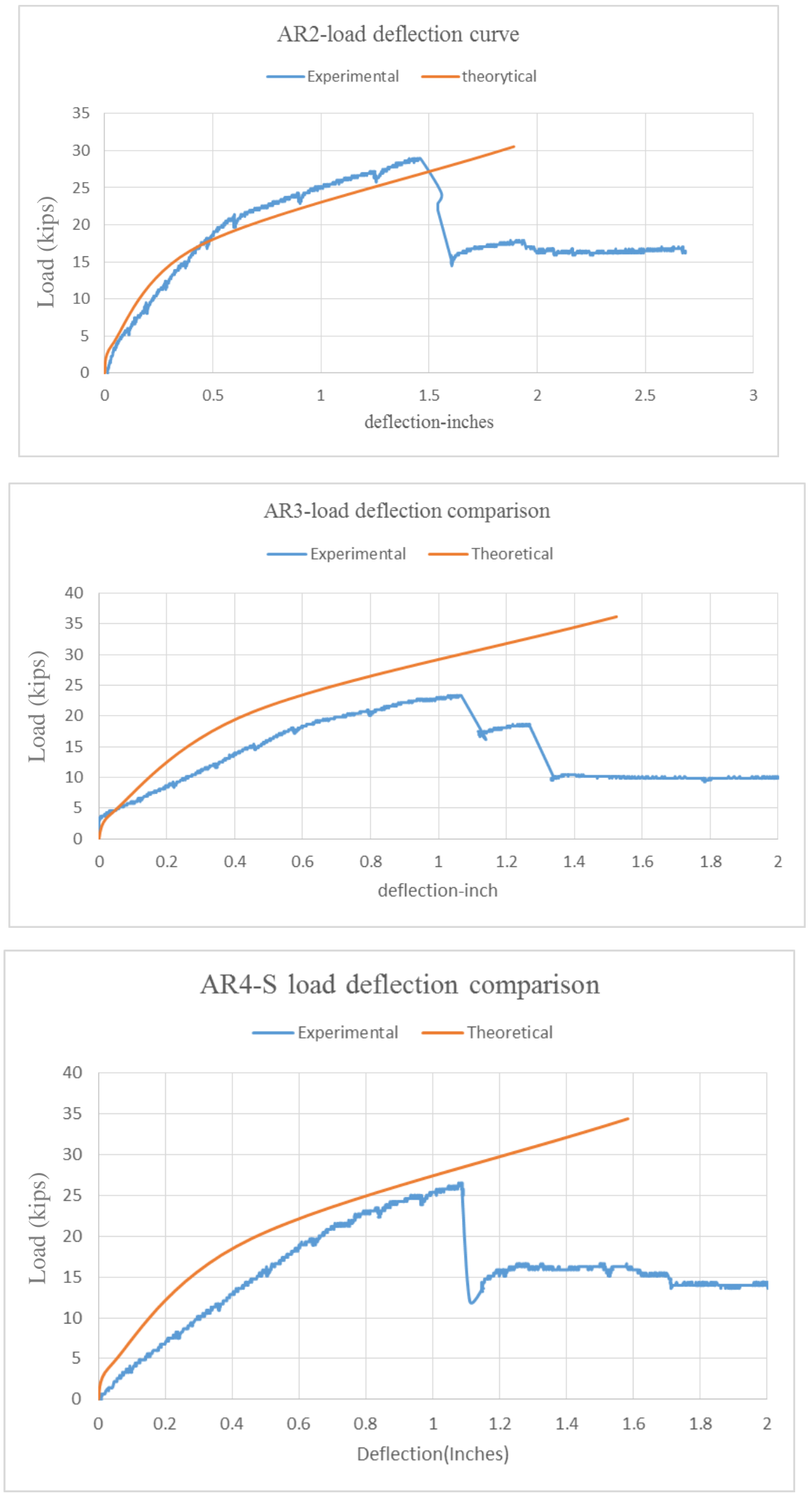


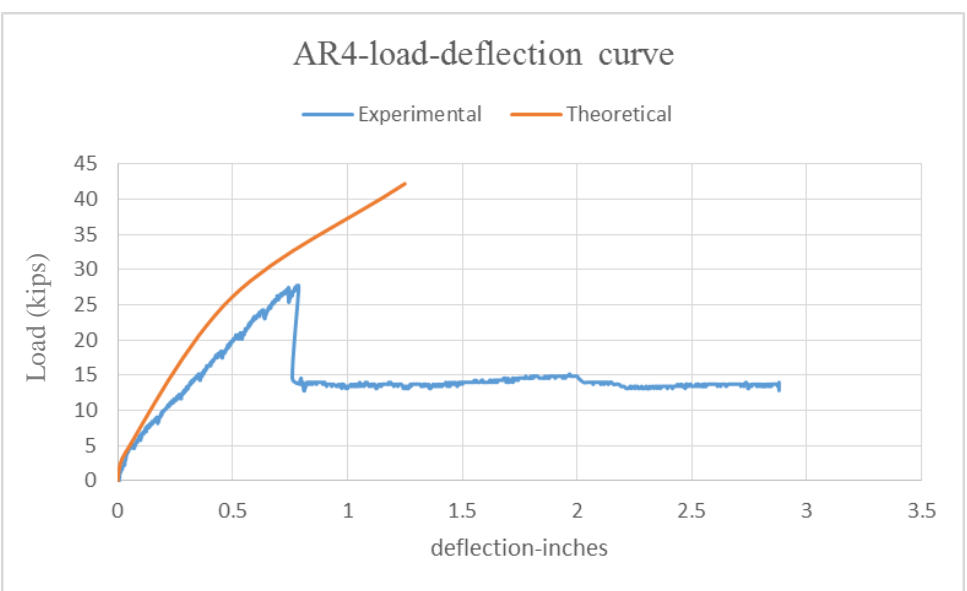

The same procedure was done to calculate the theoretical load deflection curve for the other specimens as shown in the following graphs.
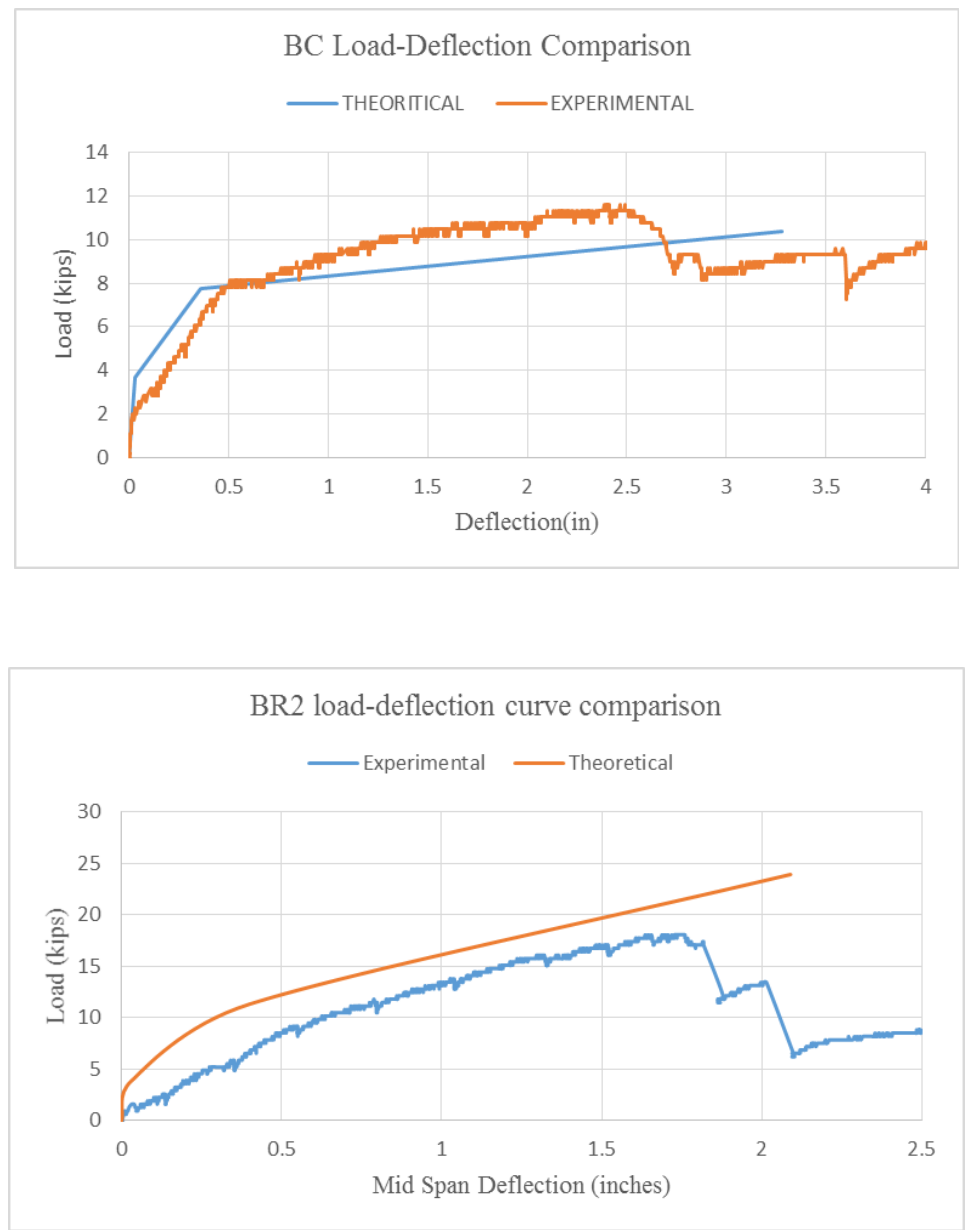

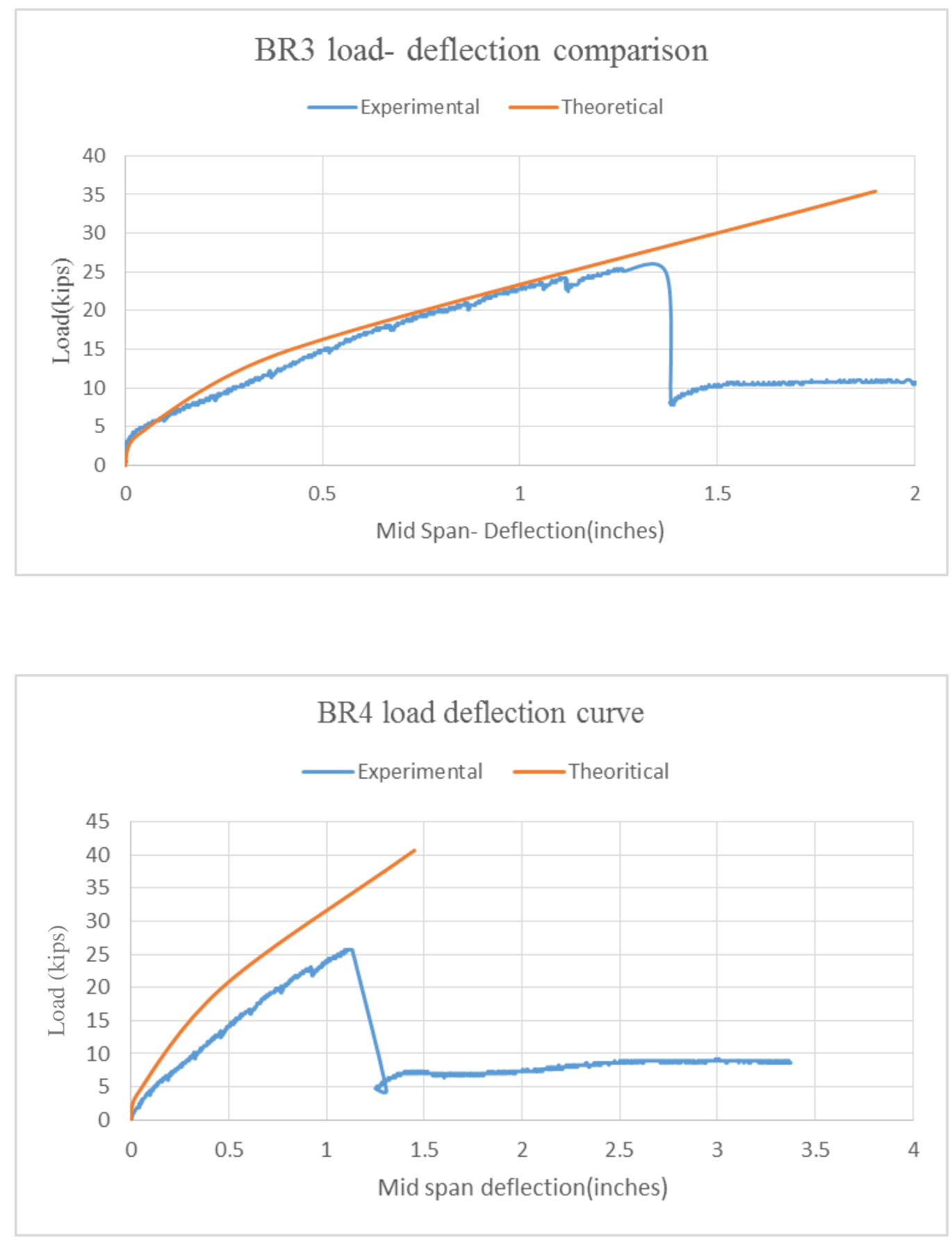